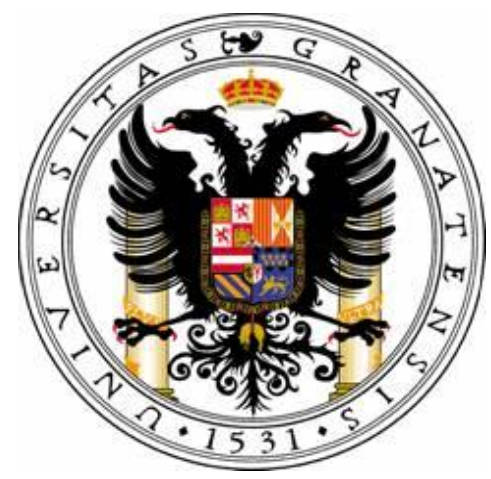

Máster en Problemas Sociales: Dirección y Gestión de Programas Sociales Facultad de Ciencias Políticas y Sociología

Universidad de Granada

$2012-2013$

\title{
LA CONSTRUCCIÓN DE INMIGRACIÓN COMO PROBLEMA SOCIAL EN ESPAÑA
}

Trabajo Fin de Máster (TFM) correspondiente al Máster en Problemas Sociales: Dirección y Gestión de Programas Sociales. 
"El principio de mundialización de la información va en contra del principio universal de la solidaridad. Ello es así porque la información se agota en sí misma y ella misma es su fin".

Baudrillard (1997) 


\section{ÍNDICE}

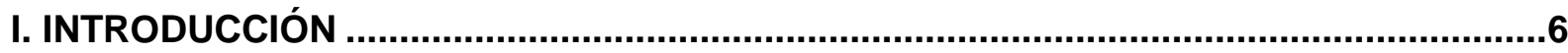

II. MARCO TEÓRICO ……..........................................................................................

A. RECORRIDO HISTÓRICO EN LA CONSTRUCCIÓN DE LOS PROBLEMAS

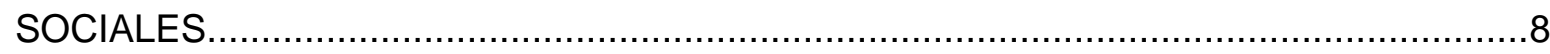

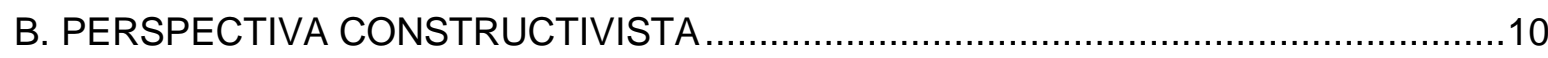

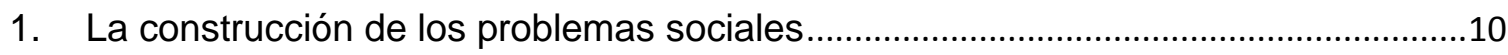

2. La formación de la agenda pública en la construcción de problemas sociales..........11

3. Los medios de comunicación en la construcción de los problemas sociales.............14

C.LA CONSTRUCCIÓN DE LA INMIGRACIÓN COMO PROBLEMA SOCIAL .................18

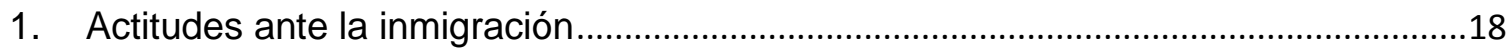

2. Factores de construcción de la inmigración como problema social.............................20

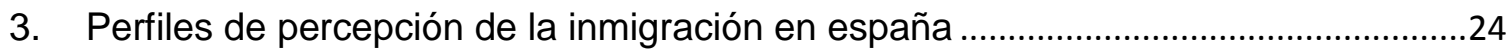

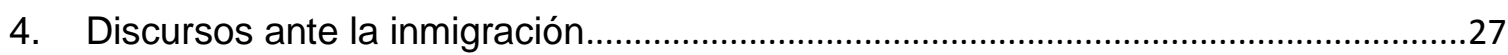

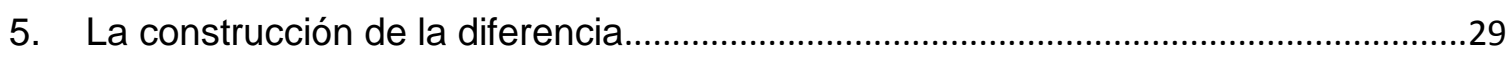

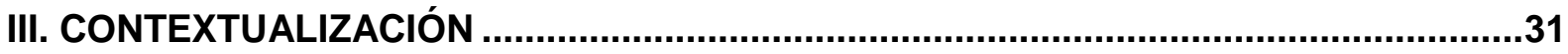

A. ETAPA DE DESPEGUE DE LA INMIGRACIÓN (1994 al 1999)..........................31

B. ETAPA DE AUGE DE LA INMIGRACIÓN (2000 a 2007) ..................................32

C. ETAPA DE LA INMIGRACIÓN EN CRISIS ECONÓMICA (2008 a 2013)..............34

IV. PROBLEMATIZACIÓN Y PREGUNTA DE INVESTIGACIÓN ......................................36

V. OBJETIVOS E HIPÓTESIS DE LA INVESTIGACIÓN.................................................37

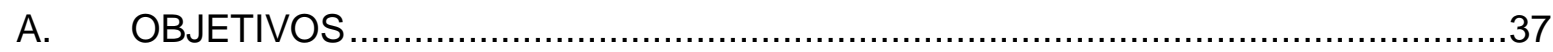

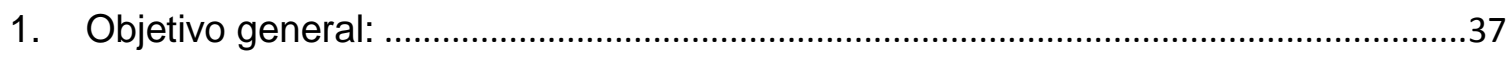

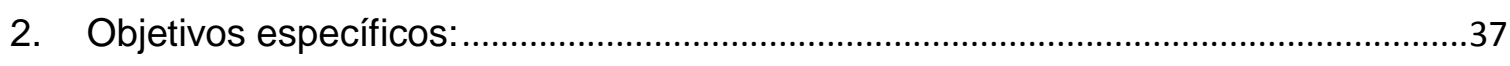

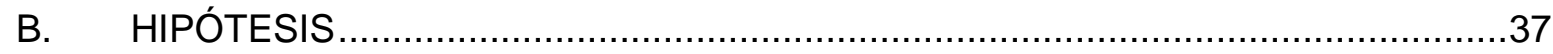

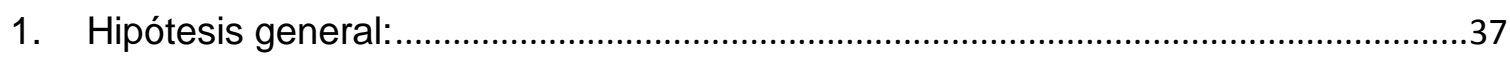

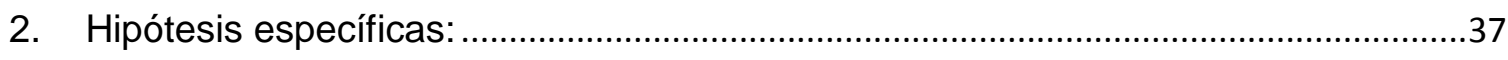

VI. METODOLOGÍA DE LA INVESTIGACIÓN .............................................................39

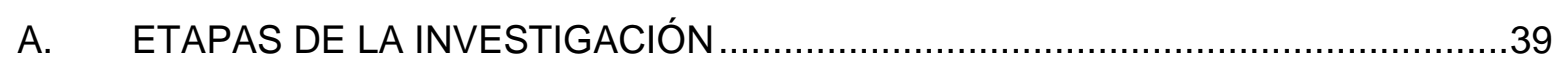

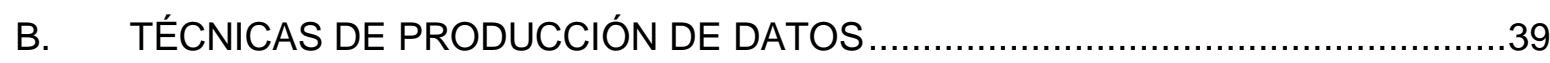

C. TÉCNICAS DE ANÁLISIS DE DATOS .........................................................

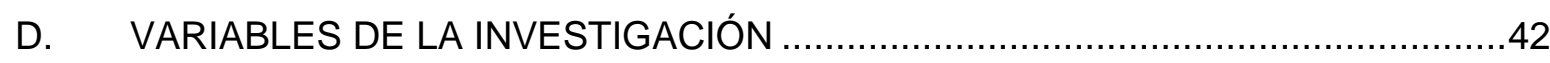

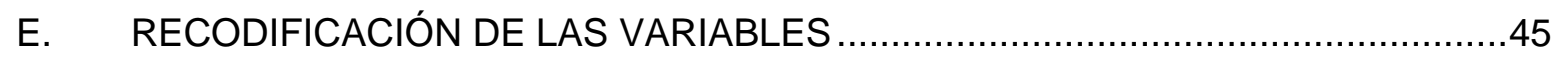


A. EVOLUCIÓN DE LOS PROBLEMAS SOCIALES POR PARTE DE LA SOCIEDAD ESPAÑOLA (2000 a 2013). .

1. Percepción de la sociedad ante los principales problemas de españa. ......................50

2. Percepción de los problemas personales de la sociedad española. ............................54

3. Contacto de la sociedad española con la población inmigrante o extranjera.............56

B. REPRESENTACIONES SOCIALES DE LA INMIGRACIÓN EN ESPAÑA (2008 a

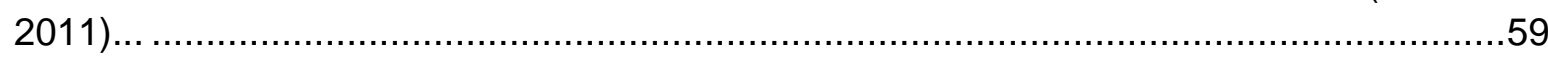

1. Representaciones sociales acerca de la inmigración...................................................59

2. Las representaciones sociales acerca de la diversidad cultural..................................65

3. Las representaciones sociales acerca de la competitividad laboral. ..........................66

4. Las representaciones sociales acerca de los medios de comunicación. .....................71

5. Las representaciones sociales acerca del trato de la población española hacia las

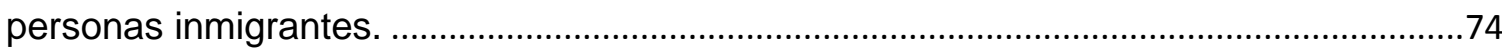

6. Las representaciones sociales acerca de las agresiones racistas...............................76

7. Foto fija de las representaciones sociales de la inmigración en españa (2011).......77

C. PERCEPCIONES SOBRE LA REALIDAD NUMÉRICA DE LA INMIGRACIÓN (2007

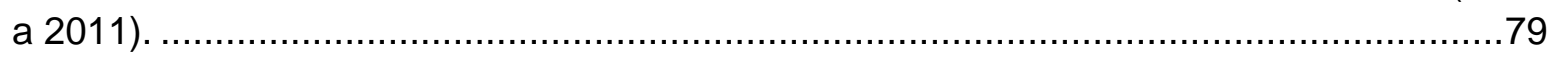

1. Evolución de la percepción de la ciudadanía sobre el número de inmigrantes. ........80

2. Realidad estadística de personas extranjeras y su percepción demoscópica. ..........81

3. Percepción demoscópica del volumen de personas extranjeras en españa por provincias..

4. Percepción de la nacionalidad de las personas inmigrantes en españa.....................86

5. Foto fija de la percepción sobre la realidad numérica de la inmigración (2011).......88

D. CREENCIAS Y VALORES SOBRE LA GESTIÓN DE LA INMIGRACIÓN (2007 a

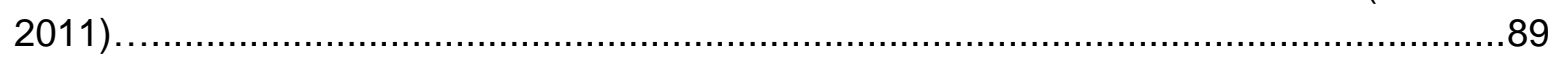

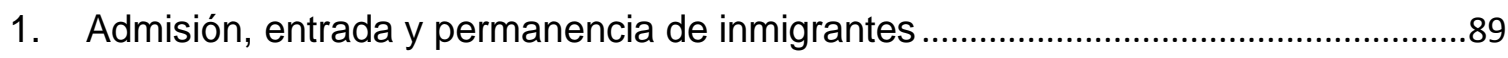

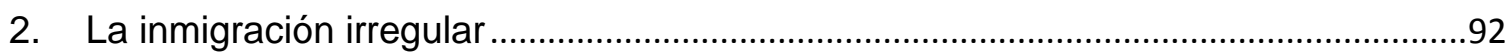

3. Ayuda del estado a las personas inmigrantes .............................................................93

4. Derechos de las personas inmigrantes regulares ..........................................................96

5. Foto fija de las creencias y valores sobre la gestión de la inmigración (2011).........98

E. ACTITUDES ANTE LA INMIGRACIÓN EN LA VIDA COTIDIANA (2007 a 2011). 100

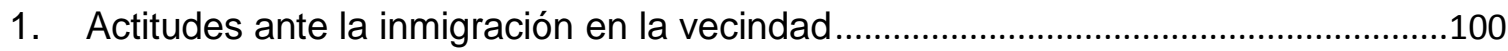

2. Actitudes ante la inmigración en el trabajo y/o estudios .............................................103

3. Actitudes ante la inmigración en las relaciones familiares. .........................................106 
4. Simpatía-antipatía dependiendo de los grupos de nacionalidades de las personas inmigrantes.

F. $\quad$ ANÁLISIS DE LOS PERFILES DE LA POBLACIÓN ANTE LA INMIGRACIÓN (2011).

VIII. CONTRASTE DE HIPÓTESIS ................................................................................119

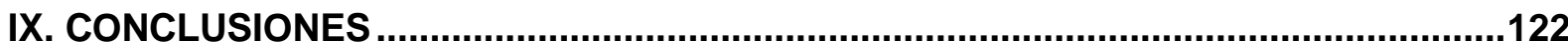

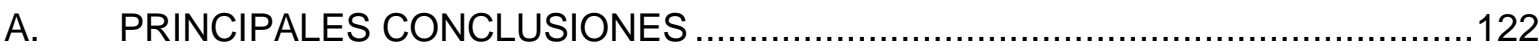

B. APLICABILIDAD DE LOS RESULTADOS ............................................... 126

C. FUTURAS LÍNEAS DE INVESTIGACIÓN ........................................................127

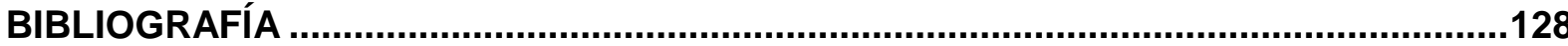

ANEXO I: ANEXO METODOLÓGICO ....................................... ¡Error! Marcador no definido.

A. Descripción del barómetro de opinión pública (CIS) ......... E Error! Marcador no definido.

B. Descripción del estudio de actitudes ante la discriminación por origen racial o étnico (CIS) ¡Error! Marcador no definido.

C. Descripción del estudio de actitudes ante la inmigración (CIS) ¡Error! Marcador no definido.

ANEXO II: ANEXO DE RESULTADOS ¡Error! Marcador no definido.

ANEXO III: AMPLIACIÓN DEL ÁRBOL DE RESULTADOS. 157 ÍNDICE DE GRÁFICOS Y TABLAS 


\section{INTRODUCCIÓN}

El punto de partida de esta investigación es conocer cómo la inmigración se ha construido como problema social en España. En lo que se refiere al estudio de los movimientos migratorios en España, está marcado por los cambios en la tendencia migratoria que se han producido en el último siglo. A principios del siglo $\mathrm{XX}$, las migraciones eran internas de campo a ciudad, y conllevaron cambios relevantes en la estructura económica del país. A mediados de siglo, España se convirtió en un país de emigrantes, especialmente con destino a Centroeuropa -Alemania, Suiza y Francia- y Latinoamérica -Venezuela, Argentina y México-; influenciadas estas migraciones, en gran parte, por la posguerra española. Es a partir de los años 90', donde el país sufre un cambio su tendencia migratoria y comienza a ser un destino para inmigrantes y emigrantes retornados del anterior periodo. En la actualidad, autores como Arango (2012), hablan del inicio de un cambio en el ciclo migratorio, debido al retorno o re-emigración de inmigrantes residentes en España y de la emigración de jóvenes españoles.

En estos cambios de ciclo en España, la sociedad se ve envuelta en una serie de transformaciones a nivel geopolítico, reestructuración del sistema productivo y el mercado de trabajo, reformas económicas y del sistema monetario, redefinición de la identidad nacional, construcción de referentes de convivencia. (Gimeno, 2001), que conllevan inestabilidad e incertidumbre entre la población autóctona, que repercute en sus actitudes y percepciones hacia la inmigración. Un instrumento para medir la opinión de la ciudadanía sobre la inmigración es el Centro de Investigaciones Sociológicas (CIS). Desde el año 2000 hasta el 2007, ininterrumpidamente, la sociedad española señalaba a la inmigración como uno los cinco principales problemas del país, y es en septiembre de 2006, donde por primera vez la mayoría de la población española -59,2\%- asegura que la inmigración es el primer problema del país, justamente después de la "crisis de los cayucos"1. Es en ejemplos como este y como el asalto a las vallas de Ceuta y Melilla $(2005)^{2}$, donde se aprecia qué es en estos momentos cuando aumenta la percepción sociedad sobre que la

\footnotetext{
1 Aumento de la llegada de embarcaciones con inmigrantes irregulares, mayoritariamente subsaharianos, a las costas de las islas Canarias procedentes de Mauritania. Durante el 2006 llegaron 31.678 personas sólo a las costas Canarias. Este hecho, causó gran impacto en la opinión pública así como los medios de comunicación que prestaron gran atención a este fenómeno, indagando en las causas y consecuencias del mismo.

2 Ante el aumento de la vigilancia policial en el estrecho de Gibraltar, la salida de pateras se reduce y se emplea como vía de acceso a España, las ciudades autónomas de Ceuta y Melilla. Provocando una gran afluencia y altercados que acaban con un incremento del control de estas fronteras tanto por Marruecos como por España.
} 
inmigración es un problema para España. A su vez, estos acontecimientos causaron una cobertura amplia por parte de los medios de comunicación, y la inmigración entró a formar parte de la agenda mediática y política.

Ante el escenario descrito, la presente investigación pretende conocer la percepción y las actitudes de la sociedad española ante la inmigración y cómo estas han variado durante el periodo 2007 a 2011. El intervalo temporal examinado es relevante debido a que se produce un cambio de ciclo económico en España y es reseñable analizar cómo afecta el impacto de la crisis económica a la percepción sobre la inmigración. Así cómo, examinar qué elementos configuran la construcción de la inmigración como problema social y la influencia que tienen sobre la opinión de la ciudadanía ante el fenómeno migratorio. La hipótesis general de la investigación es que en la construcción de la inmigración como problema social en España han influido más los agentes externos al fenómeno migratorio -medios de comunicación y la politización de las migraciones- que el contacto directo con la población inmigrante.

La investigación se compone de un (II) marco teórico, en el cual se recopilan las principales teorías sobre la construcción de los problemas sociales, haciendo hincapié en la teoría construccionista y posteriormente, en la construcción de la inmigración como problema social. Después, se realiza una (III) contextualización de la inmigración en España, en la que se señalan las principales etapas de la misma. Una vez realizado un estudio teórico y contextual del objeto de estudio, se presenta (IV) la problematización y la pregunta de investigación; de donde surgen (V) los objetivos y las hipótesis de la investigación. A raíz de esto, se detalla (VI) la metodología que se ha seguido, especificando cuales han sido las técnicas de producción de datos y las técnicas de análisis de datos. De este proceso se llega al (VIII) análisis de resultados en el que se examinan los seis principales bloques de la investigación; paro luego (IX) corroborar las hipótesis planteadas con anterioridad. Para finalizar, se realizan las $(X)$ conclusiones de la investigación, la aplicabilidad de los resultados y las futuras líneas de investigación que derivan de esta investigación. 


\section{MARCO TEÓRICO}

El marco teórico de esta investigación se centra en tres grandes áreas: (A) recorrido histórico en la construcción de los problemas sociales; (B) la perspectiva constructivista y (C) la inmigración como problema social.

\section{A. RECORRIDO HISTÓRICO EN LA CONSTRUCCIÓN DE LOS PROBLEMAS SOCIALES.}

Las teorías más representativas en la construcción de los problemas sociales en el siglo XX son: el funcionalismo, el interaccionismo simbólico y el enfoque crítico. Sin embargo, es muy clarividente realizar un recorrido histórico por las siete perspectivas teóricas para el estudio de los problemas sociales que elaboran Rubington y Weiberg (1995).

1. La perspectiva de patología social. Surge a finales del siglo XIX, y realiza una distinción entre lo considerado normal y lo patológico. Esta perspectiva hace énfasis en los rasgos psicológicos y biologicistas de los problemas. Por tanto, para esta concepción, el problema social surge como una transgresión de las normas establecidas, como pueden ser la disfunción, la anomía y la desviación; causando conflicto a uno o varios grupos sociales. Los principales representantes de esta disciplina son Spencer y Durkheim.

2. La perspectiva de la desorganización social. Teoría desarrollada en los años 20'. Para los representantes de esta perspectiva, los problemas sociales aparecen por cambios bruscos en el medio ambiente social y laboral -industrialización, globalización-. Dichos cambios generan en los individuos problemas de desorganización con el medio -alcoholismo, violencia de género. Los propulsores de esta perspectiva son Znaniecki y Park.

3. La perspectiva del conflicto. Aparece en los años 30' como consecuencia de la gran depresión. Para esta teoría, los problemas sociales surgen porque en las sociedades capitalistas existe una competición por los recursos entre grupos que tienen un desigual acceso a los mismos. Los principales exponentes de esta teoría son Coser y Dahrendorf.

4. La perspectiva del comportamiento desviado. Esta perspectiva tuvo su auge en los años 50' y 60', sus ideas giraban en torno a que la desviación social es un 
vehículo que algunos individuos emplean para vencer las barreras sociales y lograr los objetivos que culturalmente han sido construidos y aceptados por la sociedad. Sus exponentes son Merton, Shaw y Mckay.

5. Teoría del etiquetamiento. Fue desarrollada en los años 50', bajo el pensamiento de que hay grupos de poder con la capacidad de etiquetar conductas como desviadas. Por tanto, el estudio de los problemas sociales consiste en indagar cómo los grupos de poder perduran en su posición hegemónica atribuyendo normalidad o patologías a las acciones y conductas de la sociedad. Los principales representantes de esa teoría son Becker y Goffman.

6. Teoría crítica. Surge a medidos de los años 30', pero es en la década de los $70^{\prime}$ donde alcanza su mayor repercusión en el estudio de los problemas sociales. El enfoque crítico ofrece una perspectiva multicausal de la construcción de los problemas sociales, pone su atención en la distancia existente entre la sociedad ideal y la real. Los principales teóricos del enfoque crítico son Mills, Wright y Marcuse.

7. Perspectiva constructivista. Para esta teoría los problemas sociales no son entendidos como "hechos sociales" en la conceptualización durkheiniana de la expresión, sino que depende de lo que la sociedad en un determinado tiempo y espacio identifique como problema social, de tal modo puede crearse y puede desaparecer. Por tanto, hacen hincapié en que los problemas sociales son cambiantes. Sus principales exponentes son Berger, Luckman y Bourdieu.

En esta línea y siguiendo a Giner, Lamo de Espinosa y Torres (2006) "Ios problemas sociales son un resultado de procesos sociales de creación, cambio y ajuste de las representaciones subjetivas públicas de los grupos; de tal manera que depende de la capacidad de los diferentes grupos para etiquetar algún aspecto de lo social o algún otro grupo como problema, para que efectivamente sea definido así". Del tal modo, que únicamente ciertos fenómenos sociales se constituyen, en momentos sociales específicos, en causa de preocupación y pasan a ser considerados como problemas sociales.

Para la presente investigación se va a utilizar la perspectiva constructivista, debido a que el interés de la misma reside en cómo la inmigración se construye como problema social en España. 


\section{B. LA PERSPECTIVA CONSTRUCTIVISTA}

Este punto sobre la perceptiva constructivista, engloba tres apartados: (1) la construcción de los problemas sociales; (2) la formación de la agenda pública en la construcción de los problemas sociales; y (3) los medios de comunicación en la construcción de los problemas sociales.

\section{LA CONSTRUCCIÓN DE LOS PROBLEMAS SOCIALES}

Para la teoría constructivista los fenómenos sociales pueden convertirse en problemas sociales, o no, para examinar esto es necesario conocer qué es lo que construye los problemas sociales y por qué acontece. Ejemplo de esto son los casos de la desigualdad hacia la mujer, la segregación racial, la inmigración y la pobreza (Lorenc, 2005). Estas situaciones ya se producían antes de considerarlas como problema social, y no necesariamente su consideración se deba a que se haya producido un cambio drástico en el fenómeno social, es decir, un agravamiento de la situación, sino que sencillamente se ha visibilizado.

Para Blumer (1971) "un problema social existe principalmente en los términos en que es definido y concebido en la sociedad", el autor sistematiza la construcción de los problemas sociales y asegura que para que un fenómeno social se considere y sea reconocido como problema social, debe pasar por cinco fases:

1) Emergencia del problema: etapa de agitación en la que el grupo social o de presión reivindica su situación e intenta que otros grupos sociales más amplios o con más peso socio-político lo reconozcan y se unan a su protesta. En esta fase se pone de manifiesto ante la sociedad que existe un problema.

2) Legitimación del problema: en este momento las instituciones asumen que hay grupo social o de presión que reivindica una problemática concreta y se comienza a definir en qué puntos y de qué manera se va a actuar desde la arena pública.

3) Movilización de la acción con respecto al problema: una vez que el grupo social está organizado y las instituciones se han hecho eco de las protestas; es el momento de diseñar y ejecutar una estrategia común en relación a la situación. Aquí surgen conflictos y disputas entre las partes implicadas en el proceso. 
4) Formulación de un plan oficial de acción: en esta fase, la relevancia del grupo social o de presión se diluye, para dejar paso a la burocratización de la acción por parte de las instituciones competentes para el proceso.

5) Implementación de este plan: las instituciones ponen en marcha el plan que han diseñado para enmendar la problemática que ha surgido. En esta etapa, es crucial la actitud del grupo social o de presión inicial que puede optar por alguna(s) de la(s) estrategia(s):

a. No aceptar el plan de actuación implementado por las instituciones competentes para la problemática.

b. Reestructura el grupo social o de presión, con el objetivo de emprender nuevas acciones de protesta.

c. Mantener el mismo grupo social o de presión, modificando las protestas iniciales por nuevos objetivos.

Los autores Kitsuse y Spector (1973) plantean otra alternativa más para el grupo social o de presión, que sería que se subdividiesen y por fracciones emprendiesen la búsqueda de soluciones parciales al problema social inicial.

Blumer (1971) resalta la importancia de las instituciones para construir problemas sociales, es decir, las políticas públicas que se implementan son básicas para visibilizar los problemas sociales, junto con los medios de comunicación. Para emprender políticas públicas es imprescindible que la problemática entre dentro de la agenda pública de la clase política.

\section{LA FORMACIÓN DE LA AGENDA PÚBLICA EN LA CONSTRUCCIÓN DE PROBLEMAS SOCIALES.}

La formación de la agenda pública en la construcción de los problemas sociales es importante para comprender la relevancia del problema social y los actores implicados en ello. Para Downs la inmersión en la agenda pública de un problema social tiene comportamiento cíclico que consiste en que "de repente surge un problema, sobresale, llama la atención durante un breve periodo y luego -muchas veces sin haber encontrado solución- desaparece paulatinamente del centro de la atención pública" (Downs 1972), además de ello, el autor puntualizó que "cualquier 
problema importante que alguna vez captó el interés del público es capaz de recapturarlo esporádicamente".

Además de ello, la formación de la agenda para Elder y Cobb (2003) es entendida como aquel "a través del cual ciertos problemas o cuestiones llegan a llamar la atención seria y activa del gobierno como posibles asuntos de política pública". Estos autores (1983) aseguran que para que un fenómeno social se incorpore en la agenda debe tener imprescindiblemente tres requisitos:

1) Que se despliegue alrededor de la problemática una cobertura y conocimiento de la sociedad;

2) que una amplia parte de la sociedad considere que es necesario implementar algún tipo de acción o actuación;

3) que la sociedad crea que la acción o actuación sea competencia de la institución correspondiente.

Una vez examinado como un problema puede entrar en la agenda pública, para ello es necesario por un lado indagar sobre los grupos sociales o de presión que intervienen en el proceso, llamados "operadores" y por otro lado sobre los ámbitos o "arenas" en las que se manejan (Hilgartner y Bosk, 1988).

Por un lado, en cuanto a los "operadores" o "reclamadores" (Best, 1990); son los actores sociales que realizan varias fases en la construcción del problema social. En un primer momento señalan cuál es la situación que está provocando un problema, posteriormente qué tipo de problema es el que se está produciendo y finalmente indican todas las alternativas de resolución del problema así como la solución que se considere más viable para el determinado problema social. Best (1990) realiza una tipología de los diferentes "reclamadores":

- La víctima: los afectados directamente por la problemática, los cuales reclaman una solución. Tienden a marcar específicamente su definición del problema social. Por lo general no tienen las aptitudes necesarias para emprender el proceso de construcción del problema social y necesitan a otro tipo de reclamador.

- Los activistas: se unen a las víctimas dependiendo de sí la problemática es afín a su ideología. Tienen experiencia en movimientos sociales. 
- Los especialistas: son expertos reclamadores. Son consultores independientes que se alían a las víctimas principalmente por un salario. Sus aptitudes son las relaciones públicas y la logística.

- Los profesionales: emplean su formación reglada para conceder peso a las solicitudes de las víctimas. Serían abogados, médicos, psicólogos, sociólogos, investigadores etc.

- Los funcionarios: emplean su cargo o estatus para ampliar su influencia social o los atributos de sus mismas instituciones.

- Los grupos de presión: pueden ser directamente los reclamadores, pero al estar dentro de la organización institucional, no demandan apoyo público, y por tanto presionan en privado para que se hagan eco de sus demandas.

Por otro lado, los principales ámbitos o arenas en el que se puede construir un problema social son: "los medios de comunicación, los debates en el Congreso, las dependencias del poder ejecutivo, los juicios en tribunales, los diversos ámbitos de la cultura -libros, películas, piezas de teatro, documentales, telenovelas-, la comunidad científica y las organizaciones religiosas" (Hilgartner y Bosk, 1988). Sin embargo cabe destacar, que los problemas sociales que tienen más repercusión son aquellos que no se encuentran focalizados en una única arena, sino que está extendida y con una relativa importancia por varios de los ámbitos de discusión anteriormente citados (Frigerio, 1995).

Es reseñable destacar que una vez esta constituido un problema social dentro de la agenda pública, la durabilidad es muy relativa, debido a que hay problemas sociales que son fruto de un momento puntual, como la epidemia de las vacas locas $(2001)^{3}$ o la preocupación medioambiental debido al hundimiento del Prestige (2003) ${ }^{4}$; y por el contrario hay problemas que una vez que se construyen como tales, se perpetúan durante un periodo de tiempo largo y estable, como es el caso de la inmigración ${ }^{5}$.

\footnotetext{
${ }^{3}$ Datos del barómetro de enero del 2001 de CIS, donde la sociedad española situaba como tercer problema del país el problema agro-ganadero derivado de las vacas locas, con el $6,3 \%$.

${ }_{5}^{4}$ Datos del barómetro de enero del 2003 de CIS, en el que el cuarto problema de España era el Prestige con el 5,9\%.

${ }^{5}$ La inmigración es considerada como uno de los cinco principales problemas de España durante los años 2000 a 2007, según los barómetros de opinión del CIS en todo ese periodo.
} 


\section{LOS MEDIOS DE COMUNICACIÓN EN LA CONSTRUCCIÓN DE LOS PROBLEMAS SOCIALES.}

Diversos autores señalan que los medios de comunicación junto con la agenda pública son los principales entes en la construcción de problemas sociales; sobre todo, a la hora de visibilizar cuáles son los problemas sociales y qué agentes son los que están involucrados. Para examinar la relevancia de los medios de comunicación se va a estudiar por un lado las teorías de la comunicación y por otro lado, más específicamente, la teoría de la Agenda Setting.

\subsection{Teorías de la comunicación en la construcción de problemas sociales.}

Luhmann (2000) señala que la comunicación es un elemento básico en la construcción social y en la configuración de la realidad social, de tal modo que la información que emana de los medios de comunicación es una construcción de la realidad; puesto que para el autor, el ser humano ${ }^{6}$ no es quien comunica sino que es el sistema social. Luhmann distingue entre comunicar e informar y es en esa diferencia en la que se otorga el "sentido de la comunicación", es decir hacerse comprender y entender para tomar una decisión (Castro, 2011). Mientras que la información crea un "estado imaginario" de la sociedad.

Para Luhmann (2000) no es real la teoría de la libertad de elección de noticia, sino que existe una tipología de selectores que se aplican a las noticias. Estos serían: la novedad de la información, el conflicto, el uso de cantidades (cifras), la referencia local, la contravención de las normal (escándalos), la valoración moral, la atribución de la acción, la recursividad y la exteriorización de opiniones.

De esta misma corriente de pensamiento es Baudrillard, quien dice que vivimos en un mundo "mediado por lo medios" donde lo que realmente acontece no es lo relevante, ósea, que la realidad queda a un lado dejando paso a los signos y simulacros creados por los medios de comunicación. El autor argumentó que lo que en realidad conocemos no es más que una "hiper-realidad" consumida por las masas y representada a través de los medios de comunicación (Macionis y Plummer, 2010).

\footnotetext{
${ }^{6}$ Entendiendo al ser humano como sistema psíquico y orgánico.
} 
Esta labor, se le facilita a los medios de comunicación en sociedades cada vez más globalizadas, puesto que la ciudadanía pierde el contacto con la realidad directa, es decir, con el problema social, a favor de la realidad mediatizada. Como señala Frigerio (1995) "nuestra dependencia de los medios para el conocimiento de ciertos hechos y sobre todo para su interpretación es mayor cuanto menos experiencia directa tenemos sobre un determinado tema".

Con el objetivo de distinguir entre la experiencia directa con el problema social y la realidad percibida por los medios de comunicación, Habermas (1999) propone analizar la sociedad a través de dos formas de racionalidad: la racionalidad sustantiva del mundo de la vida, que haría referencia a los propios sujetos que conviven en sociedad; y la racionalidad formal del sistema que sería lo externo a la persona. En su reflexión, el autor resalta que existe una "colonización" del sistema externo en el mundo de la vida, limitando así la comunicación, empobreciendo el mundo de la vida. (Habermas, 1999).

\subsection{La teoría de la Agenda Setting}

Desde los años 70' con el auge de la teoría de la dependencia de Ball-Rokeach y DeFleur (1976) y las primeras ideas sobre la Agenda Setting, se mostraba la influencia que tienen los medios de comunicación sobre la estructuración de la agenda pública. Lippmann (1922) ya aseguraba que los medios moldean nuestras imágenes de la realidad, puesto que seleccionan y organizan símbolos para facilitarnos la comprensión directa de los acontecimientos. Es por ello, que se afirma que los medios de comunicación construyen las noticias (Alsina 1989, Van Dijk 1990), esto se pone de manifiesto cuando ciertos temas o eventos pasan desapercibidos por los medios de comunicación, que según el prisma de otros actores sociales serían vitales; o por el contrario se le otorga una cobertura desmesurada a otros eventos.

Profundizando sobre la teoría de la Agenda Setting, describe y explica la influencia de las noticias de los medios de comunicación sobre la ciudadanía. Su principal exponente es Maxwell McCombs, para quien "los medios ejercen influencia en las 
audiencias mediante los temas considerados de mayor relevancia" (Rodríguez Díaz, 2004).

Para la teoría de la Agenda Setting, los medios de comunicación ofrecen la imagen de la realidad que tienen las personas acerca de su visión del mundo y de ciertos temas. De tal modo, que los medios de comunicación no intervienen tanto sobre el modo de procesar la información de los individuos, sino que concentran su influencia sobre los temas en los que hay que reflexionar, en función de la selección de noticiable/no noticiable que hayan realizado anteriormente los medios. Rodríguez Díaz (2004) afirma que "hablar de Agenda Setting es hablar de las imágenes que se reproducen en nuestras cabezas o mundo interior. La idea principal, por tanto, se centra en observar que las imágenes destacadas en los medios también son destacadas por la audiencia". Debido al filtro que realizan los medios de comunicación sobre los temas noticiables, es decir, el establecimiento de la agenda influye en la percepción de los temas que son más importantes para la sociedad en ese momento. Así pues, la repetición de un tema en cualquier medio informativo, con cierta constancia, es el modo más fuerte y eficaz para que la sociedad sea consciente de su importancia (McCombs, 2006).

La Agenda Setting se compone de diferentes elementos que ayudan a comprender más óptimamente la teoría:

- Issues (los temas): son los temas relevantes que influirán en las audiencias a través de los medios de comunicación, "serian los acontecimientos de siempre que más preocupan a la sociedad, tales como la política, sanidad o economía" (Rodriguez Diaz, 2004).

- Sailence (la relevancia): característica de los temas que están incluidos dentro de la agenda. Estos temas son fácilmente identificables puesto que ocupan los lugares más significativos en los medios de comunicación -portada de un periódico, noticia con la que se abre el informativo-. The salience (la relevancia) indica que existe un gradiente de los temas dentro del establecimiento de la agenda.

- Obtrisuve (temas cercanos): son los temas de la agenda con los que parte de audiencia tiene más cercanía, ya sea porque tienen un mayor conocimiento previo o porque afectan a su entorno o vida personal de manera directa. En el 
Obtrisuve (temas cercanos) es más difícil modificar los esquemas mentales $u$ opiniones sobre los mismos.

- Unobtrosive (temas desconocidos): al contrario que los obstrisuve (temas cercanos); estos resultan más lejanos para una parte de la audiencia, son desconocidos y/o más alejados de la cotidianidad. Ante los unobtrosive (temas desconocidos) las opiniones y percepciones expresadas por los medios de comunicación tienen una mayor influencia, puesto que esta parte de la audiencia no tiene una experiencia directa con los temas de la agenda.

- Gatekeeper (seleccionador de noticias): son los individuos encargados de seleccionar las noticias de la agenda. Son personas con la influencia suficiente para filtrar cuáles son los temas de interés, el tiempo que estarán en la agencia, el espacio que ocuparán y la importancia con la que se va a tratar el tema.

Siguiendo a Rodríguez Díaz, además de los elementos que componen la Agenda Setting, existen unos factores que influyen en la agenda; estos serían: time frame (marco temporal); la naturaleza de los temas; las variables demográficas; el tipo de medio de comunicación; y el entorno físico.

La Agenda Setting al delimitar y definir el problema públicamente, condiciona en gran parte la solución del problema social (Guirao, 2010). Siguiendo a Martín Llaguno (2002) los medios de comunicación "definen los aspectos a destacar de estas situaciones, en detrimento de otros y así reconstruyen los temas en función de unas características determinadas y, proponen sus causas y soluciones".

En segundo nivel de la teoría de la Agenda Setting ${ }^{7}$ es la investigación sobre el framing o encuadre noticioso. El framing es el modo en el que la persona que comunica encuadra un tema y realiza una agenda de atributos sobre la temática (Igartua, Muñiz y Cheng, 2005). De tal modo que el framing no hace una referencia directa a la temática, sino al tratamiento que se le otorga al tema (D'Angelo, 2000). Las fases del framing serían: encuadrar un tema de una determinada manera; crear una agenda de atributos; seleccionar un conjunto clave de palabras y/o expresiones

\footnotetext{
${ }^{7}$ Existen dos consideraciones sobre el framing como teoría. En primer lugar, quienes creen que es el segundo nivel de la Agenda Setting, representada por: Chyi y McCombs, 2004; McCombs y Ghanem, 2001; McCombs, Llamas, López-Escobar y Rey 1997; McCombs, López-Escobar y Llamas 2000; McCombs y Reynolds, 2002. En segundo quienes creen que el framing debería ser una teoría propia desligada de la Agenda Setting, seguida por los autores; Entman, 1993; Kin, Scheufele y Shanahan, 2002; Maher, 2001; Prince y Tewksbury, 1997; Scheufele, 1999, 2000, 2004. (en Iguarta et al, 2005).
} 
para generar el discurso; manipular the salience (la relevancia) de algunos elementos; y elaborar un "idea organizadora central para construir la historia informativa (Tankard, 2001).

El framing o encuadre noticioso es muy útil para analizar y explicar cómo las noticias aparecidas en los medios de comunicación, ejercen una gran influencia en la percepción de los acontecimiento y de los procesos sociales (Entman, 1993).

\section{C.LA CONSTRUCCIÓN DE LA INMIGRACIÓN COMO PROBLEMA SOCIAL}

Antes de analizar cómo se construye la inmigración como problema social, es necesario especificar sobre la terminología que se va a utilizar en la presente investigación. Por un lado, la diferenciación entre inmigrante y extranjero. El primer término designa los cambios de residencia más o menos permanentes, y que, por lo común, son debidos a factores económicos, laborales, sociológicos o políticos. Mientras que el segundo término -extranjeros- son aquellas personas que no poseen la nacionalidad del país donde viven (Soriano, 2008). Por otro lado, la distinción entre inmigración e inmigración internacional reside en que el primer término engloba al segundo, puesto que la inmigración puede ser interna, es decir, dentro de las fronteras nacionales, como por ejemplo de una Comunidad Autónoma hacia otra, o internacional que exige un desplazamiento fuera de las fronteras nacionales, es decir, de un país hacia otro. La presente investigación se centra en la inmigración internacional.

En la construcción de la inmigración como problema social se tratan cinco aspectos: (1) las actitudes ante la inmigración; (2) los factores de construcción de la inmigración como problema social; (3) los perfiles de percepción de la inmigración en España; (4) los discursos ante la inmigración; y (5) la construcción de la diferencia.

\section{ACTITUDES ANTE LA INMIGRACIÓN}

El termino actitud es objeto de estudio tanto por su concepto como por su medición. Respecto al concepto de actitud, el primer gran estudio data de 1935 por Allport, llamado Acttitudes, en el cual se recogían más de cien definiciones del concepto actitud. En un inicio el concepto de actitud estaba ligado a concepciones 
"mentalistas", es decir, como disposiciones previas que tienen los individuos ante una temática o una conducta específica. Para Katz (1974) la actitud es "una predisposición del individuo a valorar ciertos símbolos u objetos o aspectos de su mundo de un modo favorable o desfavorable". Otra rama de estudios sobre las actitudes abogan por una concepción "conductual”, es decir sí las actitudes son causa de determinadas conductas. Para Lamberth (1980) la actitud es "una respuesta evaluativa, relativamente estable, en relación a un objeto, que tiene componentes o consecuencias cognitivas, afectivas y probablemente comportamentales". Bajo este enfoque conductual, Cea D’Ancona (2002) señala "su conocimiento [la actitud] permitirá no sólo predecir la conducta, sino también modificarla o controlarla, cambiando la actitud".

En relación a la medición de las actitudes, se suele realizar mediante el uso de encuestas. El problema de la actitud es que no se puede medir directamente, siguiendo la psicosociología de las actitudes, al ser procesos internos del individuo, únicamente se pueden conocer indirectamente, pidiendo a los individuos que expresen su postura ante diferentes hechos o conductas. Es por ello, que las encuestas dependen de "la sinceridad, la información y la capacidad de introspección, el interés en proporcionar información, la comprensión de las preguntas etc., por parte de las personas preguntadas" (Gimeno 2001). La medición de las actitudes es especialmente interesante en el tema de inmigración, ya que numerosos autores ponen en duda, que el método para medir las actitudes ante la inmigración sea el más idóneo, uno de estos autores es Izquierdo (1995) quien señala que la medición de la actitud hacia inmigración indica que la persona racista es la ciudadanía "con menos recursos educativos y económicos, aquel que está sobrado de edad y desnudo de medios. Si esto fuera del todo cierto, el racismo tendría sus días contados en las sociedades desarrolladas y su base social estaría en franco retroceso". Este mismo autor afirma que los estudios de actitudes ante la inmigración no ponen de manifiesto los nuevos tipos de racismo, ya que las capas medias de la sociedad contestan a estas encuestas según la "deseabilidad social"; por tanto las encuestas de actitudes ante la inmigración miden el racismo tradicional, esquivando el racismo sutil ${ }^{8}$. De hecho las personas que poseen un mayor nivel

${ }^{8}$ Desde los años 80' existen nuevas concepciones de racismo, llamado "nuevos racismos", en el que la concepción de raza ya no es importante en la construcción de las diferencias raciales. Existen manifestaciones más sutiles de racismo. 
educativo son las más proclives al sesgo de la deseabilidad social ${ }^{9}$; la explicación se encuentra en que tienen unos mayores conocimientos para percibir la intencionalidad de la pregunta y están más interesadas en no mostrarse racistas o xenófobas (Krysan, 1998).

Una manera de solventar las deficiencias en el método de análisis de las actitudes hacia la inmigración es el análisis de datos longitudinal, ya que según Cea D'Ancona (2002) permite por un lado conocer las tendencias en la población española de las actitudes declaradas ante la inmigración, y por otro lado comprobar la fiabilidad del instrumento de medición que normalmente es el cuestionario. Siguiendo esta línea de análisis los autores McBroom y Reed (1992) señala que "los datos longitudinales proporcionan una ventaja de diseño importante al estudiar la consistencia actitudconducta".

\section{FACTORES DE CONSTRUCCIÓN DE LA INMIGRACIÓN COMO PROBLEMA SOCIAL.}

Tal y como se señaló con anterioridad, para Blumer (1971) la construcción de un problema social pasa por cinco fases. Aplicando esto a la inmigración internacional en España, se aprecia que la etapa de emergencia del problema se produce a finales de los 90', que causaron un gran revuelo social, además en este momento comienza a haber una amplia literatura especializada en inmigración. La segunda fase, legitimación del problema, acontece el planteamiento de la Ley 4/2000 sobre derechos y libertades de los extranjeros en España y su integración social, que surge a causa de que la anterior ley (1985) se había quedado obsoleta. En la tercera etapa, la movilización de la acción con respecto al problema, aparece tras los incidentes de El Ejido en el 2000, que hicieron que sectores anti-inmigración y proinmigración se movilizasen para defender sus ideales. La posterior fase es la formulación de un plan oficial de acción, en la que se reunieron instituciones gubernamentales y sociales, las primeras con el objeto de realizar acuerdos bilaterales con los países emisores de inmigración para fomentar el control y las segundas con el propósito de idear planes de integración y cooperación entre

9 Schuman y Presser, 1981/1996; Krosnick y Alwin, 1987; Narayan y Krosnick, 1996; Ross y Mirowski, 1998; Krysan, 1998. En Cea D'Ancona (2002). 
autóctonos e inmigrantes. La última fase, implementar el plan de acción, se pone un marcha los acuerdos previstos con los países, ejemplo de eso con Guinea Bissau (2003), Marruecos (2004), Senegal (2006) y así como programas específicos del gobierno para impulsar la integración, como el Foro para la Integración Social de los Inmigrantes $(2006)^{10}$.

\subsection{Los medios de comunicación}

Los medios de comunicación en la construcción de la inmigración como problema social, tienen una importancia vital, como ya se ha explicado anteriormente en la relevancia de los medios para construir problemas sociales, uno de los principales factores es la presencia continuada de la inmigración en los medios de comunicación con noticias que fomenten una actitud negativa.

Por un lado, hay que destacar que los medios de comunicación cumplen una serie de funciones: legitimadora (Van Dijk, 1991), socializadora y gestora de la opinión pública (Zapata-Barrero, 2004); en base a esto, los medios de comunicación generan un conjunto de argumentos para justificar discursos migratorios y legitimarlos; de tal modo, que no únicamente forman estereotipos, sino que además los consolidan y mantienen a lo largo del tiempo. Las demandas que se les realizan a los medios de comunicación son que ofrezcan un equilibrio respecto a las noticias relacionadas con la inmigración, y que no se sobredimensionen las noticias con connotaciones negativas. Puesto que esto contribuye a la asociación de la inmigración con la delincuencia, la ilegalidad y los problemas de convivencia, haciendo que se criminalice a las personas inmigrantes, lo cual daña gravemente la convivencia entre autóctonos e inmigrantes. (Cea D'Ancona, 2009). En esta misma postura Checa (2003) afirma que "ser inmigrante en España ya no indica únicamente el hecho de ser extranjero, de no poseer la nacionalidad española, sino que ha pasado a tener un significado más simbólico, al estar directamente relacionada con la pobreza, el desorden, la delincuencia y la ilegalidad". Como señalan Igartua et al. (2004), existe una correlación positiva entre la cobertura informativa que se le otorgue a la inmigración y su consideración como problema social.

\footnotetext{
${ }^{10}$ Datos extraídos de la Secretaria General de Inmigración y Emigración. Ministerio de Empleo y Seguridad Social.
} 
Por otro lado, como señalan los barómetros de actitudes del $\mathrm{CIS}^{11}$, la mayoría de la ciudadanía española no tiene un contacto directo con la inmigración de manera habitual, por lo que la principal fuente de información y formación de las opiniones y actitudes hacia las personas inmigrantes proviene de los medios de comunicación (Colectivo IOÉ, 2005). Al no ser la inmigración un tema cercano -obtrisuve según la teoría de la Agenda Setting-; es más fácil que la ciudadanía esté más influencia por las opiniones vertidas en los medios de comunicación. Así lo señalan Piñuel y Gaitan (1995) "de la realidad social ya no se tiene experiencia sino noticia"; de tal modo que a mayor desconocimiento sobre otras culturas existe un mayor riesgo de tomar como verdad objetiva la realidad que se ha construido mediáticamente (Sobrados, 2011), como se verá posteriormente en la presente investigación.

\subsection{La politización de las migraciones}

Otro factor que influye en la construcción de la inmigración como problema social, es la politización que se realiza de las migraciones, la cual se apoya en el grado de atención que recibe y el nivel de conflicto que suscita. De tal modo, que cuando la inmigración recibe gran atención -es decir, atención pública y política que hace que entre en la agenda pública- y/o altos nivel de conflicto -entra dentro del debate público-, está muy politizada la inmigración (Morales y Ros, 2012).

Para Van Dijk (1993), no todos los discursos tienen la misma relevancia social, "así, mientras los discursos de las élites acceden libremente al dominio público, otros discursos son silenciados y excluidos sistemáticamente"; en el caso del gobierno, diputados y senadores; y partidos políticos tienen una posición prioritaria en los canales de difusión y por parte de la ciudadanía, lo que el propio autor denomina "contextos discursivos dominantes". Los discursos políticos conllevan actitudes negativas hacia la inmigración en dos aspectos: respecto a su volumen y con la asociación de la inmigración con la delincuencia.

Por un lado, en cuanto al volumen de inmigrantes en España, el discurso político se manifiesta cuando se anuncia un endurecimiento de la legislación de entrada de

\footnotetext{
${ }^{11}$ Pregunta: Entre sus vecinos, ¿hay alguno que sea inmigrante o extranjero? ¿y entre sus compañeros de trabajo o estudios? ¿y entre sus amigos? ¿y entre sus familiares?
} 
inmigrantes. Esto provoca una asociación directa con que el número de inmigrantes es demasiado y por tanto genera un aumento del rechazo a la inmigración. Este factor cobra aún más peso para la ciudadanía sí el mensaje procede de partidos político afines a su ideología, ya que se les otorga más credibilidad (Cea D’Ancona, 2009). Un elemento importante en el análisis de la politización de las migraciones es la legislación en política migratoria, debido a que los cambios legislativos pueden activar la politización o desactivarla evitando el debate sobre la temática (Cunningham, 2012). Realizando un seguimiento de los barómetros de opinión del CIS, se muestra que aumentar la percepción de la población sobre que la inmigración es uno de los principales problemas del país, cuando el gobierno anuncia o inicia procesos de regularización de inmigrantes -tanto el 2001 como en 2004-, o el endurecimiento de la política migratoria -ejemplo de 2002-; así como el anuncio del gobierno de iniciar procesos de regularización y la reforma de la Ley de Extranjería, para aumentar el control de la inmigración irregular -en 2006- (Cea D'Ancona 2005 y 2007). Estos anuncios y/o iniciativas generan un aumento en la cobertura mediática especialmente aquellas que hacen referencia a la necesidad de control de la inmigración y de la legalidad. En base a esto, no es de extrañar que los medios de comunicación hagan hincapié en el control social ya que como señala Soriano (2011) "la mayoría de los partidos políticos resaltan la necesidad tanto de controlar el acceso al territorio, como de controlar socialmente a la nueva población. Esta situación genera una fractura cada vez más diferenciada entre el ellos y el nosotros que puede derivar en la emergencia de un potencial conflicto enraizado en el imaginario colectivo de la sociedad española"; esto se pone de manifiesto en el espíritu de la legislación -Ley 4/2000, Ley 8/2000, Ley 14/2003 y Ley 2/2009- donde el control está impreso en los debates parlamentarios. Cabe reseñar que la situación de descontrol provoca un aumento en la xenofobia (Cea D’Ancona, 2009).

Por otro lado, la politización de las migraciones, hasta un cierto grado, es normal por la relación directa que existe con la idea de nación y con los derechos humanos, mientras que la intensidad depende de permeabilidad de la agenda política del gobierno y de la competición partidista (Weil, 1998 en Cebolla y González, 2008). De hecho la inmigración se ha utilizado como un instrumento para cohesionar la identidad nacional, para ello se ha empleado la diferenciación entre "nosotros" y "otros" que se ha caracterizado por una progresiva culturalización de la diferencias y 
una naturalización de ellas (Franzé, 1999) y a raíz de ello se ha presentado a la inmigración como un problema en sí mismo (Checa, 2008). Un ejemplo de la politización de las migraciones y su asociación con la delincuencia se produce en España del año 2000 al 2004, donde los agentes del discurso político inician un debate sobre inseguridad ciudadana e inmigración. Ante esta asociación, los medios de comunicación se hacen eco de este debate, en el que se encuentran titulares en prensa del Director de la Política, del Ministro de Interior y del Presidente del Gobierno relacionando inmigración y delincuencia ${ }^{12}$. Además de ello, la utilización de la inmigración es tema recurrente en campaña electoral, por la rentabilidad política que se logra de la inmigración, al carecer las personas inmigrantes de derechos políticos, y no ser un nicho de votos hace que sea empleado sin un riesgo electoral directo. La primera vez que se emplea es en la elecciones de 2000 , donde se emprende una campaña en contra de la Ley de Extranjería 4/2000; en el que utilizan en los debates políticos argumentos como invasión, efecto llamada de la ley y repercusiones negativas para la sociedad española (Sobrados, 2011).

\section{PERFILES DE PERCEPCIÓN DE LA INMIGRACIÓN EN ESPAÑA}

\subsection{Actitudes ante las minorías étnicas en Europa}

En 1985, el Parlamento europeo mostró su preocupación por el avance del fascismo y el racismo en Europa. Al hilo de esto, se realizó el informe "Racismo, xenofobia e intolerancia. Derechos humanos e inmigración en la Comunidad Europea" en 1988, del cual surgieron de una serie de encuestas realizadas a la ciudadanía de los diferentes países europeos sobre racismo, intolerancia y xenofobia. Los resultados del estudio, mostraron la existencia de diferentes posturas ante la inmigración diferenciado por zonas europeas, de tal modo que los países del sur de Europa -Grecia, Portugal, España y en menor medida Italia- así como Irlanda, tenían posicionamientos más tolerantes sobre las minorías étnicas que los países del centro y norte de la Comunidad Europea. A raíz de este informe, el Parlamento

\footnotetext{
12 "El director de la policía achaca a la inmigración irregular la subida de la delincuencia en un 10,52\%" (El País, 11/02/2001). "Rajoy anuncia 560 nuevos policías para atajar una escalada de delitos que atribuye a la inmigración" (El País, 21 de febrero de 2002); "Interior atribuye a la inmigración el aumento de la criminalidad en más de un 9\%" (El País, 03/01/02); "Rajoy relaciona a los inmigrantes con el aumento de la delincuencia" (EI Mundo, 21/03/02); "Aznar pide blindar a la UE contra la inmigración ilegal. El sindicato policial acusa a interior de inflar los datos de extranjeros detenidos" (EI País, 21/05/02, publicado en portada).
} 
europeo decidió seguir midiendo las actitudes ante la inmigración en Europa, con preguntas especificas de inmigración en el Eurobarómetro. En el 2000, se realizó un estudio pormenorizado sobre las actitudes ante las minorías étnicas, llamado informe SORA (2001), que alumbró interesantes resultados.

El Informe SORA cuantifica las actitudes ante los "otros" -inmigrantes y minorías étnicas- de los países europeos en siete dimensiones: culpar a las minorías; apoyar políticas de mejora de la coexistencia social; aceptación restrictiva de inmigrantes; molestia; optimismo cultural; condiciones de repatriación; y asimilación cultural. Estos factores se cruzan con variables sociodemográficas consideradas relevantes sexo, edad, estudios, ideología política y pertenencia grupal-. De las respuestas encontradas y el cruce de variables se establecieron cuatro perfiles de actitud ante las minorías étnicas de la ciudadanía europea: intolerante, ambivalente, pasivamente tolerante y activamente tolerante, y su distribución en cada uno de los países (Colectivo IOÉ, 2005). Con los datos de este informe, Cea D’Ancona (2004) realiza una clasificación de los perfiles más presentes en los países europeos:

- Intolerantes: Grecia, Bélgica, Dinamarca y Francia.

- Ambivalentes: Grecia, Portugal, Luxemburgo y Austria.

- Pasivamente tolerantes: España, Italia, Irlanda y Portugal

- Activamente tolerantes: Suecia, Dinamarca, Finlandia y Países Bajos.

En el informe SORA-2001 también se apreció que no existen diferencias por sexo o afiliación a grupos de mayorías o minorías étnicas. Las diferencias se observan en función del nivel de estudios, la edad y la ideología -resultados muy semejantes a los estudios que se habían realizado en España-. También resalta el informe, que las actitudes negativas hacia la inmigración se producen entre las mismas minorías étnicas y quienes tienen una menor clase social; probablemente esto se pueda deber al temor a perder su posición social por la llegada nuevos competidores inmigrantes (Colectivo IOÉ, 2005). 


\subsection{Perfiles migratorios en España}

El informe SORA-2001, es un antecedente para Cea D'Ancona, quién a partir de los barómetros del CIS desde 1996 en adelante, se valió de la metodología del informe SORA, para realizar una tipología de actitudes hacia la inmigración en España. La autora empleó diez dimensiones:

- Derechos sociales (educación pública, vivienda digna, asistencia sanitaria, práctica de la religión, trabajo en igualdad, constituir asociaciones, traer la familia, cobrar el paso, mantener las costumbres);

- Derechos de ciudadanía (voto en municipales, voto elecciones generales, afiliarse a partidos, obtener nacionalidad); sociabilidad con marroquíes (tener como vecino, compañero de trabajo, casar, colegio, simpatía);

- Política migratoria (valoración migración, supresión fronteras, refugiados, control migración, regularización, leyes, facilitar entrada, número inmigrantes);

- Imagen tópica negativa (bajan salarios, quitan puestos de trabajo, aumentan delincuencia);

- Discriminación étnica (condiciones de vida; dificultades de inmigrantes; trabajo no cualificado, ampliación derechos);

- Postura ante partidos racistas (aceptación partidos; auge partidos racistas);

- Aceptación del inmigrante (amistad; aumentará número; cupo inmigrantes);

- Violencia contra inmigrantes (agresiones);

- Temor al asentamiento de inmigrantes (intención de quedarse, trato con desconfianza).

Así como nueve variables sociodemográficas -género, edad, estudios, ideología política, ocupación laboral, ingresos, clases social subjetiva, religiosidad y tamaño del municipio-. Como resultado de la combinación de tres técnicas multivariantes -factorial, discriminante y conglomerados- se establecieron tres perfiles de actitudes ante la inmigración: tolerantes, ambivalentes y reacios ante la inmigración (Cea D’Ancona, 2009).

Los perfiles de la actitud ante la inmigración se fueron perfeccionando a través de los proyectos MEXEES es el acrónimo de un proyecto I+D financiado por el MEC (SEJ2005-00568), titulado La medición de la xenofobia en la España de comienzos 
del siglo XXI: nuevos indicadores y diseños de encuesta para las políticas de integración social de los inmigrantes. Proyecto que tiene su continuidad en MEXEES II (CSO2009-07295): La medición de la xenofobia en España II: modelos para la implementación de políticas de integración social. Así como mediante los barómetros de actitudes ante la inmigración (2007 a 2011) financiados por Observatorio Español del Racismo y la Xenofobia (OBERAXE) y realizados por el CIS; los cuales son también cruciales en esta investigación.

\section{DISCURSOS ANTE LA INMIGRACIÓN}

Para Rinken y Peréz Yruela (2007) "el discurso son aquellos razonamientos acerca de la inmigración que configuren una visión global del fenómeno en función de un determinado principio o presupuesto básico". Estos autores diferencian entre cuatro tipos de discursos ante la inmigración: solidario, funcionalista, desconfiado y excluyente.

a. En el discurso solidario la integración social en igualdad de condiciones de las personas inmigrantes es la mayor máxima, apostando por la diversidad cultural de la sociedad. De tal modo, que los incidentes o problemas que puedan generar algunas personas inmigrantes no puede generalizarse al conjunto de la población inmigrante. El discurso solidario ve a la inmigración como positiva, no tanto por los beneficios económicos que pueda derivar de ella, sino más bien por el enriquecimiento cultural que supone para el país. Rasgos particulares del discurso solidario es que está a favor de la escolarización conjunta del alumnado culturalmente heterogéneo; así como se valora también positivamente la educación plurilingüe.

b. El discurso funcionalista centra su atención en las condiciones socio-económicas; muy cercano a la teoría del mercado dual (Piore, 1979). Está teoría resalta que existe un segmentación del mercado laboral en el cual hay dos sectores, el sector primario -en el caso que nos ocupa, serían las personas autóctonas.- que disfrutan de unas condiciones socio-laborales óptimas, buena remuneración, estabilidad y seguridad, equidad y procesos claros en la imposición de las reglas y las oportunidades para avanzar dentro de la empresa, es decir en el 
escalonamiento laboral. Mientras que en el sector secundario -estarían las personas inmigrantes- tiene unas condiciones laborales contrapuestas con el primario, ya que los salarios son bajos, existen malas condiciones laborales, una disciplina dura y arbitraria y pocas oportunidades para avanzar dentro de la entidad. La estabilidad del sector primario se contrapone con la del sector secundario. (Doeringer y Piore, 1971).

El discurso funcionalista, se centra en la aportación económica que realizan las personas inmigrantes como mano de obra y valoran positivamente la capacidad de esfuerzo y sacrificio que muestran. Además de ello, este discurso aprecia el aporte al Estado de bienestar que realizan las personas inmigrantes al aumentar el número de hijos por mujer. Este discurso es pragmático, únicamente valora la utilidad de las personas inmigrantes para el país (Rinken y Peréz Yruela, 2007).

c. El discurso desconfiado se manifiesta por unos elevados nivel de desconcierto ante el fenómeno de la inmigración; provocado por el aumento de la presencia de población inmigrante en poco tiempo, lo cual despierta inquietud y prevención al asociarse, a veces, con problemas de orden público -principalmente la delincuencia-. En este discurso se muestran actitudes desconfiadas en el sector económico y cultural, en el primero la desconfianza deriva de los agravios comparativos, ya que pueden perder el trabajo a favor la población inmigrantes, o que la mano de obra inmigrantes puede bajar los salarios. El segundo -aspectos culturales-, la desconfianza se fundamenta en que las personas inmigrantes no asimilen las normas y códigos culturales autóctonos. Como señala Solé et al. (2000), "el autóctono tiende a aceptar al inmigrante siempre que renuncie a su propia cultura -idioma, costumbres, religión etc.-. Un rasgo característico del discurso desconfiado es que pone énfasis en la igualdad de género, es decir el rechazo de la población autóctona a las prácticas que le dan los varones inmigrantes a las mujeres inmigrantes.

d. El discurso excluyente tiene rasgos similares al discurso desconfiado, puesto que ambos perciben a la inmigración como un fenómeno negativo para la población autóctona; pero el discurso excluyente tienen más radicalizados los prejuicios. EI discurso excluyente pone de relieve la falta de adaptación de la población inmigrante a la cultura del país, así como que la población inmigrante actúa con malas intenciones. Un rasgo del discurso excluyente es la imputación 
generalizada de rasgos negativos a la población inmigrante y la intención de aprovecharse de todas las ventajas de la sociedad autóctona sin asumir las obligaciones correspondientes. Este es un discurso muy centrado en la hostilidad hacia la población inmigrante.

\section{LA CONSTRUCCIÓN DE LA DIFERENCIA}

La construcción de la diferencia, se fundamenta en la idea de poner en contacto a dos o más grupos culturalmente diferentes puede generar un proceso de "defensa de los grupos étnicos culturalmente homogéneos" (Soriano, 2011). Según Blanco (1993) "para que se produzca un contacto interétnico, basta con que existan dos -o más- grupos étnicos en interacción; esto es, que se produzca un encuentro entre dos categorías adscriptivas previamente definidas: el nosotros y el ellos. La inmigración es generadora -o reactivadora- de la etnicidad, en tanto que supone la inserción de otro -inmigrante extranjero- en el territorio perteneciente, y sentido como tal a un nosotros -autóctonos-“. Para comprender la relevancia de la construcción de la diferencia es imprescindible explicar que se entiende por alteridad, (Olmos, 2009) lo define como "un proceso social vehiculado por relaciones simbólicas de poder en el que influye, definitivamente, un mecanismo de naturalización que da como resultado la construcción de la diferencia".

En la actualidad es importante estudiar la construcción de la diferencia, ya que debido al contexto socio-económico español, la diferenciación entre el nosotros y el otro se hace más visible. Como señala Subirats (2002), existen semejanzas entre la situación obrera a principios del siglo XX y la situación de la inmigración, de tal modo que lo que antes era la "cuestión obrera", ahora es la "cuestión migratoria". De tal modo, que "los inmigrantes ocupan así el viejo papel de clases peligrosas reservado hace cien años a la clase obrera" (Subirats, 2002).

Este razonamiento se justifica en varios puntos, por un lado, hay una separación entre objeto y sujeto, de tal modo, que son los agentes institucionalización en el sistema -medios de comunicación e instituciones del gobierno- quienes controlan el discurso sobre la inmigración -como se ha señalado anteriormente en las teorías de la comunicación, lo que se conoce es una "hiper-realidad" consumida por las masas 
y representada a través de los medios de comunicación-, de tal modo, que la inmigración como colectivo no tiene voz propia. Por otro lado, respecto al mercado laboral, se ha fomentado la mano de obra inmigrante obviando que producía bajo la precariedad, puesto que la población autóctona no rechazaba tanto los puestos de trabajo que tenían las personas inmigrantes, sino las condiciones de trabajo que albergaban -sueldos bajo, inseguridad, dureza etc. (García Borrego, 2005).

Al cambiar la situación económica del país, la población autóctona siente la necesidad de diferenciarse por temor a que "un descenso de la posición social de los nativos que se emplean en esos tipos de trabajo, por su tendencia a una más baja situación de mercado, a una más baja situación de trabajo y a una más baja situación de estatus ocupacional" (Lockwood, 1962), situación que en la actualidad está aconteciendo con la situación de crisis económica en España. 


\section{CONTEXTUALIZACIÓN}

La contextualización de esta investigación se centra en la situación de inmigración en España. El desarrollo de la inmigración en España se divide en tres etapas principalmente: (A) etapa de despegue de la inmigración (1994 a 1999); (B) auge de la inmigración (2000 a 2007); y (C) la inmigración en crisis económica (2008 a 2013).

\section{A. ETAPA DE DESPEGUE DE LA INMIGRACIÓN (1994 al 1999).}

De todos los cambios que se han producido en España -en su etapa democrática-, la recepción de intensos flujos migratorios desde los años 90' es quizás el que más ha transformado la estructura social española (González y Requena, 2005). Es cierto que a España le costó un tiempo tomar conciencia de la realidad migratoria y el cambio de ciclo migratorio -España tradicionalmente fue un país de emigrantes- que le estaba aconteciendo en los años 90'. Uno de los antecedentes migratorios aparece con la aprobación de la Ley Orgánica 7/1985 sobre derechos y libertades de los extranjeros en España, lo cual era un requisito para formar parte de la Comunidad Económica Europea (CEE). La incorporación de España en la CEE generó un estimulo a los flujos migratorios.

El inicio de esta etapa se caracteriza por varios factores, en 1994 España estaba inmersa en una dura crisis económica fruto de la reconversión industrial que se estaba produciendo; y es en este año, en el que por primera vez, alrededor de dos tercios de la ciudadanía española consideraban que el número de personas de otras nacionalidades que viven en España son muchas o demasiadas -según el estudio del CIRES- (Díez de Nicolás, 1999). Este mismo autor señala que este cambio en la percepción del número de personas extranjeras se debe a la crisis económica y la escasez de empleo.

Según los datos extraídos del padrón, el número de personas extranjeras empadronadas ha ido aumentando en esta etapa, ya que el 1991 el número de personas extranjeras empadronadas era de 360.655 , que representaba el $0,91 \%$ de la población española. En 1996 la cifra aumenta hasta las 542.314 personas extrajeras empadronadas, lo que supone el 1,37\% del total de la población del país; dos años más tarde, el número de personas extranjeras en España es de 637.085, en términos relativos un 1,6\% de la población de España. Es en el año 2000 donde 
se produce un aumento más considerable, ya que el número de personas extranjeras empadronadas es de 923.879 , lo que representa el 2,28\% del total de población en España. Este incremento Guisán (2005) lo atribuye "a la flexibilización del mercado laboral y el incremento del empleo en España que favorecieron la incorporación de inmigrantes durante el período 1996-2000. A partir de dicho año el incremento del empleo fue menor, pero la evolución de la inmigración continuó en general de forma creciente, produciéndose un desajuste entre la oferta y la demanda de trabajadores procedentes de la inmigración".

El perfil de persona extranjera, en esta etapa, era principalmente persona europeas que residían en España por ocio, a excepción de la población portuguesa que emigraba a España que si tenía una motivación laboral. Otras nacionalidades residentes en el país era la población latinoamericana, aunque con una representación escasa, y su presencia en el país se debía al exilio por cuestiones políticas (Izquierdo, 1992). En esta etapa ya se comenzaban a percibir indicios de flujos migratorios africanos y asiáticos (Cebolla y González, 2008).

\section{B. ETAPA DE AUGE DE LA INMIGRACIÓN (2000 a 2007).}

En el año 2000 se produce un cambio de etapa en la situación migratoria de España, ya que es el año en el que se hace evidente que es un "polo de atracción" tanto para sus propios emigrantes retornados cómo para los flujos de inmigración, principalmente por motivos económicos (Cebolla y González, 2008). Las cifras de las personas empadronadas así lo muestran, ya que se produce un incremento de 923.879 personas extranjeras en el 2000 a 4.482.568 personas extranjeras en 2007; en términos relativos, en el 2000 la población extranjera en España representaba el 2,28\% de la población total del país, mientras que en 2007 representaba el 9,93\%. Como se observa en la tabla 1, el aumento más pronunciado se produce del 2002 al 2003 con el incremento de 688.222 personas extranjeras empadronadas. Es importante señalar que el padrón tiene ventajas, pero también limitaciones (Garrido, 2004), cuando una persona extranjera llega a un municipio se empadrona, y adquiere los derechos universales a la educación y sanidad gratuita. Únicamente se necesita tener un domicilio en el municipio, no es necesario presentar la tarjeta de 
residencia -las personas inmigrantes irregulares pueden estar empadronadas, de hecho en esta investigación se utilizará el padrón y la tarjeta de residencia para estimar el número de personas irregulares-. La limitación deriva, de que desempadronarse no es obligatorio y a efectos prácticos pocos inmigrantes lo hacen. Por tanto, introduce sesgos de sobreestimación del número de inmigrantes (Cebolla y González, 2008).

Tabla 1: Evolución personas extranjeras empadronadas (2000 a 2007).

\begin{tabular}{lll} 
AÑO & Personas extranjeras empadronadas & $\begin{array}{l}\% \text { que representan respecto al total } \\
\text { de población }\end{array}$ \\
$\mathbf{2 0 0 0}$ & 923.879 & $2,28 \%$ \\
$\mathbf{2 0 0 1}$ & 1.370 .657 & $3,33 \%$ \\
$\mathbf{2 0 0 2}$ & 1.977 .946 & $4,73 \%$ \\
$\mathbf{2 0 0 3}$ & 2.664 .168 & $6,24 \%$ \\
$\mathbf{2 0 0 4}$ & 3.034 .326 & $7,02 \%$ \\
$\mathbf{2 0 0 5}$ & 3.730 .610 & $8,46 \%$ \\
$\mathbf{2 0 0 6}$ & 4.144 .166 & $9,27 \%$ \\
$\mathbf{2 0 0 7}$ & 4.482 .568 & $9,93 \%$ \\
\hline
\end{tabular}

Elaboración propia con datos del Padrón Municipal.

En la composición por origen de estos flujos migratorios destacan dos grupos de nacionalidades: las personas de origen latinoamericano $-43 \%$ del total de la población inmigrante ${ }^{13}$ - y las personas norteafricanas $-20 \%$ del total de la población inmigrante-, especialmente marroquíes. Además de estos dos grupos, la población europea tiene una presencia importante en España. Por un lado, la población más envejecida, cuyo objeto de residir en España no es trabajar en el país -representa el $12 \%$ del total de inmigrantes-, y por otro lado grupos de nacionalidades que tienen una motivación laboral como son la población rumana y búlgara $-17 \%$ de la población inmigrante en España-. También hay que señalar, a la población subsahariana, que pese a no tener un porcentaje muy amplio de población residiendo en España -2\% respecto al total de inmigrantes-, son el "colectivo que en origen tiene un mayor potencial migrante" (Cebolla y González, 2008).

La población extranjera residente en España se asienta en los núcleos urbanos más dinámicos, en los cuales se demanda mayor mano de obra, como son Madrid, el litoral mediterráneo y las islas. De hecho el $44,8 \%$ de la población inmigrante se

\footnotetext{
${ }^{13}$ Datos de la población inmigrante en España son extraídos del INE en 2006.
} 
concentra en tres provincias: Madrid, Barcelona y Alicante. Así como la población europea -que no son inmigrantes económicos- prefieren residir en las costas: de la Comunidad Valenciana, Andalucía, Baleares y Canarias. Las zonas con menor inmigración son: Extremadura, Asturias y Galicia ${ }^{14}$. Una manifestación de esto, es que aparte de la magnitud y rapidez de los flujos migratorios, la experiencia migratoria en España en esta etapa se ha centrado, por un lado en la concentración geográfica y ocupacional de los inmigrantes económicos; y por otro lado por la entrada irregular de personas extranjeras al país (Cebolla y González, 2008).

\section{ETAPA DE LA INMIGRACIÓN EN CRISIS ECONÓMICA (2008 a 2013)}

En 2008, comienzan a notarse señales de un cambio en el flujo de inmigración, tras la visibilización de los efectos de la crisis económica en España, la población inmigrante al tener empleos más flexibles y en sectores muy afectados por la coyuntura económica -construcción y sector servicios, en menor medida en el servicio doméstico-, son los primeros damnificados de la situación del país. En los datos de la afiliación de la Seguridad Social se denota que desde septiembre de 2005 a mayo de 2008, el número de personas extranjeras afiliadas a la Seguridad Social aumenta progresivamente, llegando al máximo de afiliaciones de personas extranjeras en mayo de 2008 con 2.145 .901 afiliaciones. Es a partir de mayo de 2008 cuando cada mes van disminuyendo las afiliaciones a la Seguridad Social de personas extranjeras, llegando a febrero de 2012 a 1.664 .028 de afiliaciones.

Pese al descenso del número de afiliaciones a la Seguridad Social y aumento del desempleo en la población inmigrante. De 2008 a 2010, el flujo de personas inmigrantes que llegaban a España no disminuyó, incluso se incremento -a un ritmo más lento que la etapa anterior- de 5.268.762 a 5.747.734 personas extranjeras asentadas en España, lo que en términos relativos es un aumento del $11,3 \%$ al $12,2 \%$ de población extranjera. En 2011, la cifra se mantiene prácticamente igual, y es en 2012 donde se aprecia un significativo descenso de la población extranjera, un $2,3 \%$, hasta 5.118 .112 residentes extranjeros.

\footnotetext{
14 Datos extraídos del censo de 2005.
} 
Analizando el saldo migratorio -inmigraciones menos emigraciones-; en 2008 el saldo migratorio en España era positivo con 310.642 personas; un 2009 se produce un fuerte descenso del saldo migratorio, que pese que es positivo, se sitúa en 12.845 personas. En 2010, el saldo migratorio es negativo -42.675 personas salieron de España más que entraron; y en 2011, el saldo migratorio sigue siendo negativo con -37.699 personas. En 2012, por tercer año consecutivo, el saldo migratorio español es negativo con -162.390 personas. Las causas del saldo migratorio se deben a dos factores principalmente, por un lado ha aumentado el número de inmigrantes que han retornado a sus países de origen; y por otro lado se ha incrementado el número de personas españolas que han emigrado. De hecho, en el Anuario de Estadística de Variaciones residenciales del INE, desde mediados de 2008 hasta finales de 2011 se han contabilizado 1.335 .000 bajas, de las cuales el 91\% son de inmigrantes y el $9 \%$ de personas españolas nacidas en España.

Respecto a las personas inmigrantes; se produjo un incremento de 2008 a 2010, mientras que en 2011 se ralentizo el ritmo de salida de inmigrantes de España. La mayoría de ellos retornaron a su país de origen, sobre todo latinoamericanos, mientras que otros optaron por "re-emigrar" a otros países con boom migratorio (Aja, Arango, Oliver Alonso, 2012). Desde el 2010 hasta el 2012 las personas de origen chino, ruso y rumano siguen llegando a España, mientras que las personas marroquíes han disminuido su ritmo de entrada -de 36025 en 2010 a 9142 en 2012-. La población latinoamericana es la que más ha retornado especialmente personas ecuatorianas -54.330 menos, de 2011 a 2012-, colombianas, bolivianas, argentinas y brasileñas.

En relación a las personas españolas nacidas en España que deciden emigrar, en el Anuario de Estadística de Variaciones residenciales del INE, se afirma que desde el inicio de la crisis económica han emigrado 115.000 personas, tanto hombres como mujeres, con un nivel de estudios medios y superiores cuyo destino, principalmente, es el noroeste de Europa y Estados Unidos. Arango (2012) afirma que "mientras la emigración de extranjeros, incluyendo la de inmigrantes nacionalizados, parece estarse ralentizando, la emigración española ha crecido especialmente en el último año -2012-". 


\section{PROBLEMATIZACIÓN Y PREGUNTA DE INVESTIGACIÓN}

El fenómeno migratorio en España ha tenido una importancia capital en la configuración del país, tanto en su composición demográfica como en su estructura económica. Por tanto, el calado de esta temática en la sociedad española es innegable, sin embargo lo peculiar de este proceso son los cambios de ciclo que se han producido, ya que sí en los años 60' la emigración de población española hacia países centroeuropeos y latinoamericanos marcaba la conducta migratoria, cuatro décadas después, España era un país receptor de inmigración. La intensidad migratoria -especialmente inmigrantes económicos, aunque también personas extranjeras centroeuropeas y población española retornada del anterior ciclo migratorio-, pusieron la inmigración como uno de los principales temas en la agenda pública española. Un ejemplo de esto, es que el barómetro de opinión del CIS se realiza desde 1979, pero no es hasta el año 2000 cuando la ciudadanía comienza a señalar a la inmigración como uno de los problemas de España, aunque en ese momento todavía no aparece entre los tres principales problemas del país.

El objeto de análisis de esta investigación, es conocer como la inmigración se convierte en un problema social para España. En todo el periodo que alberga de 2000 a 2007, la sociedad española indica que la inmigración es uno de los cinco principales problemas que tiene el país. En 2005, por primera vez la ciudadanía sitúa a la inmigración como segundo problema del país -influenciado por el asalto a las vallas en Ceuta y Melilla- y es en 2006, cuando el 59,2\% de la población española afirma que la inmigración es el principal problema del país -después de la crisis de los cayucos-. Como se observa, el aumento de la preocupación de la ciudadanía ante la inmigración se produce tras un acontecimiento migratorio relevante, que fue tuvo una cobertura mediática intensa y prolongada. Por lo tanto, respecto a la construcción de la inmigración como problema social en España, es necesario preguntarse:

¿La construcción de la inmigración como problema social está basada en los factores externos-medios de comunicación y politización de las migraciones-que generan actitudes reacias ante la inmigración en la sociedad española? 


\section{OBJETIVOS E HIPÓTESIS DE LA INVESTIGACIÓN}

\section{A. OBJETIVOS}

\section{OBJETIVO GENERAL:}

Estudiar el proceso de construcción de la inmigración como problema social en España.

\section{OBJETIVOS ESPECÍFICOS:}

a) Analizar las representaciones sociales sobre la inmigración en España en materias de diversidad cultural, competitividad laboral, medios de comunicación, trato a la población inmigrantes y agresiones racistas.

b) Examinar las percepciones sobre la realidad numérica de la inmigración, comparando la realidad numérica y la percepción demoscópica.

c) Estudiar las creencias y valores sobre la gestión de la inmigración y la percepción de la ayuda que recibe la población inmigrante por parte del Estado.

d) Identificar las actitudes ante la inmigración en la vida cotidiana así como en la antipatía hacia ciertos grupos de nacionalidades.

\section{B. HIPÓTESIS}

\section{HIPÓTESIS GENERAL:}

En la construcción de la inmigración como problema social en España han influido más los agentes externos al fenómeno migratorio -medios de comunicación y la politización de las migraciones- que los efectos del contacto directo con la inmigración.

\section{HIPÓTESIS ESPECÍFICAS:}

a) Respecto al objetivo específico 1: La representación social de la inmigración tiende a ser negativa, especialmente en el mercado laboral, en crisis económica.

b) Respecto al objetivo específico 2: La población sobre-representa la inmigración, principalmente a los grupos de nacionalidades más visibles. 
c) Respecto al objetivo específico 3: La construcción de la diferencia se incrementa en épocas de recesión económica, al convertir a la inmigración en el chivo expiatorio en la lucha de los recursos y las prestaciones socio-laborales.

d) Respecto al objetivo específico 4: La sociedad tiene actitudes más reacias hacia la inmigración cuando la vinculación entre ambos es menos cercana y se centra menos en el contacto directo con la población inmigrante. 


\section{METODOLOGÍA DE LA INVESTIGACIÓN}

La metodología de la investigación consta de los siguientes apartados: (A) etapas de la investigación; (B) técnicas de producción de datos; (C) técnicas de análisis de datos; (D) variables de la investigación; y (E) recodificación de las variables.

\section{A. ETAPAS DE LA INVESTIGACIÓN}

La investigación se ha centrado en una serie de etapas que le han dado una visión holística y una coherencia interna a la misma:

- Revisión bibliográfica.

- Planteamiento de la pregunta inicial.

- Producción del marco teórico de la investigación.

- Elaboración de los objetivos y las hipótesis de la investigación.

- Búsqueda de las bases de datos oportunas para el análisis cuantitativo.

- Explotación de las bases de datos.

- Análisis de los resultados obtenidos en la explotación de las bases.

- Contraste de las hipótesis planteadas.

- Elaboración de conclusiones y delimitación de las siguientes líneas de investigación.

\section{B. TÉCNICAS DE PRODUCCIÓN DE DATOS}

Los datos secundarios de la investigación, se han obtenido mediante la extracción y la explotación de bases de datos e indicadores estadísticos de diferentes instituciones tanto nacionales como internacionales. Las fuentes de información de la investigación $\operatorname{son}^{15}$ :

- Centro de Investigaciones Sociológicas (CIS): es un organismo autónomo vinculado al Ministerio de la Presidencia. La función más reconocida del CIS es la elaboración de encuestas que miden la opinión pública de la sociedad española y su evolución con el tiempo. El CIS dispone del banco de datos

\footnotetext{
${ }^{15}$ La ficha técnica de las bases de datos empleadas, se adjuntan en el anexo metodológico.
} 
(http://www.cis.es/cis/opencms/ES/2 bancodatos/) en el cual se pueden descargar todas las investigaciones, puesto que son de dominio público. En la presente investigación, el CIS es la fuente principal se extracción y explotación de datos cuantitativos; para ello se han utilizado dos tipos de estudios:

- Barómetros de opinión pública: se realizan mensualmente -excepto en el mes de agosto-. Constan de un bloque de preguntas fijas y otro variable, dependiendo de la temática social o política de actualidad. Estos barómetros se han empleado para medir la evolución de los problemas sociales en la sociedad española (2000 a 2013).

- Actitudes ante la inmigración: realizado mediante un convenio con el Ministerio de Trabajo e Inmigración (Observatorio Español de Racismo y Xenofobia "OBERAXE"). Este estudio se realizó de 2008 a 2011. En 2007 tiene un antecedente, -también a cargo del Ministerio de Trabajo y Asuntos Sociales- el estudio de las actitudes ante la discriminación por origen racial o étnico. Estos estudios (2007 a 2011) se han utilizado en la investigación para conocer las actitudes y opiniones de la sociedad española ante la inmigración en dicho periodo.

- Instituto Nacional de Estadística (INE): es un organismo autónomo de carácter administrativo que está vinculado al Ministerio de Economía y Competitividad. EI INE aporta datos estadísticos sobre la economía, la demografía y sobre aspecto de la sociedad española. Los datos del INE se pueden descargar en la página web de INEbase (http://www.ine.es/inebmenu/indice.htm). Los datos del INE se han empleado para ampliar información y/o cotejar la percepción de la sociedad española con la realidad. Para ello, se utilizaron las siguientes secciones del INE:

- Encuesta de Población Activa (EPA): es una sección dentro del INE, que se publica trimestralmente. La función de la EPA es obtener datos de la fuerza de trabajo y del mercado laboral. En esta investigación se ha utilizado la EPA para conocer los datos de desempleo en España. 
- Padrón Municipal: esta realizado por el INE. Es un registro administrativo de la población de cada municipio, se actualiza de forma continua y se publica cada año. El padrón se ha utilizado para conocer la población inmigrante diferenciando por los diferentes grupos de nacionalidades que residen en España; así como para hallar una aproximación ${ }^{16}$ de la inmigración irregular.

- Secretaria General de Inmigración e Emigración: organismo perteneciente al Ministerio de Empleo y Seguridad Social. Esta institución elabora datos estadísticos sobre la inmigración en España. Se ha empleado está fuente de información para extraer los datos de la tarjeta de residencia de las personas extranjeras en España, con el objeto de conocer la cifra aproximada de inmigrantes irregulares. Estos datos se han obtenido restado el número de personas extranjeras empadronadas con las tarjetas de residencia vigentes.

- Encuesta Social Europea (ESE): es una encuesta que mide la opinión pública de la ciudadanía europea. Es una herramienta muy útil para comparar la percepción de la ciudadanía de distintos países europeos. La ESE se elabora cada dos años. Los datos se pueden descargar de su página web (http://www.upf.edu/ess/datos/). Es esta investigación, la ESE se ha utilizado para comparar la percepción ante la inmigración de algunos países europeos en una situación económica similar a la española.

\section{TÉCNICAS DE ANÁLISIS DE DATOS}

En esta investigación, la técnica de análisis de datos que se ha considerado más adecuada, es el análisis de tipo descriptivo. La elección se debe, a que el análisis descriptivo tiene como finalidad estudiar una información específica de un determinado grupo -en el caso de esta investigación, la población española de 18 años en adelante- a partir de una serie de variables que son influyentes para describir el objeto de la investigación -la percepción de la población española ante la inmigración-. Para Hernández, Fernández y Baptista (2007): "los estudios

\footnotetext{
${ }^{16}$ Se habla de aproximación en las cifras de la inmigración irregular, porque en el padrón no existe obligación de darse de baja. Es por ello, que en el padrón municipal existe una sobreestimación de la población inmigrante.
} 
descriptivos buscan especificar las propiedades, las características y los perfiles importantes de personas, grupos, comunidades o cualquier otro fenómeno que se someta a un análisis".

La investigación es cuantitativa, es decir, expresa la realidad social en términos matemáticos así como las relaciones existes entre ellos (Doblas, 2005). Para ello, los datos recolectados han sido codificados, lo que Bardin (1986) define como: "la trasformación que se realiza según reglas precisas de los datos brutos (...) que por descomposición, agregación y numeración permite desembocar en una representación del contenido, o de su expresión, susceptible de ilustrar al analista sobre las características del texto que pueden servir de índices".

Los datos, ya codificados, se han analizado estadísticamente por el software informático Statistical Package for the Social Science (SPSS). Con el paquete informático SPSS se ha realizado un análisis descriptivo de las principales variables de la investigación utilizando: análisis univariante (distribución de frecuencias), bivariante (análisis de contingencia), y multivariante (análisis factorial, correspondencias y árbol de segmentación por el método CHAID). Una vez analizados los datos, se procedió a la representación gráfica de los resultados más significativos para la investigación mediante el programa informático Excel. Para la realización de la representación cartográfica sobre la percepción del volumen de inmigrantes en España por provincias (2007 a 2011), se utilizó el software de sistemas de información geográfica (SIG), ArcGis.

\section{VARIABLES DE LA INVESTIGACIÓN}

Las variables utilizadas se distribuyen en variables independientes, dependientes o ninguna de ambas, en función de los análisis de interdependencia o dependencia que se hayan realizado en los principales ejes de la investigación: 

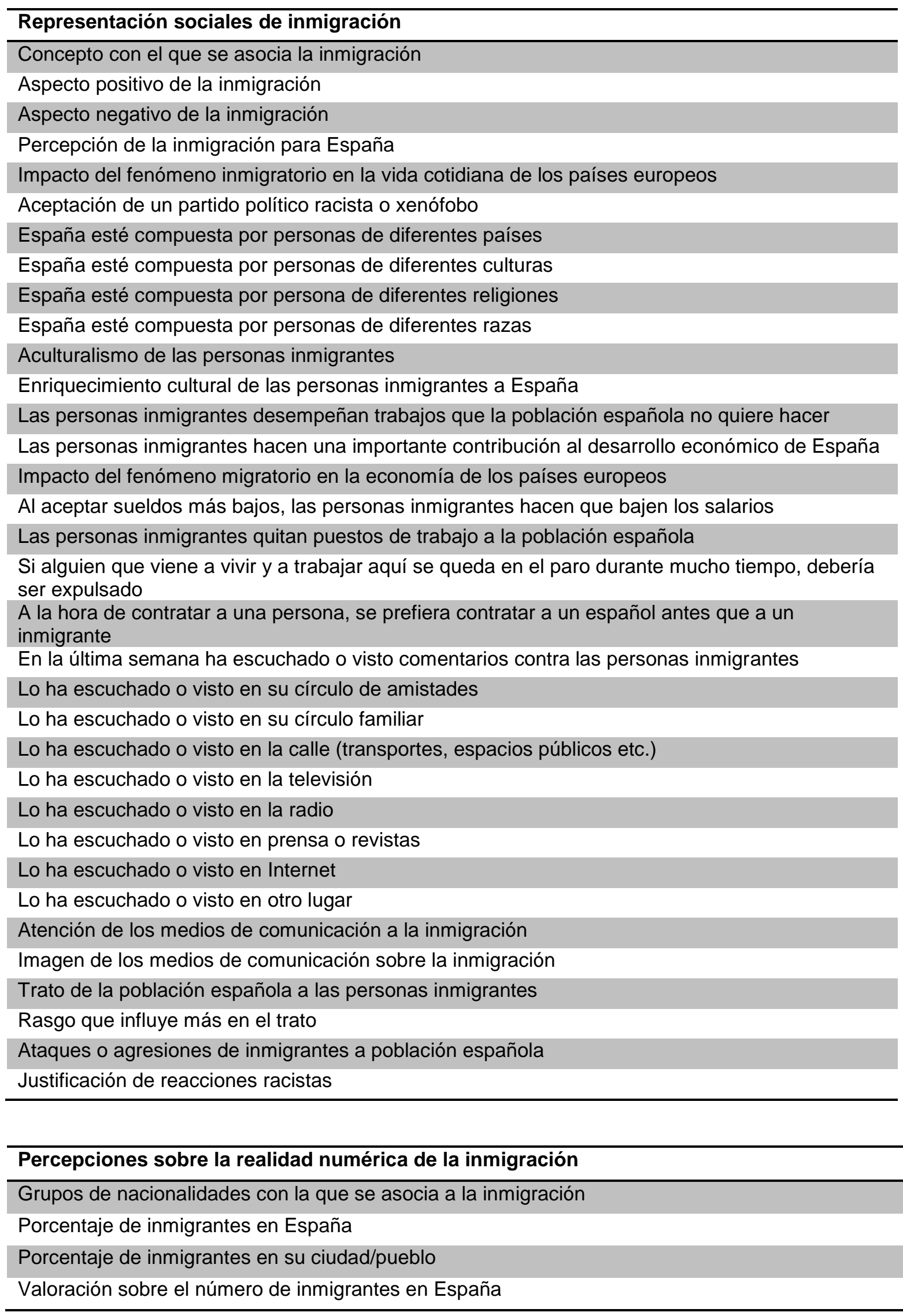


\section{Creencias y valores sobre la gestión de la inmigración}

Permitir la entrada a una persona que tenga un buen nivel educativo

Permitir la entrada a una persona que tenga familiares cercanos viviendo en España

Permitir la entrada a una persona que hable castellano

Permitir la entrada a una persona que sea de un país de tradición cristiana

Permitir la entrada a una persona que sea de raza blanca

Permitir la entrada a una persona que tenga mucho dinero

Permitir la entrada a una persona que una cualificación laboral de la que España necesita

Permitir la entrada a una persona que esté dispuesto a adoptar el modo de vida del país

Tolerancia de las leyes que regulan la entrada y salida de personas inmigrantes

Opinión sobre las medidas que se deben tomar en la inmigración irregular

Postura más adecuada respecto a las personas que solicitan el asilo

Ayuda que reciben las personas inmigrantes del Estado

Grupos vulnerables que reciben ayuda del Estado

Las personas inmigrantes abusan de la atención sanitaria gratuita

Derecho de las personas inmigrantes regulares a traer a su familia

Derecho de las personas inmigrantes regulares a cobrar el subsidio si se quedan parados

Derecho de las personas inmigrantes regulares a votar en las elecciones generales

Derecho de las personas inmigrantes regulares a votar en las elecciones municipales

Derecho de las personas inmigrantes a crear asociaciones para defender sus derechos

Derecho de las personas inmigrantes para obtener la nacionalidad española

\section{Actitudes ante la inmigración en la vida cotidiana}

Grado de aceptación de vivir en el mismo barrio en el que viven muchas personas inmigrantes

Grado de aceptación de vivir en el bloque en el viven inmigrantes

Grado de aceptación de alquilar un piso a inmigrantes

Grado de aceptación de trabajar/estudiar con inmigrantes

Grado de aceptación de que una persona inmigrante sea su jefe en el trabajo

Grado de aceptación de que su hijo y/o hija lleve inmigrantes a casa

Grado de aceptación de que su hijo y/o hija se case con una persona inmigrante

Grado de aceptación de llevar a su hijo y/o hija a un colegio donde muchos niños/as hijos/as de inmigrantes

La calidad de la educación empeora en los colegios donde hay muchos hijos/as de inmigrantes

Grupo de inmigrantes que causan más simpatía

Grupo de inmigrantes que generan más antipatía

Causa por que generan antipatía

\begin{tabular}{l}
\hline Variables sociodemográficas \\
\hline Edad \\
Nivel de ingresos mensuales \\
Ideología \\
Grado de confianza hacia otras personas \\
Nivel de racismo \\
Nivel de estudios \\
Clase social \\
Situación laboral \\
Contacto directo con personas inmigrantes o extranjeras \\
\hline
\end{tabular}




\section{E. RECODIFICACIÓN DE LAS VARIABLES}

Las variables utilizadas en la investigación, tiene asignadas una serie de códigos que son necesarios para el análisis estadístico de las mismas. Estos códigos, en algunos casos, ha sido necesario modificarlos, realizando una recodificación de la variable. Las variables sociodemográficas han sido recodificadas para convertirlas en variables más operativas estadísticamente.

- Edad: la variable edad se ha agrupado, siguiendo la recodificación del CIS en esta variable, en 18 a 24 años (1); de 25 a 34 años (2); de 35 a 44 años (3); de 45 a 54 años (4); de 55 a 64 años (5); de 65 años en adelante (6) y no contesta (99).

- Ideología: esta variable era ordinal y se recodificado en los valores de 0 a 2 (1) como extrema izquierda; de 3 a 4 (2) como centro izquierda; 5 (3) es el centro; 6 a 7 (4) como centro derecha y de 8 a 10 (5) como extrema derecha. Se mantiene el no sabe (98) y no contesta (99).

- Confianza hacia la gente: la variable era ordinal y se recodificado en los siguientes valores de 0 a 2 (1) como muy desconfiada; de 3 a 4 (2) como más desconfiada que confianza; 5 (3) es ni confiada ni desconfiada; 6 a 7 (4) como más confiada que desconfiada y de 8 a 10 (5) como muy confiada. Se mantiene el no sabe (98) y no contesta (99).

- Nivel de racismo: era un variable era ordinal, la cual se recodificó en los valores 0 (1) es nada racista; de 1 a 2 (2) es poco racista; de 3 a 4 (3) ni mucho ni poco racista; de 5 a 7 (4) es bastante racista y de 8 a 10 (5) es muy racista. Los valores de no sabe (98) y no contesta (99) se mantienen iguales.

- Nivel de estudios: en el nivel de estudios, la Formación Profesional se agrupa dentro de estudios secundarios, quedando del siguiente modo (1) sin estudios; (2) estudios primarios; (3) estudios secundarios; (4) estudios universitarios; y (5) estudios superiores. La categoría de respuesta no contesta (9) se mantiene igual.

- Nivel de ingresos mensuales: el nivel de ingresos se recodificó en intervalos más amplios, quedando de la siguiente manera; menos o igual a 300 euros, 301 a 600 euros y 601 a 900 euros, se recodifica a menor o igual a 900 euros (1). De 901 a 1200 euros y de 1201 a 1800 euros se convierte en de 901 a 1800 euros 
(2). De 1801 a 2400 euros, de 2401 a 3000 euros, de 3001 a 4500 euros, de 4501 a 6000 euros y más de 6000 euros se recodifica a más de 1801 euros (3). La categoría de respuesta no contesta (9) se mantiene igual.

- Situación laboral: se ha agrupado los pensionistas con los jubilados; así como los parados que han trabajado con los parados que buscan su primer empleo. La variable que ha resultado es: trabaja (1); jubilado o pensionista (2); parado (3); estudiante (4); y trabajo doméstico no remunerado (5). La categoría de respuesta en otra situación (8) y no contesta (9) se mantienen igual.

El resto de variables recodificadas son:

- Problemas que le afectan personalmente: esta variable se recodifica en cinco categorías de respuesta: problemas económicos (1); problemas políticos (2); problemas sociales (3); inmigración (4); y otras respuestas (96). Los problemas económicos agrupan: al paro, las infraestructuras, los problemas de índole económica, problemas relacionados con la calidad del empleo y problemas de la agricultura, ganadería y pesca. Los problemas políticos engloban: el terrorismo, ETA; la corrupción y el fraude; la clase política, los partidos políticos; la Administración de Justicia; el Gobierno, los políticos, los partidos; el funcionamiento de los servicios públicos; los nacionalismos; y los estatus de autonomía. Los problemas sociales agrupan: las drogas; la sanidad; la vivienda; las pensiones; los problemas de índole social; la violencia contra la mujer; los problemas relacionados con la juventud; la crisis de valores; la educación y los problemas relacionados con la mujer. La inmigración engloba a la inmigración y al racismo. Así como otras respuestas agrupa a: inseguridad ciudadana; los problemas medioambientales; las preocupaciones y situaciones personales; $y$ otras respuestas -no especificadas por el CIS-.

- Concepto con el que se asocia a la inmigración: esta variable engloba categorías de respuesta en función de la similitud de su contenido. La categoría extranjeros (1) agrupa a extranjeros y nacionalidades o etnias concretas. Irregularidad, pateras (2) engloba la imagen de las pateras e ilegalidad e irregularidad. La categoría sentimientos de empatía y solidaridad (4) agrupa analogías con la experiencia de emigrantes españoles y sentimiento de empatía y solidaridad. El aumento desmedido de los problemas de integración (9) consta del aumento 
desmedido de inmigrantes y de problemas de integración y convivencia. Sentimientos negativos hacia la inmigración (10) agrupa referencias genéricas a que es un problema y sentimientos negativos hacia la inmigración. Otras respuestas (96) engloba efectos positivos sobre la cultura y economía y otras respuestas. Mientras que la necesidad de venir a trabajar (3); pobreza y desigualdad (5); privilegios sociales frente a los españoles (6); delincuencia e inseguridad (7); impacto negativo en el mercado laboral (8); todos (95); ninguno (97); no sabe (98) y no contesta (99) se mantienen igual.

- Grupos de nacionalidades con la que se asocia a la inmigración: la recodificación de esta variable se ha realizado debido a que existían categorías de respuesta que tenían igual significado. Por ello, que para facilitar los análisis estadísticos se han agrupado, dando como resultado: magrebíes (1) agrupa a marroquíes y otros norte africanos, árabes, musulmanes y moros. Latinoamericanos aglomera a ecuatorianos, peruanos, colombianos, argentinos, otras nacionalidades latinoamericanas y latinoamericanos. Asiáticos (3) engloba a chinos y otras nacionalidad asiáticas. Subsaharianos (4) agrupa a senegaleses, nigerianos y africanos subsaharianos. Europeos del este (5) lo forman rumanos, búlgaros y nacionalidades de los países del este de Europa. Otras respuestas peyorativas (96) lo componen negros, integristas, la gente que busca trabajo, los de las pateras y los que causan problemas y delincuencia. Otras nacionalidades europeas (6); todos (95); ninguno (97); no sabe (98) y no contesta se mantienen igual.

- Porcentaje de inmigrantes en España: la recodificación de esta variable se ha realizado agrupando los valores en intervalos; dando como resultado: poca presencia (1) valores del $1 \%$ a $5 \%$; ni mucha ni poca presencia (2) de $6 \%$ al $15 \%$; bastante presencia (3) del $16 \%$ al 25\%; y mucha presencia (4) más el $25 \%$. Las categorías de respuesta (96) 96\% y más; ninguno (97); no sabe (98) y no contesta (99) se mantiene del mismo modo.

- Porcentaje de inmigrantes en su ciudad/pueblo: se realiza la misma recodificación que en porcentaje de inmigrantes en España, al tener idénticas categorías de respuesta. 
- Grupo de inmigrantes que causan más simpatía: se realiza la misma recodificación que en grupos de nacionalidades con la que se asocia a la inmigración, al tener idénticas categorías de respuesta.

- Grupo de inmigrantes que causan más antipatía: se realiza la misma recodificación que en grupos de nacionalidades con la que se asocia a la inmigración, al tener idénticas categorías de respuesta.

- Causa por que generan antipatía: esta variable se recodifica para hacerla más operativa, ya que alguna causas de antipatía son similares. La variable recodificada queda del siguiente modo: delincuencia (1) engloba por su vinculación con la delincuencia, porque están organizados en banda, porque pertenecen a bandas y porque son violentos, agresivos, conflictivos. Creencias religiosas (2) que agrupa por sus creencias religiosas y por su extremismo religioso. Respuestas peyorativas (3) que aglomera porque son sucios, porque son maleducados, incívicos; por otros rasgos negativos (taimados, vagos), porque nos desprecian, respuestas imprecisas de rechazo y porque no vienen a trabajar. No se integran, son demasiados (4) engloba a porque no se integran; forman guetos y Porque son demasiados; nos invaden. Por sus costumbres y actitudes hacia la mujer (6) agrupa a por sus costumbres, formas de vida, etc. y por su actitud hacia la mujer. Otras respuestas (96) aglutina a respuestas no expresadas en primera persona, por mi experiencia personas y otras respuestas. Así como porque son malas personas (10); no sabe (98) y no contesta (99) se mantienen igual. 


\section{ANÁLISIS DE RESULTADOS}

En este capítulo, se va a realizar un análisis a partir de datos secundarios de diferentes fuentes estadísticas, sobre la percepción de la sociedad española ante la inmigración. Para ello, se realizará un análisis longitudinal del periodo de 2007 a 2011, centrándose en: (A) la evolución de los problemas sociales por parte de la población española durante el periodo de 2000 a 2013; (B) las representaciones sociales de la inmigración en España; (C) las percepciones de la sociedad sobre la realidad numérica de la inmigración; (D) las creencias y los valores sobre la gestión de la inmigración; y (E) las actitudes ante la inmigración en la vida cotidiana; (F) análisis de los perfiles de la población ante la inmigración.

\section{A. EVOLUCIÓN DE LOS PROBLEMAS SOCIALES POR PARTE DE LA SOCIEDAD ESPAÑOLA (2000 a 2013).}

Analizar la construcción de la inmigración como problema social, es una ardua tarea, dicha dificultad reside en diferenciar entre la realidad subjetiva y la realidad objetiva de la sociedad española, es decir, cuando la ciudadanía indica cual es su creencia acerca de los problemas del país -realidad subjetiva-, frente a cuando la propia población señala cuáles son sus problemas a través del contacto real que tiene con la población inmigrante -realidad objetiva-. Siguiendo a Habermas (1999) -como se ha señalado en el marco teórico- la racionalidad formal del sistema que sería lo externo a la persona, que en esta investigación sería la realidad objetiva y la racionalidad sustantiva del mundo de la vida, que haría referencia a los propios sujetos que conviven en sociedad, que en esta investigación la realidad subjetiva.

Con el objeto de realizar un análisis más exhaustivo de la realidad subjetiva y objetiva; y cómo afecta en la construcción de los problemas sociales; se plantea por un lado analizar la formación de la opinión como constructo social y por otro lado estudiar la opinión como experiencia vital, buscando coherencias y conflictos entre ambas realidades. 


\section{PERCEPCIÓN DE LA SOCIEDAD ANTE LOS PRINCIPALES PROBLEMAS DE ESPAÑA.}

Para indagar dentro del ámbito de las creencias, en el cual se forma la opinión como constructo social, en gran parte adquirida mediante la información que transmiten los medios de comunicación -teoría de la Agenda Setting-, es importante examinar la evolución de los cinco principales problemas que la sociedad española ha indicado en los barómetros de opinión pública de 2000 a 2007 y de 2012 a 2013; así como los barómetros sobre actitudes hacia la inmigración en el periodo de 2008 a 2011.

En el análisis longitudinal sobre la evolución de los cinco principales problemas que la ciudadanía española encuentra en el país, se observa en los últimos años, cómo no puede ser de otro modo, el peso de un factor muy relevante como es la crisis económica en la que España se está viendo sumergida y muy particularmente el elevado desempleo. Deteniéndonos en el primer año de este periodo, el principal problema del país era el terrorismo. En el caso del terrorismo al estar ligado con la banda terrorista ETA (Euskadi Ta Askatasuna ${ }^{17}$ ) y a la violencia callejera vinculada a esta organización, sufre muchos altibajos dependiendo de la actividad criminal de la banda y de las negociaciones que se estén llevando en cada momento con el gobierno. En el año 2000 el terrorismo ligado a ETA es el primer problema de España ya el 43,2\% de la población que así lo señalaba. A partir del 2002, la importancia del terrorismo en España ya no es apreciada como el primer problema, hasta el 2005 donde el $30,1 \%$ de población vuelve a situar al terrorismo como primer problema del país. Este aumento probablemente esté propiciado, por los atentados islamistas del 11-M en Madrid y la ruptura de las negociaciones del pacto antiterrorista del 2005. Posteriormente, ETA en 2006 anuncia un alto al fuego que rompe en 2007 causando otro incremento de la preocupación de la ciudadanía, ya que el $23,9 \%$ lo señalaba como primer problema de España. Desde ese momento la preocupación de la sociedad española ante el terrorismo disminuye bruscamente debido al descenso de la actividad criminal y por el agudizamiento de la crisis económica. En 2000 desaparece la preocupación por el terrorismo en España, tras el alto al fuego de ETA y el anuncio del cese definitivo de la actividad armada en

\footnotetext{
${ }^{17}$ Euskadi Ta Askatasuna en castellano sería traducible por País Vasco y Libertad.
} 
2011. Por tanto, se observa entonces la relación entre los acontecimientos, los medios de comunicación y la construcción social de los problemas.

El siguiente problema que aparece señalado en el periodo analizado, es el paro ${ }^{18}$. En el 2000 , el 29,1\% de la población afirmaba que el paro era el primer problema del país, esta preocupación comienza a aumentar hasta el 2004, donde el 35,9\% de la ciudadanía pensaba que era el principal problema de España -la tasa de desempleo era del $11,0 \%{ }^{19}$-. A partir del 2004 , el paro como problema en el país comienza a decaer hasta el 2007 en el que es señalado por el 14,9\% de la sociedad española como el principal problema del país por debajo del terrorismo; -en ese mismo año la tasa de desempleo en España es la más baja del periodo, con el 8,3\%-. La preocupación por el paro comienza a aumentar, a partir de aquí, en el seno de la sociedad como problema de España de manera vertiginosa, así lo señalan 30,5\% de la población en 2008, es decir, casi veinte puntos porcentuales más que el año anterior. En 2009 el paro es para la población el primer problema del país, alcanzando su pico en el 2011 donde el 69,0\% aseguraba que es el primer problema de España -en ese año la tasa de desempleo era del 21,5\%-. En el 2011 disminuye tenuemente, hasta el 58,8\% de la población que lo señalaba como primer problema de España en 2013, este descenso del paro en el último periodo examinado coincide con el incremento de la preocupación por los problemas sociales y políticos -esto se verá con más detalle posteriormente-. Los datos del paro simbolizan que la mitad de la ciudadanía española cree que el paro es el principal problema del país, -los datos del primer trimestre de desempleo marcan la tasa de desempleo del $27,2 \%$-.

Uno de los problemas más identificados por la ciudadanía española son los problemas de índole económica ${ }^{20}$. Estos han sufrido un importante aumento en el periodo del 2000 al 2013. Desde el 2000 al 2005 los problemas de índole económica eran percibidos para alrededor del 2,5\% de la población como el primer problema del país. A partir del 2006, comienza a aumentar la preocupación de la sociedad al respecto, tanto que del 2007 al 2008 aumenta del 6,2\% al 36,5\%, es decir más de treinta puntos porcentuales de incremento en un año. Justo es el 2007 cuando la ciudadanía lo señala como el principal problema del país por encima del paro. A

\footnotetext{
${ }^{18}$ Paro se entiende como el desempleo, los parados, la falta de trabajo etc.

${ }^{19}$ Datos extraídos de la Encuesta de Población Activa (EPA) mediante el Instituto Nacional de Estadística (INE).

20 Problemas de índole económica incluye carestía de la vida, precios, quejas generales de cómo está la situación económica.
} 
partir del 2007 comienza a descender y establecerse como segundo problema del país, situándose en 2013 con el 13,1\% de la población que cree que los problemas de índole económica son el primer problema del país. La explicación del descenso de 2007 a 2013, puede deberse a que en 2007 en el seno de la opinión pública española se habla sobre la crisis económica, pero sus efectos, principalmente el paro, no es en ese momento especialmente visible, es años después donde el incremento del paro en la sociedad española aumenta y por tanto su percepción como principal problema del país.

Otro de los principales problemas que la sociedad española identifica en España es la clase política ${ }^{21}$, factor que se ha visto muy influenciado por la situación socioeconómica del país. En el 2000, únicamente el 1,6\% de la población lo percibía como el primer problema de España, cifra que se mantiene estable hasta el 2003 donde aumenta hasta el 4,1\%, posiblemente debido a decisiones con poco respaldo en la sociedad civil del partido en el gobierno, especialmente por la entrada en la guerra de Irak. Desde el 2003 hasta el 2007 se acrecienta entre la ciudadanía la idea de que el primer problema de España es la clase política, hasta llegar al 6,1\% de la población que así lo creía. En 2008 desciende hasta el 1,7\%; esto se puede producir porque la sociedad española alumbra otros problemas más relevantes en ese momento como el terrorismo, el paro y los problemas de índole económica. Desde el 2008 la clase política como primer problema del país se mantiene en niveles bajos, pero en aumento progresivo, y es el 2012 donde el 6,6\% de la sociedad española cree que el primer problema del país es la clase política; y en el 2013 este porcentaje aumenta hasta el $11,1 \%$.

En relación a la inmigración vista por la sociedad española como problema del país, es importante reseñar que durante el periodo de 2000 a 2005 se mantiene constantemente entre los cinco principales problemas de España. En ese periodo, alrededor del 4,0\% de la sociedad señala la inmigración como primer problema del país y es que son años de una elevada llegada de pateras y cayucos a las costas españolas -especialmente a Andalucía, Murcia y Canarias- y de una cobertura mediática respecto a este fenómeno muy intensa. En el 2006 se produce un aumento significativo de la percepción de la inmigración como problema de España,

\footnotetext{
21 La clase política agrupa a los partidos políticos y las críticas a la política en general.
} 
ya que el $13,9 \%$ de la sociedad española así lo asegura. Este considerable incremento se puede deber en primer lugar a la crisis de los cayucos de 2006 y en segundo lugar, a la regularización de inmigrantes del 2005, únicamente en 2006 llegaron a Canarias un total de $31.245^{22}$ personas extranjeras en cayucos, principalmente subsaharianos y senegaleses, aunque también llegaron personas asiáticas. Un incremento muy considerable, ya que en 2005 únicamente fueron detectadas 4.700 personas extranjeras. Esto generó un debate político -politización de las migraciones- y se incrementaron el número noticias y su relevancia (salience) relacionadas con la inmigración por parte de los medios de comunicación. Un tratamiento un tanto sensacionalista donde calificaban la llegada de inmigrantes en términos de "desbordada" la situación o como una "avalancha" de inmigrantes ${ }^{23}$.

A partir de 2007, la consideración de la inmigración como uno de los principales problemas de España comienza a disminuir. En 2008 únicamente el 5,0\% de la población así lo manifestaba y ya en el 2011 no es identificado ni por un 1,0\% de la población como primer problema del país. En 2013, como se observa en el gráfico 1, es el $0,4 \%$ de la sociedad la que asegura que la inmigración es uno de los principales problemas de España. Esto puede indicar que a la inmigración no se la identifica directamente como principal causante de la crisis económica, si bien es necesario un análisis más minucioso para percibir los efectos de la percepción de la inmigración por parte de la ciudadanía en el transcurso de la crisis económica ${ }^{24}$.

La explicación sobre la pérdida de importancia de la inmigración como principal problema de la país, se puede en parte, entender por la "politización de las migraciones" (Morales y Ros, 2012) que se intensifica cuando no hay una temática que despierte un fuerte interés en los principales generadores de problemas sociales, es decir, los medios de comunicación y la agenda pública. Es por ello que decae la inmigración como problema prioritario para el país cuando emergen los problemas económicos y el desempleo masivo en España. De modo que es más probable que la inmigración se politice en tiempos de prosperidad económica y de menor desempleo que es época de crisis.

\footnotetext{
22 Cifras de la Secretaria de Inmigración y Emigración del Ministerio de Empleo y Seguridad Social.

23 "Canarias se declara desbordada ante la mayor avalancha de inmigrantes. Más de 1.200 subsaharianos han llegado entre el viernes y el domingo a bordo de 14 embarcaciones y se espera que la avalancha prosiga. El gobierno autonómico se plantea incluso pedir ayuda a la ONU" (EI País, 21 de agosto de 2006); o, "Hay cien mil africanos que esperan en Senegal para cruzar a Canarias" (ABC, 20 de agosto de 2006).

${ }^{24}$ Los datos del barómetro de enero de 2008 sobre los problemas del país son: paro 20,1\%; problemas de índole económica 17,1\%; terrorismo, ETA 16,3\%; vivienda 12,2\% y inmigración 8,4\%.
} 
Gráfico 1: Percepción de la sociedad ante los principales problemas de España (2000 a 2013).

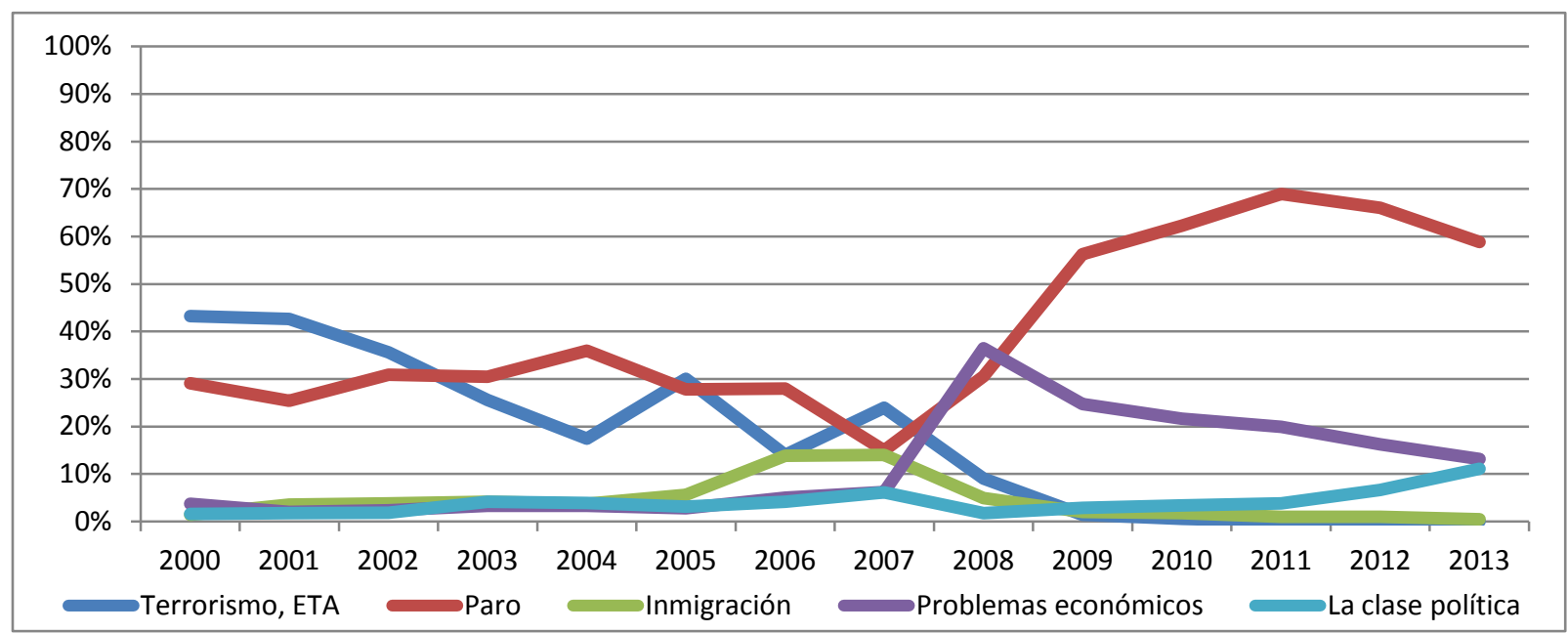

Fuente: Elaboración propia con datos del CIS; estudios 2398 (2000), 2406 (2001), 2444 (2002), 2477 (2003), 2554 (2004), 2589 (2005), 2636 (2006), 2673 (2007), 2773 (2008), 2817 (2009), 2846 (20109, 2918 (2011), 2927 (2012) y 2976 (2013).

\section{PERCEPCIÓN DE LOS PROBLEMAS PERSONALES DE LA SOCIEDAD ESPAÑOLA.}

En el ámbito de la realidad en el que se forja la opinión como experiencia vital, es decir, mediante el conocimiento propio adquirido por la praxis de uno mismo, esto se manifiesta mediante la percepción de la sociedad española de sus propios problemas.

En el periodo de 2000 a 2013, la principal problemática que afecta a la ciudadanía son los problemas económicos ${ }^{25}$, ya que desde el año 2000 hasta el 2005 para alrededor del 45,0\% de la población era su primer problema. En el 2005 desciende al 39,6\% de la ciudadanía que así lo creía, -punto más bajo en todo el periodo-. Este problema aumenta considerablemente en 2006 al 48,0\%, para volver a descender al año siguiente al $40,4 \%$ de la población cuyo principal problema es económico. En 2008, los problemas económicos son el primer problema del $70,3 \%$ de la ciudadanía, significando un aumento de treinta puntos porcentuales en un año. El incremento de población cuyo primer problema es el económico es progresivo, hasta llegar al 2012, donde significaba el 79,6\% de las preocupaciones de la sociedad. En el 2013 se aprecia un descenso al $73,3 \%$, es decir más de tres puntos porcentuales respecto al año anterior.

25 Por problemas económicos se entiende: el paro, las infraestructuras, los problemas de índole económica, los problemas relacionados con la calidad del empleo y los problemas de la agricultura, ganadería y pesca. 
Otra de las principales problemáticas de la sociedad española son los problemas sociales $^{26}$ que le afectan a sí mismos. En el 2000 el 37,8\% de la población señalaba que su principal problema era de tipo social. En el año siguiente alcanza su punto más elevado con el $44,2 \%$ de la población que principalmente se encuentra afectada por un problema social, muy cerca de los problemas económicos que representaban el $47,2 \%$ de las preocupaciones de la población en el 2001, al siguiente año, los problemas sociales disminuyen al 24,2\% de la ciudadanía que así lo cree. En 2008 con la irrupción del aumento de los problemas económicos para la ciudadanía, decrece la preocupación de la sociedad por los problemas sociales, situándose en el $18,0 \%$ de la población que sufre prioritariamente un problema social. En el 2013 se advierte un aumento al 20,3\% como principal problema de la población, lo cual supone en términos relativos un aumento de cuatro puntos porcentuales respecto al año anterior.

En el periodo estudiado, los problemas políticos ${ }^{27}$ son una preocupación constante para la sociedad, puesto que las decisiones políticas afectan de manera directa 0 indirecta al resto de problemáticas. Los problemas políticos sufren muchos altibajos en el periodo de 2000 a 2013, debido en gran parte, a las decisiones políticas que se vayan adoptando en cada momento. En el 2000, el 5,3\% de la ciudadanía aseguraba que su principal problema era de tipo político, este porcentaje aumenta bruscamente al $24,4 \%$ en 2002 , en ese año están igualados problemas sociales y problemas políticos en cuanto a las preocupaciones personales de la ciudadanía. Es a partir del 2003 donde los problemas políticos comienzan a descender y distanciarse de los problemas sociales; en 2008 con la visibilización de la crisis, desciende aún más, hasta el $9,1 \%$ de la población para quienes su principal preocupación es un problema de tipo político. Desde el 2008 sigue descendiendo, hasta el 2013 en el que sufre un repunte para situarse en el 5,8\% de la población para quien su principal problema es de carácter político.

En cuanto a la inmigración ${ }^{28}$ como problema personal de la sociedad española sufre variaciones en el periodo de 2000 a 2013. En el 2000, el 1,1\% de la ciudadanía

\footnotetext{
26 Problemas sociales engloba: las drogas, la sanidad, la vivienda, las pensiones, los problemas de índole social, la violencia contra la mujer, los problemas relacionados con la juventud, la crisis de valores, la educación y los problemas relacionados con la mujer.

${ }^{27}$ Los problemas políticos son: el terrorismo, ETA; la corrupción y el fraude; la clase política; la administración de justicia; el gobierno, los políticos y los partidos; el funcionamiento de los servicios públicos y los nacionalismos.

${ }^{28} \mathrm{La}$ inmigración engloba a la misma inmigración y el racismo.
} 
española señala que su principal problema es la inmigración, cifra que aumenta lentamente hacia porcentajes alrededor del 3,0\%. En 2005 es para el 3,8\% de la población su principal problema y al siguiente año aumenta al 5,6\%. Llegando a su punto más elevado en 2007 con el 5,9\% de la sociedad que considera a la inmigración como su principal problema. En 2008, posiblemente por la visibilización de los efectos de la crisis económica, la inmigración desciende al 2,6\%. En 2013 únicamente el $0,6 \%$ de la sociedad española señala, como se observa en el gráfico 2 , a la inmigración como su principal problema personal. ${ }^{29}$ Se puede apreciar que el porcentaje de población afectada por un problema con la inmigración es muy reducido, en el periodo analizado, por lo que es probable que la sociedad no vea tanto a la inmigración como un problema que le afecte personalmente, sino más bien como un problema social del país en su conjunto.

Gráfico 2: Percepción de la sociedad ante los problemas que le afectan personalmente (2000 a 2013).

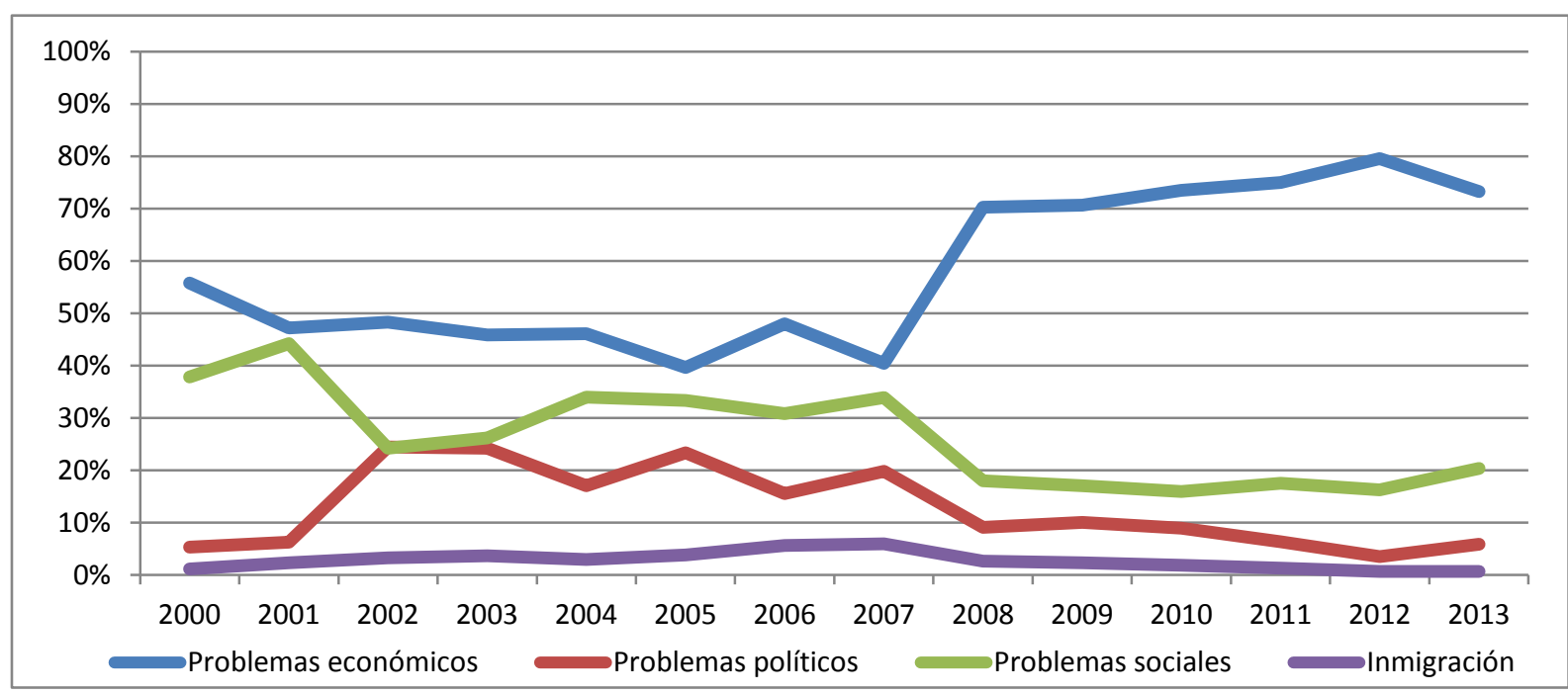

Fuente: Elaboración propia con datos del CIS; estudios 2383 (2000), 2406 (2001), 2444 (2002), 2477 (2003), 2554 (2004), 2589 (2005), 2636 (2006), 2673 (2007), 2773 (2008), 2817 (2009), 2846 (20109, 2918 (2011), 2927 (2012) y 2976 (2013).

\section{CONTACTO DE LA SOCIEDAD ESPAÑOLA CON LA POBLACIÓN INMIGRANTE O EXTRANJERA.}

Para seguir examinando la percepción de la sociedad española sobre la inmigración como experiencia vital, es relevante conocer el contacto que la población tiene con las personas inmigrantes o extranjeras, lo que se considera como la experiencia personal sobre la inmigración.

${ }^{29}$ Resultados del barómetro de enero de 2008 para los problemas que afectan personalmente son: problemas económicos $51,8 \%$; problemas sociales $32,1 \%$; problemas políticos $13,0 \%$ e inmigración $3,2 \%$. 
El contacto directo de la sociedad española con la población inmigrantes, en el periodo de 2008 a 2011, se produce primordialmente al ser sus vecinas y vecinos. En 2008 , el $54,2 \%$ de la ciudadanía tenía entre su vecindad a alguna persona inmigrante, este porcentaje desciende levemente al 51,2\% en 2010, mientras que al siguiente año aumenta al 53,7\% la población que entre sus vecinas y vecinos tienen a alguna persona inmigrante. En relación al contacto con la población inmigrante por medio de ser compañeras y compañeros de trabajo o estudios. En 2008, el 41,6\% de la población tenía a algún inmigrante que trabajase o estudiase con ellos. Ese porcentaje se mantiene estable, en los siguientes años, hasta el 2011 donde se registra un aumento de casi tres puntos porcentuales respecto al año anterior, es decir, en 2011 un 44,6\% la sociedad española trabaja o estudia con una compañera o compañero inmigrante. Este incremento en 2011, se puede deber a que con los efectos de la crisis económica y la masiva destrucción de empleo, la ciudadanía ha optado por trabajos que en principio estaban destinados al sector secundario en la teoría del mercado dual (Doeringer y Piore, 1971), es decir, para la inmigración.

Respecto a la ciudadanía que considera que en su círculo de amistades hay una persona inmigrante, sigue una distribución similar al de las compañeras y compañeros de trabajo o estudios. En 2008, el 40,4\% de la población se consideraba amiga $\mathrm{y} / \mathrm{o}$ amigo de alguna persona inmigrante y aumenta progresivamente hasta el $44,1 \%$ de la sociedad que tiene en su círculo de amistades a personas inmigrantes en 2011. En cuanto a la población española que entre sus familiares hay algún inmigrante, es considerablemente inferior al resto de grupos -vecindad, compañeras y compañeros, y amistades-, en 2008 únicamente el 15,7\% de la ciudadanía eran miembros de su familia personas inmigrantes. Al año siguiente sufre un aumento al $17,5 \%$ en el que se mantiene estable, siendo el $17,8 \%$ de la sociedad española que tiene en su familia a una persona inmigrante en 2011.

Tras examinar los datos que muestra el gráfico 3, el contacto directo con la población inmigrante por medio de que sean familia presenta un porcentaje mucho más pequeño que la relación de amistad o de vecindad, por lo que las conclusiones que se pueden extraer de esto es que incorporar o considerar de la familia a una persona inmigrante no se realiza con la misma frecuencia que tener alguna vecina 0 vecino, compañera o compañero de trabajo o estudios, y amigos y/o amigas. Esto se 
puede deber al sentimiento de perdurabilidad de la familia como símbolo de los valores tradicionales que se representa en el imaginario español. De hecho, siguiendo a Oskamp (1991), la distancia social es el grado de separación considerado como aceptable en las relaciones entre personas de países o de etnias diferentes, por tanto el matrimonio y el noviazgo -formar parte de la familia- es un grado de intimidad máximo, mientras que vivir en el mismo vecindario, compartir espacios público sería un grado de intimidad intermedio; y compartir el transporte público o ir a los mismo bares, sería un grado de intimidad mínimo (Cea D’Ancona, 2002).

El contacto directo con la población inmigrante o extranjera es especialmente relevante para comprobar que la población que tiene mayor proximidad, tanto por afinidad como por contacto, con la población inmigrante presenta actitudes más positivas hacia la inmigración. Así como la población que no se han relacionado o que su experiencia haya sido mala tendrá actitudes negativas hacia la misma. (Berry, Kalin y Taylor, 1977).

Gráfico 3: Contacto directo de la sociedad española con inmigrantes o extranjeros (2008 a 2011).

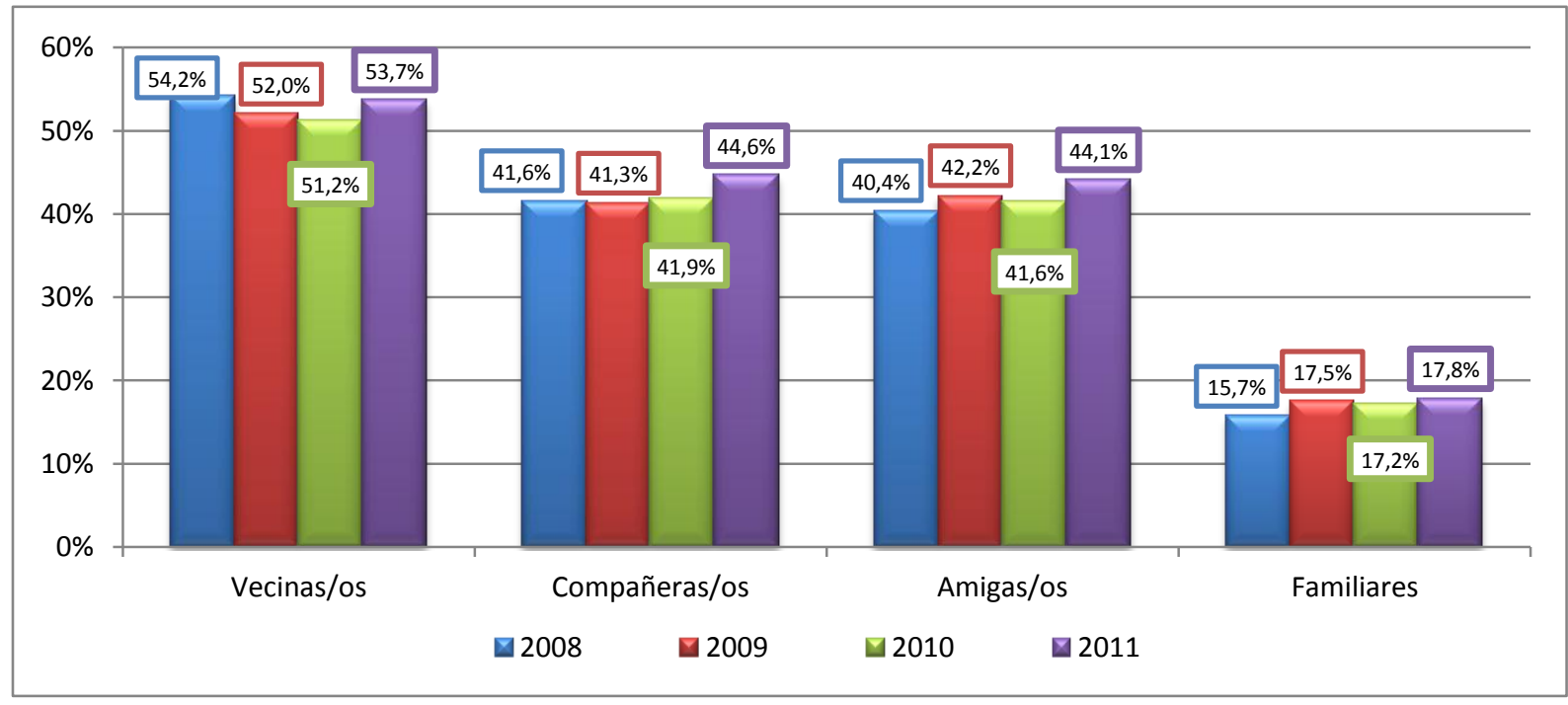

Fuente: Elaboración propia con datos del CIS; estudios 2773 (2008), 2817 (2009), 2846 (2010) y 2918 (2011). 


\section{B. REPRESENTACIONES SOCIALES DE LA INMIGRACIÓN EN ESPAÑA (2008 a 2011).}

Para examinar las representaciones sociales sobre la inmigración en España, es necesario tener en consideración varios factores que condicionan en mayor o menor medida el fenómeno. Estos factores son las percepciones acerca de: la inmigración, la diversidad cultural, la competitividad en el mercado laboral, los medios de comunicación, el trato de la población española a las personas inmigrantes; y las agresiones racistas. Además de ello, este apartado incluye un análisis específico de la realidad en el año 2011.

\section{REPRESENTACIONES SOCIALES ACERCA DE LA INMIGRACIÓN.}

En el estudio de las representaciones sociales acerca de la inmigración se va a analizar: el primer término con el que ciudadanía relaciona la inmigración; los aspectos tanto positivos como negativos que se asocian a la inmigración; la consideración por parte de la sociedad sobre sí la inmigración es positiva para España; la comparativa con los países europeos sobre la percepción de la inmigración como positiva; y la aceptación por parte de la ciudadanía de un partido con unos ideales xenófobos o racistas en España.

La primera idea asocia la ciudadanía española el concepto de inmigración es con la necesidad de venir a trabajar. Durante el periodo analizado, de 2008 a 2011, este concepto aumenta del $20,4 \%$ de 2008 al $23,0 \%$ del 2011. A su vez, de especial interés es el descenso de la asociación de la inmigración con la ilegalidad, la irregularidad, y la llegada de pateras; concepciones que se aminoran progresivamente del $12,1 \%$ en 2008 al $7,1 \%$ en 2011 . Este hecho está muy influenciado, con los datos reales de la llegada de pateras a las costas españolas, y la disminución de la cuota de pantalla de los medios de comunicación para retrasmitir esta información. Además de ello, también es relevante el comportamiento de la asociación de los conceptos de pobreza y desigualdad, que alcanzan su pico más elevado en 2010 con el 13,9\% y al año siguiente sufre un descenso, para situarse en el $11,7 \%$. Es probable que esta bajada se deba a que la sociedad ya no relacione tan directamente pobreza y desigualdad únicamente con la 
inmigración; puesto que debido a la crisis económica, es cada vez más la población española que se encuentra con dificultades económicas.

Además de ello, un conjunto de categorías de respuesta que sufren un incremento en el periodo examinado, son aquellas que se refieren a aspectos socio-laborales relacionados con la inmigración, tales como tener privilegios sociales frente a la población española, que aumenta del 3,3\% en 2008 al 5,1\% en 2010; así como el impacto negativo de la inmigración en el mercado laboral, que crece del 5,9\% al $7,8 \%$ en el mismo periodo; y los sentimientos negativos que despierta la inmigración en cuanto mercado laboral, que aumenta del 4,4\% en 2008 al 6,2\% en el 2011.

Por lo cual, se puede observar en el gráfico 4, una tendencia en el aumento de aspectos poco favorables de la ciudadanía española hacia la primera idea con la que se asocia la inmigración en lo referente a los derechos sociales y laborales.

Gráfico 4: Concepto que la población asocia a la inmigración (2008 a 2011).

\begin{tabular}{|c|c|c|c|c|c|}
\hline $100 \%$ & $4,4 \%$ & $6,1 \%$ & $4,3 \%$ & $6,2 \%$ & $\begin{array}{l}\text { Sentimientos negativos } \\
\text { hacia la inmigración }\end{array}$ \\
\hline $90 \%$ & $11,8 \%$ & $9,4 \%$ & $10,7 \%$ & $10,7 \%$ & $\triangle$ Aumento desmedido y \\
\hline $80 \%$ & $5,9 \%$ & $6,0 \%$ & $7,9 \%$ & $7,8 \%$ & problemas de integracion \\
\hline $70 \%$ & $\begin{array}{l}6,5 \% \\
3,3 \% \\
\end{array}$ & $\begin{array}{l}5,3 \% \\
2,8 \%\end{array}$ & $\begin{array}{l}5,0 \% \\
5,0 \%\end{array}$ & $5,1 \%$ & mercado laboral \\
\hline $60 \%$ & $12,4 \%$ & $13,6 \%$ & $13,9 \%$ & $11,7 \%$ & $\square$ Delincuencia e inseguridad \\
\hline $50 \%$ & $12,2 \%$ & $14,0 \%$ & $12,2 \%$ & $12,4 \%$ & $\begin{array}{l}\text { Privilegios sociales trente a } \\
\text { los españoles } \\
\text { Pobreza y desigualdad }\end{array}$ \\
\hline $30 \%$ & $20,4 \%$ & $20,8 \%$ & $19,3 \%$ & $23,0 \%$ & $\begin{array}{l}\text { Sentimientos de empatía y } \\
\text { solidaridad }\end{array}$ \\
\hline $20 \%$ & $12,1 \%$ & $9,1 \%$ & $7,3 \%$ & $7,1 \%$ & $\begin{array}{l}\text { Necesidad de venir a } \\
\text { trabajar }\end{array}$ \\
\hline $10 \%$ & $10,9 \%$ & $12,8 \%$ & $14,4 \%$ & $10,9 \%$ & 口 Irregularidad, pateras \\
\hline & 2008 & 2009 & 2010 & 2011 & Extranjeros \\
\hline
\end{tabular}

Fuente: Elaboración propia con datos del CIS; estudios 2773 (2008), 2817 (2009), 2846 (2010) y 2918 (2011).

Una vez detectados los conceptos con los que la población española asocia la inmigración, es importante conocer cuáles son los aspectos positivos y los negativos con los que se relaciona la inmigración. Por un lado, los principales aspectos positivos son el enriquecimiento cultural, que aumenta del 43,2\% en 2008 al $61,4 \%$ en 2011; por el contrario, la mano de obra secundaria disminuye del $23,5 \%$ al $13,5 \%$ 
en el mismo periodo -véase el gráfico 1 del anexo de resultados-. Este proceso se puede deber a la realidad económica del país, que ante el elevado desempleo, la inmigración ya no es percibida como una fuente de mano de obra, sino como una competencia en el mercado laboral. Por otro lado, en relación a los aspectos negativos con los que se asocia a la inmigración, estos son la delincuencia e inseguridad que decrece del 42,7\% al 34,3\% en el periodo de 2008 a 2011; así como a su vez, aumenta la competitividad en el mercado laboral del $13,9 \%$ al $20,4 \%$, en la misma franja temporal -véase el gráfico 2 del anexo de resultados-. Observando así, un incremento de los factores socio-laborales como los principales aspectos negativos que la sociedad española relaciona con la inmigración.

Continuando con la representación social acerca de la inmigración, es importante dar un paso más, profundizando sobre la postura de la sociedad española en cuanto a sí la inmigración es positiva o negativa para España. En periodo de 2008 al 2011 hay cambios en la percepción de la inmigración como un fenómeno positivo o negativo para el país. Se aprecia un descenso entre la población que considera la inmigración como muy positiva para el país, se pasa del $4,2 \%$ al 2,6\% en el periodo estudiado. Mientras que la postura mayoritaria en todo el periodo, es que la inmigración es positiva para España, pero sufre un descenso del 44,0\% al 39,2\%, siendo espacialmente intensa la caída del 2008 al 2009, con la pérdida de cuatro puntos y medio porcentuales. La población que percibe la inmigración como ni positiva ni negativa desciende del 19,2\% en 2008 al 18,2\% en 2011.

Por el contrario, la población que cree que la inmigración es negativa para el país, aumenta del 27,5\% en el 2008 al $31,8 \%$ en el 2011, al igual que ocurría en el descenso de quienes creen que la inmigración es positiva, el incremento más fuerte se produce del 2008 al 2009, con más de tres puntos porcentuales. Mientras que la población que piensa que la inmigración es muy negativa para España, aumenta progresivamente del 5,1\% en el 2008 al 8,2\% en 2011.

Tras analizar la percepción de la sociedad sobre la inmigración, se observa en el gráfico 5, que con el paso de los años la opinión de la población sobre la inmigración ha tendido a ser más negativa. Aunque es necesario remarcar que incluso en 2011, es mayor la parte de la sociedad que ve la inmigración como positiva para el país que como negativa. 
Gráfico 5: Inmigración como aspecto positivo o negativo para España (2008 a 2011).

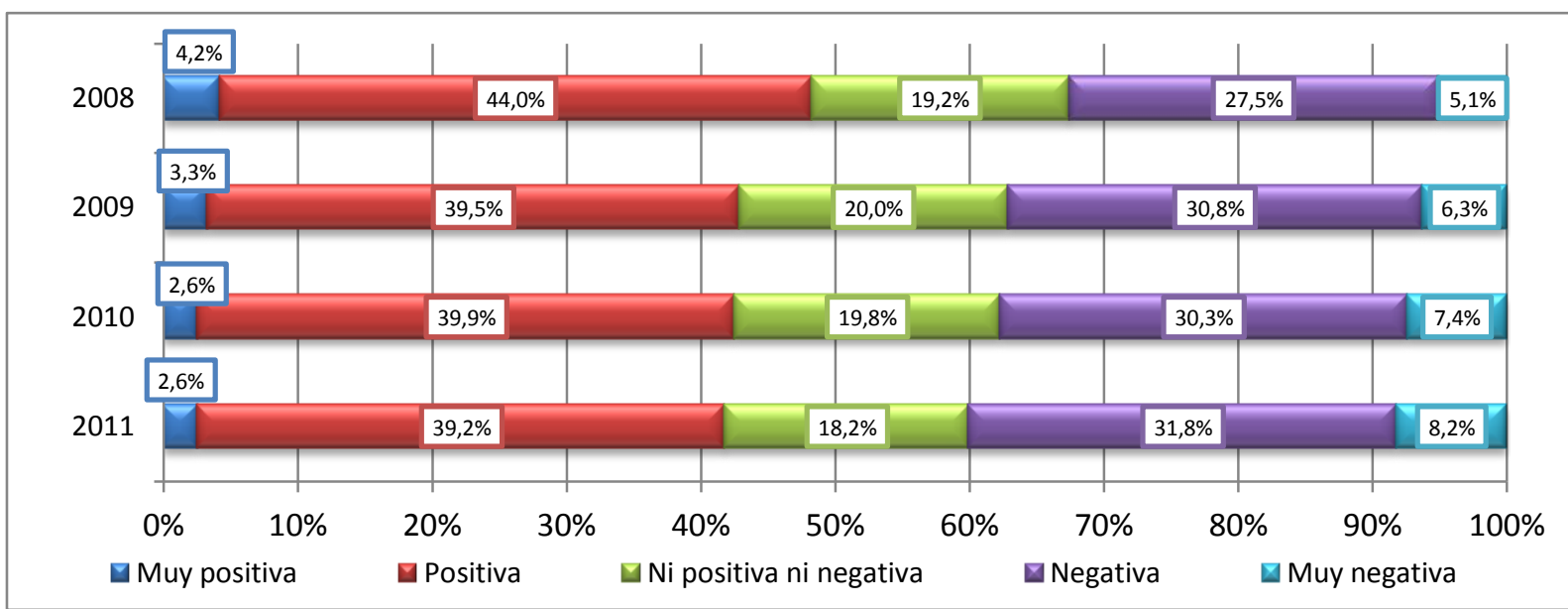

Fuente: Elaboración propia con datos del CIS; estudios 2773 (2008), 2817 (2009), 2846 (2010) y 2918 (2011).

Para conocer la percepción de la ciudadanía respecto a la inmigración, es importante examinar los aspectos socio-demográficos que son determinantes entre quienes piensan que la inmigración es negativa para España. Se aprecia que la edad es un factor a considerar, ya que a medida que aumenta la edad también lo hace la percepción de la inmigración como negativa para el país, ya el 38,1\% de las personas de 18 a 24 años creen que es negativa ${ }^{30}$ mientras que las personas mayores de 65 años lo creen el $69,4 \%{ }^{31}$. Otro factor, es el nivel de estudios, ya que en $20,4 \%$ de quienes tienen un nivel de estudios superiores creen que la inmigración es negativa, mientras para quienes no tienen estudios lo es un 66,7\%. Así como el contacto directo, es decir tener familiares inmigrantes repercute, puesto que $30,1 \%$, de quienes tienen algún familiar inmigrante creen que la inmigración es negativa, mientras que $53,2 \%$ de quienes no tienen familiares inmigrantes piensan que es negativa $^{32}$.

Además de ello, al realizar una comparación entre los países europeos en una situación económica similar a la española, es decir, afectados por la crisis económica, se observa, en el gráfico 6, que en una escala donde el 0 es un impacto muy negativo y 10 muy positivo de la inmigración sobre la vida cotidiana del país. España $(5,2)$ es aquella que tiene mejor percepción en cuanto al impacto de la inmigración en la vida cotidiana del país, puesto que junto con Irlanda $(5,1)$ son los únicos países por encima de la media europea $(4,9)$. El resto de países europeos

\footnotetext{
${ }^{30}$ Recodificación en la que se agrupan los valores de negativa y muy negativa en una misma variable.

31 Significación del chi-cuadrado $0,00 \%$. Por lo que se rechaza la hipótesis nula (no hay relación) y se acepta la asociación entre las variables. Datos del estudio 2918 (2011).

${ }^{32}$ Todas las tablas de contingencia de la presente investigación se encuentran en el anexo de resultados.
} 
afectados por la crisis presentan valores más bajos, Portugal $(4,1)$, Chipre $(3,8)$ y Grecia $(2,8)$.

Gráfico 6: Media del impacto del fenómeno migratorio en la vida cotidiana

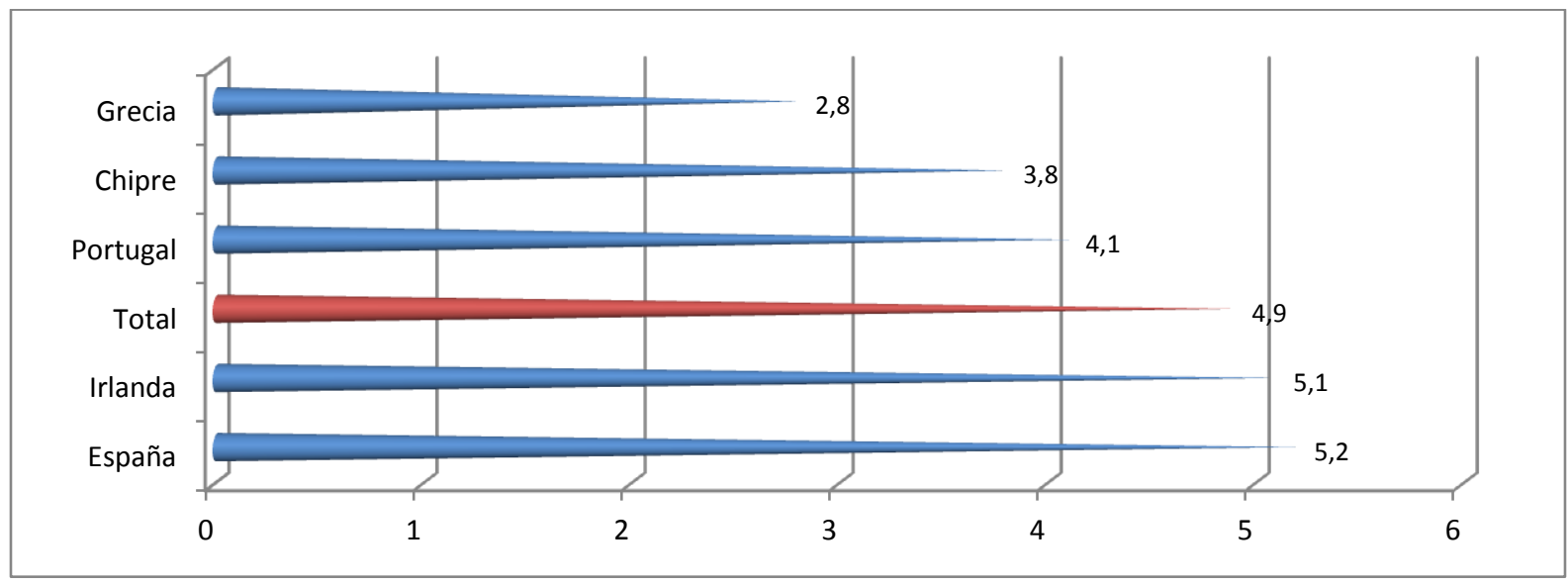

Fuente: Elaboración propia con datos de la Encuesta Social Europea 2010.

Para finalizar con la representación social acerca de la inmigración, se va a examinar la opinión de la población ante la aceptación de la creación de un partido racista o xenófobo en España, durante el periodo de 2008 a 2011. Se aprecia un leve aumento entre la población que cree que un partido de ese perfil tendría mucha aceptación entre el electorado español, ya que en el 2008 esta postura estaba representada por 2,6\% de la población y en 2011 representa el 3,3\%. Mientras que la población que piensa que tendría bastante aceptación, se sitúa en valores próximos al $17,8 \%$. En la postura adversa, la población que cree que un partido político racista o xenófobo tendría poca aceptación en España se mantiene en cifras similares durante el periodo estudiado, con una representación del 44,0\% de la población. A su vez, la población que piensa que un partido político racista o xenófobo no tendría ninguna aceptación en España, ha disminuido en el periodo analizado, del 36,8\% en 2008 al 34,7\% en 2011.

Al examinar los datos del gráfico 7 para el periodo 2008 al 2011, se percibe que la sociedad cree que un partido político racista o xenófobo en España no tendría mucho calado, puesto que en todo el periodo el agregado entre poca aceptación y ninguna aceptación superan el 75,0\% del total. También es necesario reseñar, que el porcentaje de la sociedad española que no sabe dar una opinión en esa cuestión es elevado, alrededor del $13,5 \%$ en el periodo estudiado. 
En relación a los datos expuestos, hay que resaltar que en España no ha existido un partido fuerte -en la etapa democrática-, que evoque unas ideas racistas o xenófobas abiertamente, como el Frente Nacional en Francia, la Liga Norte en Italia o Amanecer Dorado en Grecia. Si bien es cierto que el intento más reciente de crear un partido de calado populismo xenófobo se encuentra en Plataforma per Catalunya $(\mathrm{PxC})$, especialmente contrario a la inmigración islámica. Los resultados electorales mostraron un aumento considerablemente en las elecciones municipales de $2011^{33}$, pero decreció de igual modo en las elecciones autonómicas de 2012. Actualmente se ha está expandiendo al conjunto de España bajo el nombre de Partido por la Libertad (PxL).

Así como, la emergencia de partidos racistas o xenófobos en España, se da exclusivamente en el ámbito local. Esto puede deberse, en gran parte, a los obstáculos para obtener representación que tiene el sistema electoral español. El Estado de las Autonomías configura un sistema federal o cuasifederal (Aja, 2003) que permite a nuevos partidos tener más posibilidades de representación en la arena local, al no sufrir los efectos del sistema electoral a nivel nacional.

Gráfico 7: Aceptación de un partido político racista o xenófobo en España (2008 a 2011).

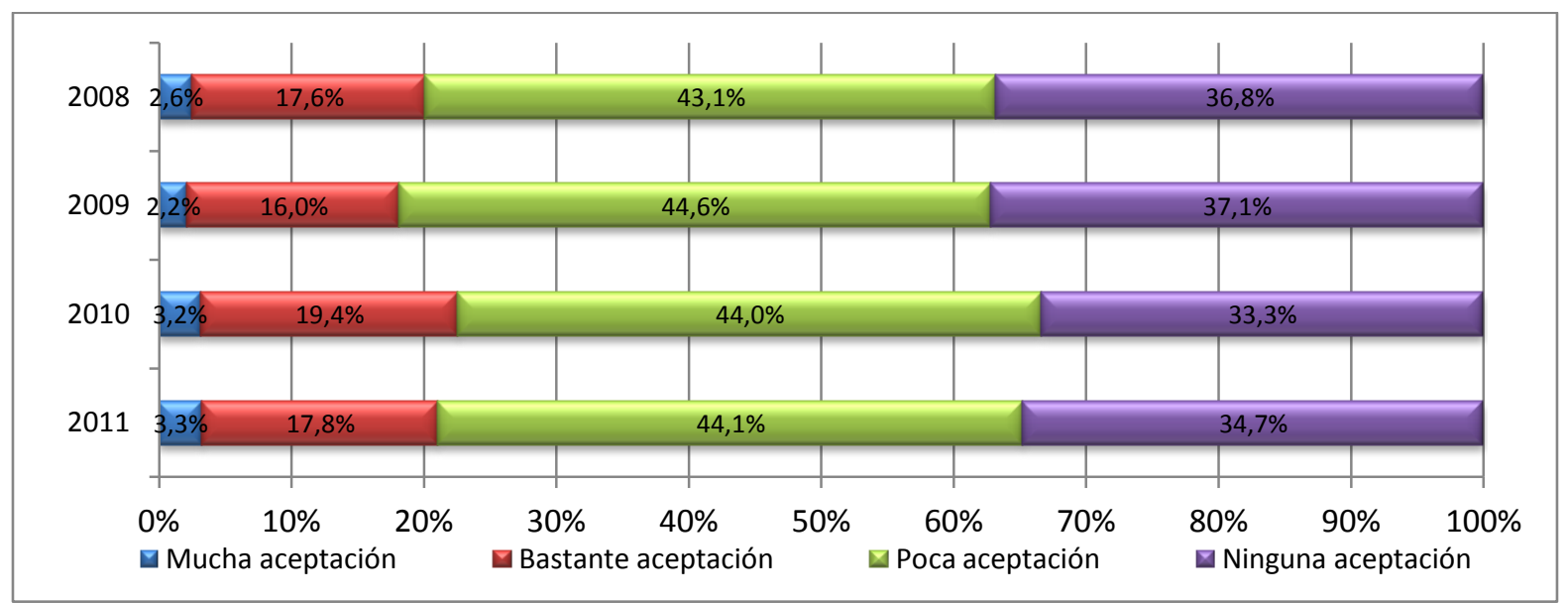

Fuente: Elaboración propia con datos del CIS; estudios 2773 (2008), 2817 (2009), 2846 (2010) y 2918 (2011).

${ }^{33}$ Aumento de 17 concejales en las elecciones de 2007 a 67 concejales de 2011. 


\section{LAS REPRESENTACIONES SOCIALES ACERCA DE LA DIVERSIDAD CULTURAL.}

Continuando con las representaciones sociales de la inmigración, es importante conocer las representaciones sociales acerca de la diversidad cultural, para lo que se va a analizar por un lado la percepción sobre la contribución de la inmigración al enriquecimiento del país; y por otro lado los rasgos que se valoran más positivamente que los que España esté compuesta.

Por un lado, la percepción de la población en cuanto a la contribución de la inmigración al enriquecimiento del país, ha variado ligeramente del 2008 al 2011. De tal modo, que las actitudes negativas hacia la inmigración como un factor que enriquece el país aumentan del 48,9\% en 2008 al 51,7\% en 2011 -véase el gráfico 4 del anexo de resultados-. Un incremento leve, pero reseñable debido a que el enriquecimiento cultural es el rasgo más positivo que la población española valoraba de la inmigración.

Por otro lado, realizando un análisis longitudinal durante el periodo 2008 a 2011 muestra que la sociedad española ve como rasgo más favorable que España esté compuesta por personas de diferentes culturas. En 2008, tenía una media de 6,38 que disminuyó en 2010 a 6,24, para al año siguiente aumentar al 6,30 de media. A su vez, que España esté formada por personas de diferentes países, se mantiene, en el periodo de 2008 a 2011, estable en el 6,19 de media; así como que España esté compuesta de personas de diferentes razas se sitúa 6,04 de media en todo el periodo. Mientras que la opinión de la ciudadanía sobre que España esté compuesta por personas de diferentes religiones es considerablemente menor que el resto de rasgos, puesto que en 2008 la media era de 5,28 y disminuyó en 2010 al 5,09, aumentando al siguiente año al 5,24 de media.

Del análisis de los datos, puede comprobarse que todos los rasgos son aceptados, ya que superan en el 5,0 de media en el espacio temporal de 2008 a 2011. Si bien es cierto que en 2010 hay un descenso en la aceptación de que España esté compuesta por personas de diferentes culturas y religiones. Esto puede deberse a que en 2010 es un año de masiva destrucción de empleo y de recrudecimiento de los efectos de la crisis económica y puede que se responsabilizase en un primer momento a la inmigración de dicha situación. 
Es reseñable que el factor que la ciudadanía percibe cómo menos positivo sea que esté compuesta por personas de diferentes religiones, como se aprecia en el gráfico 8; esto puede ser interpretado como una alusión hacia la religión musulmana, ya que de los principales grupos de nacionalidades, la religión más dispar en cuanto a costumbres y ritos es la musulmana. Esto unido a la importancia que la religión católica tiene en la sociedad española, puede explicar que la religión sea el rasgo peor considerado por la población.

Gráfico 8: Aceptación de los rasgos de los que España esté compuesta (2008 a 2011).

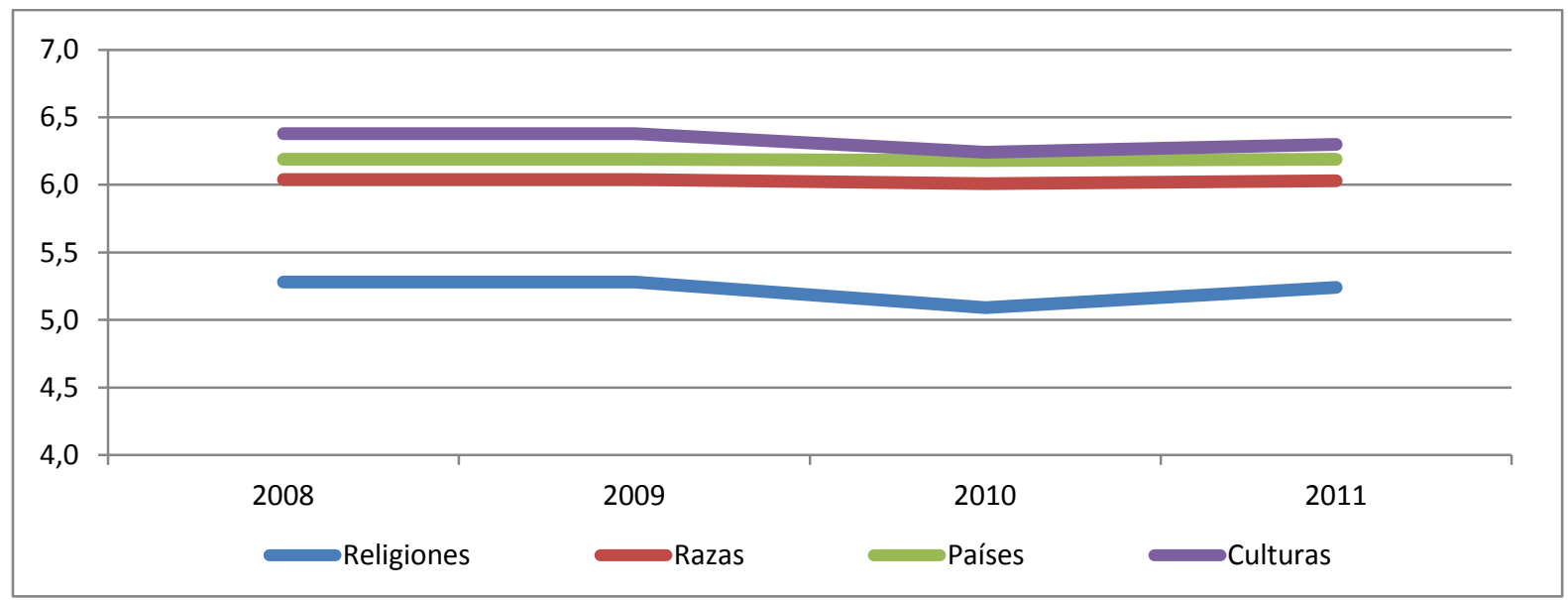

Fuente: Elaboración propia con datos del CIS; estudios 2773 (2008), 2817 (2009), 2846 (2010) y 2918 (2011).

\section{LAS REPRESENTACIONES SOCIALES ACERCA DE LA COMPETITIVIDAD LABORAL.}

Dando un paso más sobre la representación social de la inmigración en España es relevante indagar sobre la percepción de la sociedad acerca de la competitividad laboral. En este apartado se examinan la opinión sobre que la población inmigrante realiza trabajos que la población activa española no quiere hacer; si las personas inmigrantes quitan puestos de trabajo a la población activa española; preferencia de contratar a una persona española antes que a una persona inmigrante; la contribución al desarrollo económico de la inmigración a España; y la comparación con los países europeos sobre la importancia en el desarrollo económico de la inmigración sobre sus respectivos países.

Respecto a la creencia de que la población inmigrante realiza trabajos o tareas que la población activa española no quiere hacer, se observa cómo ha variado 
considerablemente en el periodo de 2008 a 2011. La población que está muy de acuerdo con la afirmación ha disminuido progresivamente del 39,2\% al 31,8\%, este descenso es especialmente marcado del 2010 al 2011 con la caída de casi cinco puntos porcentuales; a su vez, también se aminora la postura de la población que está más bien de acuerdo con la afirmación, del 45,6\% al 42,6\% de 2008 al 2011. Sin embargo, las posturas adversas, es decir quienes están más bien en desacuerdo con que la población inmigrante realiza trabajos que la población española no quiere realizar, aumenta progresivamente del 10,8\% en 2008 al 16,1\% en 2011. Mientras quienes están muy en desacuerdo con la afirmación, aumentan de 4,3\% en 2008 al $9,5 \%$ en el 2011.

Estos datos reflejan, como se aprecia en el gráfico 9, un cambio en la percepción del nicho laboral de la población inmigrante, es posible que sea como consecuencia de la crisis económica y la caída del empleo en España. Bajo esta situación la sociedad española ve a la población inmigrante como una competencia laboral y no únicamente como la masa laboral o el "ejército de reserva" (Doeringer y Piore, 1971) para realizar los empleos que la ciudadanía española rechaza.

Gráfico 9: Las personas inmigrantes realizan trabajos que la población española no quieren hacer (2008 a 2011).

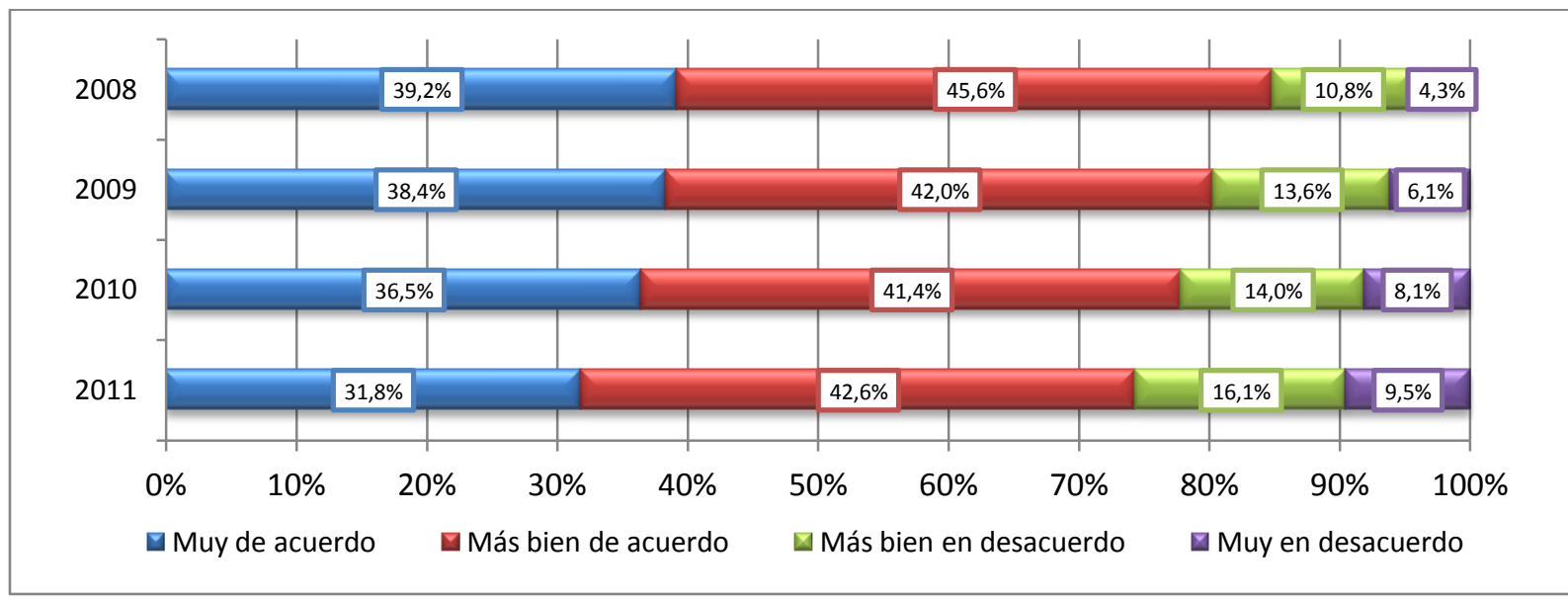

Fuente: Elaboración propia con datos del CIS; estudios 2773 (2008), 2817 (2009), 2846 (2010) y 2918 (2011).

Otra afirmación que dilucida la percepción de la ciudadanía sobre la competitividad laboral, es el aumento de la preferencia de contratar a una persona española antes que a una persona inmigrante. En 2008 el 23,1\% de la población estaba muy de acuerdo con la afirmación, y este porcentaje aumenta progresivamente hasta el 29,1\% en 2011 -véase el gráfico 7 del anexo de resultados-. Estos datos ponen de 
manifiesto el discurso funcionalista de la inmigración (Rinken y Peréz Yruela, 2007) expuesto en el marco teórico de la presente investigación.

Continuando con la representación social acerca de la competitividad laboral, un aspecto a tratar es sí las personas inmigrantes quitan puestos de trabajo a la población activa española. Respecto a esta afirmación, se observan posturas que han cambiado en el periodo de 2008 a 2011. El mayor cambio se experimenta en la población que está muy de acuerdo con la afirmación, la cual se incrementa del $20,9 \%$ en 2008 al 31,4\% en 2011, si bien es cierto que es en el 2010 donde alcanza el porcentaje más elevado con el $32,6 \%$ de la ciudadanía que piensa que las personas inmigrantes quitan trabajo a la población española. La ciudadanía que está más bien de acuerdo con la afirmación, disminuye del $36,3 \%$ al $33,2 \%$ en el periodo 2008 a 2011; es probable que este descenso revierta hacia una posición menos ambivalente. Por el contrario, la población que está más bien en desacuerdo con la afirmación disminuye del $29,8 \%$ en 2008 al $23,6 \%$ en el 2011 ; a su vez, también desciende, aunque con menor intensidad, la población que está en desacuerdo con que las personas inmigrantes quietan puestos de trabajo a la población activa española, concretamente del 13,0\% al 11,7\% en el periodo de 2008 al 2011.

Analizando la opinión de la ciudadanía, se observa una tendencia de la sociedad a pensar que la población inmigrante quita puestos de trabajo a la población activa española como se muestra en el gráfico 10. Principalmente, esto se manifiesta en el aumento de la opinión de quienes están muy de acuerdo con la afirmación, que se incrementa en diez puntos y medio porcentuales. Proveniente del incremento, en gran parte de posturas ambivalentes, ya que la opinión opuesta, es decir quienes están muy en desacuerdo, sufre una caída leve, de menos de dos puntos porcentuales en el periodo de 2008 a 2011. 
Gráfico 10: Las personas inmigrantes quitan puestos de trabajo a la población española (2008 a 2011).

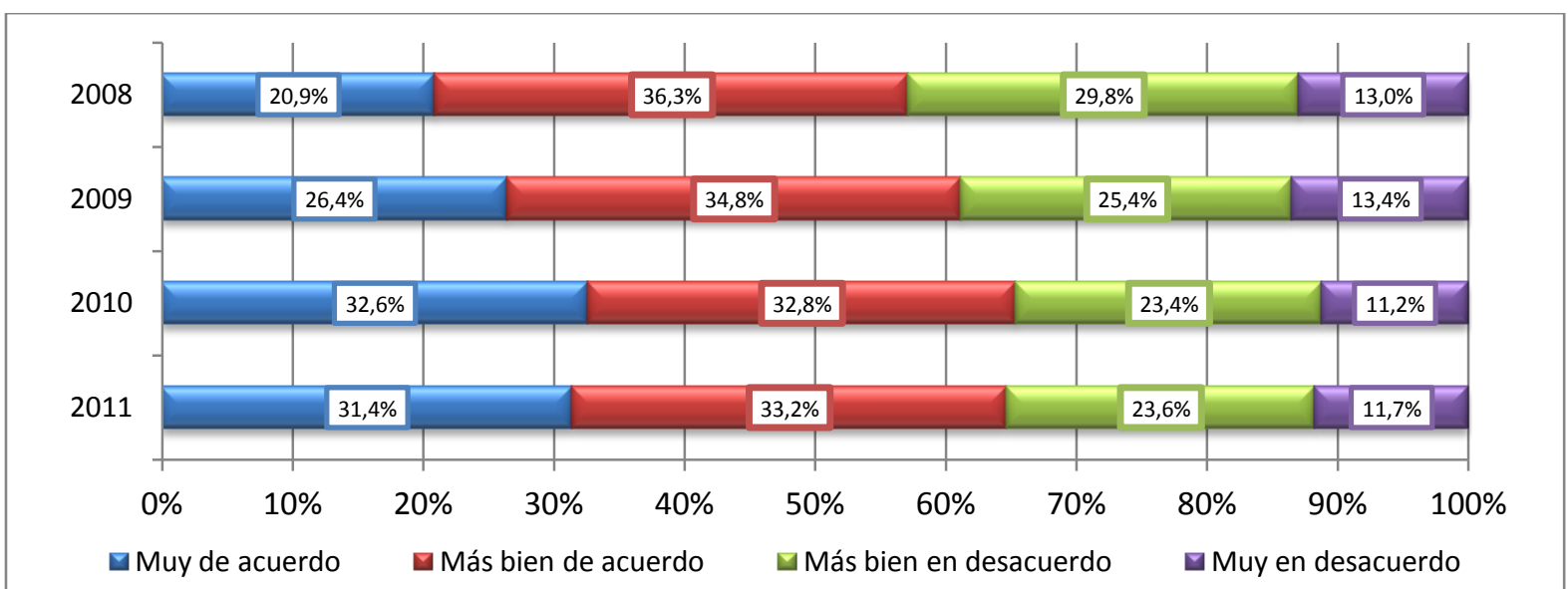

Fuente: Elaboración propia con datos del CIS; estudios 2773 (2008), 2817 (2009), 2846 (2010) y 2918 (2011).

Indagando sobre el perfil de población que está más de acuerdo con que las personas inmigrantes quitan puestos de trabajo a la población activa española, se observa que el estatus socioeconómico influye, puesto que el $42,5 \%$ de la clase alta/media alta está a favor de la afirmación, mientras en la clase social más baja, el porcentaje aumenta hasta el $74,4 \%$ dentro de los obreros no cualificados. Otro factor es la ideología, cuando la población es más de izquierda está menos de acuerdo con la afirmación, así pues la extrema izquierda está de acuerdo un 43,2\% con la afirmación y la extrema derecha un $77,3 \%$. Respecto al contacto con inmigrantes, quienes tienen compañeras y/o compañeros de trabajo inmigrantes, están menos de acuerdo con la afirmación, un $49,6 \%$ por el $67,3 \%$ de quienes no tienen compañeras y/o compañeros de trabajo inmigrantes ${ }^{34}$.

Otro aspecto a tratar es la percepción de la sociedad española sobre la contribución al desarrollo económico de la inmigración a España. Se muestra datos significativos del cambio influenciado probablemente por la situación laboral española, puesto que en 2008 la población que estaba muy de acuerdo con que las personas inmigrantes hace una importante contribución al desarrollo económico del país se situaba era más de una cuarta parte de la población, dicha proporción cae año tras año, hasta situarse en el 13,3\% en el 2011. Un caso igual de evidente de la tendencia, deriva de quienes estaban más bien de acuerdo con la afirmación, que descienden rápidamente del 48,0\% al 38,4\% en el periodo que alberga de 2008 al 2011 . Por el contrario, quienes están más bien en desacuerdo sobre la contribución al desarrollo

${ }^{34}$ Significación del chi-cuadrado $0,00 \%$. Por lo que se rechaza la hipótesis nula (no hay relación) y se acepta la asociación entre las variables. Datos del estudio 2918 (2011). 
económico de España por parte de la inmigración, aumenta progresivamente del $23,9 \%$ en 2008 al 32,6\% en el 2011. A su vez, la postura de quienes están muy en desacuerdo con la afirmación, aumenta bruscamente del 6,8\% al 15,7\% en el periodo estudiado.

Una vez examinados los datos que se observan en el gráfico 11, se aprecia un cambio en la opinión de la sociedad española ante que la contribución de la inmigración al desarrollo económico de España; ya que sí en 2008 la ciudadanía que mostraba posiciones positivas hacia la afirmación era el 69,3\%, tres años después es el $51,7 \%$ de la población española.

Gráfico 11: La población inmigrante hace una importante contribución al desarrollo económico de España (2008 a 2011).

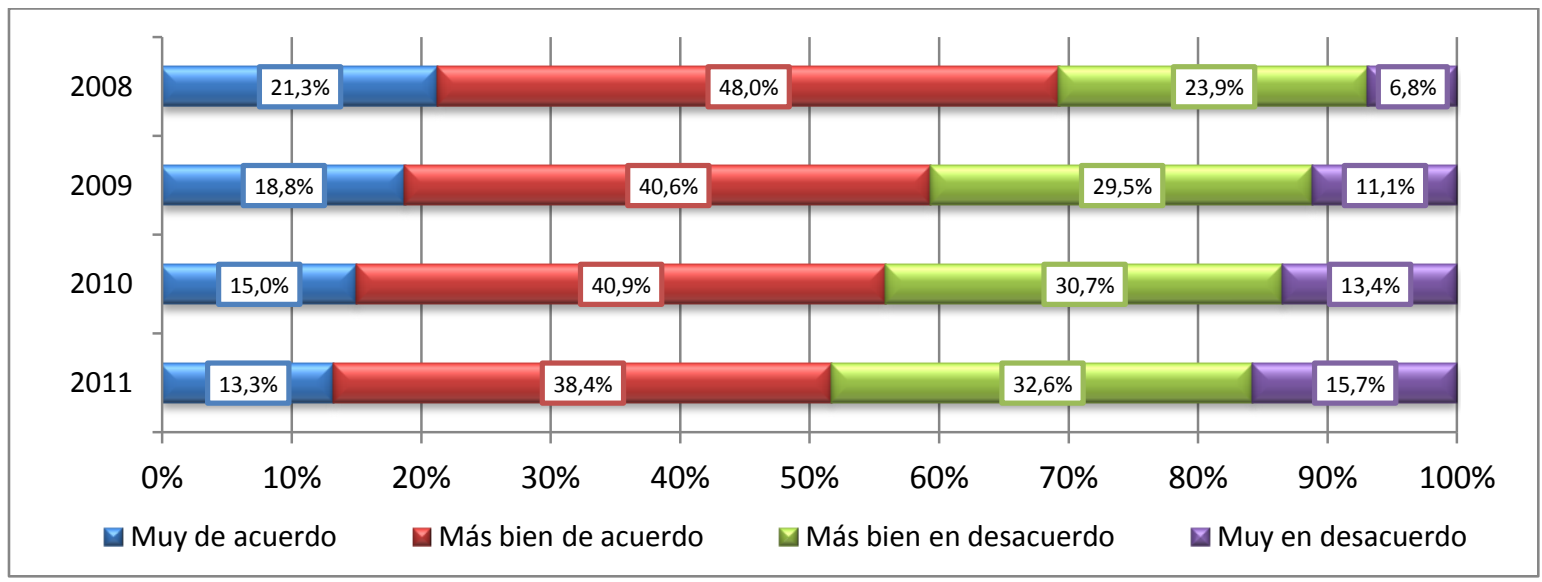

Fuente: Elaboración propia con datos del CIS; estudios 2773 (2008), 2817 (2009), 2846 (2010) y 2918 (2011).

Para finalizar este apartado, es interesante realizar una comparativa con los países europeos afectados por la crisis económica, se observa que España $(5,0)$ es el único país que otorga una posición no negativa sobre la contribución económica de la inmigración al país, incluso por encima de la media europea $(4,7)$ y de Portugal $(4,7)$. Otros países como Irlanda $(4,4)$, Chipre $(3,8)$ y Grecia $(3,1)$ están más alejados de la media, y valoran la contribución de la inmigración en la economía como un factor más negativo que positivo. 
Gráfico 12: Media del impacto del fenómeno migratorio en la economía.

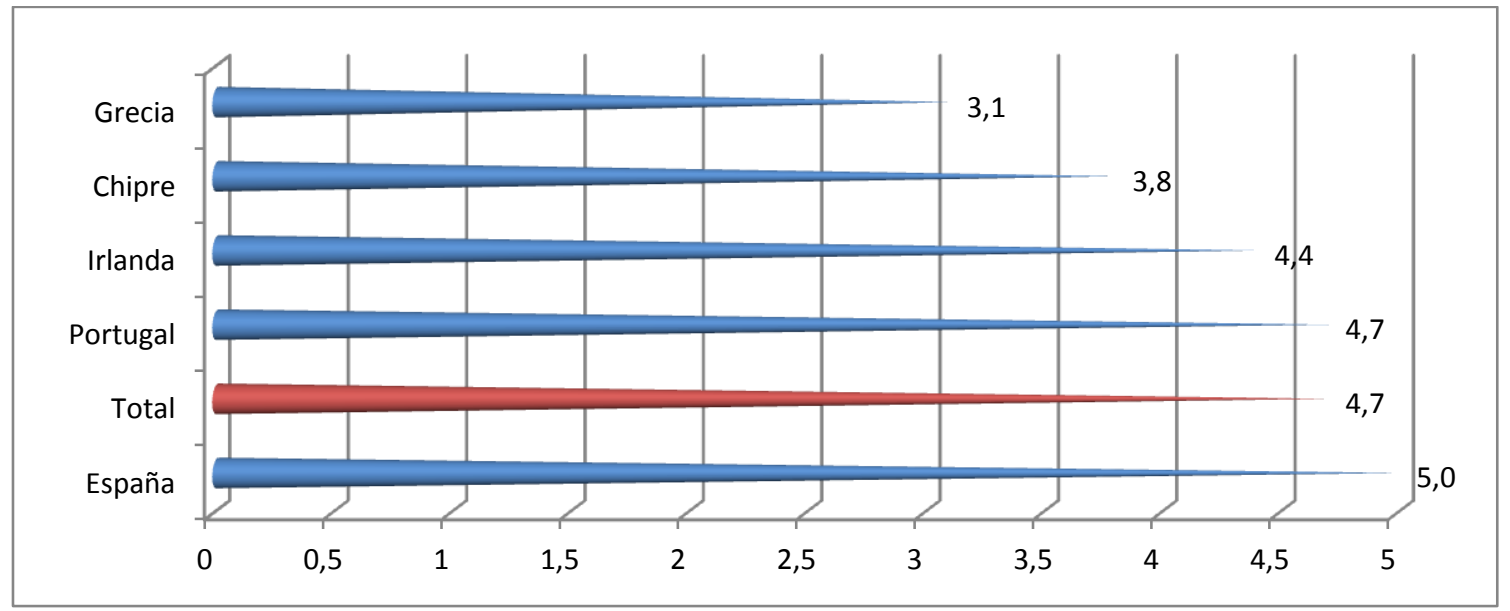

Fuente: Elaboración propia con datos de la Encuesta Social Europea 2010.

\section{LAS REPRESENTACIONES SOCIALES ACERCA DE LOS MEDIOS DE COMUNICACIÓN.}

La importancia de los medios de comunicación es crucial para examinar la representación social que la sociedad tiene acerca de la inmigración, así como se ha señalado en el marco teórico de la presente investigación. Para analizar este punto, se estudiará la frecuencia que percibe la sociedad sobre los comentarios en contra la población inmigrante; los canales en los que se vierten información negativa sobre la inmigración; la percepción sobre la atención que los medios de comunicación le prestan a la inmigración y la imagen que dan de mismos.

Para comenzar la representación social acerca de los medios de comunicación, cabe señalar en 2010 , el $45,9 \%$ de la población afirmaba que en las últimas semanas había escuchado o visto algún comentario en contra de población inmigrante; al año siguiente esta cifra disminuye al 39,0\%. Si bien es importante destacar que es probable que la ciudadanía haya visto o escuchado más comentarios en contra de la población inmigrante de que lo afirma, en algunos casos por olvido y otros por no haberlos procesado como tales.

Posteriormente, tras conocer qué porcentaje de la sociedad española ha escuchado o visto comentarios contra la población inmigrante en las últimas semanas, es interesante conocer donde se vierten ese tipo de comentarios. La opinión de la 
sociedad tanto en 2010 como en 2011 alumbra que el lugar en el que más comentarios contra la población inmigrante se arrojan es en la calle (transportes, espacios públicos etc.) con el 22,5\% y el 23,7\% respectivamente. Es reseñable, como la televisión en el 2010 era el lugar en el que la ciudadanía más detectaba que había escuchado o visto comentarios contra las personas inmigrantes con el 22,3\% de la población y al año siguiente desciende considerablemente al 10,6\%. En el caso de la radio, desciende del 5,2\% al 2,9\%; al igual que ocurre con la prensa o las revistas que disminuyen del 4,8\% al 2,8\%. Sobre internet, las cifras son iguales en ambos años, con el 2,0\% de la población que ha visto comentarios en contra de la población inmigrante por medio de Internet.

En el gráfico 13, se observa que donde la sociedad escucha o ve comentarios, mayoritariamente, en contra de la población inmigrante, no es en los medios de comunicación, sino en la calle (transportes, espacios públicos etc.) y en su círculo de amistades, especialmente en 2011.

Gráfico 13: Ubicación en la que se escuchan o ven comentarios en contra de la población inmigrante (2010 a 2011).

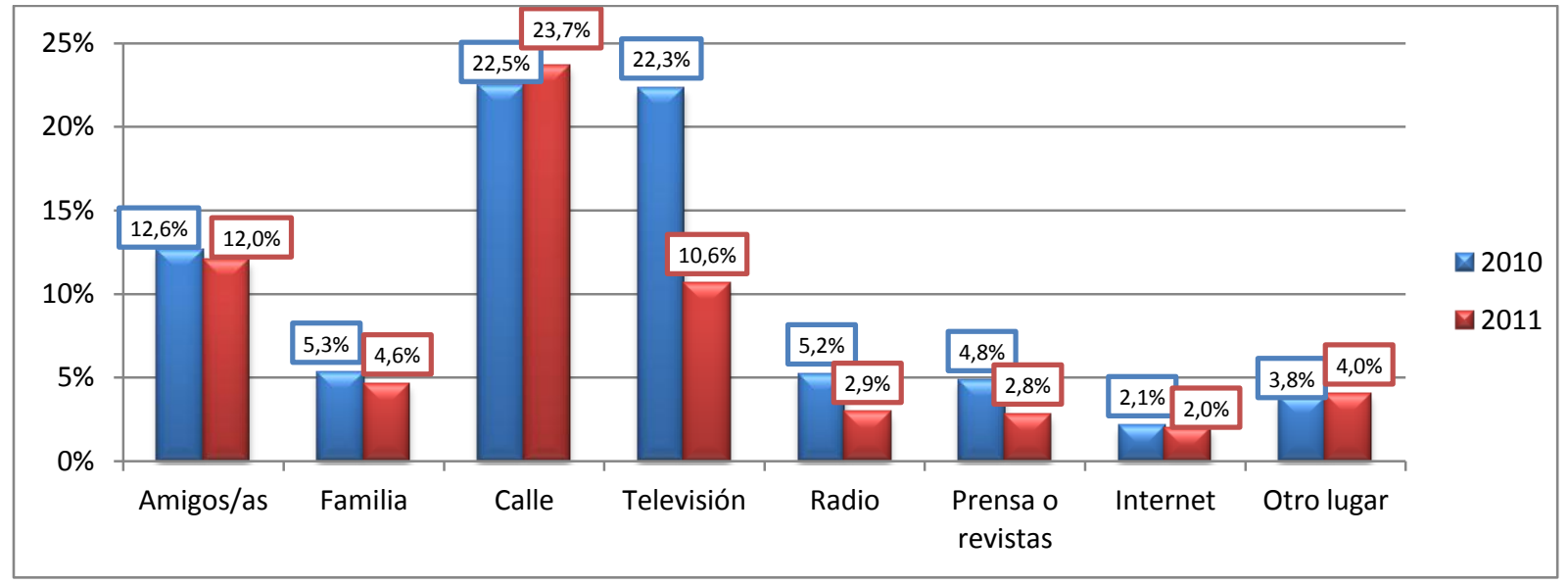

Fuente: Elaboración propia con datos del CIS; estudios 2846 (2010) y 2918 (2011).

La población asegura que escucha o ve comentarios contra la población inmigrante en la calle o en su círculo de amistades más que en los medios de comunicación, así pues, se va a analizar el grado de atención de los medios de comunicación a la inmigración, según la ciudadanía española.

Al realizar un análisis de la percepción de la ciudadanía en 2010 y 2011, se observa como quienes piensan que se le presta mucha atención a la inmigración en los medios de comunicación ha disminuido del 12,9\% en 2010 al 8,1\% en el 2011 . Así 
como, la postura de bastante atención, disminuye, aunque sigue siendo la mayoritaria en ambos años con el $55,5 \%$ y el $49,7 \%$ respectivamente. La población que piensa que la atención que los medios de comunicación le prestan a la inmigración es poca, aumenta del $28,7 \%$ en el 2010 al 39,6\% en el 2011; mientras que la ciudadanía que cree que no se le presta ninguna atención sigue prácticamente inalterable en ambos años, con el $2,8 \%$ de la población que así lo asegura.

Por lo cual, del 2010 al 2011 la sociedad española percibe que los medios de comunicación prestan menos atención a la inmigración, como refleja el gráfico 14. Esto puede deberse a que al encrudecerse la crisis económica, los temas económicos han copado más la agenda mediática. También hay que destacar que el tercer trimestre de 2011, los medios de comunicación comenzaron a centrar su atención más en los jóvenes españoles que emigran que a la inmigración; lo que Joaquín Arango (2012) denomina un cambio en el ciclo migratorio en España.

Gráfico 14: Atención de los medios de comunicación a la inmigración (2010 a 2011).

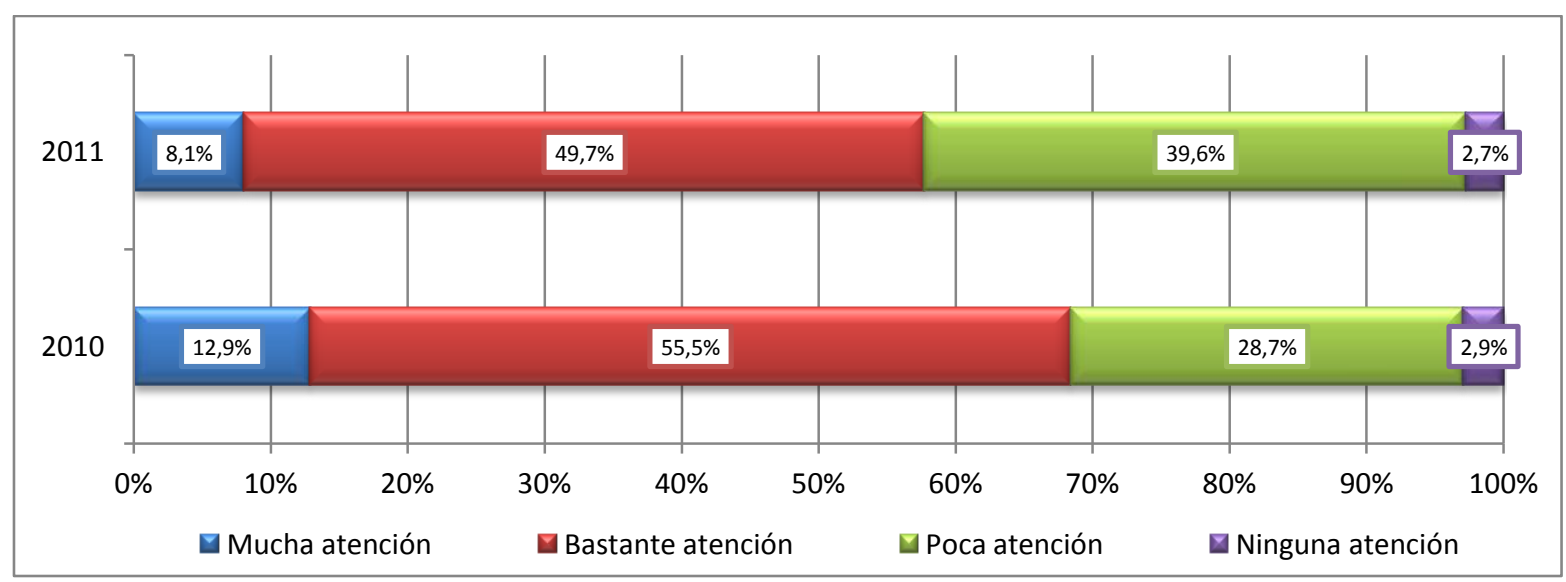

Fuente: Elaboración propia con datos del CIS; estudios 2846 (2010) y 2918 (2011).

Para finalizar con la representación social de la inmigración acerca del tratamiento en los medios de comunicación, es importante conocer la percepción de la sociedad española sobre la imagen que transmiten los medios de comunicación (televisión, radio, prensa) sobre la inmigración. La población que cree que la imagen que transmiten los medios de comunicación sobre la inmigración es muy positiva ha aumentado ligeramente del 1,6\% del 2009 al 2,0\% del 2011. Así como quienes piensan que la imagen que se proyecta sobre la inmigración es más bien positiva también aumenta del $22,9 \%$ al $28,1 \%$ en el periodo analizado. Una parte de la ciudadanía española se mantiene en un término intermedio, es decir, cree que la 
imagen que transmiten los medios de comunicación no es ni positiva ni negativa respecto a la inmigración, esta proporción aumenta en el periodo estudiado del $18,4 \%$ al $23,3 \%$.En el lado opuesto, quienes piensan que la imagen que transmiten los medios de comunicación sobre la inmigración es más bien negativa, son la mayoría de la población, en el periodo del 2009 al 2011. Dicha afirmación disminuye del $49,8 \%$ al $41,0 \%$. La población que piensa que se proyecta una imagen muy negativa sobre la inmigración disminuye del 7,3\% en 2009 al 5,7\% en el 2011.

Como se ha estudiado, el gráfico 15 recoge la percepción de la imagen que transmiten los medios de comunicación sobre la inmigración; estos datos muestran que pese a seguir siendo mayoritaria la opinión de la ciudadanía sobre que la imagen es más bien negativa, existe una tendencia de la sociedad a creer que la imagen que proyectan los medios es más bien positiva o ni positiva ni negativa.

Gráfico 15: Imagen que transmiten los medios de comunicación sobre la inmigración (2009 a 2011).

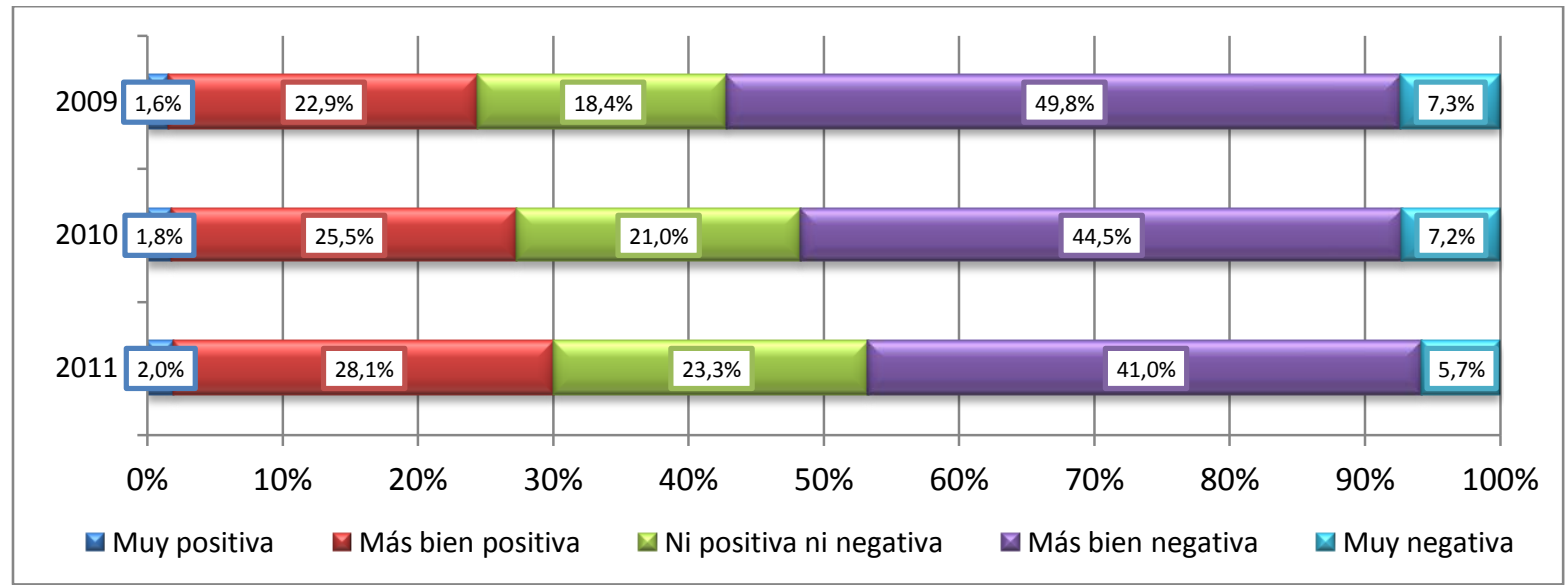

Fuente: Elaboración propia con datos del CIS; 2817 (2009), 2846 (2010) y 2918 (2011).

\section{LAS REPRESENTACIONES SOCIALES ACERCA DEL TRATO DE LA POBLACIÓN ESPAÑOLA HACIA LAS PERSONAS INMIGRANTES.}

Un tema de especial interés es la representación social acerca del trato -es decir, la manera con la que actúan e interaccionan- de la población española hacia las personas inmigrantes, para ello se van a analizar por un lado los rasgos que influyen en el trato a la población inmigrante, y por otro lado, los atributos y/o adjetivos acerca de cómo asegura la población española trata a las personas inmigrantes. 
Por un lado, la sociedad española distingue el trato a la población inmigrante dependiendo de una serie de rasgos. Los dos rasgos más relevantes para la población son la nacionalidad y la cultura de la población inmigrante. En relación a la nacionalidad, es el rasgo más importante en el 2008 con el 28,9\%, aumenta hasta el $30,5 \%$ en el 2010 , pero al año siguiente sufre un descenso al 27,6\% de la población que asegura que es el rasgo más relevante. Mientras que la cultura, en el 2008 representa el 28,3\% y aumenta progresivamente hasta el 32,1\% en el 2011; situándose así como el rasgo más dominante en el trato de la ciudadanía a la población inmigrante.

Además de ello, respecto a la posición económica del inmigrante, en 2008 el 18,8\% de la población lo señalaba como el más influyente a la hora de tratar a las personas inmigrantes, tras varios altibajos poco significativos en el periodo de estudio, en 2011 es el rasgo más influyente para el 19,9\% de la población. Otro factor relevante en el trato de la población española a las personas inmigrantes es el color de la piel, que se mantiene en niveles del $13,0 \%$ de la población que considera que es muy relevante.

El análisis de los datos del gráfico 16 muestra los rasgos más influyentes en el trato de la sociedad española hacia la población inmigrante, sin especificar sí esos factores provocan un buen trato o todo lo contrario.

Gráfico 16: Rasgo más influyente en el trato de la ciudadanía española a la población inmigrante (2008 a 2011).

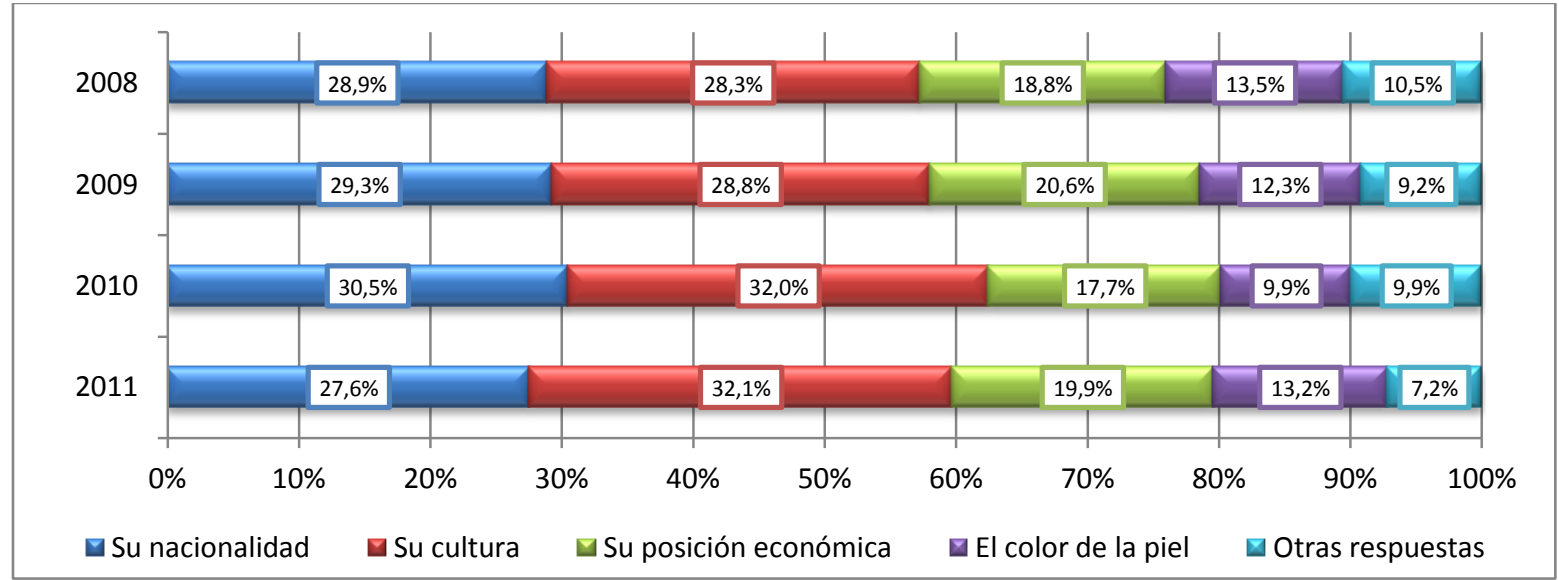

Fuente: Elaboración propia con datos del CIS; estudios 2773 (2008), 2817 (2009), 2846 (2010) y 2918 (2011).

Por otro lado, respecto a la manera en la que la población española trata a las personas inmigrantes, es principalmente con desconfianza. Este modo de tratarlos 
desciende del 43,3\% al 37,9\% en el periodo de 2008 al 2011 . Otro atributo con el que la sociedad española asegura tratar a la población inmigrante es con normalidad, es decir, igual que si fuesen población española. Este atributo aumenta del $21,6 \%$ al $27,1 \%$ en mismo periodo de tiempo -véase gráfico 8 del anexo de resultados-.

\section{LAS REPRESENTACIONES SOCIALES ACERCA DE LAS AGRESIONES RACISTAS.}

Para finalizar el análisis sobre la representación social de la inmigración, es importante estudiar la percepción sobre los ataques o las agresiones racistas de la población inmigrante hacia la ciudadanía española durante el periodo de 2008 a 2011. Así como examinando sí la sociedad española lo contempla como un problema o como hechos aislados; y sí los ataques justifican un comportamiento racista por parte de la ciudadanía española.

Por un lado, la sociedad española, se mueve en el periodo de 2008 a 2011 en términos de equidad entre la población que cree que es un problema y quienes piensan que son hechos aislados, es decir hay una división dicotómica entre ambas posturas. En 2008, el 44,6\% de la población española pensaba que los ataques y las agresiones violentas de la población inmigrante hacia la ciudadanía española suponían un problema importante, al siguiente año esta proporción aumenta, llegando a pensar la mayoría de la sociedad que es un problema, con el 51,9\%. Desde la cifra del 2009, los siguientes años desciende progresivamente la población española que cree que los ataques y las agresiones violentas son un problema importante hasta el $42,3 \%$ en 2011. Por otro lado, respecto a sí estos ataques o agresiones violentas de inmigrantes justifican reacciones racistas, la ciudadanía española mayoritariamente expresa que en ningún caso es una justificación. Sin embargo su percepción varía significativamente del 81,1\% en 2008 al 62,5\% en 2011 -véase gráfico 9 del anexo de resultados-. 
Gráfico 17: Ataques o agresiones violentas de población inmigrante a población española (2008 a 2011).

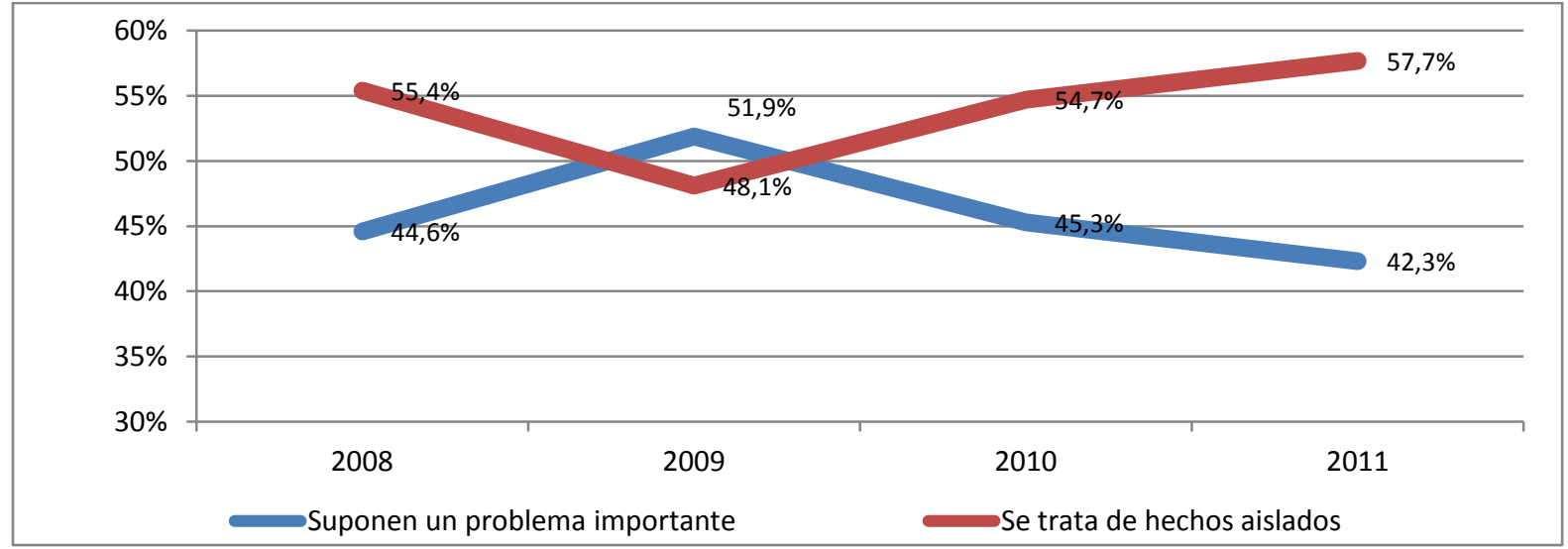

Fuente: Elaboración propia con datos del CIS; estudios 2773 (2008), 2817 (2009), 2846 (2010) y 2918 (2011).

Al analizar a qué segmentos o grupos de población corresponde una opinión u otra, se observa como el nivel de racismo de la población se asocia con la percepción de las agresiones violentas. De hecho para quienes suponen un problema importante las agresiones o los ataques de la población inmigrante es mayor cuanto más racista es la población, ya que para el $36,9 \%$ de quienes no son nada racista suponen un problema importante, mientras que el $74,4 \%$ de quienes son muy racistas es un problema las agresiones o los ataques de la población inmigrante a población española. El grado de confianza también es un factor, el 31,7\% de las personas muy confiadas piensa que es un problema importante por el $55,6 \%$ de quienes son muy desconfiadas. En el caso de las personas que tienen amistades inmigrantes es inferior el porcentaje de personas que creen que los ataques o las agresiones de inmigrantes a personas española son un problemas importante, con el 37,7\% por el $46,4 \%$ de quienes entre sus amistades no tienen inmigrantes ${ }^{35}$.

\section{FOTO FIJA DE LAS REPRESENTACIONES SOCIALES DE LA INMIGRACIÓN EN ESPAÑA (2011).}

Al realizar una foto fija sobre la representación social de la inmigración en 2011, se aprecia que la diversidad cultural aporta información relevante sobre la percepción de la sociedad en este aspecto. Para indagar sobre esto punto, se ha realizado un

35 Significación del chi-cuadrado $0,00 \%$. Por lo que se rechaza la hipótesis nula (no hay relación) y se acepta la asociación entre las variables. Datos del estudio 2918 (2011). 
análisis factorial mediante el cual las variables se han agrupado en torno a dos componentes principales:

- Homogeneidad cultural: este componente está formado por las variables: países, culturas y razas. Dichas variables se asocian entre sí en el componente, mediante la afirmación de que España esté compuesta por personas de diferentes países, culturas y razas.

- Religiones: este componente está constituido únicamente por la variable de religiones, ósea, que España esté compuesta por personas de diferentes religiones.

La explicación de la distinción entre los dos componentes, es necesario centrarla en las religiones (componente 2), puesto que el hecho de que España esté compuesta por personas de diferentes religiones sea el único elemento de este componente es objeto de análisis. Esta relación puede derivar en gran parte de la imagen con la que se tiene asociada a la religión en el imaginario colectivo de inmigración, es decir, con la religión musulmana. Sobrados (2011) señala que "la sociedad española basa su preferencia por los latinoamericanos en la existencia de una afinidad cultural -lengua y religión- que facilitarían su integración, a diferencia de otros colectivos como el marroquí, en los que destaca la religión musulmana como el mayor obstáculo".

Por un lado, hay que reseñar la importancia del pensamiento encumbrado bajo el concepto de "nuevo racismo" (Baker, 1981) en el que ya no es relevante construir la diferencia en torno a una explicación biologicista de razas inferiores, sino que se construye en base a los inferiores, que son los "otros" por tener unos rasgos culturales incompatibles con el progreso civilizatorio occidental (Terren, 2002). Este es el caso de la religión musulmana, ya que en España el peso de la religión católica es incuestionable puesto que el $73,1 \%^{36}$ de la ciudadanía española se considera de religión católica. En 2008 según el INE la religión musulmana representaba el 0,6\% en España seguida por personas procedentes de Marruecos, Argelia y Senegal principalmente.

Por otro lado, en 2011, la sociedad española se encuentra dividida en cuanto a las cuestiones que atañen directamente a la religión musulmana, ya que el 48,4\% de la

36 Datos del estudio 2976 del CIS (2013). 
población cree que es bastante o muy aceptable que se excluya a una alumna del colegio por llevar el velo islámico. Además de ello, el 49,1\% de la sociedad española piensa que es bastante o muy aceptable que la gente proteste contra la edificación de una mezquita en su barrio. Respecto a estas concepciones sobre la religión musulmana, especialmente en temas concretos como la construcción de mezquitas y espacios para el culto islámico, son hechos que generan conflictos entre la población autóctona e inmigrante que los medios de comunicación cubren con bastante frecuencia y relevancia, creando en cierto modo una imagen sobredimensionada del número de mezquitas en España -únicamente hay trece(Cebolla y González, 2008).

Por lo cual, la población española tiene una postura formada sobre la religión musulmana, así como muestra la percepción ante manifestaciones del Islam en la vida cotidiana del país. La islamofobia está presente en la sociedad española.

Tabla 2: Factorial sobre la diversidad cultural en España.

\begin{tabular}{|c|c|c|}
\hline \multicolumn{3}{|l|}{ ANÁLISIS FACTORIAL } \\
\hline \multirow{2}{*}{$\begin{array}{c}\text { Matiz de componentes rotados } \\
\text { İtems }\end{array}$} & \multicolumn{2}{|c|}{ Componente } \\
\hline & 1 & 2 \\
\hline Países & 0,906 & 0,316 \\
\hline Culturas & 0,858 & 0,407 \\
\hline Religiones & 0,368 & 0,919 \\
\hline Razas & 0,721 & 0,557 \\
\hline \multicolumn{3}{|c|}{ Método factorial y pruebas estadísticas } \\
\hline \multicolumn{3}{|c|}{ Método de extracción: Análisis de componentes principales. } \\
\hline \multicolumn{3}{|c|}{ Método de rotación Varimax con Kaiser. La rotación ha convergido en 3 iteraciones. } \\
\hline Medida de adecuación muestral del Kaiser-Meyer-Olkin & Medida & 0,828 \\
\hline Prueba de esfericidad de Bartlett & Sig. & 0,000 \\
\hline Varianza total explicada & Porcentaje & 90,77 \\
\hline
\end{tabular}

Fuente: Elaboración propia con datos del CIS del estudio 2918 (2011).

\section{PERCEPCIONES SOBRE LA REALIDAD NUMÉRICA DE LA INMIGRACIÓN (2007 a 2011).}

La percepción que tiene la ciudadanía española sobre el volumen de personas inmigrantes es relevante, por el mero hecho de que una apreciación sobredimensionada del número de inmigrantes puede influenciar en las actitudes hacia la inmigración que tenga la ciudadanía. Si bien es cierto, que la sociedad 
española percibe que existe un volumen considerable de población inmigrante, esa idea se genera en el imaginario colectivo creando según esos conocimientos todas las actitudes y las valoraciones sobre la inmigración, como se señala en el teorema de Thomas (Thomas \& Thomas, 1928) "sí las personas definen las situaciones como reales, éstas son reales en sus consecuencias". Para indagar sobre ello, se analizará la percepción numérica de la sociedad española respecto al volumen de inmigrantes en el territorio nacional y cuáles son los grupos de nacionalidades más representativos, mostrándolo a su vez, el número real de inmigrantes.

\section{EVOLUCIÓN DE LA PERCEPCIÓN DE LA CIUDADANÍA SOBRE EL NÚMERO DE INMIGRANTES.}

En cuanto a la evolución de la percepción de la ciudadanía sobre el número de inmigrantes que residen en España, resalta que en términos generales la percepción no ha variado en exceso del 2008 al 2011, pese a que la condición del país sí ha cambiado, especialmente a nivel económico.

La evolución de la población que cree que el número de inmigrantes es excesivo, ya que ha sufrido un descenso de algo más de dos puntos porcentuales del $47,7 \%$ en 2008 al 45,5\% en 2011, como se muestra en el gráfico 18. También es destacable, el cambio en la percepción entre 2010 y 2011, entre la población que cree que es insuficiente el número de inmigrantes, es decir, que se necesitan más personas inmigrantes, aumenta del $0,4 \%$ en 2010 al 1,2\% en 2011. Así como, la población que piensa que es aceptable el número de inmigrantes pasa del 17,3\% en 2010 al 20,1\% en 2011.

Gráfico 18: Evolución de la percepción del número de inmigrantes (2008 a 2011).

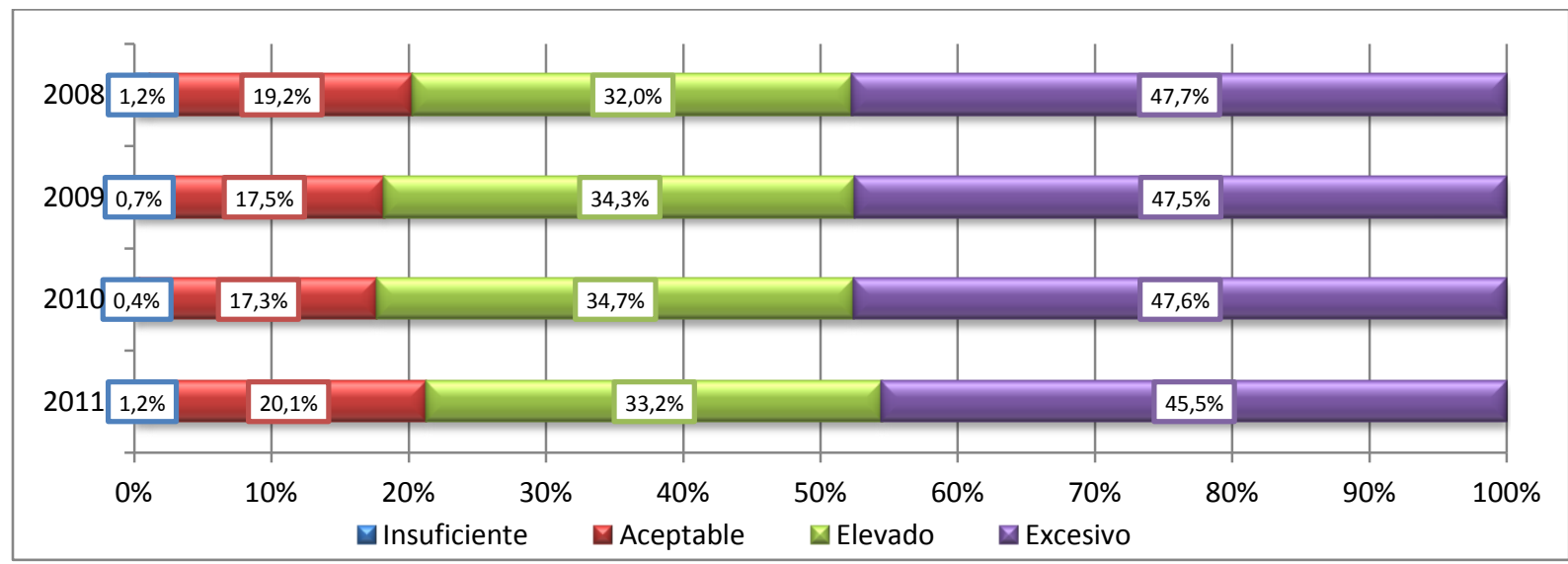

Fuente: Elaboración propia con datos del CIS; estudios 2773 (2008), 2817 (2009), 2846 (2010) y 2918 (2011). 
El perfil de ciudadanía que cree que es excesivo el número de inmigrantes en España, se asocia a unas características socio-demográficas concretas. En primer lugar al nivel de estudios ya que a medida que aumenta el nivel de estudios disminuye la percepción de que es excesivo el número de inmigrantes, esto se ejemplifica en que el $56,7 \%$ de la población que no tiene estudios cree que es excesivo, así como 54,5\% de los que tienen estudios primarios, mientras que el $21,0 \%$ de la población que tiene estudios superiores piensa que el número de inmigrantes es excesivo. En segundo lugar, otro factor es el nivel de racismo, que a medida que la sociedad se considera más racista también aumenta su percepción sobre el volumen de inmigrantes, puesto que el $81,3 \%$ de la población que es muy racista cree que es excesivo el número de inmigrantes, mientras que $38,3 \%$ de quienes son nada racistas piensan de ese modo. En tercer lugar, respecto al contacto con inmigrantes, quienes tienen en su círculo de amistades algún inmigrante, el $37,2 \%$ cree que es excesivo el número, mientras que el $52,0 \%$ de quienes no tienen amistades inmigrantes piensan que excesivo el número de inmigrantes en España ${ }^{37}$.

\section{REALIDAD ESTADÍSTICA DE PERSONAS EXTRANJERAS $Y$ SU PERCEPCIÓN DEMOSCÓPICA.}

Respecto al análisis sobre la percepción numérica de las personas extranjeras en España, es especialmente interesante comparar la cifra real de personas extranjeras empadronadas y el volumen de personas que han nacido fuera de España que estima la ciudadanía.

Los datos muestran que la ciudadanía sobre-representa el volumen de personas extranjeras en España. El análisis de esta distorsión numérica explica en cierto grado las actitudes positivas o negativas hacia la inmigración. Dicha sobrerepresentación en el periodo estudiado es amplia, puesto que el número de personas extranjeras empadronadas y la percepción de la ciudadanía del volumen de personas que han nacido fuera de España, es el doble. En 2007, la población extranjera registrada por el padrón era del 10,0\% mientras que la ciudadanía en ese

37 Significación del chi-cuadrado $0,00 \%$. Por lo que se rechaza la hipótesis nula (no hay relación) y se acepta la asociación entre las variables. Datos del estudio 2918 (2011). 
mismo año estima que era el 24,1\%; En 2008, las personas extranjeras empadronadas en España eran el 11,30\% del total de la población española, mientras que la ciudadanía estimaba más del doble, el 22,69\%. En los tres años siguientes las proporciones se mantienen muy similares con el 12,20\% de la población extranjera registrada en el padrón y el 21,42\% de la población extranjera estimada por la ciudadanía en 2011.

La tendencia del gráfico 19, muestra que la población extranjera empadronada aumenta en el periodo 2007 a 2011, así como, la estimada por la población decrece. Esta tendencia se puede deber, sobre todo el descenso progresivo de la percepción de la sociedad española respecto al volumen de población extranjera, a la reducción de la atención de los medios de comunicación sobre la inmigración a favor de las temáticas relacionadas con la crisis económica.

Gráfico 19: Evolución del volumen de inmigrantes (2007 a 2011)

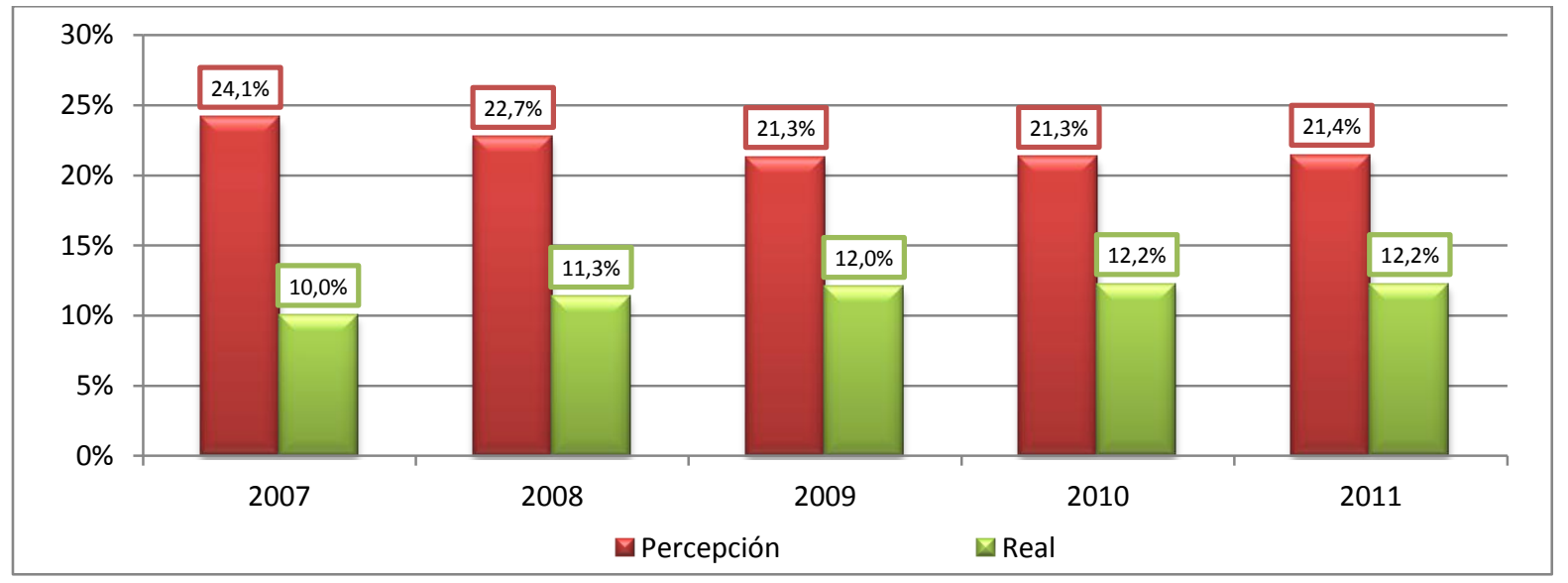

Fuente: Elaboración propia con datos del CIS; estudios 2731 (2007), 2773 (2008), 2817 (2009), 2846 (2010) y 2918 (2011); y con datos del INE por el padrón municipal de 2007, 2008, 2009, 2010 y 2011.

A nivel local, en el periodo de 2008 a 2011, la población española señala que de cada 100 personas que residen en su municipio, una cuarta parte son personas que han nacido fuera de España, esta cifra se mantiene estable en todo el periodo. Estos datos muestran que la percepción de la ciudadanía española respecto al volumen de personas nacidas fuera de España, es menor a nivel local que a nivel nacional. 


\section{PERCEPCIÓN DEMOSCÓPICA DEL VOLUMEN DE PERSONAS EXTRANJERAS EN ESPAÑA POR PROVINCIAS.}

En lo referente a la percepción demoscópica del volumen de personas extranjeras en España por provincias durante el periodo de 2007 a $2011^{38}$, se ha realizado una representación cartográfica para medir su evolución. En primer lugar se extrajo la capa de la distribución territorial por provincias, en segundo lugar se elaboró la media aritmética entre la ciudadanía de cada provincia sobre el número exacto de personas extranjeras hay en España. En tercer lugar, las medias por provincia se introducen como capa en el software ArcGIS y en cuarto lugar, se les asigna los intervalos correspondientes -que se detallan a continuación-. Este proceso se repitió con cada uno de los mapas correspondientes a cada año.

Las provincias que consideran que hay mucha presencia de personas extranjeras en España (más de un 26\%), en 2007 son dieciséis provincias, cifra que se va reduciendo año tras año, siendo en 2011 únicamente cuatro provincias las que creen que hay mucha presencia de personas extranjeras en España. De ellas solamente las Islas Baleares y Santa Cruz de Tenerife perciben durante todo el periodo que hay mucha presencia de personas extranjeras en España. La explicación del fenómeno se puede deber, a que ambas provincias están muy expuestas a la población extranjera por diferentes causas. Por un lado las Islas Baleares tienen una población residente extranjera elevada, que se incrementa en época estival. El perfil de la población extranjera balear son personas procedentes de países centroeuropeos. Por otro lado, Santa Cruz de Tenerife, sin descartar el turismo centroeuropeo que atrae, es una de las principales entradas migratorias a España, principalmente de personas de origen subsahariano. Por lo cual la percepción sobre la alta presencia de población extranjera en su provincia versa sobre la percepción que tienen a nivel nacional.

Respecto a las provincias que creen que el número de personas extranjeras en España es bastante (del 16\% al 25\%) es la opinión mayoritaria en todo el periodo de 2007 a 2011, pero especialmente se intensifica en 2011, donde casi la totalidad de las provincias españolas cree que es bastante la presencia de personas extranjeras en España. En relación a las provincias que creen que la presencia de personas

${ }^{38}$ Las provincias sin datos, es debido a que no había una muestra representativa. 
extranjeras en España se encuentra en un término intermedio, en el que no es ni mucha ni poca la presencia (del 6\% al 15\%), en 2007 eran cinco las provincias con esa percepción y va aumentando progresivamente hasta las diez provincias en 2010 aunque en 2011 desciende a seis provincias. La única provincia que se mantiene en esa opinión durante todo el periodo es Cáceres, probablemente porque es una provincia en la cual la presencia y llegada de población extranjera no es elevada. Mientras que la percepción de poca presencia de población extranjera en España es prácticamente nula, únicamente en Burgos en 2007 se percibe esta opinión.

Después de analizar la percepción de la presencia de población extranjera por provincias se dilucida una tendencia hacia un aminoramiento de la percepción de mucha presencia de personas extranjeras y un aumento del término intermedio de ni mucha ni poca presencia de personas extranjeras en España. 
Representación cartográfica 1: Evolución de la percepción población extranjera en España por provincias (2007 a 2011).
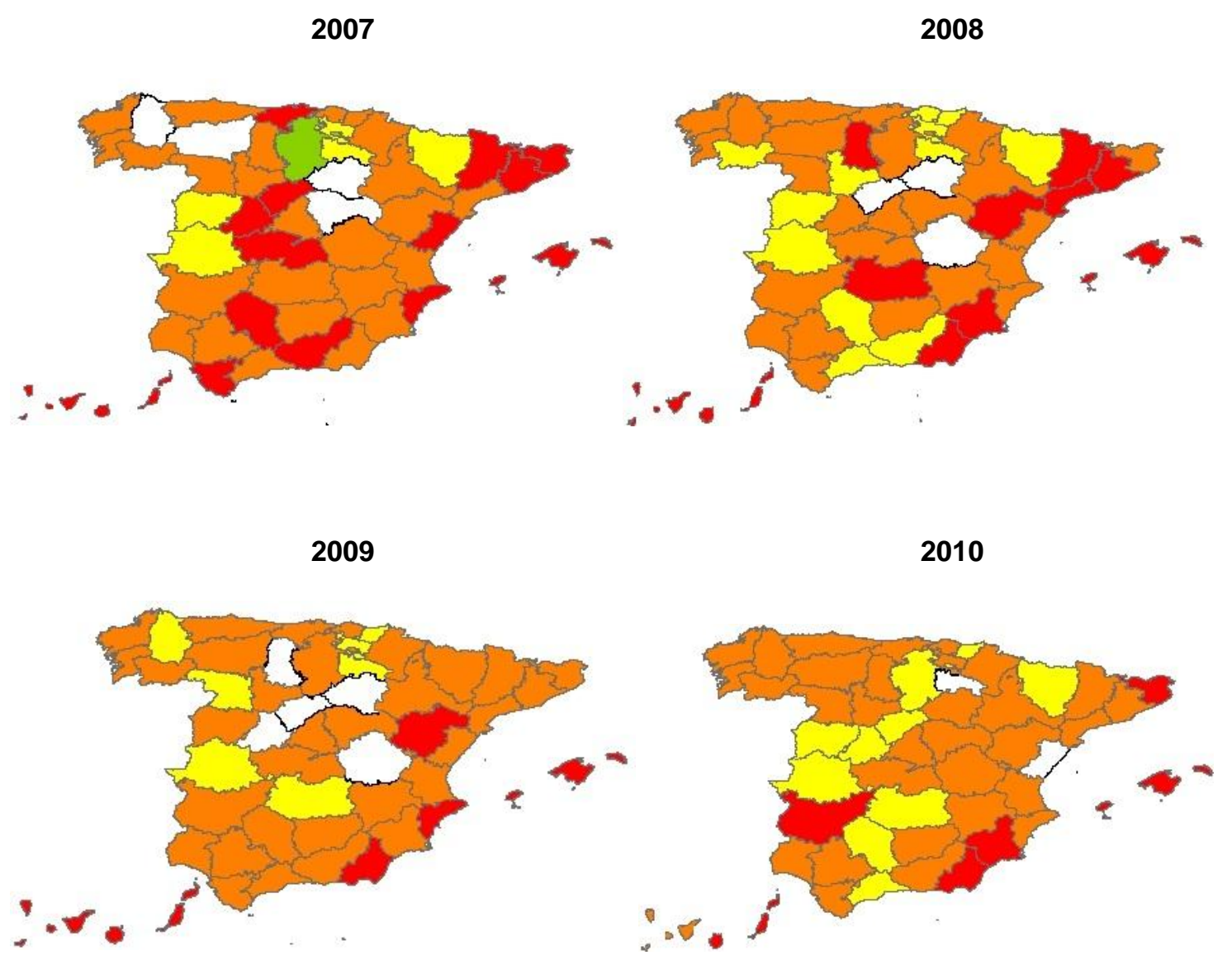

2011
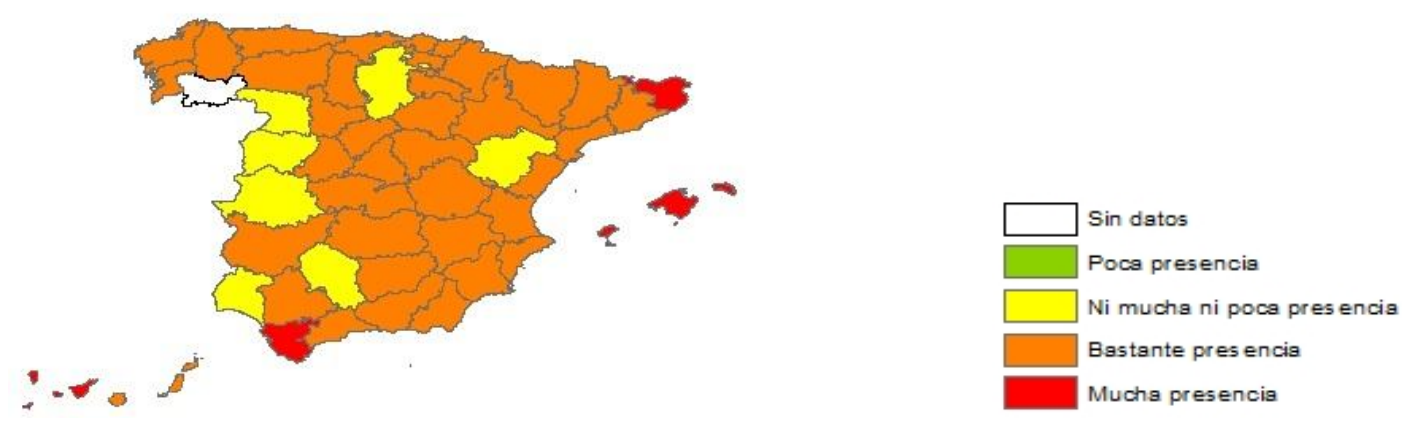

Fuente: Elaboración propia con datos del CIS; estudios 2731(2007), 2773 (2008), 2817 (2009), 2846 (2010) y 2918 (2011). Realización de los mapas mediante el programa ArcGIS con las capas extraídas del Instituto Geográfico Nacional. 


\section{PERCEPCIÓN DE LA NACIONALIDAD DE LAS PERSONAS INMIGRANTES EN ESPAÑA.}

Una vez analizado el volumen de personas extranjeras en España, es necesario conocer a quién identifica la sociedad como inmigrante y cómo de acertada es la percepción de la ciudadanía con la realidad que acontece.

La percepción sobre los grupos de nacionalidades que componen la idea de inmigrante en la sociedad española es la de magrebíes y latinoamericanos, principalmente. Esta apreciación ha variado del 2008 al 2011, especialmente en algunos grupos de nacionalidades, por ello es necesario analizar más minuciosamente este apartado. La percepción de la sociedad sobre las personas subsaharianas han descendido del $13,0 \%$ de la ciudadanía que asociaba inmigración a este grupo en 2008 al 10,0\% en 2011. Por el contrario, aumenta la percepción de la sociedad que asocia la inmigración con la ciudadanía de Europa del este, del $13,8 \%$ al $17,8 \%$ en el periodo examinado. También aumenta la asociación entre inmigrantes y las personas asiáticas, pasando del 1,9\% en 2008 al $2,7 \%$ en el 2011. A su vez, la asociación de la inmigración con otras nacionalidades europeas aumenta ligeramente del 0,2\% al 1,3\% de 2008 al 2011. Mientras que los grupos mayoritarios con quienes la sociedad española asocian la inmigración, es decir magrebíes y latinoamericanos se mantiene en los mismos porcentajes todo el periodo, en el $29,0 \%$ y el $27,0 \%$ respectivamente, -véase gráfico 11 del anexo de resultados-.

Además de ello, existe una distorsión entre el peso de los grupos de nacionalidades y el volumen real que tienen en España. Respecto a las personas magrebíes, la sociedad identifica inmigración con este grupo en el periodo 2008 a 2011 en valores alrededor del 19,5\%, mientras que el volumen real de magrebíes se sitúa en el 12,0\% del total de personas extranjeras en España; a excepción del 2010 donde representaban el 18,3\%. En cuanto a las personas latinoamericanas, el 19,0\% de la población asocia inmigrantes a latinoamericanos, en 2008 es más bajo con el 17,5\%; mientras que la población real de inmigrantes latinoamericanos gira en torno al $32,0 \%$. Respecto a la población rumana, aproximadamente el $14,5 \%$ de la ciudadanía española relaciona inmigrante con personas rumanas, cifra muy próxima a los valores de población real rumana asentada en España, que oscila alrededor del $13,5 \%$. 
Estos tres grupos de nacionalidades tienen sus particularidades. La población de origen rumano se triplicó en la última década, tanto que en 2008 era la población más numerosa en España. Esto está influenciado por la entrada de Rumanía en la Unión Europea en 2007, que permitió la libre circulación de personas rumanas por todo el territorio europeo. La comunidad latinoamericana se explica su considerable presencia en España debido a los vínculos lingüísticos y culturales entre el lugar de origen y destino. Así como las personas magrebíes es generado por la proximidad geográfica entre ambos países. (Moreno y Bruquetas, 2011).

En la comparativa realizada en el gráfico 20, se observa que está sobredimensionada la imagen con la que la sociedad española asocia a la inmigración en el caso de las personas magrebíes. Así como está muy infra-dimensionada la representación de la inmigración latinoamericana en el imaginario colectivo español. La causa de la distorsión puede deberse por la visibilización o invisibilización, según Marsal (1969); “allí donde el aluvión inmigratorio encuentra obstáculos insalvables de orden lingüístico, religioso, étnico, económico o de otro tipo que no permitan su invisibilidad, la sociedad receptora a corto o largo plazo se convertirá en una sociedad pluralista más o menos conflictiva". Respecto a las personas latinoamericanas su invisibilización es patente de ahí la infra-dimensión, al contrario que con las personas magrebíes. En el caso de la población rumana, están muy cercanas las cifras en las que la ciudadanía española asocia inmigración con población rumana y el volumen real de personas rumanas en España.

Gráfico 20: Inmigrantes reales y percibidos por principales grupos de nacionalidades (2008 a 2011).

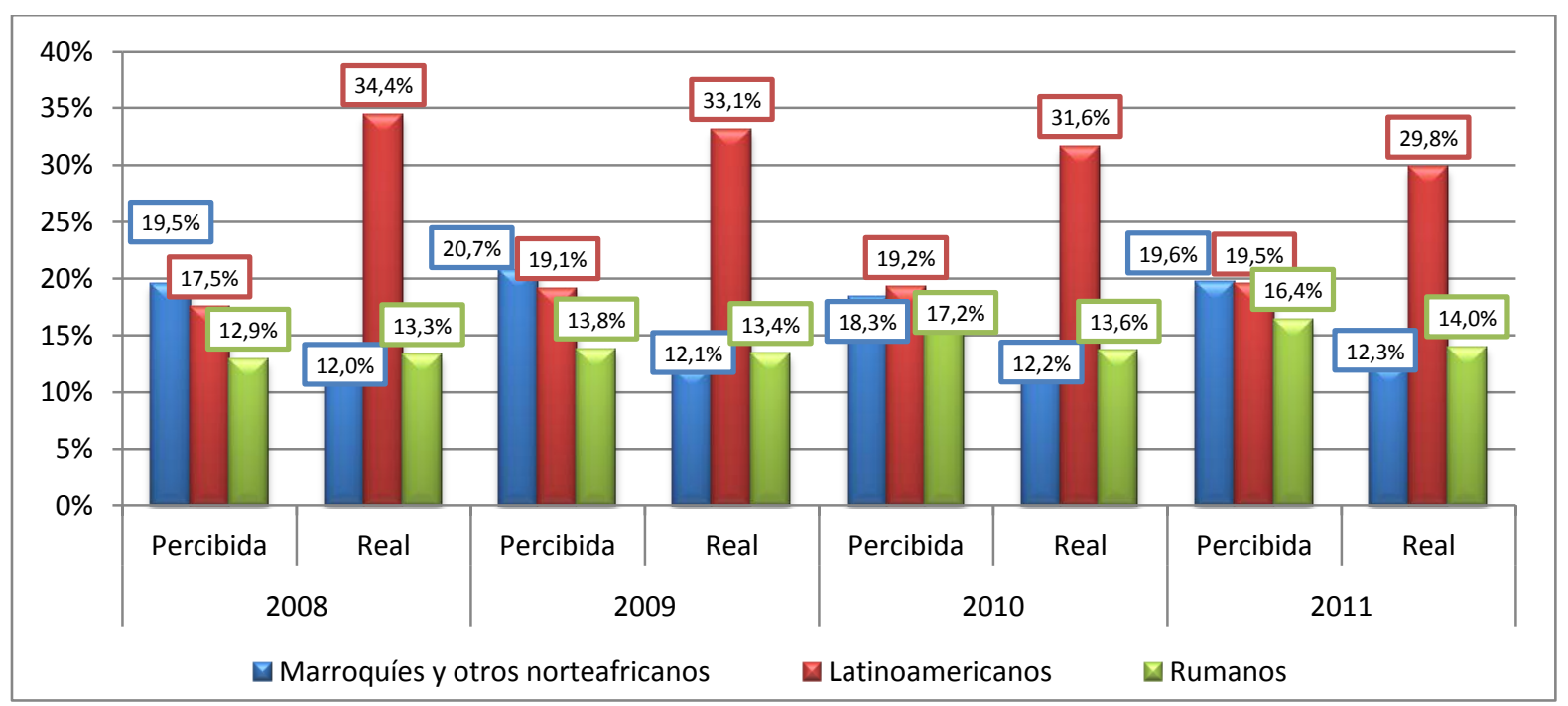

Fuente: Elaboración propia con datos del CIS; estudios 2773 (2008), 2817 (2009), 2846 (2010) y 2918 (2011); y con datos del INE por el padrón municipal de 2008, 2009, 2010 y 2011. 


\section{FOTO FIJA DE LA PERCEPCIÓN SOBRE LA REALIDAD NUMÉRICA DE LA INMIGRACIÓN (2011).}

En relación a la percepción numérica de la realidad migratoria, se observa como la confianza hacia otras personas influye en la apreciación sobre el volumen de inmigrantes en España. De tal modo, que quienes creen que el volumen de inmigrantes es excesivo son aquellas personas que se consideran muy desconfiadas. Así como, la población que cree que el volumen de inmigrantes es elevado corresponde a personas más desconfiadas que confiadas y quienes no se consideran ni personas confiadas ni desconfiadas. Por el contrario, la población que cree que el volumen de inmigrantes es aceptable son las personas más confiadas que desconfiadas y quienes son muy confiadas. Además de ello, quienes creen que el volumen de inmigrantes es insuficiente, ósea, que se necesitan más inmigrantes, no se asocia directamente con ningún valor, pero se aproxima a las personas más confiadas que desconfiadas y muy confiadas ${ }^{39}$.

El análisis de correspondencias muestra como la escala de confianza se relaciona con la percepción numérica de la inmigración. La explicación de esta asociación se puede deber a que dentro del imaginario colectivo, los estereotipos y los prejuicios que se agrupan con la inmigración están íntimamente relacionados con la desconfiada hacia el "otro", es decir, manifestación de temor a la invasión, a que impongan su cultura y tradiciones o diluyan la cultura autóctona, así como el miedo a que quiten puestos de trabajo a la población española etc.

${ }^{39}$ Significación del chi-cuadrado $0,00 \%$. Por lo que se rechaza la hipótesis nula (no hay relación) y se acepta la asociación entre las variables. Datos del estudio 2918 (2011). 
Gráfico 21: Correspondencias entre el nivel de confianza y la percepción numérica de la inmigración.

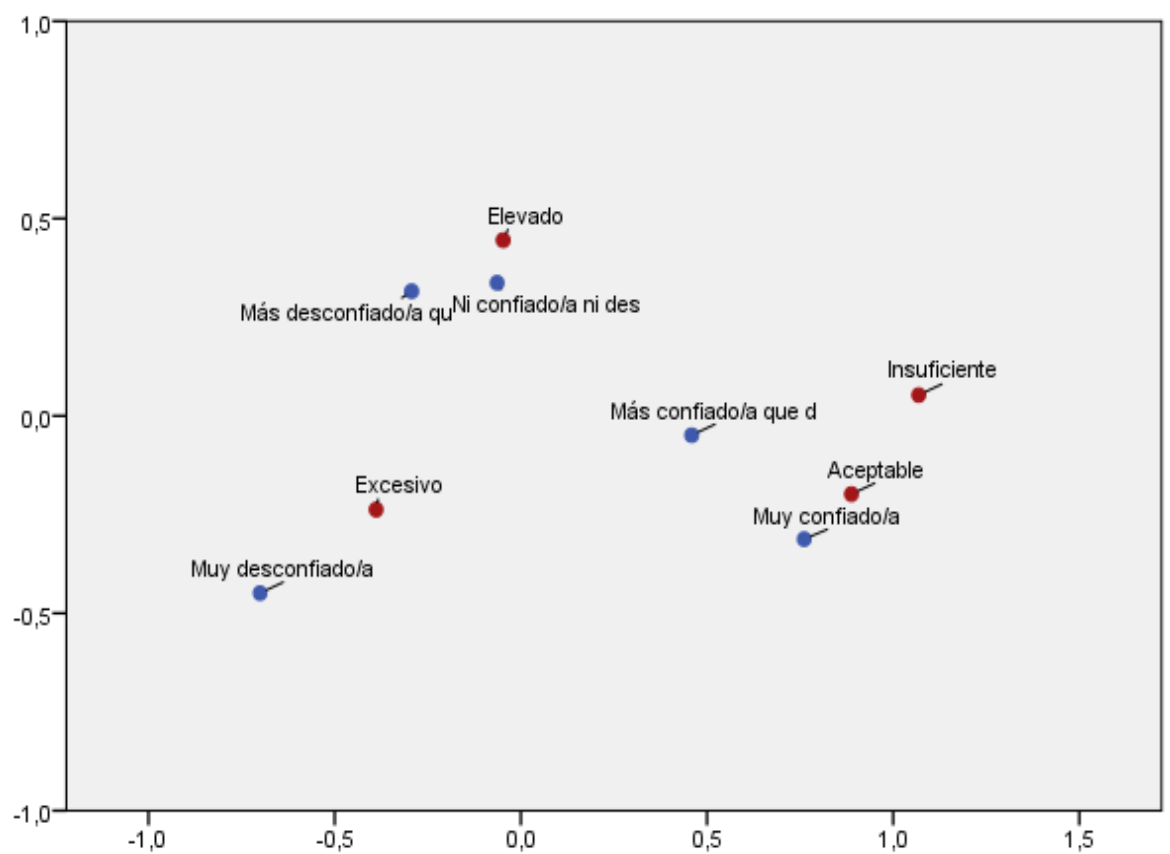

Fuente: Elaboración propia con datos del CIS del estudio 2918 (2011).

\section{CREENCIAS Y VALORES SOBRE LA GESTIÓN DE LA INMIGRACIÓN (2007 a 2011).}

La gestión que se realiza de la inmigración es una temática muy controvertida, puesto que hay que analizar la inmigración en una esfera desagregada. Hay que diferenciar entre inmigrantes regulares (admisión, entrada y permanencia), inmigración irregular, ayuda del Estado a las personas inmigrantes; y los derechos de las personas inmigrantes regulares.

\section{ADMISIÓN, ENTRADA Y PERMANENCIA DE INMIGRANTES}

En primer lugar en cuanto a la admisión, entrada y permanencia de las personas inmigrantes, es necesario tratar los tres aspectos de manera diferente. En relación a la admisión, es muy relevante analizar cuáles son los factores que la sociedad cree que son más o menos importantes.

La ciudadanía cree que los factores más determinantes para la admisión de personas no españolas en el país son: que esté dispuesto o dispuesta a adoptar el 
modo de vida del país, que tenga una cualificación laboral de las que España necesita, que tenga un buen nivel educativo, que hable castellano o la lengua oficial de la Comunidad Autónoma en la que resida y que tenga familiares cercanos viviendo en España. Por el contrario aquellos factores que se consideran menos importantes para la admisión en España son: que sea de raza blanca, que tenga mucho dinero y que sea de un país de tradición cristiana. La evolución de estos factores, se ha mantenido estable como se aprecia en el gráfico 22.

Gráfico 22: Relevancia de los factores de admisión de personas inmigrantes (2008 a 2011).

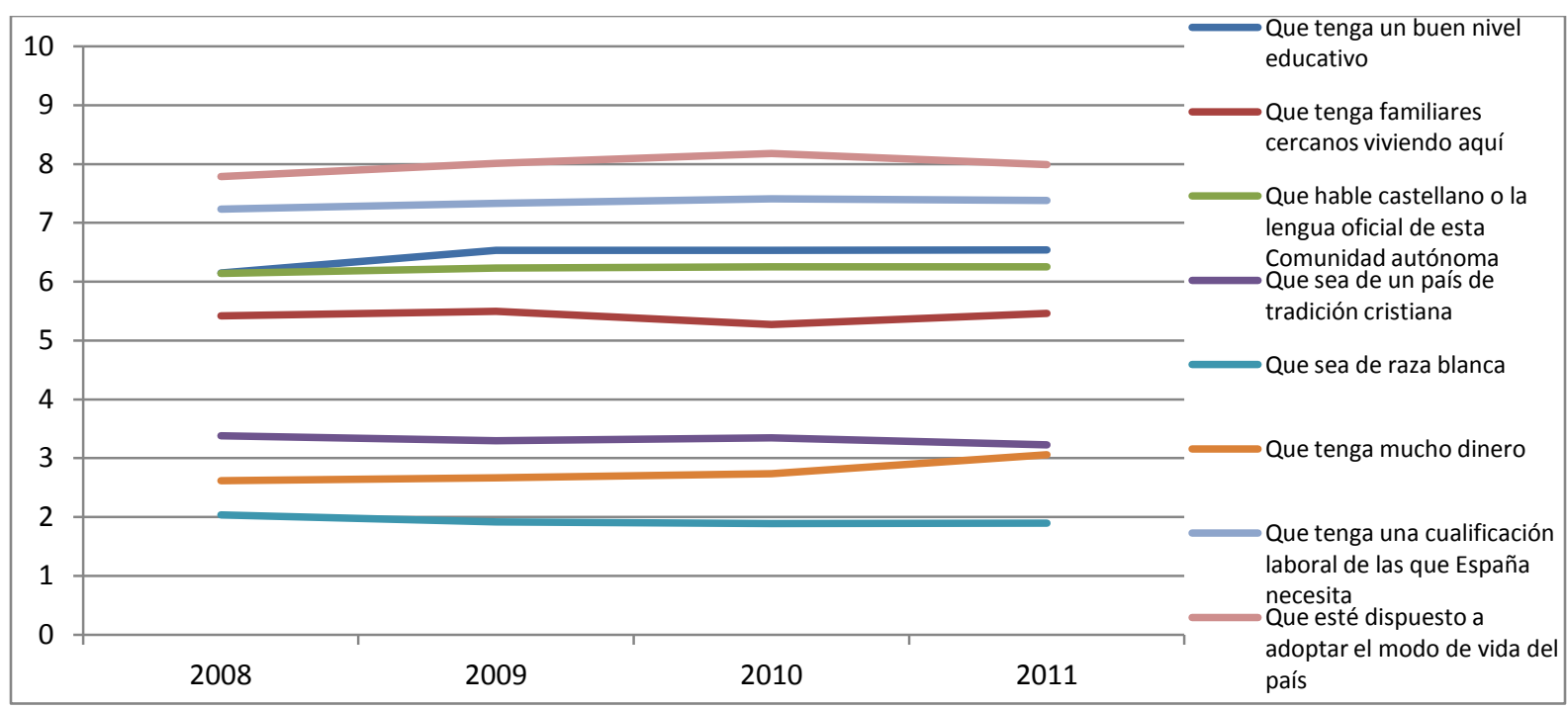

Fuente: Elaboración propia con datos del CIS; estudios 2773 (2008), 2817 (2009), 2846 (2010) y 2918 (2011).

En relación a la entrada y permanencia de las personas inmigrantes en España se muestra un incremento quienes creen que la legislación a este respecto es tolerante. Al realizar un análisis longitudinal desde el 2008 hasta el 2011, se aprecia que la posición más generalizada es que la legislación migratoria es demasiado tolerante en cuanto a la entrada y permanencia de personas inmigrantes. En 2008 el 45,2\% de ciudadanía pensaba que era demasiado tolerante, a partir de ahí, se observa una tendencia al aumento de esta creencia, situándose en 2011 en el 46,0\%, en detrimento del un término más intermedio, como es más bien tolerante, que desciende del 34,3\% en 2008 al 33,9\% en 2011.

La percepción de que la legislación migratoria es correcta, no está muy extendida entre la sociedad española; de hecho en 2008 únicamente el 14,8\% de la población lo creía así, y esta postura comienza a descender hasta situarse en el 2010 con el 12,6\%, aumentando ligeramente en 2011 para situarse en el 13,7\%. Sin embargo 
muy poca población cree que la legislación española sea más bien dura o dura, tanto es así que acumulando estas dos percepciones, el porcentaje más elevado de población que así lo cree es el 6,5\% en 2009, mientras que la creencia más baja sobre que la legislación que regula la entrada y permanencia de las personas inmigrantes se halla en el 2010 con el 5,7\%.

Tras estudiar el gráfico 23, se observa que no producen cambios bruscos de tendencia y además de ello, se extrae que la mayoría de la población cree que la legislación migratoria en entrada y permanencia es tolerante lo que en palabras de Cea D’Ancona (2009) es un indicador de que la población española es xenófoba.

Gráfico 23: Percepción de la legislación migratoria (2008 a 2011).

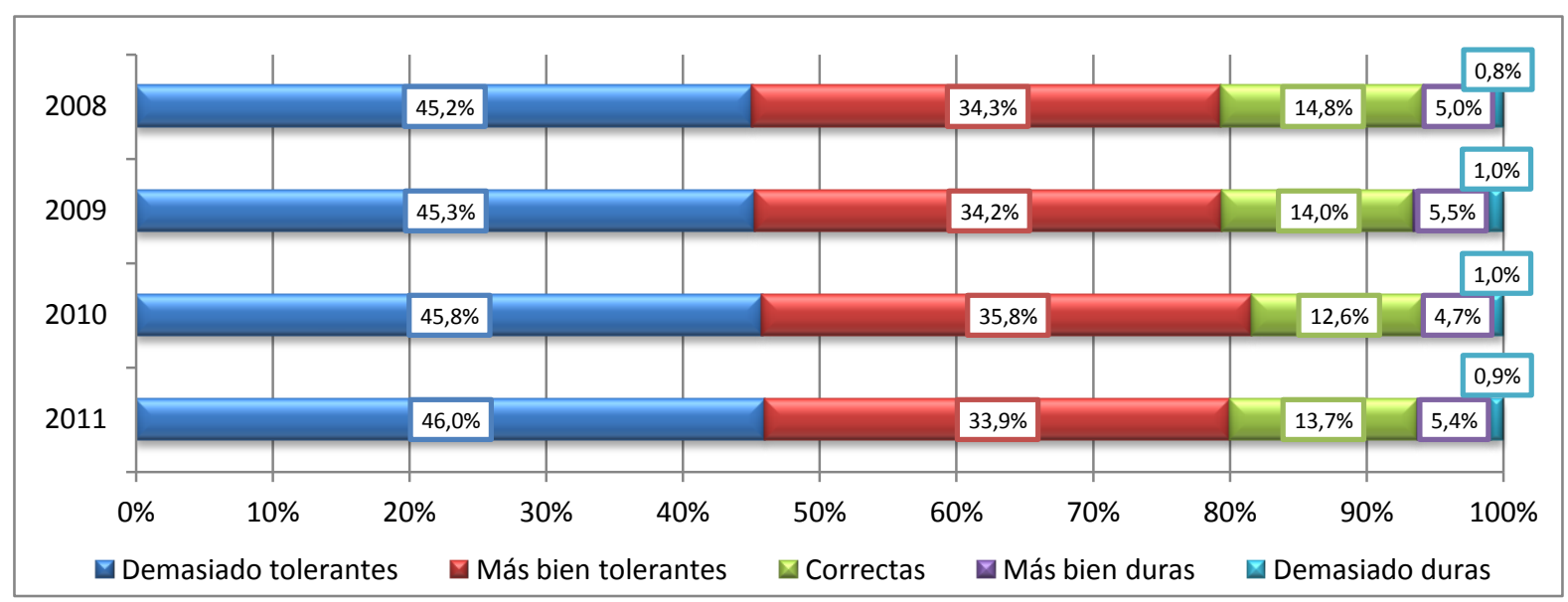

Fuente: Elaboración propia con datos del CIS; estudios 2773 (2008), 2817 (2009), 2846 (2010) y 2918 (2011).

Respecto al asilo -estar perseguidas personas por su país debido a causas políticas, religiosas, racial, etc.-, el endurecimiento de la legislación migratoria que se produjo en 2009 en esta materia ha generado, en gran parte, que España no sea un país muy tendente a conceder el asilo, porque al igual que los países del sur de Europa -Italia y Grecia- se sienten en la necesidad de blindar las fronteras europeas. Según Comisión Española de Ayuda al Refugiado (CEAR); en 2012 se redujeron la concesión de asilo un $54 \%{ }^{40}$ en los tres principales países del sur de Europa, es decir, España, Italia y Gracia; acción que combinada con el cambio de legislación más estricta en España se han reducido en el periodo de 2008 a 2012 un 24\% las solicitudes de asilo ${ }^{41}$. En cuanto a la postura de la ciudadanía española ante el asilo la opción prioritaria para la sociedad española es acoger una vez se ha comprobado que están perseguidas, pero esta opción disminuye progresivamente, ya que en

\footnotetext{
40 Datos extraídos del Informe del CEAR 2013. La situación de las personas refugiadas en España.

${ }^{41}$ Datos extraídos del ACNUR. Tendencias de Asilo 2012. Niveles y tendencias en países industrializados.
} 
2008 representaba el 45,9\% y en 2011 era el 40,0\%; mientras que la opción de acoger a un número limitado sí son perseguidas, aumenta su peso de $29,8 \%$ al $32,1 \%$ en el mismo periodo -véase el gráfico 14 del anexo de resultados-.

\section{INMIGRACIÓN IRREGULAR}

En lo que se refiere a la situación de las personas inmigrantes irregulares en España, hay que señalar que es una temática especialmente delicada, puesto que al no tener cifras exactas sobre el volumen de personas que se encuentran en esta situación en España, hace difícil realizar un análisis exhaustivo sobre la percepción del volumen por parte de la sociedad y la realidad numérica. Se estima que en 2008 había 795.263 inmigrantes en situación irregular, esta cifra aumentó al siguiente año en 60.000 personas y comenzó a descender. En 2011 eran 500.393 inmigrantes irregulares en España ${ }^{42}$. En este apartado únicamente se va a examinar la posición que la ciudadanía creería más oportuna para resolver la situación de la inmigración irregular -es decir, las personas que no tienen el permiso de residencia ni de trabajo-

La opción mayoritaria de la ciudadanía española, en el periodo del 2008 al 2011 , es regularizar sólo a quienes tengan un trabajo en ese momento. En 2008 esta opción la respaldaba del 53,0\% de la población, aunque va perdiendo peso, y en el 2011 la apoyan el $47,4 \%$ de la sociedad española. Otra postura que cuenta con bastante apoyo de la ciudadanía es regularizar a las personas inmigrantes que lleven años viviendo en España, la cual sufre un leve descenso del 19,7\% al 18,5\% en el periodo analizado. Posturas más radicales, como regularizar a toda la inmigración irregular aumenta el apoyo de la población, del 9,1\% al 11,2\% de 2008 a 2011 . Mientras que en el sentido contrario, la opción de devolver a las personas irregulares a su país de origen incrementa su peso del $17,0 \%$ al $21,1 \%$ en el periodo examinado.

Tal y como se aprecia en el gráfico 24, hay un cambio en la manera de pensar por parte de la sociedad española en relación a la inmigración irregular. El factor del mercado laboral, es el que más influencia a la ciudadanía, seguido de que lleven una cantidad determinada de años residiendo en España.

\footnotetext{
42 Cifras estimadas por la resta de las personas extranjeras del Padrón Municipal y quienes tienen la tarjeta de residencia de Secretaria General de Inmigración y Emigración.
} 
Gráfico 24: Postura respecto a la inmigración irregular (2008 a 2011).

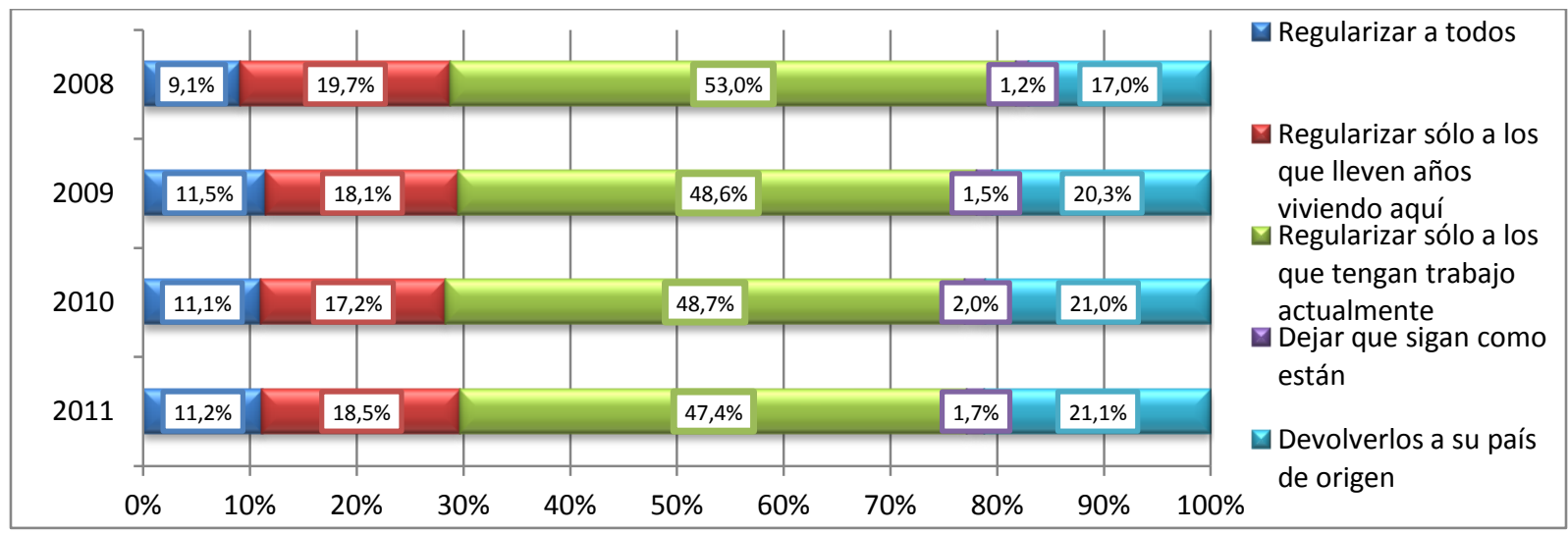

Fuente: Elaboración propia con datos del CIS; estudios 2773 (2008), 2817 (2009), 2846 (2010) y 2918 (2011).

El perfil socio-demográfico de la postura menos tolerante respecto a la inmigración irregular, es decir, devolver a las personas inmigrantes irregulares a su país de origen estaría compuesto, por el nivel de estudios, ya que el 29,5\% de la población que no tiene estudios son favorables a esa opción, mientras que el 9,1\% de quienes tienen estudios superiores apoyan esa postura. El nivel de ingresos también es relevante, ya que el $28,8 \%$ de quienes menos de 900 euros al mes está a favor de la repatriación, mientras que $11,9 \%$ de quienes ingresan más de 1800 euros mensuales está de acuerdo con la medida. En cuanto al contacto con inmigrantes, el $24,3 \%$ de quienes no tienen amistades inmigrantes están de acuerdo con devolver a las personas inmigrantes a su país, mientras quienes en su círculo de amistades tienen amigas y/o amigos inmigrantes apoyan la medida un $17,2 \% 43$.

\section{AYUDA DEL ESTADO A LAS PERSONAS INMIGRANTES}

En la actualidad, una de las principales cuestiones en la agenda pública y en los medios de comunicación es la sostenibilidad del Estado de bienestar en España. La percepción que se tiene sobre la inmigración en este aspecto es capital, puesto que la opinión sobre la inmigración gira alrededor de dos posturas principalmente. Por un lado, sí la inmigración es útil para mantener el sistema de pensiones o por otro lado, sí supone un gasto excesivo para los pilares del Estado de bienestar.

\footnotetext{
${ }^{43}$ Significación del chi-cuadrado $0,00 \%$. Por lo que se rechaza la hipótesis nula (no hay relación) y se acepta la asociación entre las variables. Datos del estudio 2918 (2011).
} 
En primer lugar, al comparar la percepción de la población sobre la ayuda por parte del Estado a los grupos vulnerables de la sociedad; se observa que la población española cree el grupo de inmigrantes es que el que más recibe mucha o bastante ayuda por parte del Estado. Esta percepción va en aumento, ya que en 2007 así lo creía el 60,1\% de la población, mientras que en 2011 es la opinión del 69,3\% de la ciudadanía. Este incremento es probable que se deba a la situación económica del país y a los recortes en prestaciones sociales por parte del Estado, lo cual genera un pensamiento de protección hacia "nosotros" en contra de los "otros"; es decir, las personas inmigrantes. Analizando la percepción hacia el resto de grupos vulnerables, se observa que la opinión sobre la ayuda a las personas paradas disminuye del $31,3 \%$ al $19,9 \%$ de la población que cree que la ayuda del Estado a este grupo es bastante o mucha. Respecto a las personas mayores que viven solas y a las personas pensionistas, aumentan ligeramente la percepción de la sociedad sobre de la ayuda del Estado a estos grupos.

Gráfico 25: Bastante o mucha ayuda que reciben los grupos vulnerables del Estado (2007 a 2011).

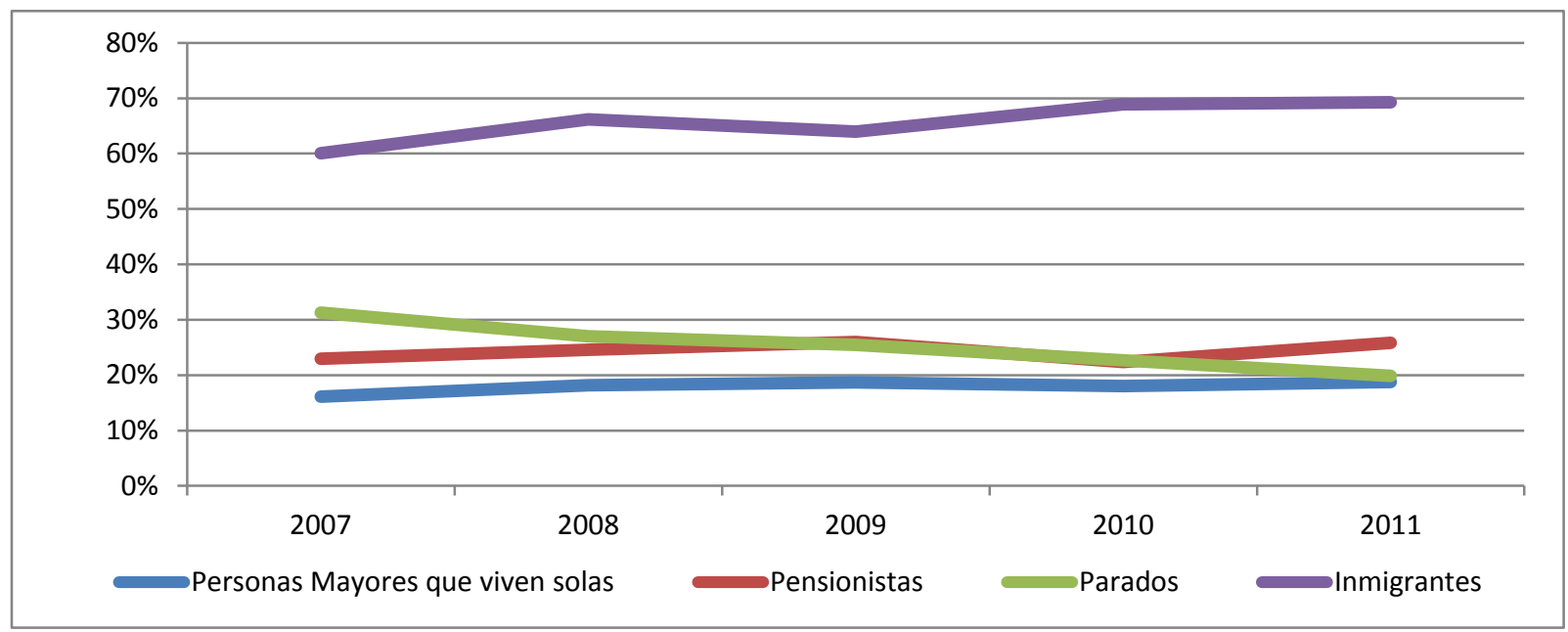

Fuente: Elaboración propia con datos del CIS; estudios 2731(2007), 2773 (2008), 2817 (2009), 2846 (2010) y 2918 (2011).

En segundo lugar, es importante conocer la percepción de la población entre lo que las personas inmigrantes aportan al Estado y lo que reciben de él. La ciudadanía cree que las personas inmigrantes reciben más de lo que aportan. Esta es la opción mayoritaria en todo el periodo de 2008 a 2011; pero aumenta progresivamente, ya que en 2008 , el $37,4 \%$ de la población pensaba de ese modo y se incrementa esta percepción hasta el 38,8\% de la población que cree que las personas inmigrantes reciben más de lo que aportan. A su vez, también se produce un aumento de la idea de que las personas inmigrantes reciben mucho más de lo que aportan, del $23,4 \%$ al 
32,3\%, es decir, casi diez puntos porcentuales de 2008 a 2011. Otro rasgo que muestra la tendencia es el descenso de la postura más ambivalente, es decir, que aportan tanto como reciben que disminuye del 28,6\% al 20,9\% de 2008 a 2011 como se muestra en el gráfico 26.

En el periodo de tiempo estudiado, no aumentaron las concisiones del Estado a las personas inmigrantes, por lo que se puede dilucidar que la variable principal en el agravamiento de posturas sobre las ayudas del Estado a las personas inmigrantes es la crisis económica y cómo afecta sobre la percepción que tiene la población española hacia este colectivo.

Gráfico 26: Relación entre lo que aportan las personas inmigrantes y lo que reciben por parte del Estado (2008 a 2011).

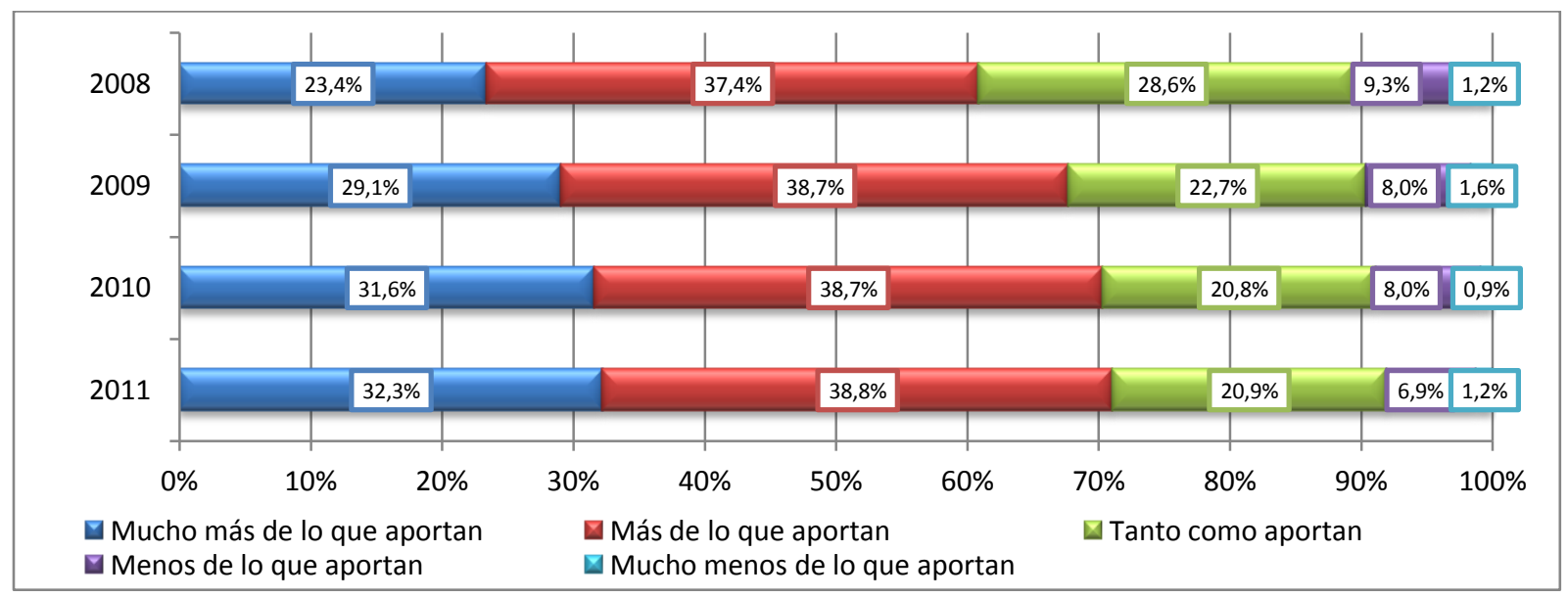

Fuente: Elaboración propia con datos del CIS; estudios 2773 (2008), 2817 (2009), 2846 (2010) y 2918 (2011).

En la memoria del 2011 del Sistema de Información de Usuarios de Servicios Sociales (SIUSS) se muestra que $84,2 \%$ de los usuarios de los servicios sociales son población española, el 3,3\% es ciudadanía de la Unión Europa y el 12,5\% son usuarios extracomunitarios. En un análisis longitudinal del 2008 al 2011 se aprecia que en 2008 es el 8,82\% de los usuarios son inmigrantes, esta cifra aumenta hasta el 9,64\% en 2009 y comienza a disminuir los siguientes años hasta el 9,21\% en 2011. Estos datos explican que en periodo de más agudeza de la crisis económica el porcentaje de inmigrantes que utilizan los servicios sociales no ha aumentado con la misma intensidad que la gravedad de la situación. Además de ello, también se pone de manifiesto que el número de inmigrantes residentes en España es muy superior al que utiliza los servicios sociales, por lo cual, los datos del SIUSS no muestran que la población inmigrantes haga un uso abusivo de los servicios sociales.. 
Continuando con los datos de la memoria del SIUSS en 2011, los servicios que más utilizan las personas inmigrantes, son las ayudas de emergencia, que ocupan el mayor porcentaje de los recursos empleados y que se ha incrementado del $10,1 \%$ en 2008 al 17,5\% en 2011. También son relevantes los recursos empleados en la tramitación de documentación a la administración civil, que desciende del 15,4\% en 2008 al 11,1\% en 2011. Además de ello, es reseñable el aumento del salario social cuyo porcentaje ha aumentado del 3,6\% al 10,6\% en el periodo de 2008 al 2011 como refleja el gráfico 27.

Gráfico 27: Evolución número de intervenciones a personas inmigrantes por recursos aplicados (2008 a 2011$).$

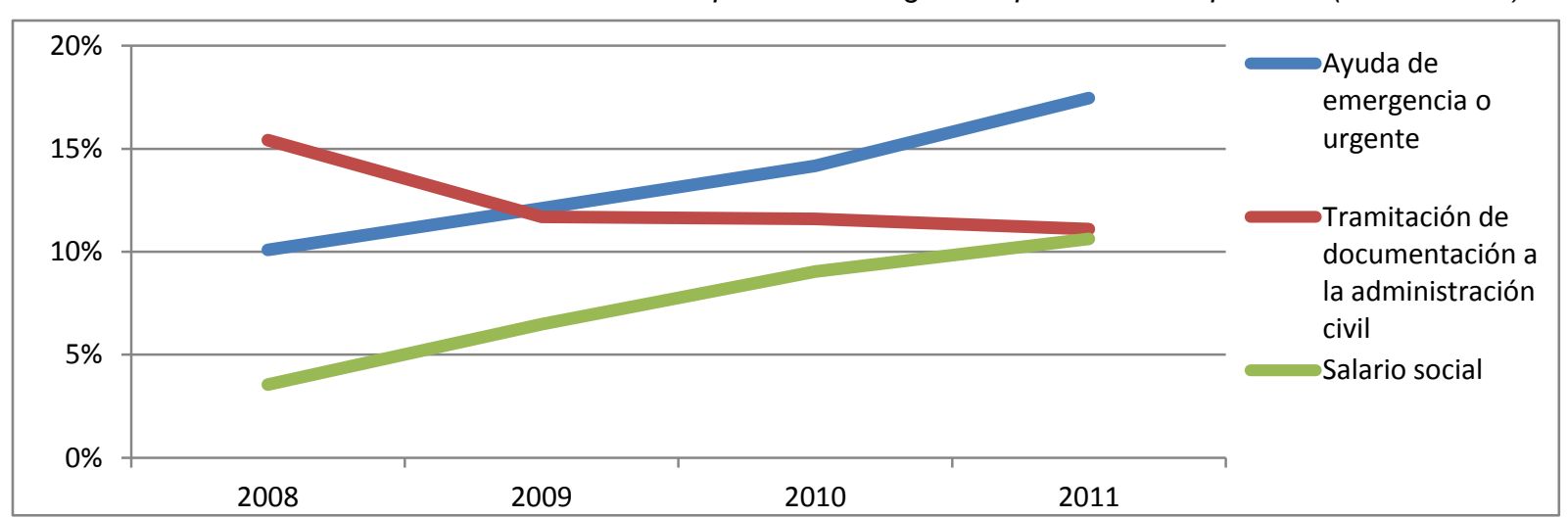

Fuente: Elaboración propia con datos memoria del Sistema de Información de Usuarios de Servicios Sociales (S.I.U.S.S) 2011

Concretamente en el caso de la sanidad gratuita ${ }^{44}$, se observa que la percepción de la población sobre sí las personas inmigrantes abusan de la atención sanitaria gratuita se ha incrementado en el periodo 2008 a 2011. La población que está muy de acuerdo con que las personas inmigrantes abusan de la atención sanitaria gratuita ha aumentado del 25,9\% en 2008 al 29,0\% en 2011. A su vez, también se produce un incremento del 33,3\% en 2008 al 35,6\% en 2011 entre la población que está más bien de acuerdo con que las personas inmigrantes abusan de la atención sanitaria gratuita.

\section{DERECHOS DE LAS PERSONAS INMIGRANTES REGULARES}

Para finalizar con el estudio de las creencias y valores sobre la gestión de la inmigración, es preciso conocer la percepción de la sociedad ante los derechos de las personas inmigrantes regulares.

\footnotetext{
${ }^{44}$ Actualmente es un aspecto de especial interés por el decreto Real Decreto-Ley 16/2012, de 20 de abril, de medidas urgentes para garantizar la sostenibilidad del Sistema Nacional de Salud.
} 
Las personas inmigrantes regulares instaladas y estables en España, han logrado una serie de derechos con el paso de los años, sin embargo hay otros derechos que en la actualidad reivindican y no los han obtenido, como son los derechos políticos sin restricciones. Al estudiar la opinión de la población española sobre los derechos de las personas inmigrantes regulares en el periodo de 2007 a 2011 se aprecia que algunos derechos han contado con más aceptación con el paso del tiempo en la sociedad, otros han perdido apoyo social y el resto se mantienen más o menos estables, como se analizará posteriormente. Es reseñable como todos los derechos analizados constan con más del 55\% del apoyo de la sociedad española.

El derecho que cuenta con más apoyo social a lo largo del periodo estudiado es poder cobrar el subsidio sí se quedan desempleados; que además consta de mucha estabilidad en el periodo, puesto que tiene su pico más elevado en 2007 con el $92,7 \%$ y el más bajo en 2009 con el 91,2\%. Así como la potestad de traer a su familia -llamada reagrupación familiar- que sufre un importante descenso, pese a contar con un importante apoyo de la sociedad, pasa del 90,7\% al 83,0\% en el periodo de 2007 a 2011. Una situación similar le ocurre al derecho de crear asociaciones para defender sus propios derechos, que desciende el apoyo de la población progresivamente del $81,0 \%$ al 78,0\% de 2008 a $2011^{45}$. Respecto a poder obtener la nacionalidad española, en el caso de ser una persona inmigrante regular y estable en España, sufre un descenso de la aceptación de la ciudadanía española pasando del 78,3\% en 2008 al 76,1\% en 2011, especialmente es muy irregular la percepción de este derecho que aumenta y disminuye de año en año. Esto puede deberse a que la sociedad no tienen una opinión muy formada de la temática.

Los derechos que menor aceptación tienen por parte de la sociedad española, son los referentes a la participación activa en las decisiones políticas de España. De hecho, poder votar en las elecciones municipales -lo cual es ya un derecho reconocido para personas originarias de países con los que España tiene acuerdos de bidireccionalidad- desciende del 74,9\% en 2007 al 70,8\% en 2011 de la ciudadanía que apoya que las personas inmigrantes regulares y estables voten en las elecciones municipales. En lo que se refiere al derecho de votar en las elecciones generales para las personas inmigrantes regulares, es el derecho que

\footnotetext{
45 No hay datos de 2007 sobre crear asociaciones y votar en las elecciones generales.
} 
cuenta con menos apoyo social por parte de la ciudadanía. En 2008 lo apoyan el $61,8 \%$ de la ciudadanía, al año siguiente sufre un descenso muy considerable, bajando al 58,8\%; y los siguientes años aumenta progresivamente hasta contar con el 62,6\% de la apoyo de la sociedad en el 2011 como se aprecia en el gráfico 28.

Gráfico 28: Percepción de los derechos de las personas inmigrantes regulares (2007 a 2011).

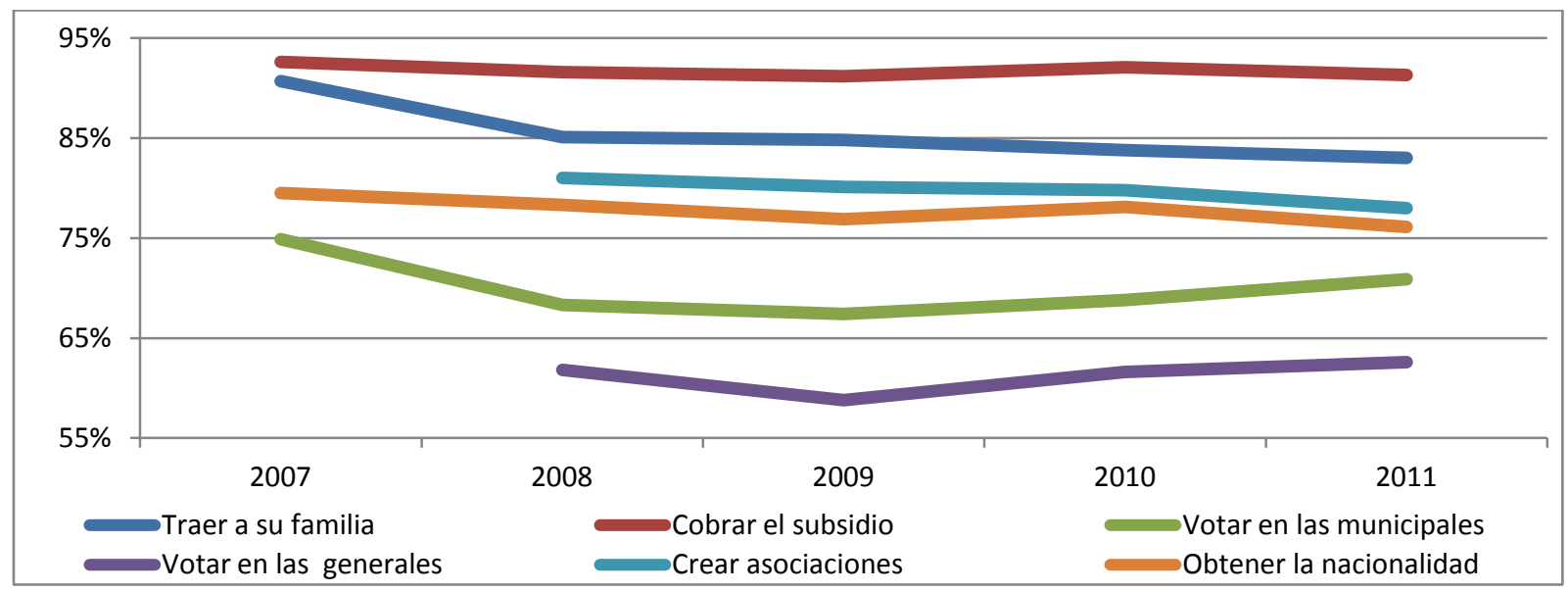

Fuente: Elaboración propia con datos del CIS; estudios 2731(2007), 2773 (2008), 2817 (2009), 2846 (2010) y 2918 (2011).

\section{FOTO FIJA DE LAS CREENCIAS Y VALORES SOBRE LA GESTIÓN DE LA INMIGRACIÓN (2011).}

Al realizar un estudio sobre las creencias y valores sobre la gestión de la inmigración, se aprecia que la percepción de la sociedad ante los factores de entrada de personas extranjeras a vivir en España en 2011, revelan una información valiosa para este apartado. Al realizar un análisis factorial, las variables se agrupan alrededor de dos componentes principales:

- Asimilacionismo: lo componen los factores: que tenga un buen nivel educativo, que tenga familiares cercanos viviendo en España, que hable castellano, que tenga una cualificación laboral de las que España necesita y que esté dispuesto a adoptar el modo de vida del país. El aculturalismo de inmigrantes económico (componente 1), son características del nivel de adaptación y aculturalismo a la sociedad receptora del inmigrante económico; es decir que la inmigración que reciba España tenga fácil la adaptación al país para que no genere problemas, ni abuse de los servicios públicos -que tenga familiares cercanos viviendo en España, que hable castellano y que 
esté dispuesto a adoptar el modo de vida-; así como que sea una inmigración orientada al mercado laboral, es decir, que sean inmigrantes económicos -que tenga un buen nivel educativo y que una cualificación laboral de las que España necesita-.

- Cercanía: se agrupa en los factores: que sea de un país de tradición cristiana, que sea de raza blanca y que tenga mucho dinero. La cercanía (componente 2) reúne los factores migratorios que se contraponen con la idea que se tiene en el imaginario colectivo sobre la inmigración, ósea con el colectivo magrebí, especialmente el marroquí. Este componente, diseña un tipo migratorio no económico -que tenga mucho dinero- y con rasgos eurocéntricos -que sea de un país de tradición cristiana y que sea de raza blanca-; por lo cual describe un perfil migratorio de nacionalidades europeas -excluyendo la ciudadanía de Europa del este- que residen en España por motivos no económicos, es decir, británicos, alemanes, franceses, holandeses y belgas.

Tabla 3: Factorial sobre la entrada de personas extranjeras a España.

\begin{tabular}{|c|c|c|}
\hline \multicolumn{3}{|l|}{ ANÁLISIS FACTORIAL } \\
\hline Matiz de componentes rotados & \multicolumn{2}{|c|}{ Componente } \\
\hline Ítems & 1 & 2 \\
\hline Que tenga un buen nivel educativo & 0,747 & \\
\hline Que tenga familiares cercanos viviendo aquí & 0,541 & \\
\hline $\begin{array}{l}\text { Que hable castellano o la lengua oficial de esta Comunidad } \\
\text { autónoma }\end{array}$ & 0,703 & \\
\hline Que sea de un país de tradición cristiana & & 0,780 \\
\hline Que sea de raza blanca & & 0,885 \\
\hline Que tenga mucho dinero & & 0,723 \\
\hline Que tenga una cualificación laboral de las que España necesita & 0,752 & \\
\hline Que esté dispuesto a adoptar el modo de vida del país & 0,738 & \\
\hline \multicolumn{3}{|l|}{ Método factorial y pruebas estadísticas } \\
\hline \multicolumn{3}{|c|}{ Método de extracción: Análisis de componentes principales. } \\
\hline \multicolumn{3}{|c|}{ Método de rotación Varimax con Kaiser. La rotación ha convergido en 3 iteraciones. } \\
\hline Medida de adecuación muestral del Kaiser-Meyer-Olkin & Medida & 0,778 \\
\hline Prueba de esfericidad de Bartlett & Sig. & 0,000 \\
\hline Varianza total explicada & Porcentaje & 57,56 \\
\hline
\end{tabular}




\section{E. ACTITUDES ANTE LA INMIGRACIÓN EN LA VIDA COTIDIANA (2007 a 2011).}

Para identificar las actitudes ante la inmigración que tiene la sociedad española, es necesario, por un lado, conocer sus actitudes sobre situaciones concretas en la vida cotidiana como son por un lado: la vecindad, el trabajo o estudios y las relaciones familiares; y por otro lado, la simpatía y antipatía en función de los grupos de nacionalidades de inmigrantes.

\section{ACTITUDES ANTE LA INMIGRACIÓN EN LA VECINDAD}

En primer lugar, respecto a las actitudes ante la inmigración en la vecindad se plantean tres casos: vivir en el mismo barrio en el que viven muchas personas inmigrantes; vivir en el mismo bloque en el que viven inmigrantes; y alquilar un piso a inmigrantes.

En primer lugar, la mayoría de la sociedad aceptaría vivir en un barrio en el que hay una alta concentración o presencia de inmigrantes. Analizando el periodo de 2007 a 2011, se aprecia que la cifra más elevada de aceptación se encuentra en 2007 con el $75,2 \%$ de la ciudadanía que aceptaría vivir en el mismo barrio en el que viven un gran número de inmigrantes. Este porcentaje de población disminuye muy pronunciadamente los siguientes años, hasta el $56,4 \%$ en el 2010 , lo que simboliza una caída de doce puntos porcentuales, sin embargo y al siguiente año aumenta al $59,6 \%$. Dicho aumento, en el 2011 , se puede deber a que con la situación de crisis económica y los desahucios que se produjeron en ese año, la sociedad española se ha sensibilizado más con el hecho de tener una vivienda, independientemente de en el barrio que sea. Además de ello, se observa que hay un cambio de 2007 al 2008 que puede deberse al impacto de la crisis económica.

La población que afirma que trataría de evitar vivir en el mismo barrio en el que viven muchas personas inmigrantes aumenta en el periodo estudiado, ya que en 2007 era el $14,5 \%$ de la población quien pensaba de ese modo, y se agranda al $30,0 \%$ en 2010, descendiendo al 26,9\% en 2011. Mientras la población que rechazaría vivir en el mismo barrio en el que viven muchas personas inmigrantes, también aumenta, ya que en 2007 era el 5,6\% y aumenta al 9,4\% en 2010 -se mantiene en la misma cifra en 2011-. Este aumento es probable que sea como consecuencia de que la 
población que ve al inmigrante como el "otro" y compite por los mismos puestos de trabajo; por lo cual, una manera de diferenciarse es no residiendo en barrios poblados mayoritariamente por inmigrantes. Respecto a la población que cree que depende de las circunstancias se mantiene en torno al 4,1\% en el periodo de 2007 al 2011.

Gráfico 29: Vivir en el mismo barrio en el que viven muchas personas inmigrantes (2007 a 2011).

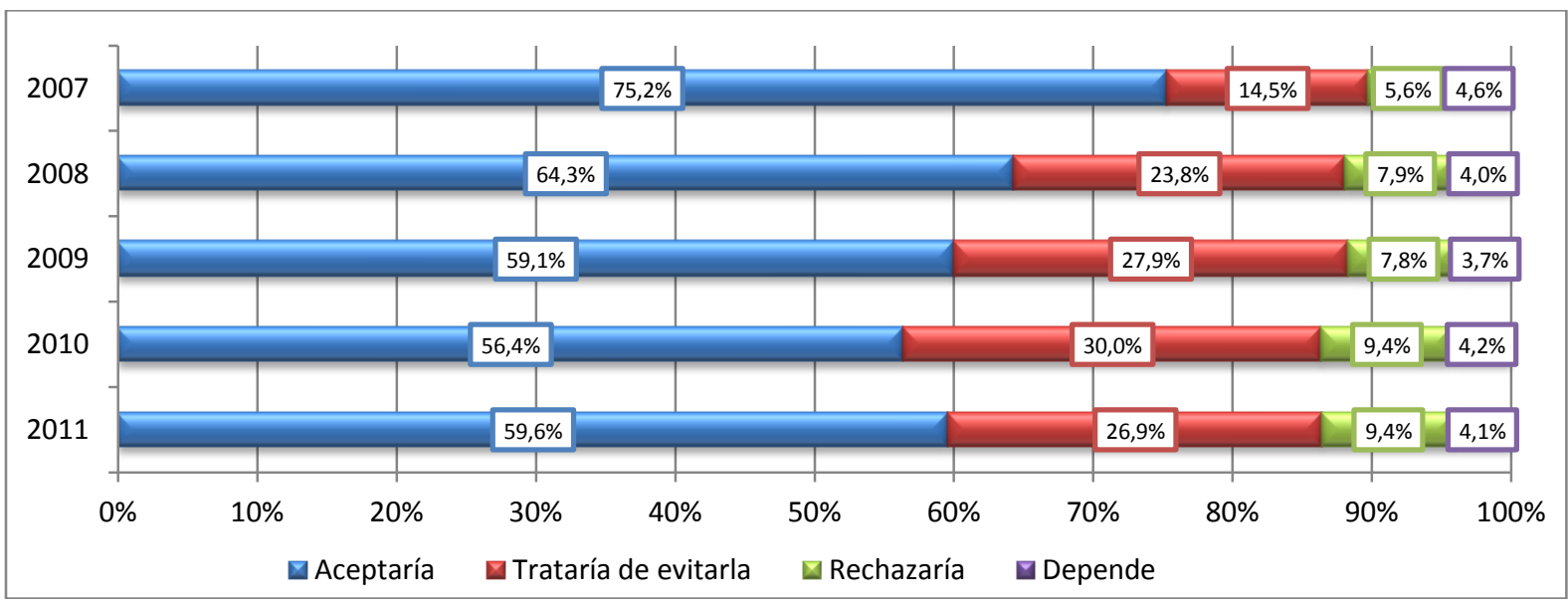

Fuente: Elaboración propia con datos del CIS; estudios 2731(2007), 2773 (2008), 2817 (2009), 2846 (2010) y 2918 (2011).

En segundo lugar, la mayoría de la población aceptaría residir en el mismo bloque en el que viven inmigrantes. En el 2007 el 70,6\% de la ciudadanía aceptaría vivir en el mismo bloque en el que viven inmigrantes, esta cifra va descendiendo hasta el $59,6 \%$ en el 2010 , pero al siguiente año aumenta al $60,4 \%$ de la población que aceptaría vivir en el mismo bloque en el que viven inmigrantes -véase en el gráfico 15 del anexo de resultados. Se observa que las trayectorias crecientes y decrecientes son muy similares al hecho de vivir en el mismo barrio en el que viven muchas personas inmigrantes, que reafirman un cambio en la mentalidad durante el periodo de 2007 a 2011.

En tercer lugar, la población española no lo aceptaría con tanta contundencia alquilar un piso a inmigrantes, como se ha mostrado que lo haría respecto a vivir en el mismo barrio y el mismo bloque que inmigrantes. Esto puede deberse a que alquilar una propiedad es una situación muy personal y se refleja como un hecho más cercano; más aún cuando en España la costumbre de alquilar viviendas no está demasiado generalizada. Este mayor rechazo a alquilar un piso a inmigrantes puede deberse en que es un acuerdo contractual más directo que exige una perdurabilidad en el tiempo y una regulación (Cea D’Ancona y Vallés Martínez, 2009). 
En 2007, el 47,8\% la ciudadanía aceptaría alquilar un piso a inmigrantes es este porcentaje va descendiendo hasta el $43,5 \%$ en 2010 , al siguiente año aumenta al $45,8 \%$ de la población. El descenso en 2010, se puede deber a que es un año especialmente duro en cuanto a la destrucción de empleo y se responsabiliza a la inmigración de la situación. En lo que se refiere a la población que trataría de evitar la situación, se aprecia que aumenta ligeramente del 19,2\% al 22,5\% en el periodo de 2007 al 2011. Así como la población española que rechazaría alquilar un piso a inmigrantes aumenta del 22,5\% en 2008 al 24,3\% en 2010, sin embargo en el 2011 desciende al 22,1\%. Así como también se aminora levemente quienes creen que depende de la situación alquilaría un piso a inmigrantes, pasando del 10,5\% al 9,7\% de la ciudadanía partidaria de esa postura como se observa en el gráfico 30 , en el periodo de 2007 a 2011.

Gráfico 30: Alquilar un piso a inmigrantes (2007 a 2011).

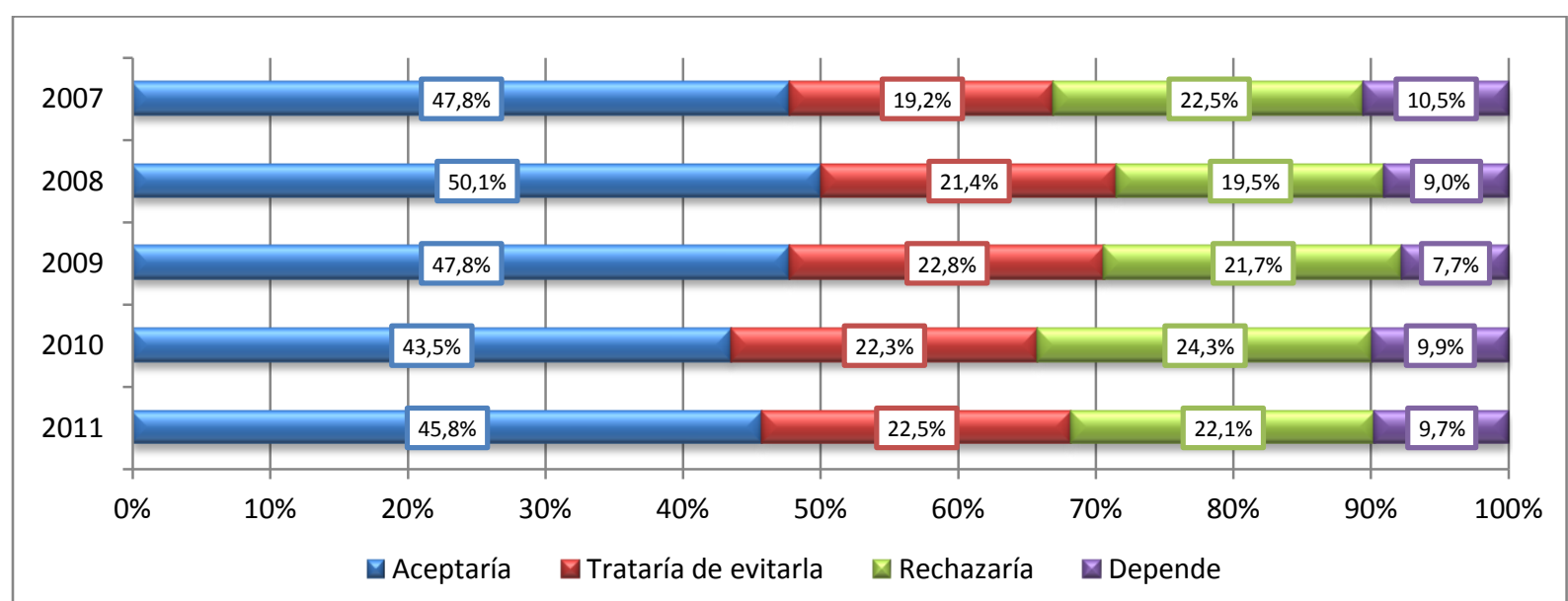

Fuente: Elaboración propia con datos del CIS; estudios 2731(2007), 2773 (2008), 2817 (2009), 2846 (2010) y 2918 (2011).

El perfil socio-demográfico de la población que rechaza alquilar un piso a inmigrantes destaca en primer lugar, la edad, ya que cuanto más mayor es una persona tiene más propensión a rechazar alquilar un piso a inmigrantes. Poco menos de la tercera parte de la población mayor de 65 años rechazarían, mientras que los jóvenes de entre 18 a 24 años únicamente el 15,2\% no alquilarían un piso a inmigrantes. Otra característica socio-demográfica influyente es la confianza hacia otras personas que se tenga, el $34,0 \%$ de las personas muy desconfiadas rechazarían alquilar un piso a inmigrantes, así como el 10,9\% de las muy confiadas lo rechazarían. En relación al contacto, quienes tienen en su vecindad a inmigrantes aceptaría alquilar un piso a inmigrantes en mayor proporción que quienes no tienen 
vecinos inmigrantes, un $50,0 \%$ respecto a un $40,6 \%{ }^{46}$. Este dato sobre el contacto directo muestra que incluso que una afirmación que es poco valorada por el conjunto de la sociedad, tener vecinos inmigrantes presenta mejores resultados que no tenerlos, por lo cual estos datos ilustran que el contacto directo con la población inmigrante reducen los prejuicios de la población.

\section{ACTITUDES ANTE LA INMIGRACIÓN EN EL TRABAJO Y/O ESTUDIOS}

En relación a las actitudes ante la inmigración en el trabajo o en los estudios se analizan dos situaciones concretas: trabajar o estudiar con inmigrantes; y que una persona inmigrante sea su jefe en el trabajo.

La primera situación, trabajar o estudiar con inmigrantes consta de una gran aceptación y estabilidad durante el periodo de 2007 a 2011, puesto que en el 2007 el $84,6 \%$ de la ciudadanía española aceptaría trabajar o estudiar con inmigrantes. Este porcentaje aumenta en 2009 hasta el 84,2\%; al siguiente año desciende al 82,5\% y en 2011 se mantiene en el 82,4\%. La parte de la población que trataría de evitar la situación se mantiene estable en torno al 10,3\%, después de un repunte respecto al $7,8 \%$ en 2007. Mientras quienes rechazarían trabajar o estudiar con inmigrantes desciende del $4,1 \%$ en 2007 al 3,3\% en 2011. Respecto a la población para quien depende de la situación y la circunstancia, aumenta del 3,5\% al $4,2 \%$ en el periodo de 2007 al 2011 como muestra en gráfico 31. Este incremento puede deberse a la situación laboral actual, ya que personas que nunca hubiesen aceptado trabajar con inmigrantes ahora dependiendo de las circunstancias podrían aceptar.

${ }^{46}$ Significación del chi-cuadrado $0,00 \%$. Por lo que se rechaza la hipótesis nula (no hay relación) y se acepta la asociación entre las variables. Datos del estudio 2918 (2011). 
Gráfico 31: Trabajar o estudiar con inmigrantes (2007 a 2011).

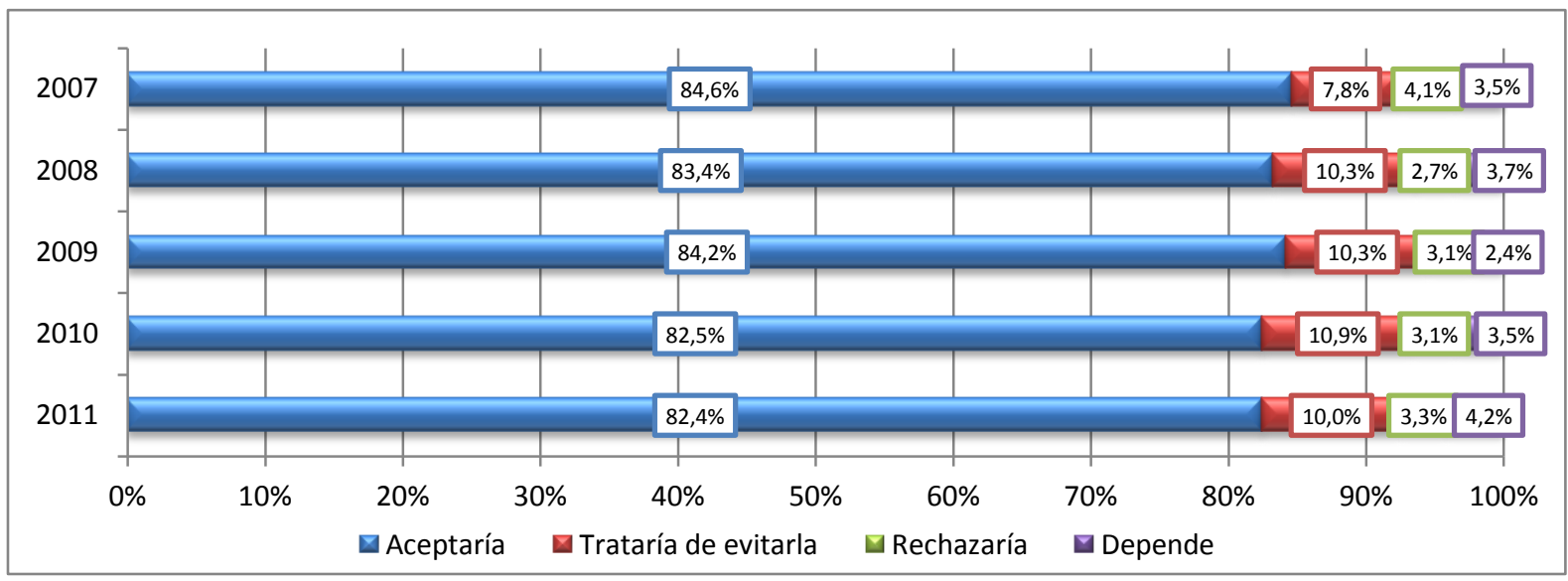

Fuente: Elaboración propia con datos del CIS; estudios 2731(2007), 2773 (2008), 2817 (2009), 2846 (2010) y 2918 (2011).

La segunda situación, que una persona inmigrante sea su jefa o jefe en el trabajo, tiene buena aceptación entre la población, también influenciado por el contexto de destrucción de empleo del periodo 2007 a 2011. En 2007, el 78,6\% de la población aceptaría que una persona inmigrante sea su jefa o jefe, posteriormente, en 2010 desciende la aceptación al 76,3\%; y en el 2011 asciende al 77,9\% de la ciudadanía que aceptaría que una persona inmigrante sea su jefa o jefe. Hay un porcentaje de población que trataría de evitar la situación, en 2007 era el 9,9\%, y aumenta al $13,6 \%$ en 2010. Al siguiente año desciende al 12,1\% de la ciudadanía que trataría de evitar que una persona inmigrante sea su jefa o jefe. Por el contrario, en 2007 el $6,7 \%$ de la población rechazaría una persona inmigrante sea su jefa o jefe y dicho porcentaje desciende hasta el 5,4\% en 2011. Así como, para quienes depende de la situación aceptarían o no que una persona inmigrante sea su jefa o jefe se mantiene alrededor del 4,6\% en el periodo de 2007 a 2011, tal y como se observa en el gráfico 32. Se aprecia a su vez, que tanto trabajar o estudiar con inmigrantes y que un inmigrante sea el jefe en el trabajo muestran trayectorias muy similares. 
Gráfico 32: Que una persona inmigrante sea su jefe en el trabajo (2007 a 2011).

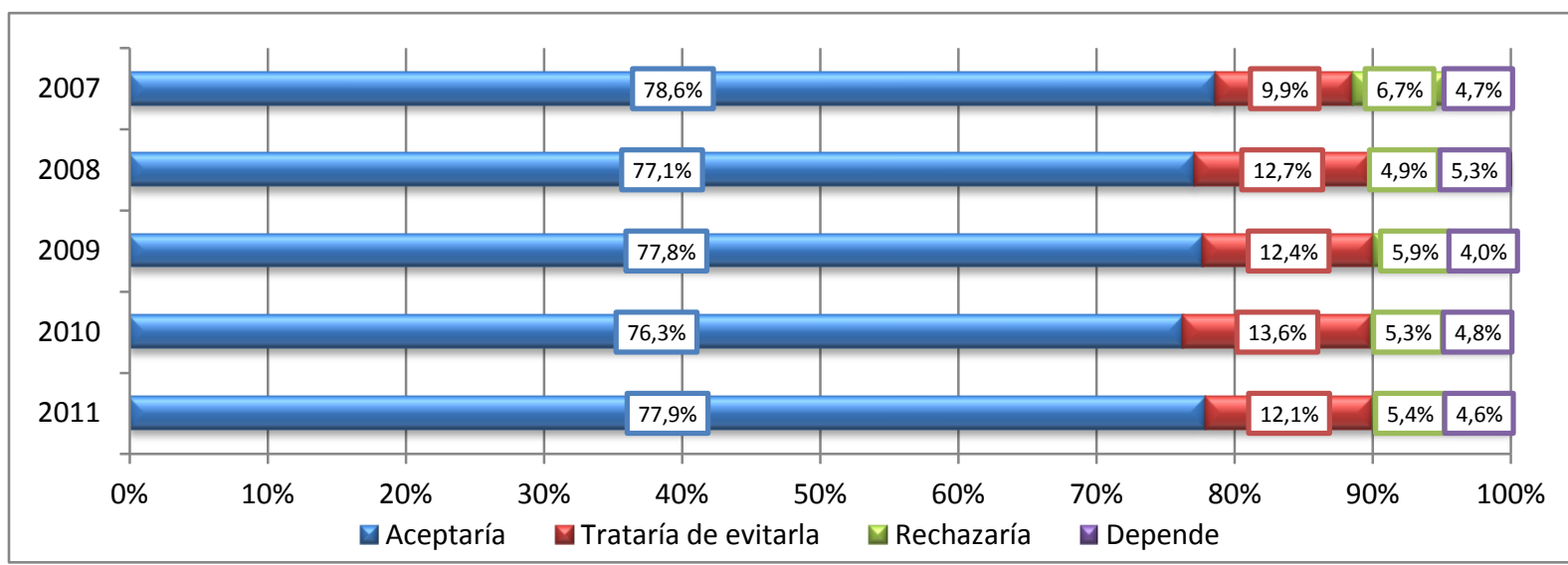

Fuente: Elaboración propia con datos del CIS; estudios 2731(2007), 2773 (2008), 2817 (2009), 2846 (2010) y 2918 (2011).

Indagando sobre el perfil de la población que rechazaría que una persona inmigrante sea su jefe en el trabajo, se detecta que el nivel de estudios influye, ya que las personas sin estudios rechazarían un $12,2 \%$ el trabajo, mientras que quienes tienen estudios superiores únicamente el 2,2\%. Así como la situación laboral, puesto que el $6,5 \%$ de las personas desempleadas rechazarían un trabajo en el que su jefe fuese inmigrante, mientras que el $4,5 \%$ de las personas que trabajan lo rechazaría. Esto se debe a la idea en el imaginario colectivo del inmigrante económico, que ocupa puestos del sector secundario -según la teoría de la dualidad del mercado laboralpor lo cual aceptar un trabajo en el que el inmigrante sea el jefe sería un empleo de paupérrimas condiciones socio-laborales. En cuanto al contacto con inmigrantes, aquellas personas que tienen en la actualidad compañeras y/o compañeros de trabajo y/o estudios inmigrantes solamente el $2,9 \%$ rechazarían un trabajo en el que su jefe sea inmigrante, mientras que quienes no tienen compañeras y/o compañeros inmigrantes lo rechazaría un $5,3 \%{ }^{47}$.

Dando un paso más, se realiza un análisis de correspondencias en el cual se observa que ante la situación de que una persona inmigrante sea su jefe en el trabajo, el nivel de estudios ayuda a explicar la percepción sobre la inmigración. De hecho, a menor nivel educativo mayor rechazo a la idea tener un trabajo en el que un inmigrante sea su jefe. La población que no tiene estudios reglados rechazarían un trabajo donde el jefe sea inmigrante; mientras que aquellas personas que tienen un nivel de estudios primarios no se asocia directamente con una categoría, sino

47 Significación del chi-cuadrado $0,00 \%$. Por lo que se rechaza la hipótesis nula (no hay relación) y se acepta la asociación entre las variables. Datos del estudio 2918 (2011). 
que se sitúa equidistante entre que trataría de evitar la situación y que dependiendo de las circunstancias, así tendría un trabajo en el que un inmigrante fuese su jefe. Tanto la población que tiene estudios secundarios como quienes tienen estudios medios universitarios y superiores aceptarían el trabajo. ${ }^{48}$

La asociación entre las variables, se puede deber a que la sociedad española tiene la percepción de que un trabajo en el que una persona inmigrante sea su jefe, -teniendo en consideración el imaginario colectivo del inmigrante económico-, estaría por debajo de sus expectativas y se generaría una distorsión entre el "nosotros" y el "otros". Mientras que a mayor nivel de estudios y por tanto probablemente de cualificación, no es tan imperante la necesidad de diferenciación entre grupos.

Gráfico 33: Correspondencias entre el nivel de estudios y que una persona inmigrante sea su jefe.

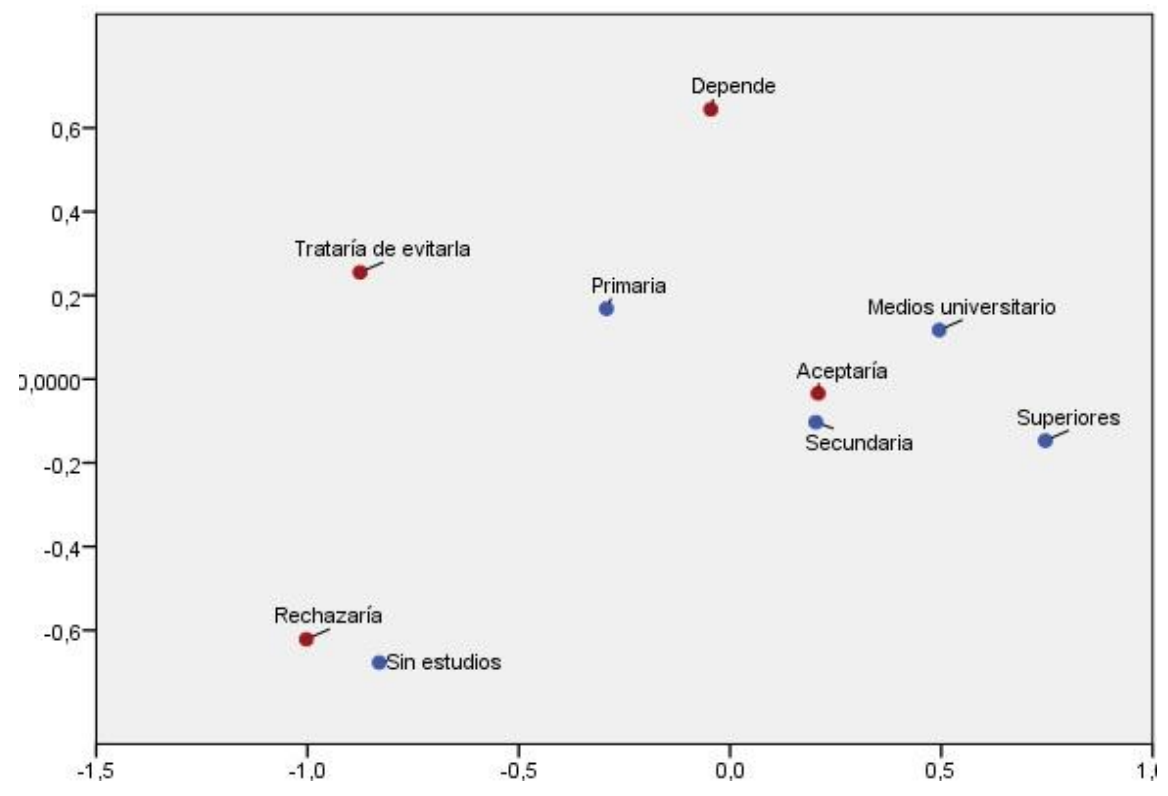

Fuente: Elaboración propia con datos del CIS del estudio 2918 (2011).

\section{ACTITUDES ANTE LA INMIGRACIÓN EN LAS RELACIONES FAMILIARES.}

En la actitud de la inmigración en la vida cotidiana en el ámbito de las relaciones familiares, se estudian tres casos: llevar a su hija y/o hijo a un colegio donde haya muchas niñas y niños hijas e hijos de inmigrantes; que su hija y/o hijo lleve amigas

48 Significación del chi-cuadrado $0,00 \%$. Por lo que se rechaza la hipótesis nula (no hay relación) y se acepta la asociación entre las variables. Datos del estudio 2918 (2011). 
y/o amigos inmigrantes a casa; y que su hija y/o hijo se case con una persona inmigrante.

En la primera situación, es decir, el hecho de llevar a su hija y/o a un colegio en el que haya muchas niñas y niños que sean hijas e hijos de inmigrantes se mantiene una tendencia estable en el periodo estudiado. Se observa que en 2008, el 63,9\% de la población española aceptaría la situación, la cual va descendiendo el apoyo de la ciudadanía hasta el 58,6\% en 2010. Al siguiente año se experimenta un leve ascenso al 59,8\% de población que aceptaría llevar a su hija y/o a un colegio en el que haya muchas niñas y niños que sean hijas e hijos de inmigrantes. A su vez, se produce un incremento de población que trataría de evitar llevar a su hija y/o a un colegio en el que haya muchas niñas y niños que sean hijas e hijos de inmigrantes. En 2008 era el 25,0\% y va aumentando hasta el 29,6\% en 2010, que desciende al 28,0\% en 2011 la ciudadanía que trataría de evitarlo. La sociedad española que rechazaría llevar a su hija y/o a un colegio en el que haya muchas niñas y niños que sean hijas e hijos de inmigrantes sufre altibajos, era en 2008 el 7,2\% y disminuye al 6,2\% en el año siguiente. En 2010 aumenta al 7,7\% y al siguiente año desciende al $7,3 \%$ la población que rechazaría la situación. Mientras que la población que cree que depende de la situación y de las circunstancias aumenta progresivamente del $3,9 \%$ al 4,9\% en el periodo de 2008 al 2011.

Gráfico 34: Llevar a su hija y/o hijo a un colegio donde haya muchas niñas y niños hijas e hijos de inmigrantes (2008 a 2011).

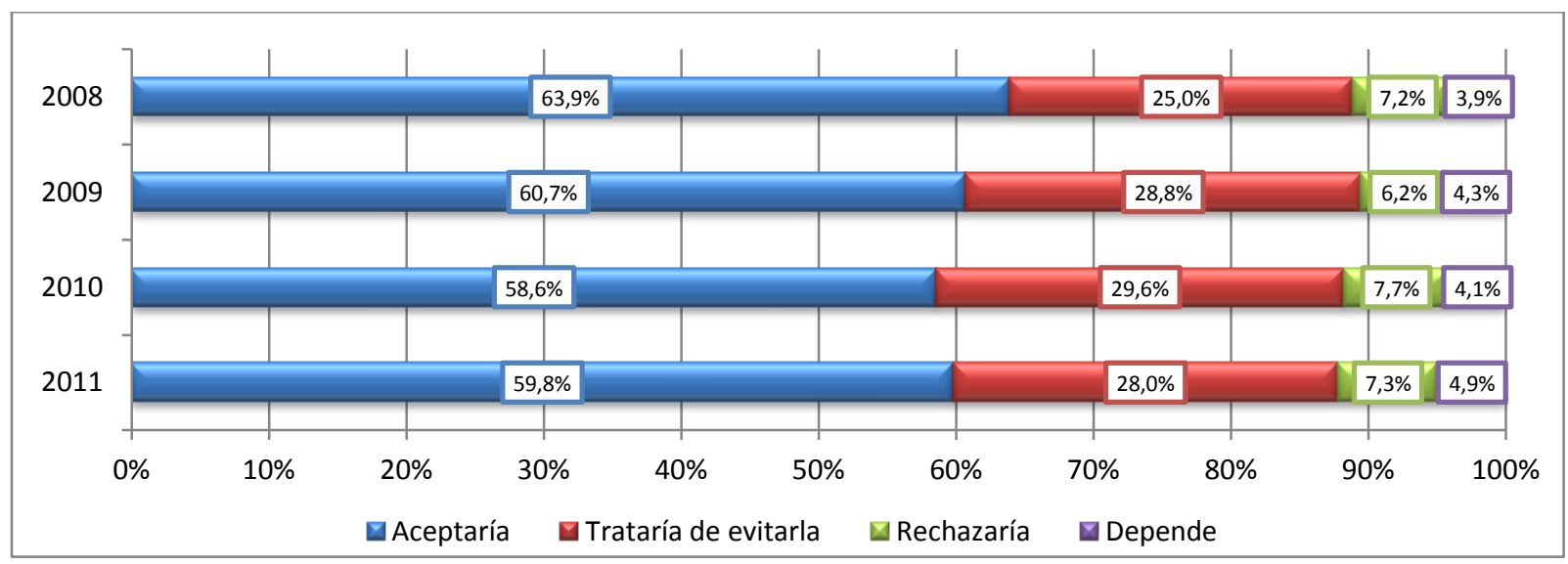

Fuente: Elaboración propia con datos del CIS; estudios 2773 (2008), 2817 (2009), 2846 (2010) y 2918 (2011).

En un análisis del perfil de la ciudadanía que rechazaría llevar a su hija y/o hijo a un colegio en el que haya muchas niñas y niños que sean hijas e hijos de inmigrantes. Se aprecia que la edad es un factor a tener en consideración, ya que el rechazo 
aumenta al igual que la edad, el 3,6\% de los jóvenes entre 18 y 24 años rechazarían llevar a su hija y/o hijo a un colegio haya muchas niñas y niños que sean hijas e hijos de inmigrantes, mientras que el 9,5\% de los mayores de 65 años lo rechazarían. Aquí hay un elemento a tener en cuenta, la posibilidad de que las personas más jóvenes no hayan tenido que plantearse este tipo de decisiones al no convertirse en padres. Otro factor que influye es la ideología, las personas de una ideología de izquierdas no muestra tanto rechazo como las personas de derechas al llevar a su hija y/o hijo a un colegio haya muchas niñas y niños que sean hijas e hijos de inmigrantes; de hecho el 3,8\% de las personas de extrema de izquierda rechazaría llevar a su hija y/o hijo a un colegio haya muchas niñas y niños que sean hijas e hijos de inmigrantes, mientras que el $15,2 \%$ de las personas de extrema derecha lo rechazaría. En referencia al contacto con inmigrantes, quienes tienen familiares inmigrantes rechazaría llevar a su hija y/o hijo a un colegio haya muchas niñas y niños que sean hijas e hijos de inmigrantes un 3,9\% mientras que quienes no tienen familiares inmigrantes lo rechazarían un $8,0 \%{ }^{49}$.

Respecto a la opinión de la población española sobre sí la calidad de la educación empeora en los colegios donde hay muchas hijas y/o hijos de personas inmigrantes. Se observa que la población que está muy de acuerdo con la afirmación no ha cambiado de 2008 a 2011, ya ambos años poco menos de una cuarta parta de la población está muy de acuerdo. Se aprecia un aumento entre la población que está muy en desacuerdo con que la calidad de la educación empeora en los colegios donde hay muchas hijas y/o hijos de personas inmigrantes, pasando del $14,1 \%$ en 2008 al $16,5 \%$ en 2011.

El capital cultural influye en la elección del centro educativo de las hijas e hijos, de hecho la clase alta o media alta tiene preferencia por los centros educativos privados o concertados, aunque como se ha observado con anterioridad, las clases sociales más elevadas muestran actitudes más favorables a la inmigración. La explicación deriva de que son las más proclives al sesgo de la deseabilidad social puesto que tienen unos mayores conocimientos para percibir la intencionalidad de la pregunta y están más interesadas en no mostrarse racistas o xenófobas (Krysan, 1998).

\footnotetext{
${ }^{49}$ Significación del chi-cuadrado $0,00 \%$. Por lo que se rechaza la hipótesis nula (no hay relación) y se acepta la asociación entre las variables. Datos del estudio 2918 (2011).
} 
En referencia a la concentración de alumnado inmigrante, esto fenómeno se produce más en centros públicos que privados. Sin embargo el llamado "efecto de los compañeros" es decir, los efectos reales que una parte del alumnado produce sobre otra parte, como resultado de la interacción en el aula y en el centro, según el análisis del informe PISA 2009, no hay un efecto de los compañeros negativo por la concentración de inmigrantes en las aulas y en los centros. (Carabaña, 2012).

En la segunda situación, que su hija y/o hijo lleve amigas y/o amigos inmigrantes a casa tiene una aceptación considerable en la sociedad española. En 2007, el 77,5\% de la población aceptaría que su hija y/o hijo lleve amigas y/o amigos inmigrantes a casa. Este porcentaje va disminuyendo, ya en el 2010 es el 75,5\% de la ciudadanía quienes aceptan que su hija y/o hijo lleve amigas y/o amigos inmigrantes a casa; en 2011 aumenta al 77,8\%. Por el contrario, la ciudadanía que rechazaría que su hija y/o hijo lleve amigas y/o amigos inmigrantes en 2007 era el 5,5\% y desciende al $3,8 \%$ quienes rechazarían que su hija y/o hijo lleve amigas y/o amigos inmigrantes a casa en 2011. Por lo tanto, se mantiene en el tiempo la tendencia.

En el segundo caso, que su hija y/o hijo se case con una persona inmigrante tiene una aceptación elevada, pero menor al caso estudiando con anterioridad. En el 2007 el $65,3 \%$ de la población aceptaría que su hija y/o hijo se casase con una persona inmigrante; estos datos van descendiendo hasta el 62,3\% en el 2010 y al siguiente año aumenta al 66,3\% la población aceptaría que su hija y/o hijo se casase con una persona inmigrante. La ciudadanía que trataría de evitar que su hija y/o hijo se casase con una persona inmigrante sufre un aumento, ya que en 2007 era el 13,7\% de la población española quien trataría de evitarlo y aumenta progresivamente al 20,0\% en 2010; y al siguiente año desciende al 17,9\%. La población que rechazaría que su hija y/o hijo se casase con una persona inmigrante decrece lentamente, del 9,7\% en 2007 al 7,8\% de la ciudadanía española rechazaría que su hija y/o hijo se casase con una persona inmigrante en 2011. Para quienes creen que depende de la situación, hay un descenso del $11,3 \%$ al $8,0 \%$ en el periodo examinado.

Como muestran los datos del gráfico 35, la opinión de la sociedad española en relación a que su hija y/o hijo se casase con una persona inmigrante es estable; a excepción de 2010, año en el que se produce un descenso considerable de la población que aceptaría que su hija y/o hijo se casase con una persona inmigrante. 
Así como un aumento de quienes tratarían de evitarlo y para quienes depende de la situación, es decir, hay un aumento de medidas más cautas y dubitativas. Esto se puede explicar debido a que 2010 fue un año especialmente duro de la crisis económica y el primer foco de responsabilidad fue la población inmigrante.

Tras conocer la opinión de la ciudadanía española respecto a que su hija y/o hijo se case con una persona inmigrante, es interesante conocer la evolución de los matrimonios mixtos en España durante el periodo de 2007 a 2011. En 2007, los estos enlaces representan el 13,2\% del total de matrimonios en España; en 2009 sufren un aumento al situarse en el $17,2 \%$, cifra que se mantiene estable en el siguiente año. En 2011 se produce una caída al 16,3\% de los matrimonios mixtos en España ${ }^{50}$. Dichos datos muestran un incremento en los matrimonios mixtos, que también se ve correspondido con posturas más favorables de la sociedad española ante que su hija y/o hijo se case con una persona inmigrante, esto puede deberse a un descenso del prejuicio por el contacto con la inmigración.

Gráfico 35: Que su hija y/o hijo se case con una persona inmigrante (2007 a 2011).

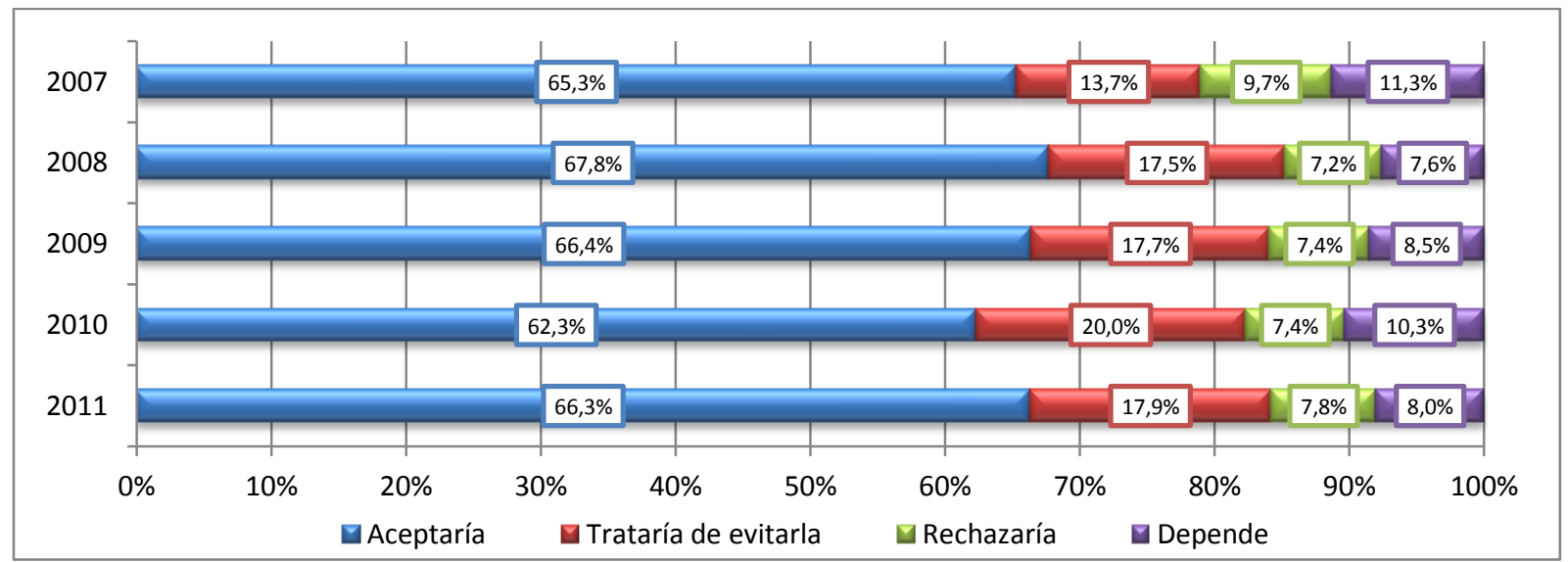

Fuente: Elaboración propia con datos del CIS; estudios 2731(2007), 2773 (2008), 2817 (2009), 2846 (2010) y 2918 (2011).

Profundizando en esta temática, se realiza un análisis de correspondencias entre que su hijo y/o hija se casase con una persona inmigrante y la ideología, en el cual se extrae que las personas de una ideología más a la derecha rechazarían el enlace. Así pues, la población que rechazaría que su hijo y/o hija se casase con una persona inmigrante está muy relacionado con las personas que se consideran ideológicamente de extrema derecha. Mientras que la población que cree que

50 Datos extraídos del Movimiento Natural de Población del INE. 
depende del contexto y situación para aceptar o rechazar que su hijo y/o hija se casase con una persona inmigrante, es la ciudadanía que se considera ideológicamente de centro. Por el contrario, la población que aceptaría el matrimonio de su hijo y/o hija con una persona inmigrante son quienes se ubican ideologías de centro izquierda y extrema izquierda. Por lo cual, la población que tiene posturas más beligerantes sobre que su hijo y/o hija se casase con una persona inmigrante, son aquellas que se posicionan más a la izquierda ideológica ${ }^{51}$.

Gráfico 36: Correspondencias entre ideología y que su hija/o se case con una persona inmigrante.

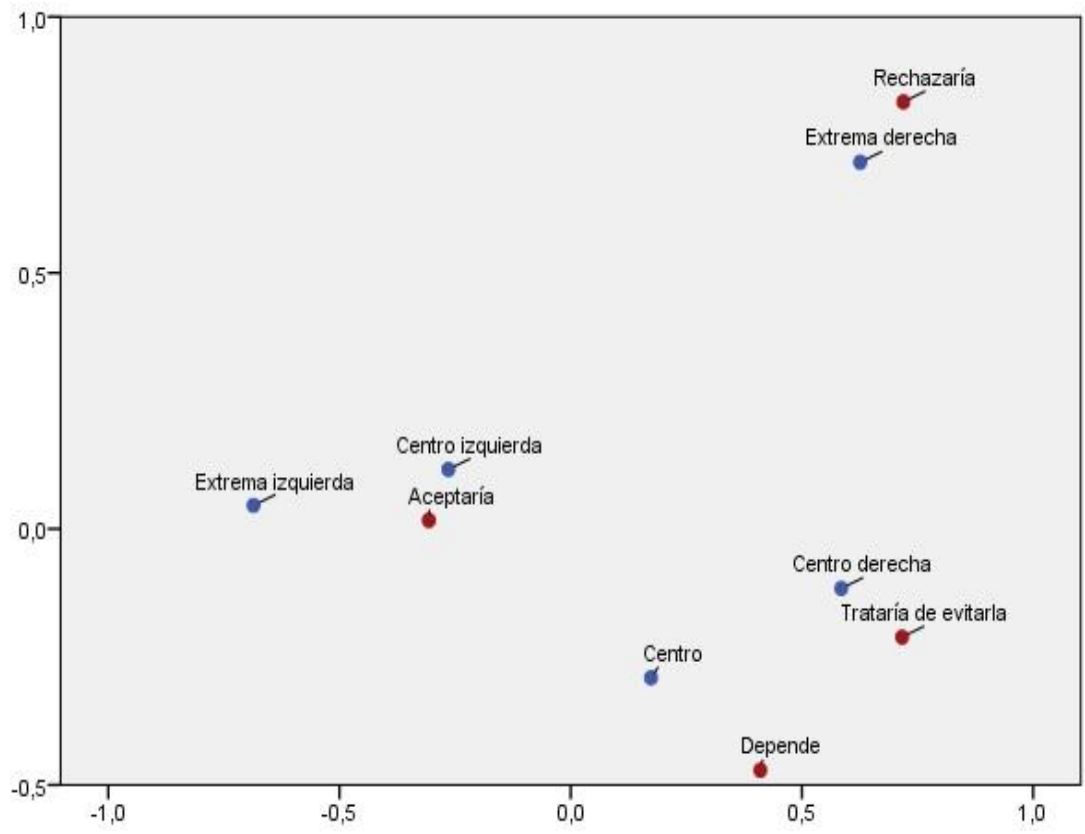

Fuente: Elaboración propia con datos del CIS del estudio 2918 (2011).

\section{SIMPATÍA-ANTIPATÍA DEPENDIENDO DE LOS GRUPOS DE NACIONALIDADES DE LAS PERSONAS INMIGRANTES.}

Por otro lado, para continuar con el propósito de identificar las actitudes ante la inmigración en la vida cotidiana; se va a proceder en primer lugar a examinar las nacionalidades que causan más simpatía y cuales más antipatía en la ciudadanía española; y en segundo lugar cuáles son las causas que despiertan la antipatía en la sociedad.

\footnotetext{
${ }^{51}$ Significación del chi-cuadrado $0,00 \%$. Por lo que se rechaza la hipótesis nula (no hay relación) y se acepta la asociación entre las variables. Datos del estudio 2918 (2011).
} 
En el primer caso, los grupos de nacionalidades que causan más simpatía entre la sociedad española son las personas latinoamericanas, aunque este colectivo ha ido perdiendo peso en simpatía. De hecho en 2008, representaban el 62,4\% de la simpatía de la sociedad ante las personas inmigrantes y ha ido descendiendo hasta el 53,6\% en 2011. Las causas del descenso en la simpatía de la ciudadanía española puede deberse a la llegada de personas latinoamericanas y su inserción en la sociedad española. Otro grupo de nacionalidades por el que la sociedad tiene simpatía son las personas subsaharianas que incrementan su buena consideración del $13,3 \%$ en 2008 al $16,3 \%$ en 2011.

Además de ello, es significativo el aumento de población que reconoce que ningún grupo de nacionalidades le inspira simpatía. En 2008 era el 25,3\% de la población quienes tenían esa postura y al siguiente año aumenta hasta el 53,7\%; a partir de ahí, comienza a descender hasta el 47,6\% de la población -véase el gráfico 17 del anexo de resultados-. Por lo cual, se observa que para casi la mitad de la ciudadanía española no hay ningún grupo de nacionalidades que le provoque simpatía.

En el segundo caso, los grupos de nacionalidades que inspiran más antipatía en la sociedad española son las personas magrebíes. En 2008, el 45,4\% de la ciudadanía española reconocía que el grupo de nacionalidades que más antipatía le generaba eran las personas magrebíes, al año siguiente disminuye ligeramente al 44,3\% y posteriormente va en aumento. En 2011 era el 48,9\% de la población para quienes las personas magrebíes eran el grupo de nacionalidades que le causan más antipatía. Ramírez Goicoechea (1996) afirma que "el inmigrante marroquí destaca como el más rechazado por la población autóctona, puesto que representa el epítome de la extranjería social y cultural para el ciudadano español. Es el banco de prueba de nuestra concepción liberal o no, del contacto entre grupos étnicos. Incluso más que en el caso de africanos de color". En relación a la ciudadanía de la Europa del este, en 2008 el 38,5\% de la población española señalaba a este grupo como quienes más antipatía les generaba. Este porcentaje de población a quienes la ciudadanía de la Europa del este les creaba antipatía ha ido disminuyendo progresivamente hasta el $36,9 \%$ en el 2011. Así como, la antipatía hacia las personas asiáticas que aumenta del 2,9\% al 4,1\% en el periodo de 2008 a 2011. 
Gráfico 37: Grupos de nacionalidades que causan más antipatía (2008 a 2011).

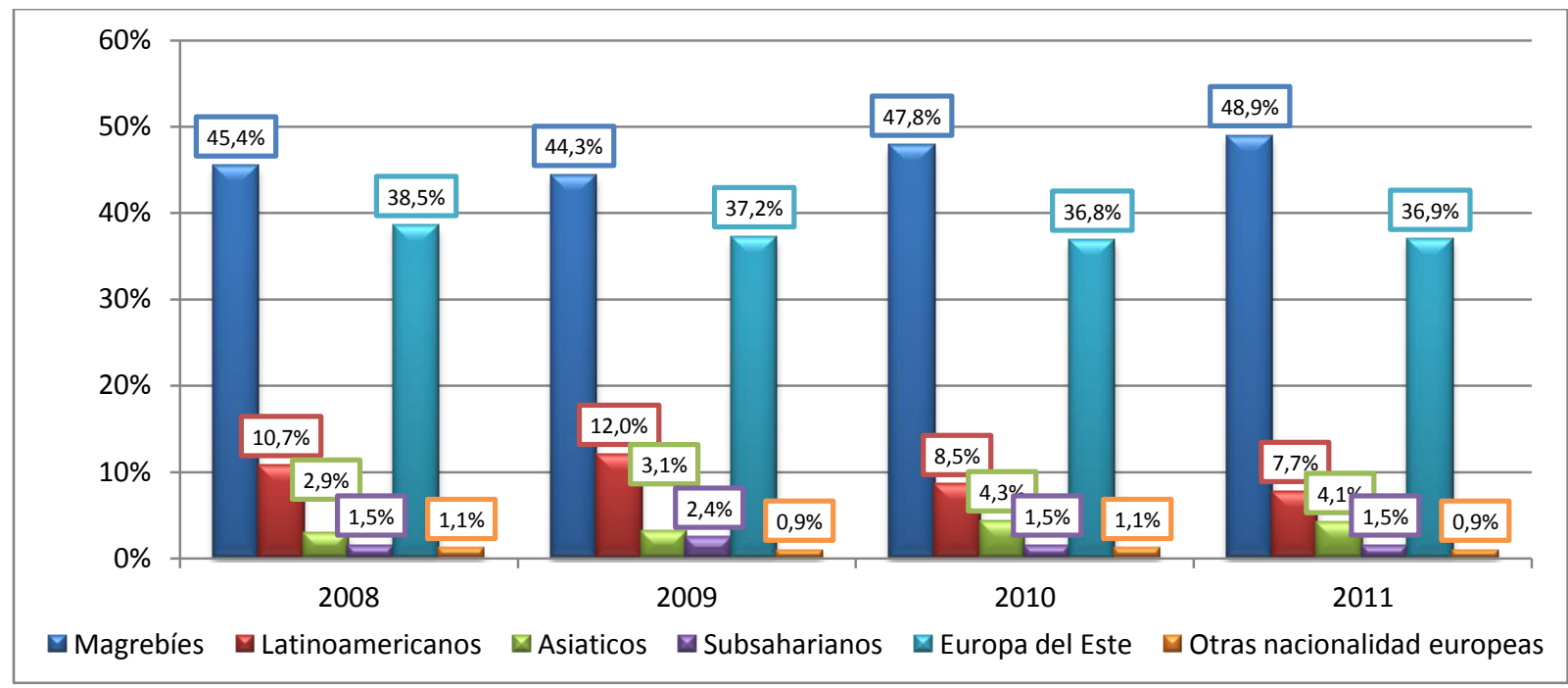

Fuente: Elaboración propia con datos del CIS; estudios 2773 (2008), 2817 (2009), 2846 (2010) y 2918 (2011).

Desagregando los grupos de nacionalidades por países, hay dos países cuya ciudadanía es la que genera más antipatía entre la población española. Por un lado, las personas rumanas que en 2008 causan antipatía al 32,7\% de la sociedad española, al siguiente año descienden al 29,6\% y los sucesivos años se mantienen en el $31,2 \%$ de la población española para quienes las personas rumanas son las que más antipatía les causa. Por otro lado, la nacionalidad que más antipatía causa en la sociedad española son las personas marroquíes con el $22,4 \%$ en 2008 . En 2010 desciende al 19,8\%; y es en el 2011 donde tiene el pico más elevado con el $23,8 \%$ de la sociedad española para quienes las personas marroquíes son la nacionalidad que más antipatía les inspira.

Por otro lado, la sociedad española afirma que existen grupos de nacionalidades que no les causa simpatía aludiendo a una razón. El motivo mayoritario de la antipatía en el periodo de 2009 a 2011 es la vinculación que se realiza de la inmigración con la delincuencia (mafias, bandas organizadas, agresivos etc.) con el 35,8\% en 2009, esta razón va aumentando hasta el 37,9\% en 2011. Seguido de motivos peyorativos unidos a la inmigración (que son sucios, maleducados, vagos etc.), esta causa disminuye del 19,0\% en 2009 al 14,2\% en 2011 como se muestra en el gráfico 38. La construcción social de la inmigración, se acuña en gran parte bajo esta serie de estereotipos y prejuicios que se van reproduciendo; a su vez, también influenciados por la repercusión en el filtrado de noticias que le otorguen los medios de comunicación. 
Gráfico 38: Razones por las que las personas inmigrantes causan antipatía (2009 a 2011).

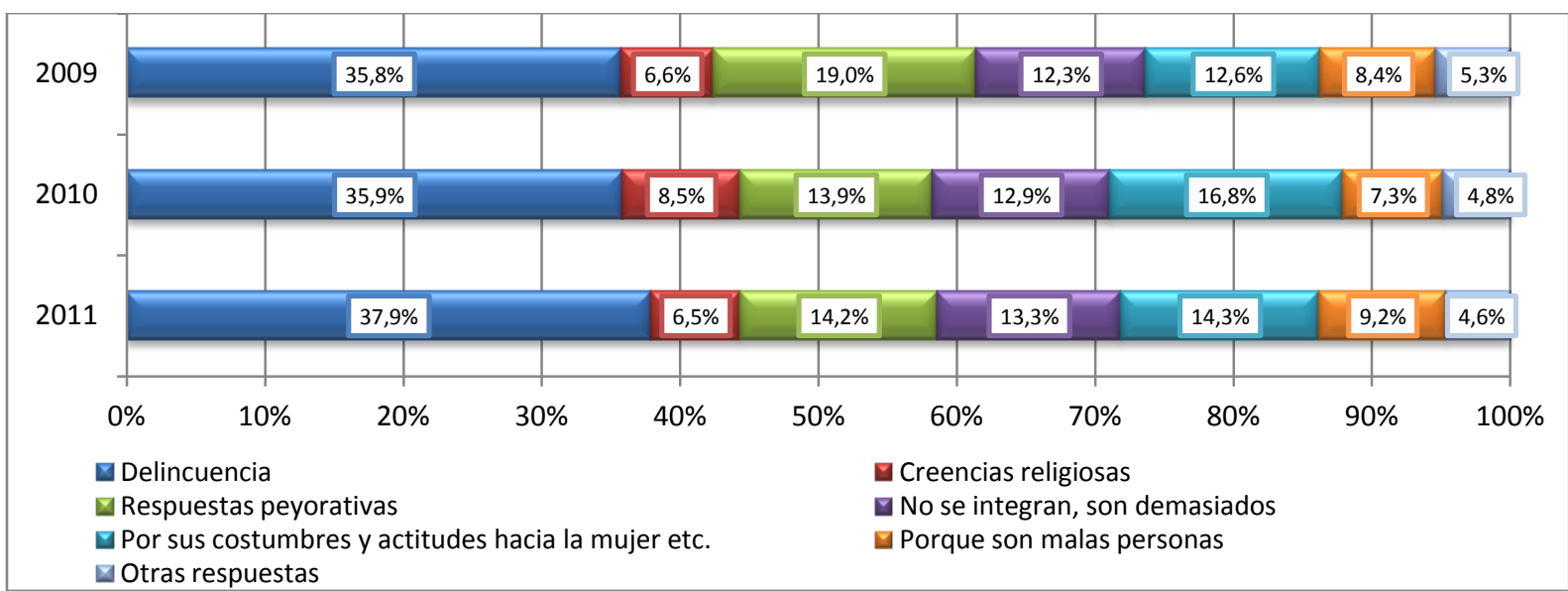

Fuente: Elaboración propia con datos del CIS; de los estudios 2817 (2009), 2846 (2010) y 2918 (2011).

A los grupos de nacionalidades se les relaciona con algunas razones de antipatía, en el caso de las personas magrebíes el $19,9 \%$ de la población las asocia con la delincuencia; seguido del $18,8 \%$ de la población que los relaciona con la falta de integración y con ser demasiados. En relación a las personas latinoamericanas, el $33,3 \%$ de la población las identifica con la delincuencia, especialmente con las disputas entre bandas callejeras; así como otro 33,3\% de la población con actitudes peyorativas (que son sucios, maleducados, vagos etc.). En lo que respecta a las personas de origen asiático, un $47,4 \%$ de la población las asocia con el hecho de que no se integran y son que demasiados; así como un 26,3\% de la población los relaciona con motivos peyorativos. Sobre las personas subsaharianas, un $29,4 \%$ de la población también se las relaciona con causas peyorativas, seguido de un $23,5 \%$ de la población que ven como motivo negativo sus costumbres y las actitudes ante las mujeres. Respecto a las personas de la Europa del este, un 69,0\% de la población las vincula con la delincuencia, así como un $12,3 \%$ con razones peyorativas $^{52}$. Estos motivos negativos con los que se relaciona a los grupos de nacionalidades son la representación creada en el imaginario colectivo de la sociedad, basados en estereotipo, así como señala Alsina (1996) son "generalizaciones simplistas que forman parte de un sentido común o comunitario de una cultura determinada" sirven para hacer comprensible un fenómeno del que no tenemos suficiente conocimiento.

52 Significación del chi-cuadrado $0,00 \%$. Por lo que se rechaza la hipótesis nula (no hay relación) y se acepta la asociación entre las variables. Datos del estudio 2918 (2011). 


\section{F. ANÁLISIS DE LOS PERFILES DE LA POBLACIÓN ANTE LA INMIGRACIÓN (2011).}

Después de realizar un análisis longitudinal -2007 a 2011- sobre la evolución de las percepciones ante la inmigración en la sociedad española, se ha apreciado, especialmente en los análisis bivariantes y multivariantes de la presente investigación, unas variables sociodemográficas que se asociaban explicando ciertas actitudes ante la inmigración. Estas variables son: la edad, los ingresos mensuales, la ideología, el grado de confianza hacia los demás, la clase social y el nivel de racismo. Al hilo de esto, se ha realización de un árbol de segmentación con el método CHAID con el objeto de detectar los diferentes perfiles de la sociedad española ante las actitudes hacia la inmigración. La variable dependiente que se utilizó para el análisis es la valoración de la población española sobre el fenómeno de la inmigración como positiva o negativa para España.

La primera división que se realiza en el análisis de segmentación es en función de la variable del nivel de racismo y a partir de ahí, se establecen tres perfiles:

Reacios a la inmigración ${ }^{53}$ : Dividido en primera estancia por las personas muy racistas (negativa 83,5\%); la siguiente subdivisión se produce por el nivel de estudios en dos nodos. El primero agrupa los estudios secundarios y universitarios (negativa 72,9\%) y el segundo nodo corresponde al nivel de estudios primarios (negativa 90,2\%). La clasificación se da por finalizada al estar el perfil definido. La población que tiene posturas más negativas hacia la inmigración son quienes se consideran muy racistas y tienen un nivel de estudios bajo -estudios primarios o sin estudios-.

Ambivalentes respecto a la inmigración: La primera clasificación del perfil ambivalente, se produce entre la población que no se considera ni muy poco ni muy racista (positiva $26,3 \%$ y negativa $73,7 \%$ ); posteriormente se subdivide por el grado de confianza en dos nodos. El primero clasifica a quienes son personas desconfiadas (positiva 13,4\% y negativa 86,6\%); y el segundo nodo agrupa a quienes no son ni desconfiadas y ni confiadas y las personas confiadas (positiva $36,8 \%$ y negativa $63,2 \%$ ). El perfil queda definido y no se necesitan más nodos para

53 Se ha utilizado para la presente investigación la misma nomenclatura para los perfiles que el proyecto Mexees (2009). 
explicarlo. El perfil corresponde a la población que tiene una postura intermedia en su nivel de racismo y su grado de confianza hacia el resto de personas es intermedio y/o confiado. Se observa que el perfil ambivalente respecto a la inmigración se asemeja al perfil rehaceos, puesto que las posturas negativas son imperantes en todos los nodos.

Tolerantes a la inmigración: La primera división que se realiza es entre la población que se considera poco racistas (positiva 60,8\%). La segunda subdivisión se realiza por el nivel de estudios generando tres nodos. El primer nodo, corresponde al nivel de estudios secundario (positiva $69,4 \%$ ), y se realiza una tercera división entre la ideología, quedando un nodo con ideología de derecha y centro $(59,7 \%)$ y otro nodo con ideología de izquierda (positiva 81,9\%). El segundo nodo, es sobre el nivel de estudios primarios (positiva 45,1\%), y se subdivide en tres nodos dependiendo del grado de confianza. Las personas que son desconfiadas (positiva 34,3\%), las personas ni desconfiadas ni confianzas (positiva 47,7\%) y las confiadas (positiva $58,4 \%$ ). El tercer nodo, atañe al nivel de estudios universitarios (positiva 83,0\%), se subdivide en dos nodos en función del grado de confianza, las personas que son desconfiadas (positiva 60,8\%) y quienes no son ni desconfiadas ni confiadas y confiadas (positiva 88,8\%). Se finalizan las subdivisiones apreciando que el perfil tolerante es más complejo al necesitarse más nodos para explicar dicho perfil, e incluso se podrían definir subperfiles. Por lo cual, el perfil que mejor explica la segmentación del perfil tolerante es el referente a la población poco racista, con un nivel de estudios superiores y confiadas e intermediamente confiadas.

Una vez detectados los perfiles de la población española ante la inmigración, en el análisis longitudinal realizado de 2007 a 2011, se observa como disminuyen las posturas ambivalentes hacia posicionamientos más reacios hacia la inmigración, quedando estables los perfiles tolerantes hacia la inmigración. Por tanto se recrudece la actitud negativa ante el hecho migratorio. Además de ello, indagando sobre los perfiles de actitudes que se han extraído de esta investigación se muestra que el perfil reacio con la inmigración es fruto de una clara diferenciación entre los "otros" y el "nosotros". De hecho el perfil se explica con la utilización de dos subdivisiones en base al nivel de racismo y del nivel educativo. Tanto es así que las actitudes negativas hacia la inmigración se producen entre las mismas minorías 
étnicas y quienes tienen una menor clase social; probablemente esto se pueda deber al temor a perder su posición social por la llegada nuevos competidores inmigrantes (Colectivo IOÉ, 2005). Este perfil está influenciado por el capital cultural -la importancia del capital cultural es básica porque se perpetúan o se diluyen las prenociones y/o prejuicios-. El nivel de estudios bajo normalmente se relaciona con empleos poco cualificados, que justamente son los que realizan los inmigrantes económicos destinados al sector secundario. De ahí deriva la construcción de la diferencia que realizan los individuos del perfil reacios, puesto que en la competitividad del mercado laboral se sienten amenazados, más aun en una situación de destrucción de empleo como la actual, en el que los sectores productivos más afectados por la crisis económica son los que tradicionalmente emplean a personal poco cualificado -construcción y sector servicios-. El "nosotros" se estructura en base al alineamiento de la clase social obrera para defender sus privilegios respecto a los inmigrantes económicos.

Así como el perfil ambivalente muestra posturas menos marcadas respecto a la percepción de la inmigración, que se aproxima a posiciones más negativas que positivas, muy probablemente influenciado por el contexto de crisis económica. Mientras que el perfil tolerante corresponde a un tipo de población, que no se siente amenazada por la inmigración económica, sino que en muchos casos se valen de los "otros" como ejército de reserva. Además de ello, el capital cultural de este perfil es más elevado y poseen las herramientas suficientes para que al medir sus opiniones estén más en consonancia con la deseabilidad social, evitando expresar actitudes racistas o xenófobas típicas del racismo tradicional. 
Gráfico 39: Árbol de segmentación de perfiles de la población ante la inmigración.

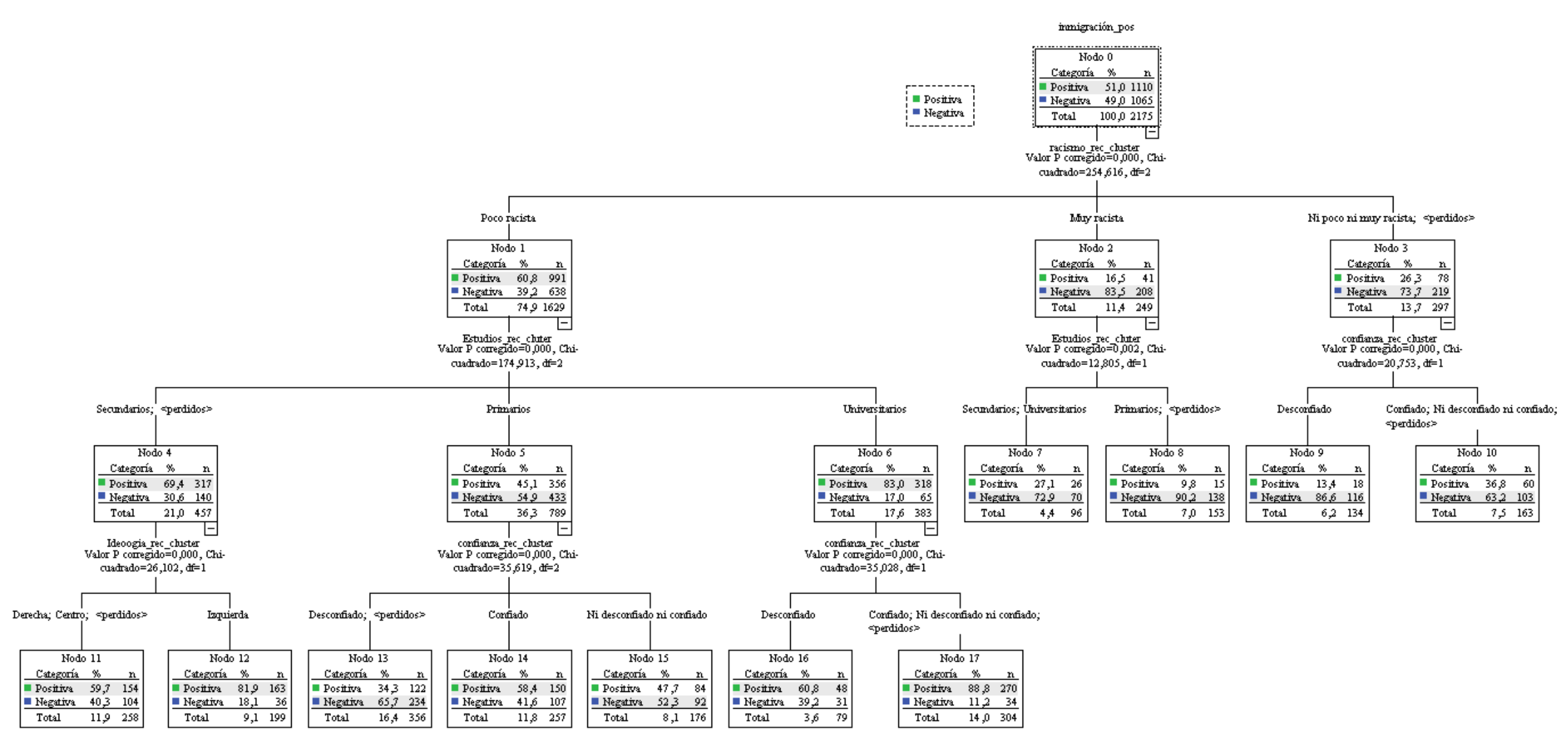

Fuente: Elaboración propia con datos del CIS del estudio 2918 (2011). 


\section{CONTRASTE DE HIPÓTESIS}

El análisis longitudinal muestra que durante el periodo objeto de estudio de la presente investigación -2007 a 2011-, la tendencia que se venía apuntando desde 2007 se ha consolidado o agudizado, en cuanto a la percepción de la sociedad española respecto a la inmigración. Especialmente estos cambios se agravan en el año 2010, donde se produce una radicalización en la tendencia que incrementa las conductas xenófobas y racistas de la población. Probablemente esto se deba a la visibilización de los efectos de la crisis económica, lo cual generó que la inmigración fuese el primer objeto de crítica, es decir el chivo expiatorio, sobre la deriva del país. A continuación se detallará con más precisión dicha tendencia.

En primer lugar, se observa que el periodo objeto de estudio, la representación social de la inmigración es más negativa que en el inicio del periodo. Esto se manifiesta en actitudes de la sociedad española ante la inmigración, especialmente en el mercado laboral. La población asocia la palabra inmigración con la necesidad de tener que trabajar, lo cual es una referencia directa al inmigrante económico. Examinado los aspectos positivos con los que la sociedad valora a la inmigración, disminuye el hecho de que sean mano de obra, posiblemente por la reducción de empleo en España, situación que ha generado que la población autóctona opte a desempeñar los puestos de trabajo antes ocupados por inmigrantes. Así mismo el aspecto más negativo que la población observa de la inmigración es la competitividad que genera en el mercado laboral, hecho que se relaciona con la idea anterior, la población autóctona percibe que debe competir por los mismos puestos de trabajo. Además de ello, aumenta la población que cree que la inmigración quita puestos de trabajo a la población autóctona, así como disminuye la ciudadanía que cree que las personas inmigrantes realizan trabajos que la población autóctona no quiere realizar. Por lo cual, se corrobora la hipótesis específica 1 de esta investigación -la representación social de la inmigración tiende a ser negativa, especialmente en el mercado laboral, en crisis económica-.

En segundo lugar, se muestra que en el periodo estudiado, la población española sobre-representa el volumen de población inmigrante en España. Si bien es cierto, que está sobre-representación es más elevada en 2007 que en 2011, este hecho, se puede explicar por la reducción de la atención de los medios de comunicación sobre 
la inmigración a favor de temáticas relacionadas con la crisis económica, puesto que el número de inmigrantes empadronados siguió aumentando de 2007 a 2011 . En relación a los grupos de nacionalidades, se observa que los dos colectivos más numerosos -latinoamericanos y magrebíes- son percibidos de manera diferente por la sociedad española, mientras que el colectivo latinoamericano es infrarepresentado, el colectivo magrebí es sobre-representado por la población. La explicación puede estar vinculada a que la visibilización de las personas magrebíes es mayor -diferente religión, cultura, costumbres, idioma-, así como, por el contrario, la población latinoamericana está invisibilizada, al compartir rasgos y vínculos comunes con la sociedad española. Por tanto, la hipótesis específica 2 -la población sobre-representa la inmigración, principalmente a los grupos de nacionalidades más visibles- es confirmada.

En tercer lugar, se aprecia que la sociedad ha girado de posiciones ambivalentes a reacias con la inmigración, ejemplo de ello, es la percepción de la legislación en materia migratoria en el que aumenta la posición de que es demasiado tolerante, en detrimento de la opinión de que es más bien tolerante, en el periodo de 2008 a 2011. Respecto a la ayuda del Estado a las personas inmigrantes, se aprecia un incremento de posiciones adversas hacia en la inmigración, ya que la sociedad cree que de los grupos vulnerables en España, las personas inmigrantes son el que más ayuda reciben; así como, que son el grupo que menos aporta al Estado y más recibe del mismo. Estas posturas se incrementan considerablemente de 2008 a 2011; probablemente por la crisis económica que sufre el país, en la que la inmigración ha sido utilizada como el chivo expiatorio para comprender la reducción de derechos y prestaciones socio-laborales. La hipótesis específica 3 -la construcción de la diferencia se incrementa en épocas de recesión económica, al convertir a la inmigración en el chivo expiatorio en la lucha de los recursos y las prestaciones socio-laborales-, se confirma.

En cuarto lugar, se extrae de la investigación que la sociedad tiene una actitud menos favorable en aspectos de vecindad, es decir, relaciones en la que hay menos cercanía y vinculación entre autóctonos e inmigrantes, que en situaciones familiares, donde la vinculación y la cercanía es mayor. La explicación acerca de este fenómeno puede encontrarse en que el contacto directo y próximo con personas 
inmigrantes reduce los prejuicios que se tienen asociados a la inmigración, de tal modo que al tener una relación de vecindad pueden interaccionar frecuentemente autóctono e inmigrante, o no, mientras que tener una vinculación familiar, por regla general, requiere de una relación más estrecha .Por lo cual la hipótesis específica 4 -la sociedad tiene actitudes más reacias hacia la inmigración cuando la vinculación entre ambos es menos cercana y se centra menos en el contacto directo con la población inmigrante- se corrobora.

No obstante, la comparativa con el resto de Europa, deja a España en muy buen lugar en lo que a la valoración hacia la inmigración se refiere, ya que en todo el periodo estudiado la población considera positiva la influencia de la inmigración para España. Estos datos en comparación con otros países europeos afectados por la crisis económica -Grecia, Portugal, Irlanda y Chipre-, se aprecia que la percepción de la sociedad española sobre la inmigración es más positiva e incluso por encima de la media europea, en aspectos como el impacto del fenómeno de la inmigración en la vida cotidiana y en la situación económica del país. Por lo cual, se puede afirmar que la población española no responsabiliza directamente de la situación económica del país a la inmigración con la misma intensidad que en otros países europeos con una situación económica similar a la española. 


\section{CONCLUSIONES}

\section{A. PRINCIPALES CONCLUSIONES}

El objetivo general de esta investigación es estudiar el proceso de construcción de la inmigración como problema social en España, para ello se han empleado concepciones teóricas sobre la materia y diferentes estudios sobre el estado de la cuestión, mediante los cuales se ha realizado un análisis de los datos secundarios más significativos basados en los estudios del CIS: 2731 (2007), 2773 (2008), 2817 (2009), 2846 (2010) y 2918 (2011). Fruto de este proceso se han extraído las siguientes conclusiones:

En primer lugar, la sociedad española se siente amenaza por la población inmigrante en dos aspectos concretos: la competitividad en el mercado laboral y las prestaciones sociales. Por un lado, la concepción que tiene la población española de la inmigración, en cuanto al mercado laboral, es la del inmigrante económico -de hecho la primera idea con la que se asocia la inmigración es con la necesidad de venir a trabajar-. Ante una situación de prosperidad económica, la sociedad percibía la inmigración como una fuente de mano de obra que ocupaba puestos de trabajo que la población española no deseaba realizar, es decir, no existía la necesidad de diferenciación entre población autóctona e inmigrante, puesto que siguiendo la teoría del mercado dual (Doeringer y Piore, 1971) la población autóctona tenía trabajos del sector primario, mientras que la población inmigrante ocupaba el sector secundario. En el caso español, el sector secundario eran empleos en la agricultura, en la construcción y en el sector servicios, principalmente. El análisis de resultados muestra, que el 2010 es un año especialmente controvertido en esta materia, ya que probablemente por la visibilización de los efectos de la crisis económica, la población española se ve obligada a competir con la población inmigrante por puestos de trabajo que antes rechazaba, y es ante esa situación de competitividad laboral donde se sienten en la necesidad de diferenciarse, aumentando las opiniones negativas sobre vivir en un mismo barrio donde habiten muchos inmigrantes o que una persona inmigrante sea su jefe en el trabajo; esto último esta al hilo de lo que afirma García Borrego (2005) sobre que la población española no rechaza los puestos de trabajo en sí mismos, sino las condiciones de trabajo que estos conllevan, por ello un trabajo en el que un inmigrante sea el jefe se asocia a 
inseguridad laboral, dureza y bajo salario. Respecto a este punto se observa un discurso funcionalista de la inmigración, como así lo señalan Riken y Pérez Yruela (2007).

Por otro lado, en lo que respecta a la competitividad por las prestaciones sociales, se aprecia que la población percibe que de los grupos vulnerables -personas mayores que viven solas, pensionistas, parados e inmigrantes- son los inmigrantes quienes reciben más ayuda del Estado de lo que aportan y que abusan de la gratuidad de los servicios públicos ${ }^{54}$, especialmente esta percepción se radicaliza en 2010. Esto se puede deber a que ante la reducción de las prestaciones sociales para el conjunto de la sociedad, la población española prefiere que sean las personas inmigrantes los que primero deben perder sus derechos y prestaciones -los otros-.

En segundo lugar, realizando una comparativa con los países europeos que están sufriendo una situación económica similar a la española. Se observa que aunque en España -como ya se ha señalado- tras la visibilización de los efectos de la crisis en 2010, se produjo un brote xenófobo principalmente en materia de competitividad laboral y social, no es tan marcado como en el resto de países europeos. De hecho en temáticas concretas como la percepción de la inmigración como positiva para la economía y para el país, presenta una valoración mejor que sus países vecinos. Tanto es así, que en todo momento -del periodo estudiado- la población española ve a la inmigración como positiva para el país. Esto puede deberse, a que a diferencia de algunos países europeos, en España no ha habido un partido político fuerte que abiertamente haya defendido ideas populistas sobre la inmigración como Amanecer Dorado en Grecia o Forza Italia en Italia. Si bien es cierto que en España la gestión de las migraciones ha sido una práctica habitual en campaña electoral.

En tercer lugar, hay colectivos que pese a su volumen son invisibilizados en la sociedad. Este es el caso de la población latinoamericana que es infra-representada en cuanto a su volumen, posiblemente se deba a que comparte rasgos lingüísticos, religiosos y culturales con la población autóctona. Sin embargo, el caso opuesto es el del colectivo magrebí, principalmente marroquí, que además de ser sobrerepresentado en la percepción de su volumen por la población española, es el grupo

${ }^{54}$ Según refleja la memoria del SIUSS 2011 el número de inmigrantes residentes en España es muy superior al que utiliza los servicios sociales 
de nacionalidad con el que la sociedad más muestra su rechazo. A su vez, la población española afirma que el grupo de nacionalidad que más antipatía le despierta son los magrebíes, a los cuales asocian con la delincuencia, con ser demasiados y con no integrarse.

En cuarto lugar, en esta investigación se detectan tres perfiles de actitudes ante la inmigración en el seno de la sociedad española, siguiendo a Cea D’Ancona (2009) quienes son reacios a la inmigración, aquellos que son ambivalentes y quienes son tolerantes respecto a la inmigración. La evolución de la población que se engloba bajo estos perfiles varia en el periodo estudiado, de tal modo que se observa que mientras el perfil tolerante con la inmigración se mantiene más o menos constante en el periodo 2007 a 2011, se aprecia un aumento del perfil reacio y un descenso de posiciones ambivalentes ante la inmigración. En definitiva, se va polarizando la opinión de la población sobre la inmigración. La explicación de este cambio por parte de la sociedad española de opiniones ambivalentes a reacias con la inmigración, puede deberse a los efectos de la crisis económica, que han activado posturas xenófobas, en gran parte causa por la competitividad percibida por la población autóctona en cuanto al acceso al mercado laboral y a las prestaciones sociales.

En quinto lugar, se observa que desde el 2007 y sobre todo desde el 2008, hay un importante descenso en la percepción de la sociedad de la inmigración como un problema para España; tanto es así que en 2013, no es ni el 0,5\% de la sociedad quien lo identifica como el primer problema del país. A su vez, la sociedad asegura que la atención que los medios de comunicación le prestan a la inmigración ha disminuido considerablemente, por lo que se afirma que en tiempos de crisis económica y alto desempleo la preocupación de la sociedad por la inmigración desciende. Esto está influenciado por la pérdida de salience (relevancia) en los medios de comunicación, así como señala Igartua et al. (2004), existe una correlación positiva entre la cobertura informativa que se le otorgue a la inmigración y su consideración como problema social.

La presente investigación partía de una hipótesis general que en la construcción de la inmigración como problema social en España habían influido más los agentes externos al fenómeno migratorio -medios de comunicación y la politización de las migraciones- que el contacto directo con la inmigración. Siguiendo las teorías de la 
comunicación desarrolladas en el marco teórico sobre la "hiper-realidad" que generan los medios de comunicación y más concretamente la teoría de la Agenda Setting, que diagnostica la percepción de los temas que son más importantes para la sociedad en ese momento y distingue entre obtrisuve (temas cercanos) y unobtrosive (temas desconocidos). Así pues, la inmigración es un unobtrosive, por lo que es más fácil influenciar a la sociedad con las opiniones manifestadas en los medios de comunicación que han consolidado en la población española una determinada valoración acerca de la migración. Por lo cual, sí en los medios de comunicación resaltan noticias negativas de la inmigración -delincuencia, llegada irregular de inmigrantes etc.-, la sociedad genera estereotipos en base a estas noticias (Alsina, 1996). Como señala Piñuel y Gaitan (1995) "de la realidad social ya no se tiene experiencia sino noticia”, lo que en esta investigación se ha denominado realidad subjetiva de la inmigración. Sin embargo, se observa en la investigación que el contacto directo con la población inmigrante, la llamada realidad objetiva, reduce la xenofobia en la sociedad, tal y como señala Frigerio (1995) "nuestra dependencia de los medios para el conocimiento de ciertos hechos y sobre todo para su interpretación es mayor cuanto menos experiencia directa tenemos sobre un determinado tema". De hecho, la población que reconoce que entre sus compañeros de trabajo hay inmigrantes tiene posturas más tolerantes en materias relacionadas con la inmigración en general y con el mercado laboral en particular. Especialmente quienes tienen amigos y familiares inmigrantes muestran actitudes tolerantes con la inmigración, como señalan Berry, Kalin y Taylor (1977) la población que tiene mayor proximidad, tanto por afinidad como por contacto, con la población inmigrante presenta actitudes más positivas hacia la inmigración. Por lo cual, son las construcciones sociales fundamentadas principalmente por las noticias de los medios de comunicación las que han generado que la inmigración sea vista como un problema social en España, tanto es así, que al disminuir las noticias de la inmigración en los medios de comunicación por noticias relacionadas con la crisis económica, la percepción de la sociedad ante la inmigración como un problema social es prácticamente inexistente, al incluirse esta -la inmigración- dentro de los problemas económicos del país. Por lo tanto, se corrobora que la hipótesis general de la investigación, es decir, en la construcción de la inmigración como problema social en España han influido más los agentes externos al fenómeno migratorio 
-medios de comunicación y la politización de las migraciones- que los efectos del contacto directo con la inmigración.

\section{B. APLICABILIDAD DE LOS RESULTADOS}

La presente investigación se ha centrado en el proceso de construcción de la inmigración como problema social en España y cuáles son los factores que más han influido. De dicho proceso, se han extraído unos resultados que pueden ser aplicables en:

- Políticas de cooperación: se deben poner en marcha y fomentar políticas basadas en la cooperación laboral. Este instrumento puede frenar la necesidad de diferenciación entre autóctonos e inmigrantes en el mercado laboral y mediante el contacto directo, reducir los estereotipos ligados a la inmigración.

- Políticas educativas: el sistema educativo español debe re-pensar su criterio de multiculturalidad y caminar hacia una interculturalidad real, fomentando talleres en los que se conozcan y respeten las culturas de las diferentes nacionalidades. Así como, introducir en las aulas un conocimiento más profundo de las diferentes religiones, no de asimilación, para reducir la islamofobia que se aprecia en los resultados de esta investigación.

- Control de las noticias en los medios de comunicación: se demanda que se genere un marco común de directrices para comunicar las noticias relacionadas con la inmigración sin reproducir estereotipos, de tal modo, que los medios den un tratamiento justo de la inmigración, no únicamente otorgándole salience (relevancia) a la noticias negativas sobre la inmigración.

- Despolitización de las migraciones: las esferas políticas no deberían utilizar la inmigración como un tema de campaña electoral, ni realizar un discurso abiertamente excluyente y/o desconfiado sobre la misma. Por el contrario, debería fomentar redes institucionales para reducir los cauces de inmigración irregular y avanzar por el camino de la integración social que no de la asimilación.

- Los perfiles de actitudes ante la inmigración: que se han descrito y detectado en esta investigación, pueden ser empleados para impulsar y crear políticas 
públicas basadas en la activación del perfil tolerante en la sociedad española y así poder diseñar diferentes campañas de sensibilización.

\section{FUTURAS LÍNEAS DE INVESTIGACIÓN}

Para finalizar esta investigación, se abren unas futuras líneas de investigación en base a los resultados presentados:

- Análisis de la influencia del capital cultural y del capital social en los prejuicios ante la inmigración. Esta investigación recoge algunos datos y resultados sobre la influencia del capital cultural en la conformación de actitudes ante la inmigración, por lo que sería relevante profundizar sobre esta temática.

- Estudio del efecto de las encuestas de medición del racismo y la xenofobia. Como se ha señalado en el marco teórico de la presente investigación, medir la actitud es algo indirecto, ósea que estriba de lo que la persona entrevistada quiera expresar en ese momento. Aquí la deseabilidad social influye, sobre todo en las manifestaciones del racismo sutil, de tal modo que la persona entrevistada contesta lo que cree que socialmente es lo correcto y no lo que piensa realmente. Esto especialmente ocurre con personas de mayor nivel de estudios.

- Análisis cualitativo de las actitudes ante la inmigración. Con el de detectar la deseabilidad social propia de la encuesta, reduciendo sus efectos y profundizar más en los discursos ante la inmigración.

- Aplicar la perspectiva de género en el análisis de las actitudes y opiniones hacia la inmigración; incluyendo temáticas y preguntas específicas.

- Estudio diferenciado de género. En esta investigación se ha utilizado la variable sexo para realizar algunos cruces de variables, sin embargo no se han observado diferencias significativas entre sexos. Sería interesante realizar una investigación sobre la actitud de la sociedad española ante la inmigración femenina, ya que como es sabido, la inmigración femenina presenta unos estándares diferentes a la masculina, que sería conveniente estudiar. 


\section{BIBLIOGRAFÍA 55}

Aja, E. (2003). El estado autonómico: federalismo y hechos diferenciales. Madrid: Alianza Editorial.

Aja, E., Arango, J. \& Oliver Alonso, J. (2012). Inmigración y crisis: entre la continuidad y el cambio. Barcelona: Anuario de la inmigración en España.

Alsina, R. (1989). Los modelos de la comunicación. Madrid: Tecnos.

Alsina, R. (1996). La construcción de la noticia. Barcelona: Paidós.

Barker, M. (1981). The New Racism Conservatives and the Ideology of the Tribe. Londres: Junction Books Barkan.

Ball-Rokeach, S. \& De Fleur, M. (1982). Teorías de la comunicación de masas. Barcelona: Paidós.

Bardín, L. (1986). El análisis de contenido. Madrid: Akal.

Berry, W.; Kalin, R.; \& Taylor, D. (1977). Multiculturalism and Ethnic Attitudes in Canada. Ottawa: Ministry of Supply and Services

Best, J. (1990). Threatened children: Rhetoric and concern about child-victims. Chicago: University of Chicago Press.

Blanco, C. (1993). La integración de los inmigrantes en las sociedades receptoras. Bilbao: Universidad de Deusto.

Blumer, H. (1971). Social Problems as Collective Behavior. Social Problems, vol. 18, ํㅜ 3, 298-306.

Carabaña, J. (2012). Concentración de inmigrantes y resultados escolares: una falsa alarma. Real Instituto Elcano, 1-7.

Castro, B. (2011). Aportes de Niklas Luhmann a la teoría de la complejidad. En Polis. Revista Latinoamericana, vol. 29.

Cea D’Ancona, Ma . A. (2002). La medición de las actitudes ante la inmigración: evaluación de los indicadores tradicionales de "racismo". Reis. Revista Española de Investigaciones Sociológicas, 99, 87-111.

Cea D’Ancona, Ma. A. (2005). La exteriorización de la xenofobia. R.E.I.S, Revista Española de Investigaciones Sociológicas, 112, 197-230.

Cea D’Ancona, Ma . A. (2007). Inmigración, racismo y xenofobia en la España del nuevo contexto europeo. Madrid: OBERAXE. Ministerio de Trabajo y Asuntos Sociales.

\footnotetext{
${ }^{55}$ Para la presentación de las referencias se han seguido los criterios definidos por la APA en su quinta edición.
} 
Cea D'Ancona, Ma . A. (2009). Filias y fobias ante la imagen poliédrica cambiante de la inmigración. Claves en la comprensión del racismo y la xenofobia. Revista del Ministerio de Trabajo e Inmigración, 80, 39-60.

Cea D’Ancona, Ma . A. \& Vallès Martínez, M. (2009). Evolución del Racismo y la Xenofobia. Madrid: Ministerio de Trabajo e Inmigración.

Cebolla, H. \& González, A. (2008). La inmigración en España (2000-2007). De la gestión de flujos a la integración de los inmigrantes. Madrid: Centro de estudios políticos y constitucionales.

Checa, F. (2003). Inmigración y diversidad en España. Una aproximación desde el extrañamiento cultural. Convergencia, 10, 139-175.

Checa, F. (2008). La inmigración sale a la calle. Comunicación y discursos políticos sobre el fenómeno migratorio. Barcelona: Icaria Editorial.

Colectivo IOÉ (2005). Ciudadanos o intrusos: la opinión pública española ante los inmigrantes. Papeles de Economía Española, 104,194-209.

Comisión Española de Ayuda al Refugiado (CEAR) (2013). La situación de las personas refugiadas en España. Madrid: Informe CEAR.

Cunningham, K (2012). Policy Shifts and the De-politizacion of Immigration. Proceedings of the IMISCOE, Amsterdam.

D'Angelo, P. (2002). News framing as a multiparadigmatic research program. A response to Entman. Journal of Comunication, 50 (4), 870-888.

Díez de Nicolás, J. (1999). Los españoles y la inmigración. Madrid: Ministerio de Trabajo y Asuntos Sociales. Observatorio permanente de inmigración.

Doeringer, P. \& Piore, M. (1985). Mercados internos de trabajo y análisis laboral. Madrid: Ministerio de Trabajo y Seguridad Social. [1971].

Downs A. (1972); "Up and Down with ecology: the issue attention cycle". The Public Interest, 28, 38-50, reproducido en PROTESS, D. y McCOMBS, M. (eds.) (1991), Agenda-setting: readings on media public opinión and policymaking, N.J.: Lawrence Erlbaum Associates, 27-33.

Elder, C. \& Cobb, R. (1983). Participation in American politics: The dynamics of agenda-building. Baltimore: Johns Hopkins University Press.

Elder, C. \& Cobb, R. (2003). Formación de la Agenda: El caso de la política de los ancianos. (Senzek, A. Trad.). En (ed) L.F. Aguilar Villanueva, Problemas políticos y Agenda de Gobierno, 77-104. México: Grupo Editorial Miguel Ángel Porrua. 
Entman, R. (1993). Framing: toward a clarification of a fractured paradigm. Journal of Comunication, 43 (4), 51-58.

Franzé, A. (1999). Lengua y cultura de origen: niños marroquíes en la escuela española. Madrid: Ediciones del Oriente y del Mediterráneo.

Frigerio, A. (1995). La construcción de problemas sociales: cultura, política y medios de comunicación. Comunicação e Política 4(2), 137-149.

García Borrego, I. (2005). La construcción social de la inmigración: el papel de la universidad en La condición del inmigrante (coordinadores Andrés Pedreño Cánovas, Manuel Hernández Pedreño). Murcia: Universidad de Murcia.

Garrido, L. (2004). Para cuantificar a los extranjeros. Economistas, 99, 28-37.

Gimeno, L. (2001). Actitudes hacia la inmigración. Relación entre las investigaciones cualitativas y cuantitativas. Opiniones y Actitudes, 34. Madrid: CIS.

Giner S.; Lamo de Espinosa E. \& Torres C. (2006). Diccionario de Sociología. Madrid: Alianza Editorial.

González, J. J. \& Requena, M. (2005). Tres décadas de cambio social en España. Madrid: Alianza Editorial.

Guirao, C. (2010). La construcción social del problema de la conciliación vida familiar y laboral en España, 1999-2009. Alicante: Universidad de Alicante.

Guisán, Ma $C$. (2005). Evolución de la inmigración neta en España, Europa y América, 1965-2004. Estudios Económicos de Desarrollo Internacional, 5-2, 91-102.

Habermas, J. (1999). Historia y crítica de la opinión pública. Barcelona: Gustavo Gili. Hernández, Fernández y Baptista (2007): Metodología de la investigación. México: McGraw Hill.

Hilgartner, S. \& Bosk, C. (1988). The rise and fall of social problems: a public arenas model. American Journal of Sociology, 94(1), 53-78.

Igartua, J.; Muñiz, C. \& Cheng L. (2005). La inmigración en la prensa española. Aportaciones empíricas y metodológicas desde la teoría del encuadre noticioso. Revista Migraciones, 17, 143-181.

Igartua J. J., Otero, J., Muñiz, C., Cheng, L. \& Gómez, J. (2006). Efectos cognitivos y afectivos de los encuadres noticiosos de la inmigración. V Jornadas de Comunicación Medios de Comunicación, Inmigración y Sociedad. Retos y propuestas para el siglo XX. Universidad de Salamanca, 7-9 de marzo de 2006. 
Izquierdo, A. (1992). La inmigración en España 1980-1990. Madrid: Ministerio de Trabajo y Asuntos Sociales.

Izquierdo, A. (1995). La inmigración inesperada. Madrid: Trotta.

Katz, D. (1974). El enfoque funcional en el estudio de las actitudes, en J. R. Torregrosa (comp.), Teoría e investigación en la psicología social actual, Madrid, Instituto de la Opinión Pública, pp. 275-296.

Kitsuse J. \& Spector M. (1973a), "Toward a sociology of social problems: social conditions, value-judgements, and social problems", Social problems, vol. 20, $n^{\circ}$ 4, 407-419.

Krysan, M. (1998). Privacy and the Expression of White Racial Attitudes: A Comparison Across Three Contexts. Public Opinion Quarterly 62, 506-544.

Lamberth, J. (1980). Psicología social. Madrid, Ediciones Pirámide, S.A., 3ª ed.

Lippmann, W. (2003). La opinión pública. Madrid: Cuadernos de Langre. [1922].

Lockwood, D. (1962). El trabajador de la clase media. Madrid: Aguilar.

López Doblas, J. (2005). Herramientas para el trabajo sociológico. En Iglesias de Ussel, J. \& Trinidad A. Leer la sociedad. Una introducción a la sociología general. Madrid: Tecnos.

Lorenc F. (2005). La sociología de los problemas públicos. Una perspectiva crítica para el estudio de las relaciones entre la sociedad y la política. Nómadas. Revista Crítica de Ciencias Sociales y Jurídicas, vol. 12.

Luhmann, N. (2000). The Reality of the Mass Media. Stanford: Stanford University Press.

Macionis, J. \& Plummer, K. (2010). Sociología. Madrid: Pearson Educations.

Marsal, J. F. (1969). Hacer la América. Autobiografía de un inmigrante español en la Argentina. Buenos Aires: Editorial del Instituto Torcuato Di Tella.

Martín Llaguno, M. (2002). La función de recuerdo de los medios de difusión: estudio de las condiciones de posibilidad del efecto. El caso del SIDA en la prensa. Alicante: Universidad de Alicante.

McBroom, W. \& Reed, F. (1992). Towards a reconceptualization of attitude behavior Consistency". Social Psychology Quartely, vol. 55 (2), 205-216.

McCombs, M. (2006). Estableciendo la Agenda: El impacto de los medios en la opinión pública. Barcelona: Paidós.

Memoria del Sistema de Información de Usuarios de Servicios Sociales (S.I.U.S.S.) (2011). Madrid: Ministerio de Sanidad, Servicios Sociales e Igualdad. 
Morales, L. \& Ros, V. (2012). La politización de la migración en España en perspectiva comparada. Documentos CIBOD, migraciones, 25.

Moreno, F. \& Bruquetas, M. (2011). Inmigración y Estados de Bienestar en España. Barcelona: Obra social La Caixa.

Olmos, A. (2009). La población inmigrante extranjera y la construcción de la diferencia. Discursos de alteridad en el sistema educativo andaluz. Granada: Universidad de Granada, tesis doctoral.

Oskamp, S. (1991). Attitudes and opinions. Englewood Cliffs: Prentice Hall, 2.. ed. Parlamento Europeo (1988). Racismo, xenofobia e intolerancia. Derechos humanos e inmigración en la Comunidad Europea. Bruselas: Informes del Parlamento Europeo.

Piñuel, J. L. \& Gaitán, J. (1995). Metodología general. Conocimiento científico en investigación en comunicación social. Madrid: Síntesis.

Piore, M. (1979). Birds of Passage. Migrant Labour in Industrial Societies. New York: Cambridge University Press.

Ramírez Goicoechea, E. (1996). Inmigrantes en España: vidas y experiencias. Madrid: Centro de Investigación Sociológicas.

Riken, S. \& Pérez Yruela, M. (2007). Opiniones y actitudes de la población andaluza ante la inmigración. Sevilla: Estudios y Monografías, 5.

Rodríguez Díaz, R. (2004). Teoría de la Agenda-Setting: aplicación a la enseñanza universitaria. Barcelona: Observatorio Europeo de Tendencias Sociales.

Rubington E. \& Weiberg M. (1995). The Study of Social Problems: Seven Perspective. Oxford: Oxford University Press.

Schnell, B. \& Rodríguez, N. (2007). Diccionario de las migraciones: del concepto a la palabra. Madrid: Adeire.

Sobrados, M. (2011). La inmigración como problema. Percepciones sociales y representaciones mediáticas. Prima Social, 6.

Solé, C., Parella, S., Alarcón, A., Bergalli, V. \& Gibert, F. (2000) El impacto de la inmigración en la sociedad receptora. R.E.I.S., 90, 131-157.

SORA (Institute for Social Research and Analysis) (2001). Attitudes towards Minority Groups in the European Union: A Special Analysis of the Eurobarometer 2000 Opinion Poll on behalf of the European Monitoring Centre on Racism and Xenophobia. Viena.

Soriano Miras, R. (2008). Inmigración e identidad social. Migraciones, 23, 117-150. 
Soriano Miras, R. (2011). Análisis sociológico de la Ley 4/2000, de 11 de enero, sobre derechos y libertades de los extranjeros en España y su integración social. Sus reformas (8/2000, 11/2003, 14/2003, 2/2009) y su implicación social. Papers, 96/3, 683-705.

Subirats, J. (2002). ¿De qué seguridad hablamos?, en El País, 25 de octubre.

Tankard, J. (1991); "Media frames: approaches to conceptualization and measurement". Ponencia presentada en Communication Theory and Methodology Division Asociation for Education in Journalism and Mass Comumunication Convertion, Boston.

Terren, E. (2002). El racismo y la escuela: clima, estructura y estrategias de representación. Migraciones, 12, 81-102.

Thomas, W. I. \& Thomas, D. (1928). The child in America: Behavior problems and programs. New York: Knopf.

Van Dijk, T. (1990). La noticia como discurso: comprensión, estructura y producción de la información. Barcelona: Paidós.

Van Dijk, T. (1993). El racismo de la élite. Archipiélago, 14, 106-111.

Zapata-Barrero, R. (2004). Multiculturalidad e inmigración. Madrid: Síntesis. 


\section{ANEXO I: ANEXO METODOLÓGICO}

\section{A. DESCRIPCIÓN DEL BARÓMETRO DE OPINIÓN PÚBLICA (CIS) \\ Barómetro de septiembre 2000. Estudio 2398}

\begin{tabular}{ll|}
\hline Ambito & Nacional. Se incluyen las provincias insulares. Se excluye Ceuta y Melilla. \\
Universo & Población española de ambos sexos de 18 años y más. \\
Tamaño de la muestra & Diseñada: 2.500 entrevistas. Realizada: 2.498 entrevistas. \\
\hline Affjación & Proporcional \\
Ponderación & No procede \\
Muestreo & Polietápico, estratificado por conglomerados. \\
Error muestral & Para un nivel de confianza del $95,5 \%$ (dos sigmas), y $P=Q$, el error es de $\pm 2 \%$ \\
\hline
\end{tabular}

\section{Barómetro de enero 2001. Estudio 2406}

Ámbito
Universo
Tamaño de la muestra
Afjación
Ponderación
Muestreo
Error muestral

Nacional. Se incluyen las provincias insulares. Se excluye Ceuta y Melilla

Población española de ambos sexos de 18 años y más.

Diseñada: 2.500 entrevistas. Realizada: 2.486 entrevistas.

Proporcional

No procede

Polietápico, estratificado por conglomerados.

Para un nivel de confianza del $95,5 \%$ (dos sigmas), y $P=Q$, el error es de $\pm 2 \%$ para el conjunto de la muestra y en el supuesto de muestreo aleatorio simple.

\section{Barómetro de enero 2002. Estudio 2444}

Ámbito
Universo
Tamaño de la muestra
Afijación
Ponderación
Muestreo
Error muestral

Nacional. Se incluyen las provincias insulares. Se excluye Ceuta y Melilla

Población española de ambos sexos de 18 años y más.

Diseñada: 2.500 entrevistas. Realizada: 2.498 entrevistas.

\section{Proporcional}

No procede

Polietápico, estratificado por conglomerados.

Para un nivel de confianza del $95,5 \%$ (dos sigmas), y $P=Q$, el error es de $\pm 2 \%$ para el conjunto de la muestra y en el supuesto de muestreo aleatorio simple.

\section{Barómetro de enero 2003. Estudio 2477}

\section{Ambito}

Universo

Tamaño de la muestra

Afjación

Ponderación

Muestreo

Error muestral

\section{Nacional.}

Población española de ambos sexos de 18 años y más.

Diseñada: 2.500 entrevistas. Realizada: 2.480 entrevistas.

\section{Proporcional}

No procede

Polietápico, estratificado por conglomerados.

Para un nivel de confianza del $95,5 \%$ (dos sigmas), y $P=Q$, el error es de $\pm 2 \%$ para el conjunto de la muestra y en el supuesto de muestreo aleatorio simple. 


\section{Barómetro de enero 2004. Estudio 2554}

$\begin{array}{ll}\text { Ámbito } & \text { Nacional. } \\ \text { Universo } & \text { Población española de ambos sexos de } 18 \text { años y más. } \\ \text { Tamaño de la muestra } & \text { Diseñada: } 2.500 \text { entrevistas. Realizada: } 2.489 \text { entrevistas. } \\ \text { Afijación } & \text { Proporcional } \\ \text { Ponderación } & \text { No procede } \\ \text { Muestreo } & \text { Polietápico, estratificado por conglomerados. } \\ \text { Error muestral } & \text { Para un nivel de confianza del } 95,5 \% \text { (dos sigmas), y } P=Q \text {, el error es de } \pm 2 \% \\ & \text { para el conjunto de la muestra y en el supuesto de muestreo aleatorio simple. }\end{array}$

\section{Barómetro de enero 2005. Estudio 2589}

Ámbito
Universo
Tamaño de la muestra
Afijación
Ponderación
Muestreo
Error muestral
Nacional.

Población española de ambos sexos de 18 años y más.

Diseñada: 2.500 entrevistas. Realizada: 2.495 entrevistas.

Proporcional

No procede

Polietápico, estratificado por conglomerados.

Para un nivel de confianza del $95,5 \%$ (dos sigmas), y $P=Q$, el error es de $\pm 2 \%$ para el conjunto de la muestra y en el supuesto de muestreo aleatorio simple.

Barómetro de marzo 2006. Estudio 2636

Ámbito
Universo
Tamaño de la muestra
Afijación
Ponderación
Muestreo
Error muestral
Nacional.

Población española de ambos sexos de 18 años y más.

Diseñada: 2.500 entrevistas. Realizada: 2.482 entrevistas.

Proporcional

No procede

Polietápico, estratificado por conglomerados.

Para un nivel de confianza del $95,5 \%$ (dos sigmas), y $P=Q$, el error es de $\pm 2 \%$ para el conjunto de la muestra y en el supuesto de muestreo aleatorio simple.

\section{Barómetro de enero 2007. Estudio 2672}

Ámbito
Universo
Tamaño de la muestra
Afjación
Ponderación
Muestreo
Error muestral
Nacional.

Población española de ambos sexos de 18 años y más.

Diseñada: 2.500 entrevistas. Realizada: 2.472 entrevistas. Proporcional

No procede

Polietápico, estratificado por conglomerados.

Para un nivel de confianza del $95,5 \%$ (dos sigmas), y $P=Q$, el error es de $\pm 2 \%$ para el conjunto de la muestra y en el supuesto de muestreo aleatorio simple. 
Barómetro de enero 2008. Estudio 2749

\begin{tabular}{ll} 
Ambito & Nacional. \\
Universo & Población española de ambos sexos de 18 años y más. \\
Tamaño de la muestra & Diseñada: 2.500 entrevistas. Realizada: 2.477 entrevistas. \\
Afijación & Proporcional \\
Ponderación & No procede \\
Muestreo & Polietápico, estratificado por conglomerados. \\
Error muestral & Para un nivel de confianza del $95,5 \%$ (dos sigmas), y $P=Q$, el error es de $\pm 2 \%$ \\
\hline
\end{tabular}

\section{Barómetro de enero 2012. Estudio 2927}

Ámbito
Universo
Tamaño de la muestra
Afjación
Ponderación
Muestreo
Error muestral
Nacional.

Población española de ambos sexos de 18 años y más.

Diseñada: 2.500 entrevistas. Realizada: 2.480 entrevistas. Proporcional

No procede

Polietápico, estratificado por conglomerados.

Para un nivel de confianza del $95,5 \%$ (dos sigmas), y $P=Q$, el error es de $\pm 2 \%$ para el conjunto de la muestra y en el supuesto de muestreo aleatorio simple.

\section{Barómetro de enero 2013. Estudio 2976}

\begin{tabular}{l} 
Ámbito \\
Universo \\
\hline Tamaño de la muestra \\
Afijación \\
Ponderación \\
Muestreo \\
Error muestral
\end{tabular}
Nacional.

Población española de ambos sexos de 18 años y más.

Diseñada: 2.500 entrevistas. Realizada: 2.483 entrevistas.

\section{Proporcional}

No procede

Polietápico, estratificado por conglomerados.

Para un nivel de confianza del $95,5 \%$ (dos sigmas), y $P=Q$, el error es de $\pm 2 \%$ para el conjunto de la muestra y en el supuesto de muestreo aleatorio simple.

\section{B. DESCRIPCIÓN DEL ESTUDIO DE ACTITUDES ANTE LA DISCRIMINACIÓN POR ORIGEN RACIAL O ÉTNICO (CIS).}

\section{Septiembre de 2007. Estudio 2731}

$\begin{array}{ll}\text { Ámbito } & \text { Nacional. } \\ \text { Universo } & \text { Población de nacionalidad española de ambos sexos de } 18 \text { años y más. } \\ \text { Tamaño de la muestra } & \text { Diseñada: } 2.800 \text { entrevistas. Realizada: } 2.778 \text { entrevistas. } \\ \text { Afijación } & \text { No proporcional } \\ \text { Ponderación } & \% \text { Extranjeros (P) Coeficiente. } P<51,109.5 \leq P>101,115 . P \geq 100,801 \\ \text { Muestreo } & \text { Bietápico, estratificado por conglomerados. } \\ \text { Error muestral } & \text { Para un nivel de confianza del } 95,5 \% \text { (dos sigmas), } P=Q \text { y en el supuesto de } \\ \end{array}$




\section{DESCRIPCIÓN DEL ESTUDIO DE ACTITUDES ANTE LA INMIGRACIÓN (CIS)}

\section{Septiembre de 2008. Estudio 2773}

Ámbito
Universo
Tamaño de la muestra
Afijación
Ponderación
Muestreo
Error muestral

Nacional.

Población de nacionalidad española de ambos sexos de 18 años y más.

Diseñada: 2.800 entrevistas. Realizada: 2.768 entrevistas.

No proporcional

\% Extranjeros (P) Coeficiente. $P<5$ 1,103. $5 \leq \mathrm{P}>101$ 1,116. $\mathrm{P} \geq 100,805$

Bietápico, estratificado por conglomerados.

Para un nivel de confianza del $95,5 \%$ (dos sigmas), $P=Q$ y en el supuesto de muestreo aleatorio simple, $1,9 \%$.

Octubre de 2009. Estudio 2817

Ámbito
Universo
Tamaño de la muestra
Afijación
Ponderación
Muestreo
Error muestral

Nacional.

Población de nacionalidad española de ambos sexos de 18 años y más.

Diseñada: 2.864 entrevistas. Realizada: 2.836 entrevistas.

No proporcional

\% Extranjeros (P) Coeficiente. $P<51,103.5 \leq P>101,116 . P \geq 100,805$

Bietápico, estratificado por conglomerados.

Para un nivel de confianza del 95,5\% (dos sigmas), $P=Q$ y en el supuesto de muestreo aleatorio simple, $1,88 \%$.

\section{Septiembre de 2010. Estudio 2846}

\begin{tabular}{ll} 
Ámbito & Nacional. \\
Universo & Población de nacionalidad española de ambos sexos de 18 años y más. \\
Tamaño de la muestra & Diseñada: 2.864 entrevistas. Realizada: 2.800 entrevistas. \\
Afijación & No proporcional \\
Ponderación & Coeficientes de la variable PESO de la matriz de datos. \\
\hline Muestreo & Bietápico, estratificado por conglomerados. \\
Error muestral & $\begin{array}{l}\text { Para un nivel de confianza del } 95,5 \% \text { (dos sigmas), P = Q y en el supuesto de } \\
\text { muestreo aleatorio simple, } 1,89 \% .\end{array}$ \\
\hline
\end{tabular}

\section{Noviembre de 2011. Estudio 2918}

\begin{tabular}{ll} 
Ambito & Nacional. \\
Universo & Población de nacionalidad española de ambos sexos de 18 años y más. \\
Tamaño de la muestra & Diseñada: 2.862 entrevistas. Realizada: 2.838 entrevistas. \\
Afijación & No proporcional \\
Ponderación & Coeficientes de la variable PESO de la matriz de datos. \\
Muestreo & Bietápico, estratificado por conglomerados. \\
\hline Error muestral & $\begin{array}{l}\text { Para un nivel de confianza del } 95,5 \% \text { (dos sigmas), P = Q y en el supuesto de } \\
\text { muestreo aleatorio simple, } 1,88 \% .\end{array}$ \\
\hline
\end{tabular}




\section{ANEXO II: ANEXO DE RESULTADOS}

Gráfico 1: Percepción de los aspectos positivos de la inmigración (2008 a 2011).

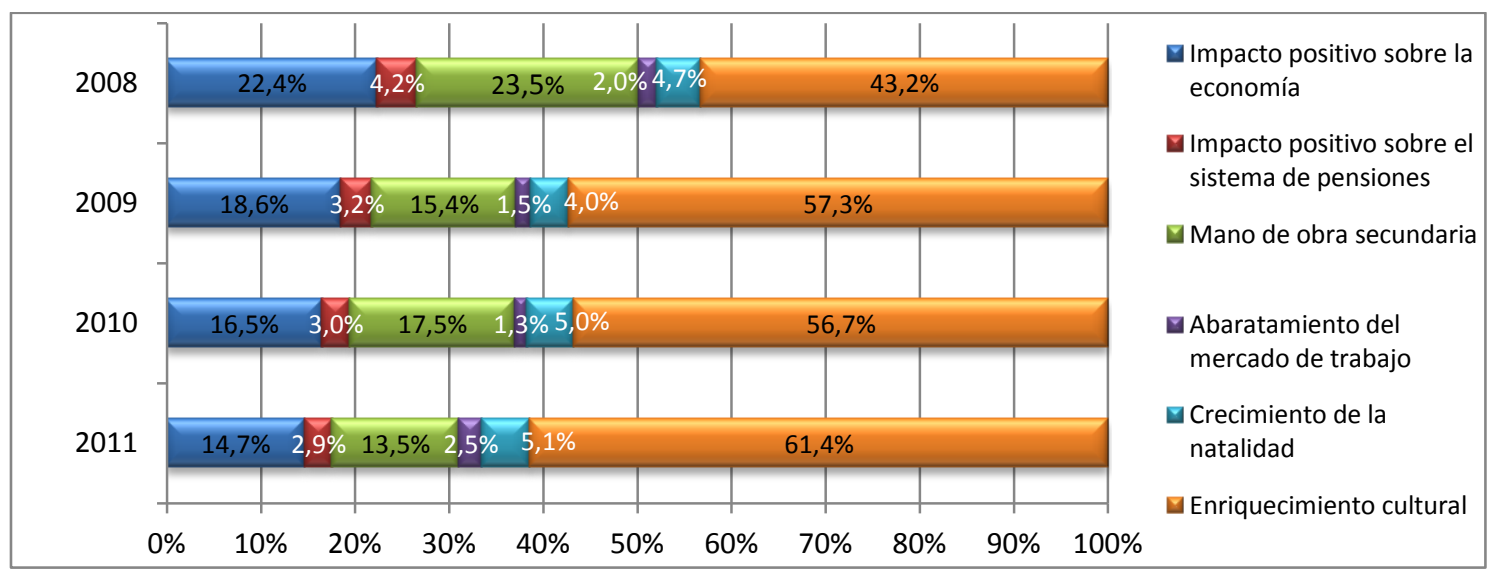

Fuente: Elaboración propia con datos del CIS; estudios 2773 (2008), 2817 (2009), 2846 (2010) y 2918 (2011).

Gráfico 2: Percepción de los aspectos negativos de la inmigración (2008 a 2011).

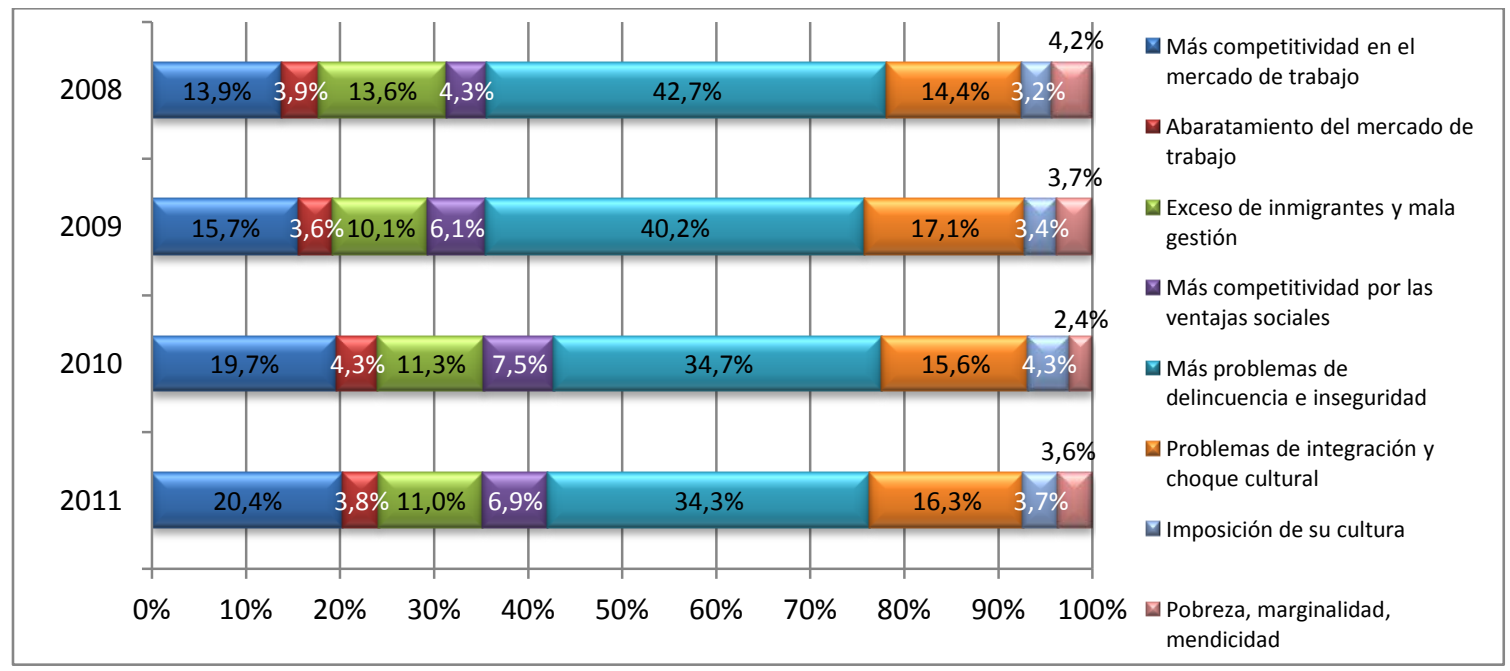

Fuente: Elaboración propia con datos del CIS; estudios 2773 (2008), 2817 (2009), 2846 (2010) y 2918 (2011).

Gráfico 3: Opinión respecto a la cultura de las personas inmigrantes (2008 a 2011).

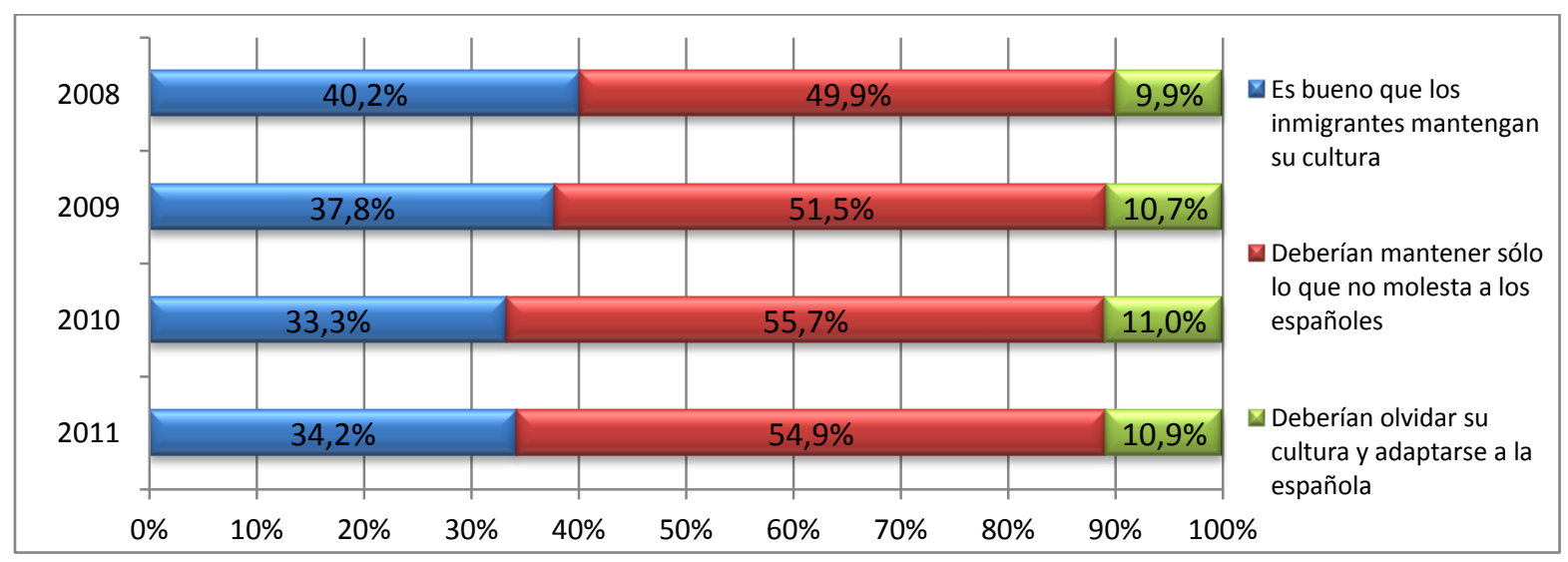

Fuente: Elaboración propia con datos del CIS; estudios 2773 (2008), 2817 (2009), 2846 (2010) y 2918 (2011). 
Gráfico 4: Contribución de la inmigración al enriquecimiento cultural de España (2008 a 2011).

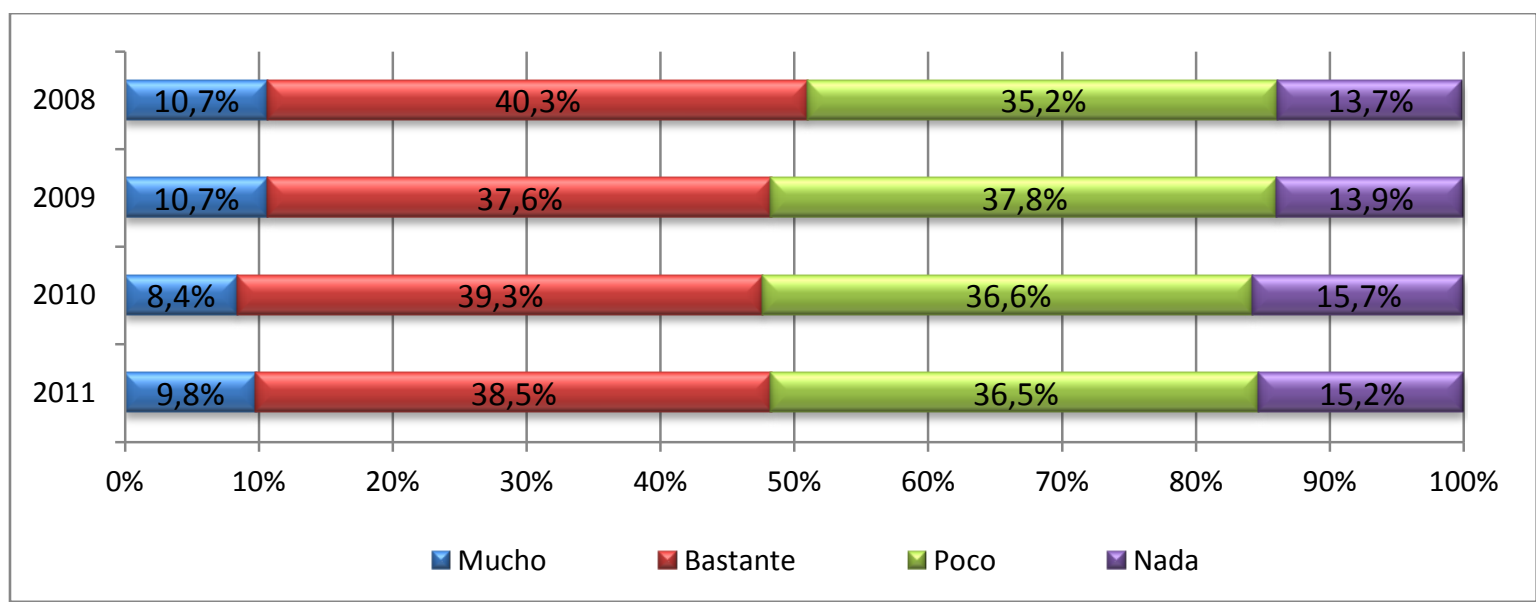

Fuente: Elaboración propia con datos del CIS; estudios 2773 (2008), 2817 (2009), 2846 (2010) y 2918 (2011).

Gráfico 5: Al aceptar sueldos más bajos, los inmigrantes hacen que bajen los salarios (2008 a 2011).

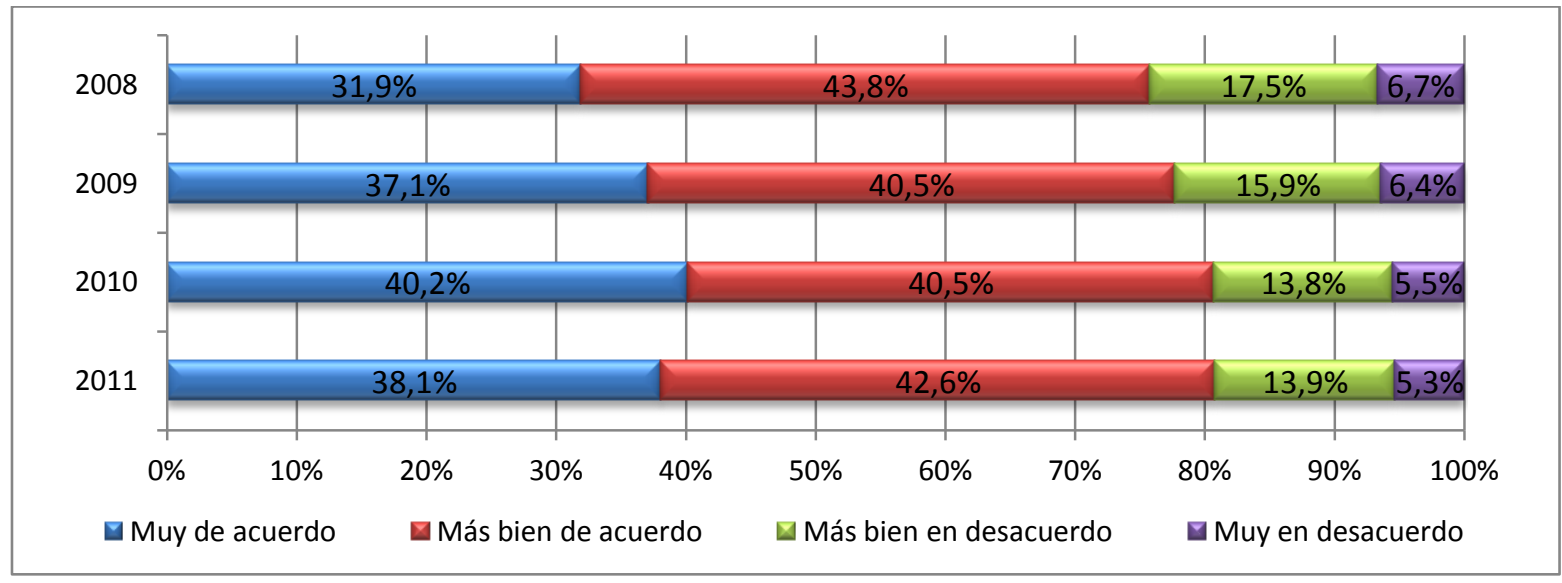

Fuente: Elaboración propia con datos del CIS; estudios 2773 (2008), 2817 (2009), 2846 (2010) y 2918 (2011).

Gráfico 6: Expulsar a las personas inmigrantes por desempleo prolongado (2008 a 2011).

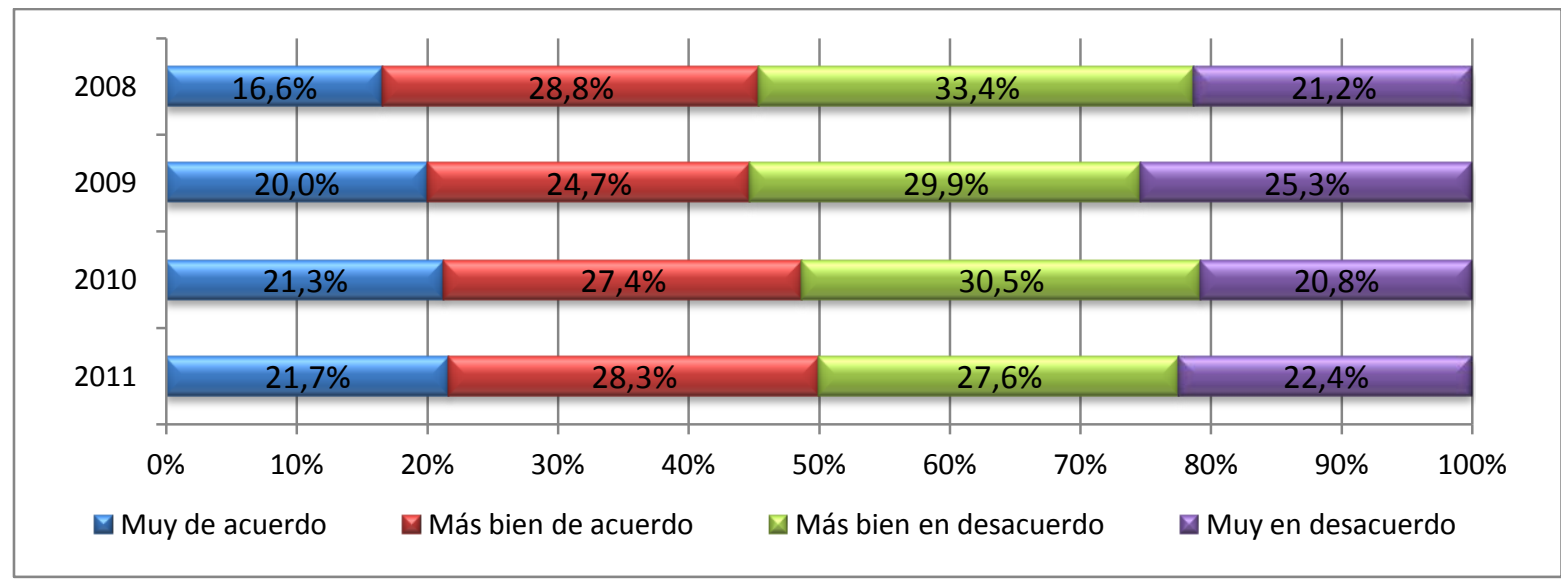

Fuente: Elaboración propia con datos del CIS; estudios 2773 (2008), 2817 (2009), 2846 (2010) y 2918 (2011). 
Gráfico 7: Preferencia en contratar a un ciudadano español que a un inmigrante (2008 a 2011).

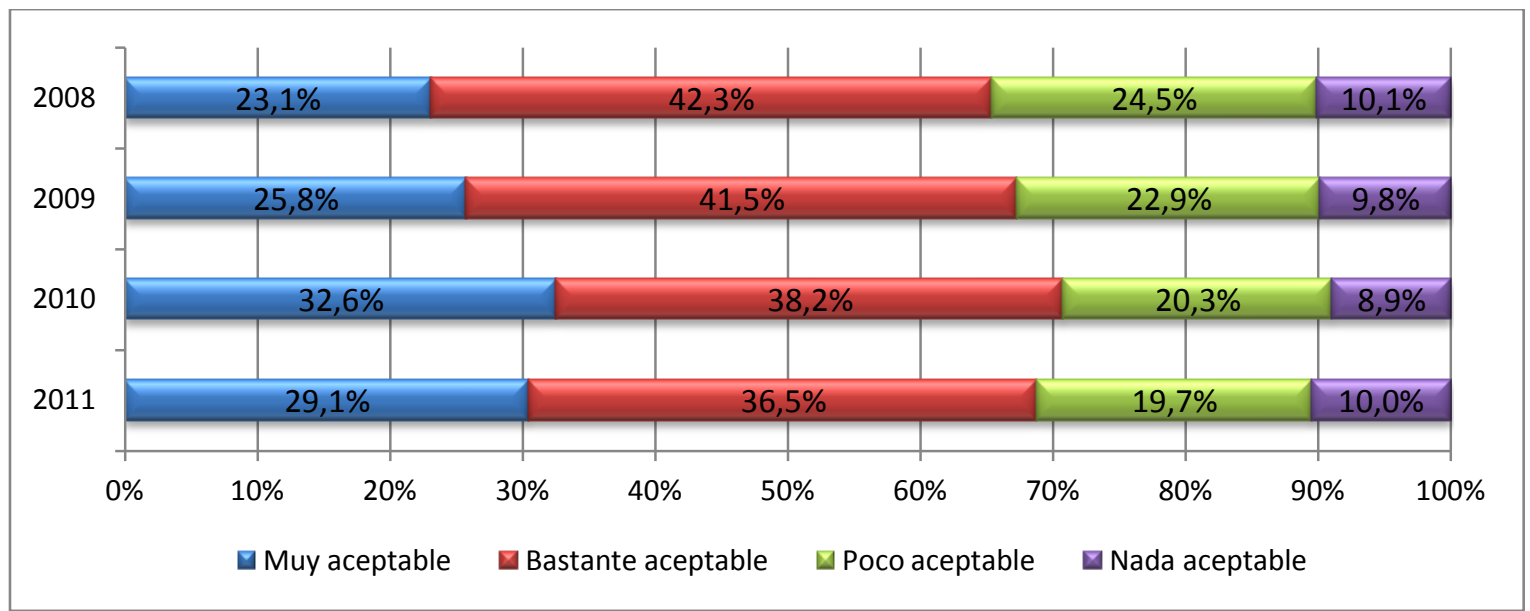

Fuente: Elaboración propia con datos del CIS; estudios 2773 (2008), 2817 (2009), 2846 (2010) y 2918 (2011).

Gráfico 8: Trato de la ciudadanía española a las personas inmigrantes (2008 a 2011).

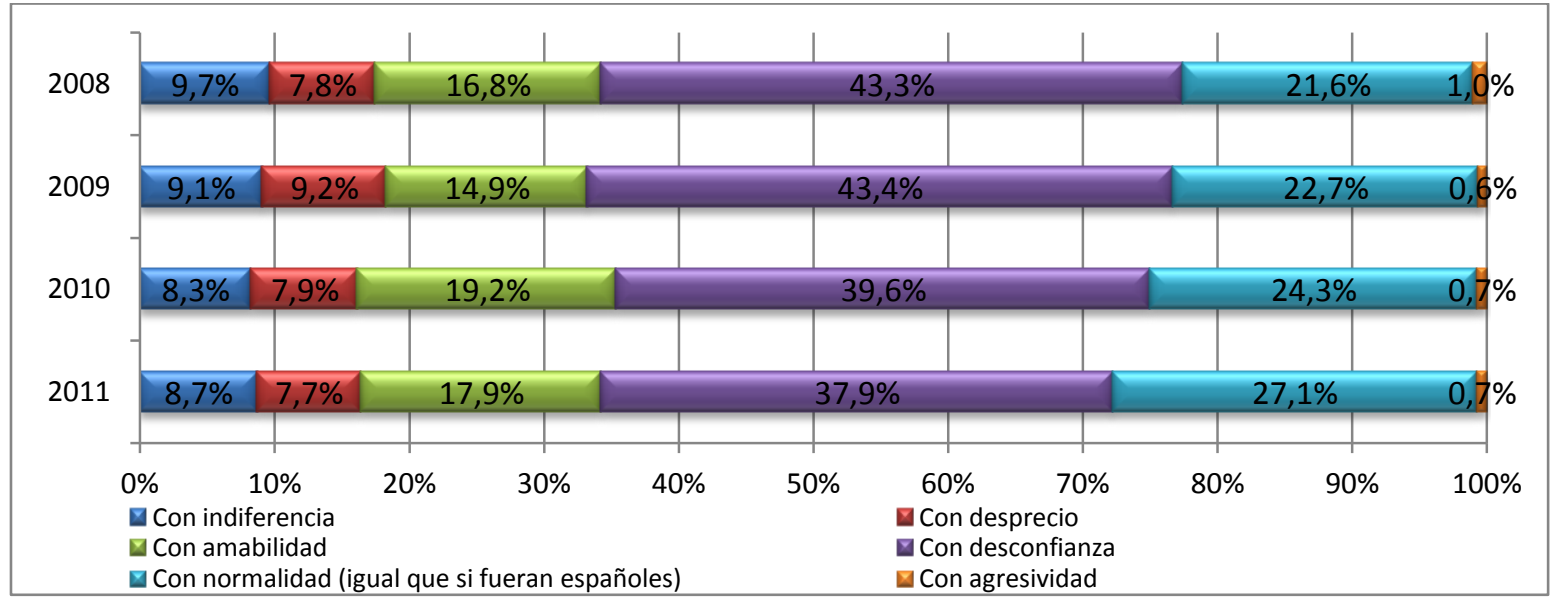

Fuente: Elaboración propia con datos del CIS; estudios 2773 (2008), 2817 (2009), 2846 (2010) y 2918 (2011).

Gráfico 9: Justificación a las reacciones racistas (2008 a 2011).

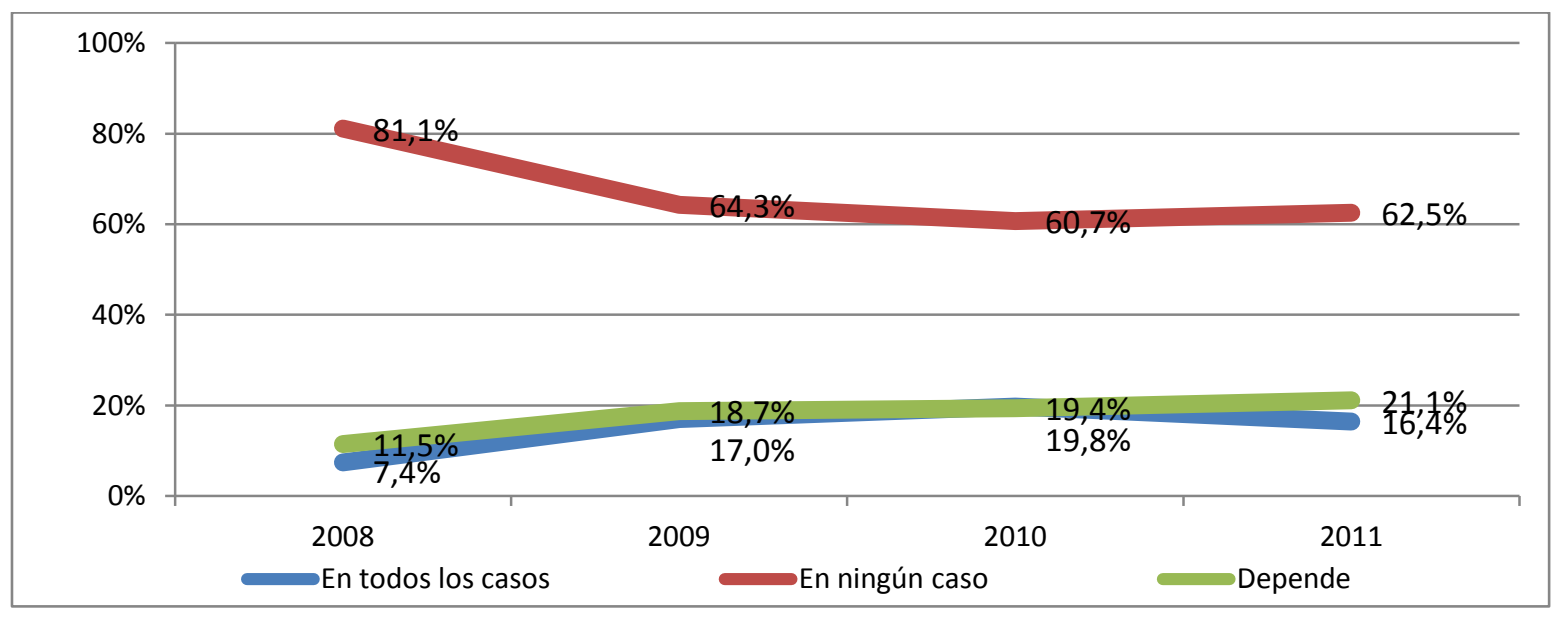

Fuente: Elaboración propia con datos del CIS; estudios 2773 (2008), 2817 (2009), 2846 (2010) y 2918 (2011). 
Gráfico 10: Protección del Estado a las personas inmigrantes (2008 a 2011).

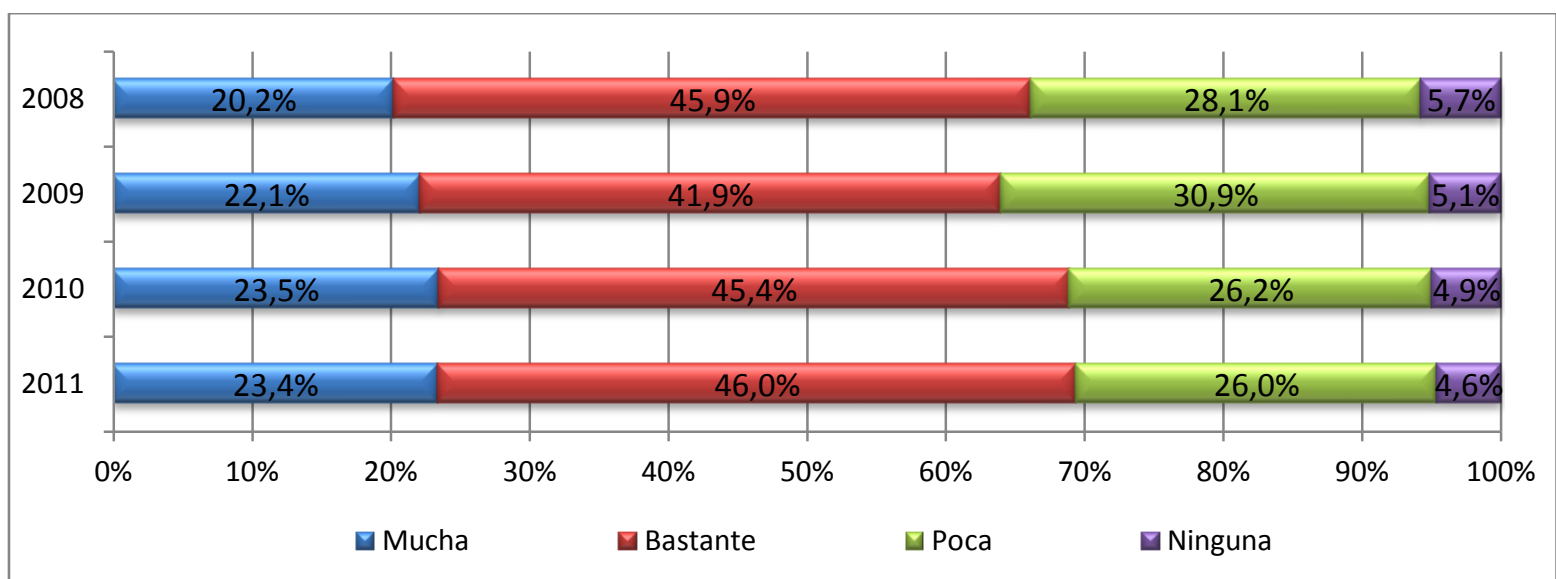

Fuente: Elaboración propia con datos del CIS; estudios 2773 (2008), 2817 (2009), 2846 (2010) y 2918 (2011).

Gráfico 11: Percepción sobre la presencia en España de grupos de nacionalidades (2008 a 2011).

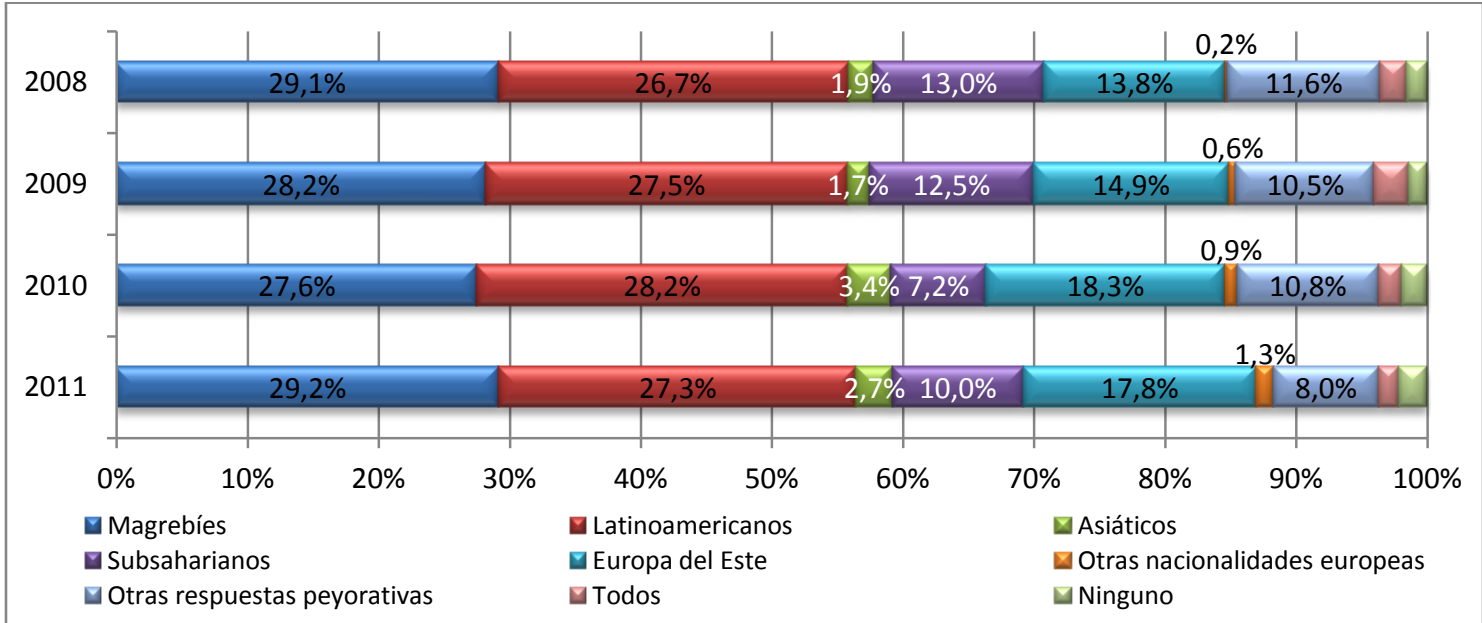

Fuente: Elaboración propia con datos del CIS; estudios 2773 (2008), 2817 (2009), 2846 (2010) y 2918 (2011).

Gráfico 12: Presencia de inmigrantes a nivel local (2008 a 2011).

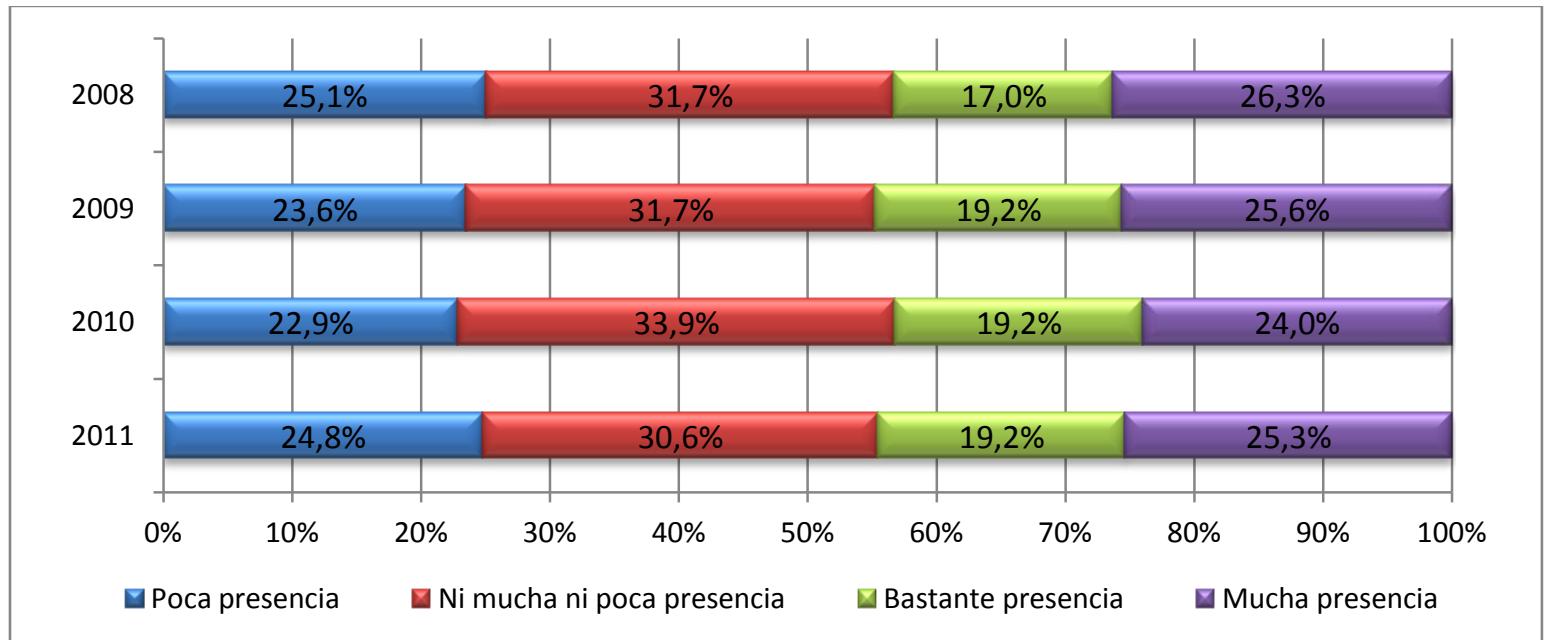

Fuente: Elaboración propia con datos del CIS; estudios 2773 (2008), 2817 (2009), 2846 (2010) y 2918 (2011). 
Gráfico 13: Presencia de inmigrantes a nivel nacional (2008 a 2011).

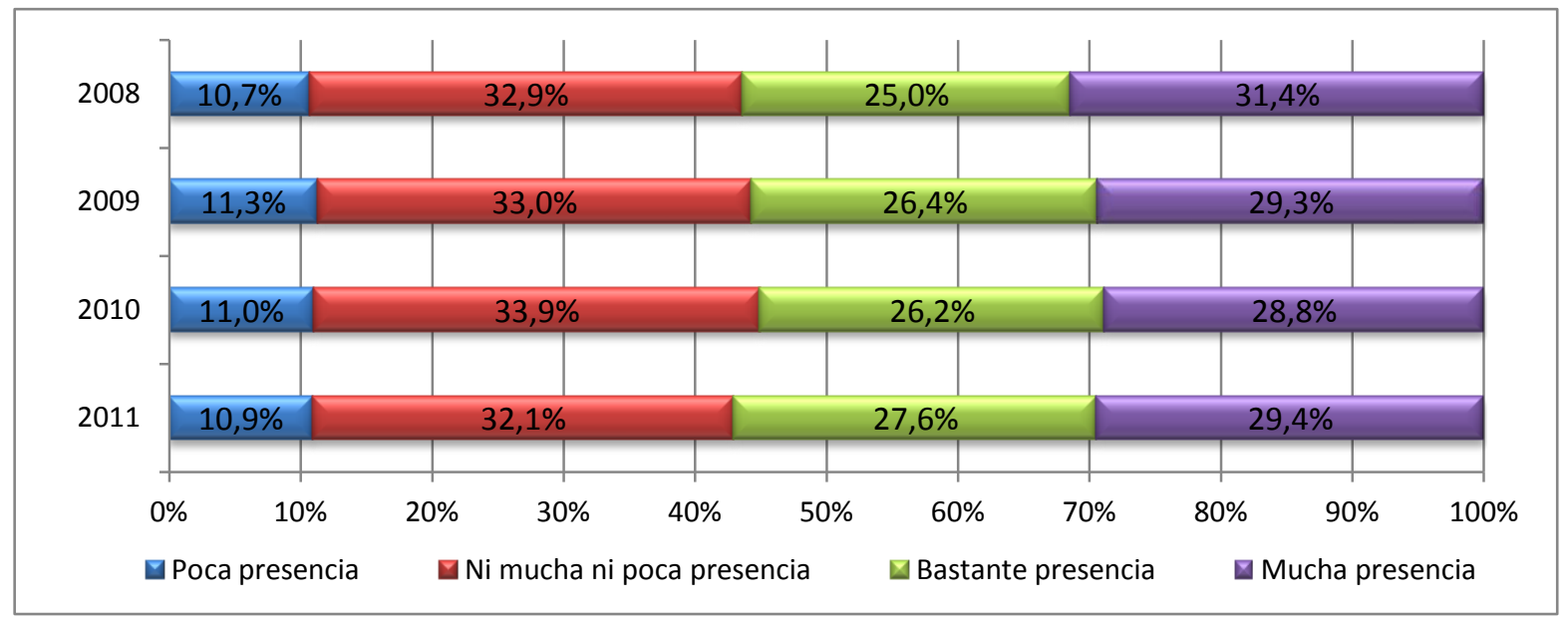

Fuente: Elaboración propia con datos del CIS; estudios 2773 (2008), 2817 (2009), 2846 (2010) y 2918 (2011).

Gráfico 14: Opciones ante las demandas de asilo (2008 a 2011).

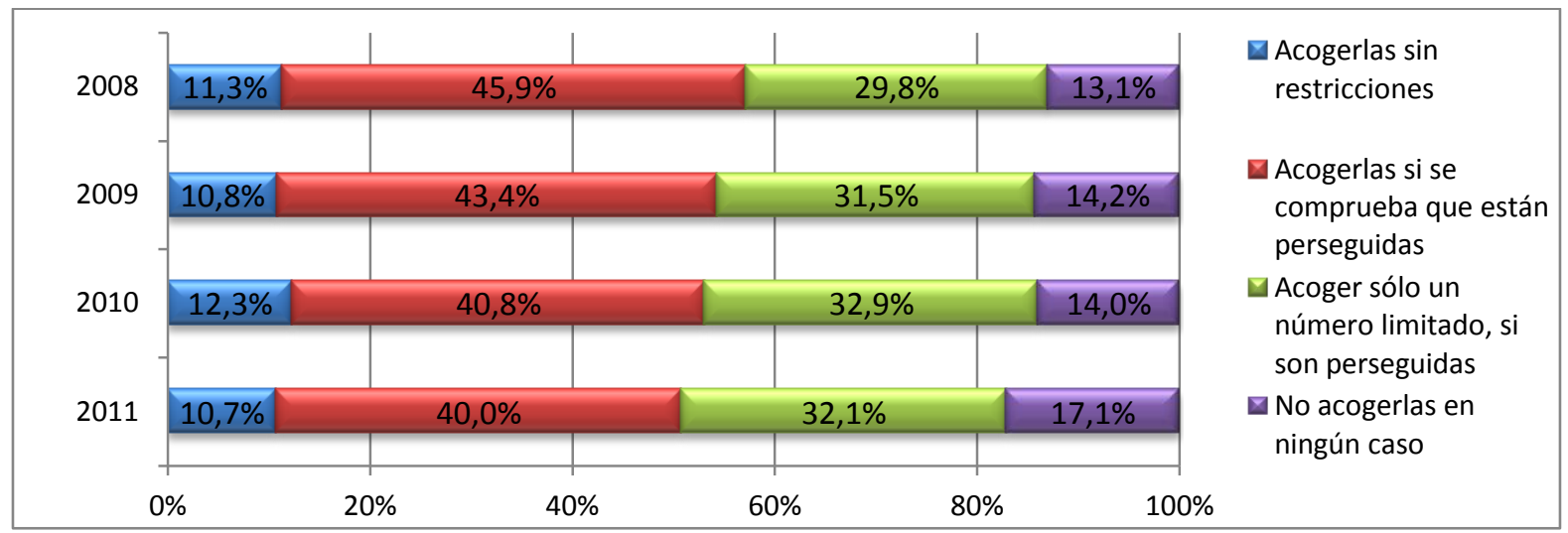

Fuente: Elaboración propia con datos del CIS; estudios 2773 (2008), 2817 (2009), 2846 (2010) y 2918 (2011).

Gráfico 15: Vivir en el mismo bloque en el que viven inmigrantes (2008 a 2011).

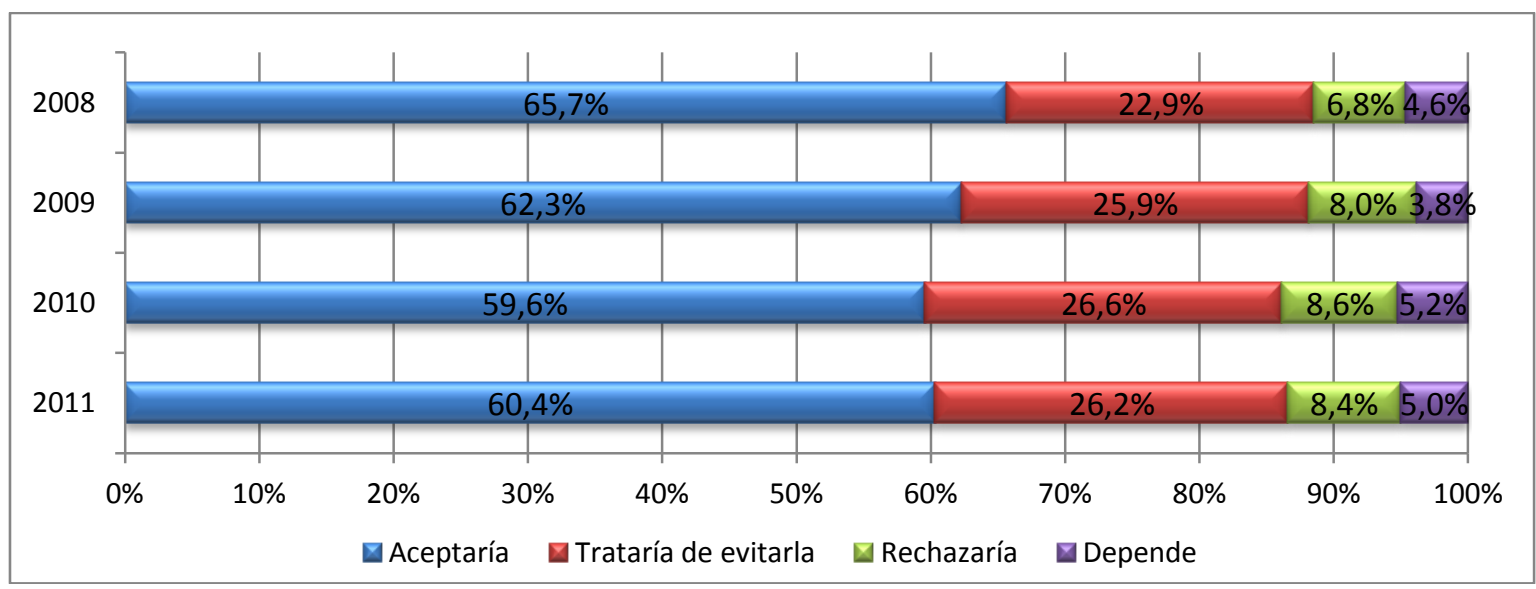

Fuente: Elaboración propia con datos del CIS; estudios 2773 (2008), 2817 (2009), 2846 (2010) y 2918 (2011). 
Gráfico 16: Comparativa de la aceptación de las actitudes ante la inmigración en la vida cotidiana.

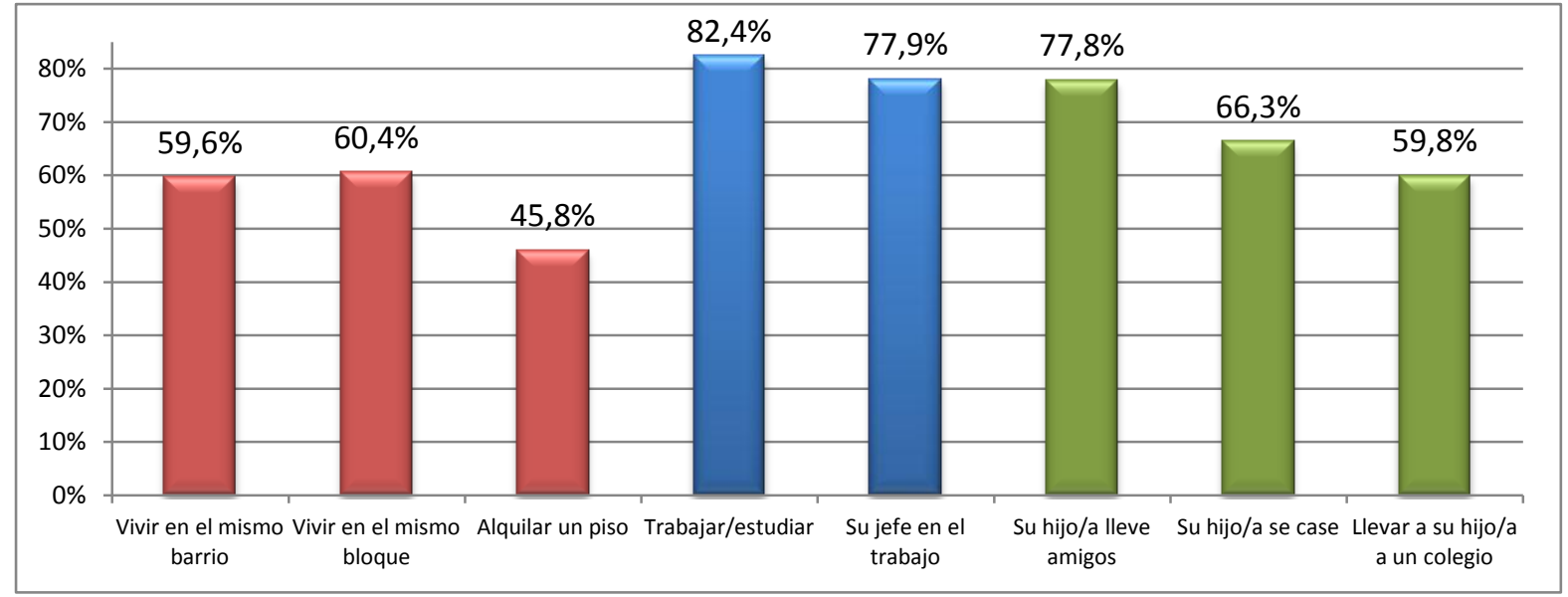

Fuente: Elaboración propia con datos del CIS; estudio 2918 (2011).

Gráfico 17: Grupos de nacionalidad que causan más simpatía (2008 a 2011).

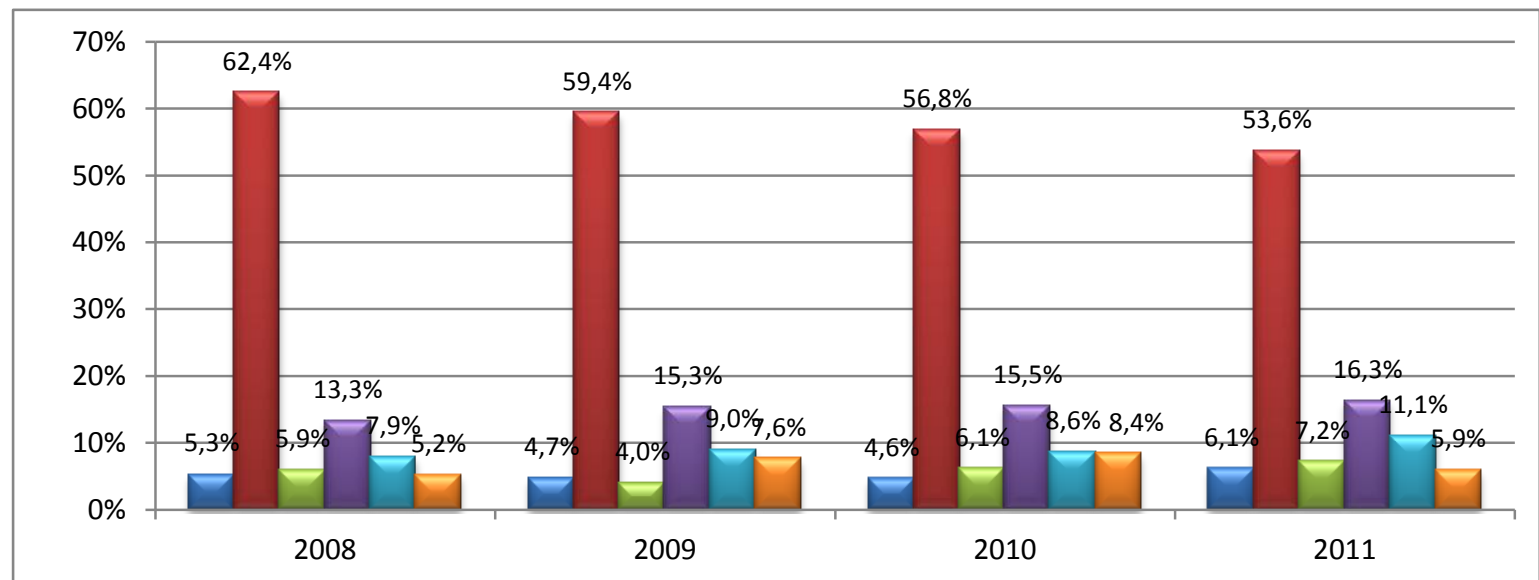

$\nabla$ Magrebíes $\mathbf{\square}$ Latinoamericanos $\square$ Asiaticos $\square$ Subsaharianos $\square$ Europa del Este $\square$ Otras nacionalidades europeas

Fuente: Elaboración propia con datos del CIS; estudios 2773 (2008), 2817 (2009), 2846 (2010) y 2918 (2011).

Tabla 1: Contingencia valoración de la inmigración por la edad

\begin{tabular}{|c|c|c|c|c|c|c|c|c|c|}
\hline & & & \multicolumn{6}{|c|}{ edad_rec } & \multirow[b]{2}{*}{ Total } \\
\hline & & & $18-24$ & $25-34$ & $35-44$ & $45-54$ & $55-64$ & $65+$ & \\
\hline \multirow[t]{4}{*}{ inmigración_pos $P$} & Positiva & Recuento & 112 & 214 & 259 & 214 & 159 & 174 & 1132 \\
\hline & & $\begin{array}{l}\% \text { dentro } \\
\text { de } \\
\text { edad_rec }\end{array}$ & $61,9 \%$ & $53,5 \%$ & $56,4 \%$ & $51,7 \%$ & $48,9 \%$ & $39,6 \%$ & $51,0 \%$ \\
\hline & Negativa & Recuento & 69 & 186 & 200 & 200 & 166 & 265 & 1086 \\
\hline & & $\begin{array}{l}\% \text { dentro } \\
\text { de } \\
\text { edad_rec }\end{array}$ & $38,1 \%$ & $46,5 \%$ & $43,6 \%$ & $48,3 \%$ & $51,1 \%$ & $60,4 \%$ & $49,0 \%$ \\
\hline \multirow[t]{2}{*}{ Total } & & Recuento & 181 & 400 & 459 & 414 & 325 & 439 & 2218 \\
\hline & & $\begin{array}{l}\% \text { dentro } \\
\text { de } \\
\text { edad_rec }\end{array}$ & $100,0 \%$ & $100,0 \%$ & $100,0 \%$ & $100,0 \%$ & $100,0 \%$ & $100,0 \%$ & $100,0 \%$ \\
\hline
\end{tabular}

Fuente: Elaboración propia con datos del CIS; estudio 2918 (2011).

Significación del chi-cuadrado 0,000 . $0 \%$ de casilla con frecuencia esperada menor a 5 . 
Tabla 2: Contingencia valoración de la inmigración por nivel de estudios

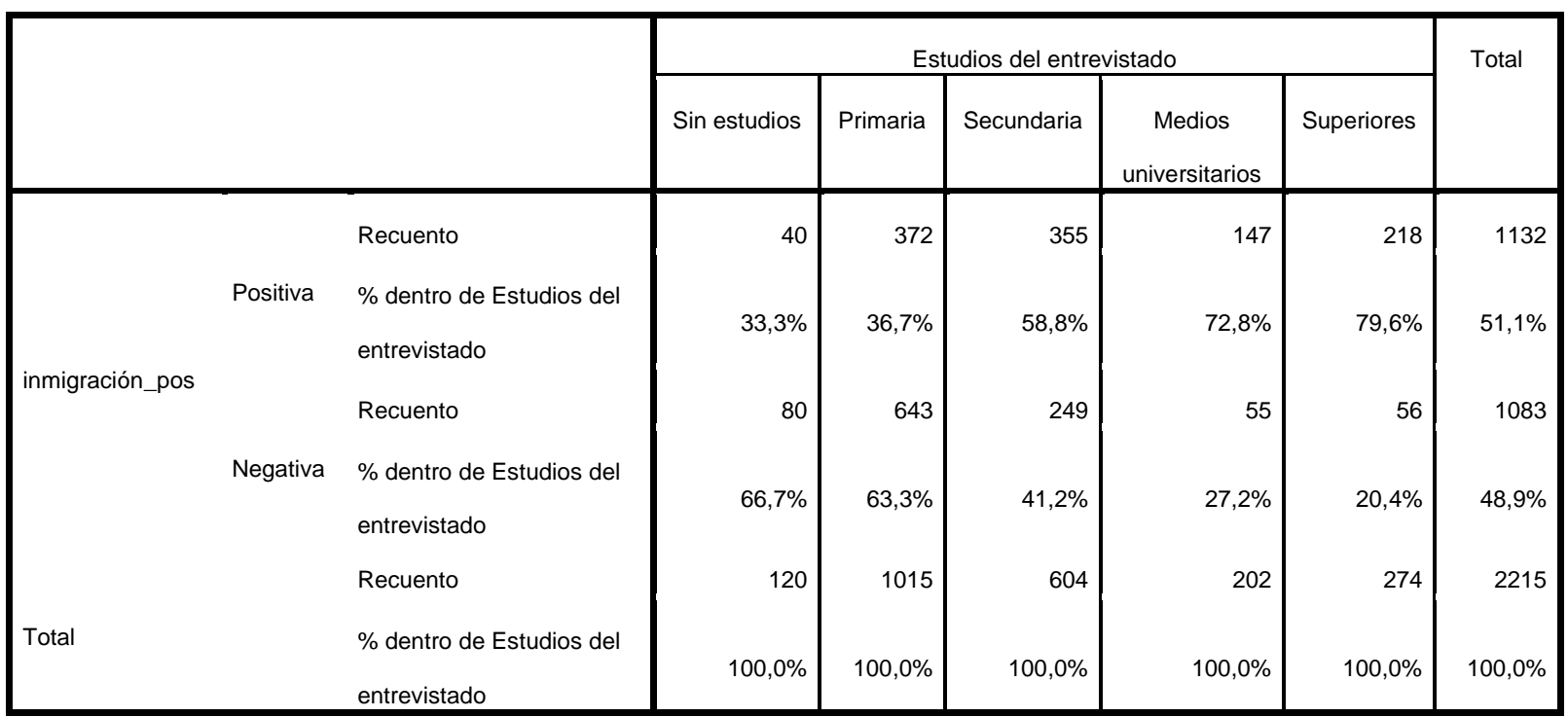

Fuente: Elaboración propia con datos del CIS; estudio 2918 (2011).

Significación del chi-cuadrado 0,000 . $0 \%$ de casilla con frecuencia esperada menor a 5 .

Tabla 3: Contingencia valoración de la inmigración por tener familiares inmigrantes

\begin{tabular}{|c|c|c|c|c|c|}
\hline & & & Fami & & Total \\
\hline & & & Sí & No & \\
\hline & & Recuento & 290 & 839 & 1129 \\
\hline & & $\%$ dentro de Familiares & $69,9 \%$ & $46,8 \%$ & $51,1 \%$ \\
\hline & & Recuento & 125 & 955 & 1080 \\
\hline & & $\%$ dentro de Familiares & $30,1 \%$ & $53,2 \%$ & $48,9 \%$ \\
\hline & & Recuento & 415 & 1794 & 2209 \\
\hline & & $\%$ dentro de Familiares & $100,0 \%$ & $100,0 \%$ & $100,0 \%$ \\
\hline
\end{tabular}

Fuente: Elaboración propia con datos del CIS; estudio 2918 (2011).

Significación del chi-cuadrado 0,000 . $0 \%$ de casilla con frecuencia esperada menor a 5 .

Tabla 4: Contingencia quitar puestos de trabajo por estatus socioeconómico

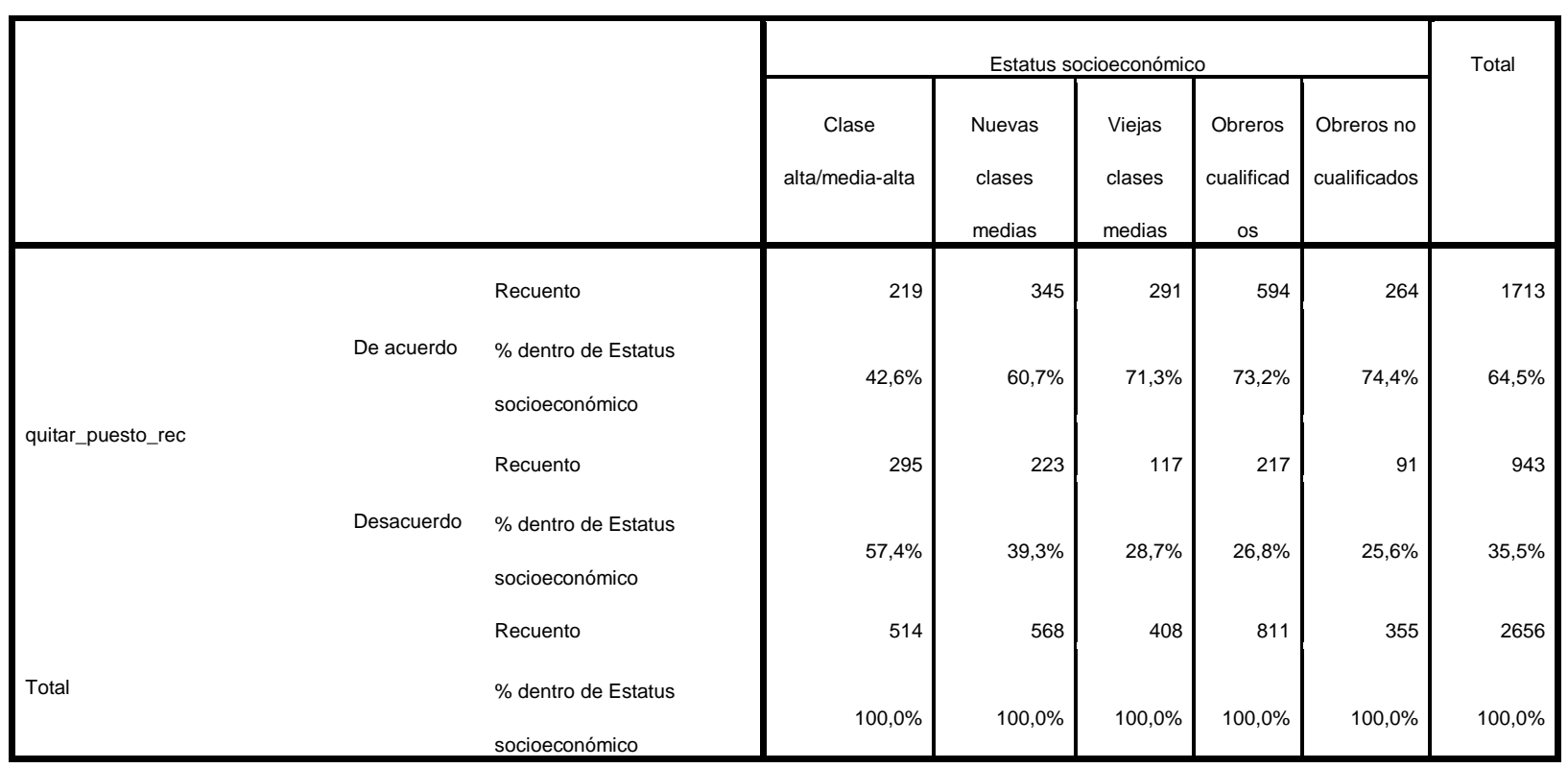


Fuente: Elaboración propia con datos del CIS; estudio 2918 (2011).

Significación del chi-cuadrado $0,000.0 \%$ de casilla con frecuencia esperada menor a 5 .

Tabla 5: Contingencia quitar puestos de trabajo por ideología

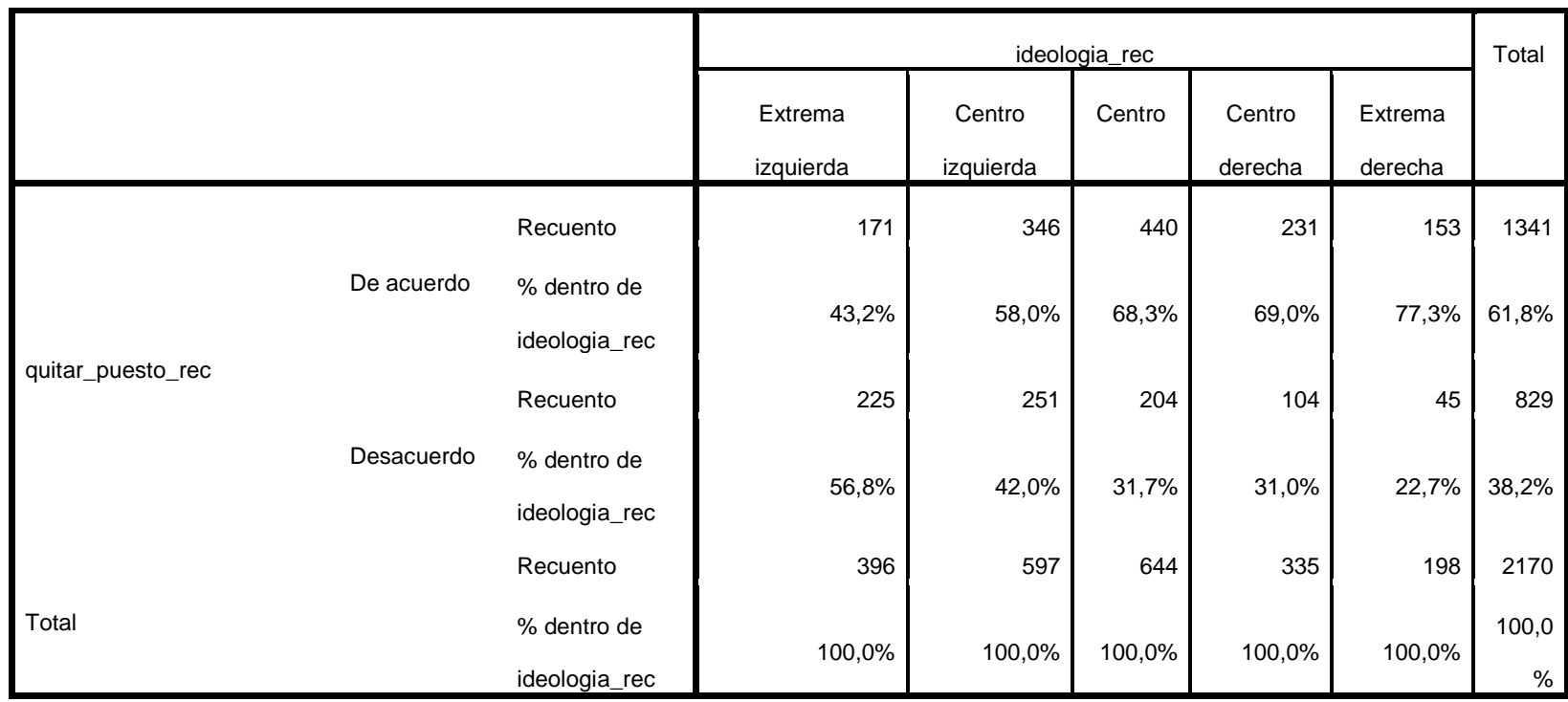

Fuente: Elaboración propia con datos del CIS; estudio 2918 (2011).

Significación del chi-cuadrado 0,000 . $0 \%$ de casilla con frecuencia esperada menor a 5 .

Tabla 6: Contingencia quitar puestos de trabajo por compañeros de trabajo

\begin{tabular}{|lll|r|r|r|}
\hline & & \multicolumn{2}{|c|}{ Compañeros } & \multirow{2}{*}{ Total } \\
\cline { 3 - 5 } & & \multicolumn{1}{c|}{ Sí } & No & \\
\hline & & & 389 & 647 & 1036 \\
quitar_puesto_rec & & Recuento & $49,6 \%$ & $67,3 \%$ & $59,3 \%$ \\
& Desacuerdo & \% dentro de Compañeros & 396 & 315 & 711 \\
& & \% dentro de Compañeros & $50,4 \%$ & $32,7 \%$ & $40,7 \%$ \\
Total & & Recuento & 785 & 962 & 1747 \\
& & \% dentro de Compañeros & $100,0 \%$ & $100,0 \%$ & $100,0 \%$ \\
\hline
\end{tabular}

Fuente: Elaboración propia con datos del CIS; estudio 2918 (2011).

Significación del chi-cuadrado $0,000.0 \%$ de casilla con frecuencia esperada menor a 5 .

Tabla 7: Contingencia ataques o agresiones violentas de inmigrantes por nivel de racismo

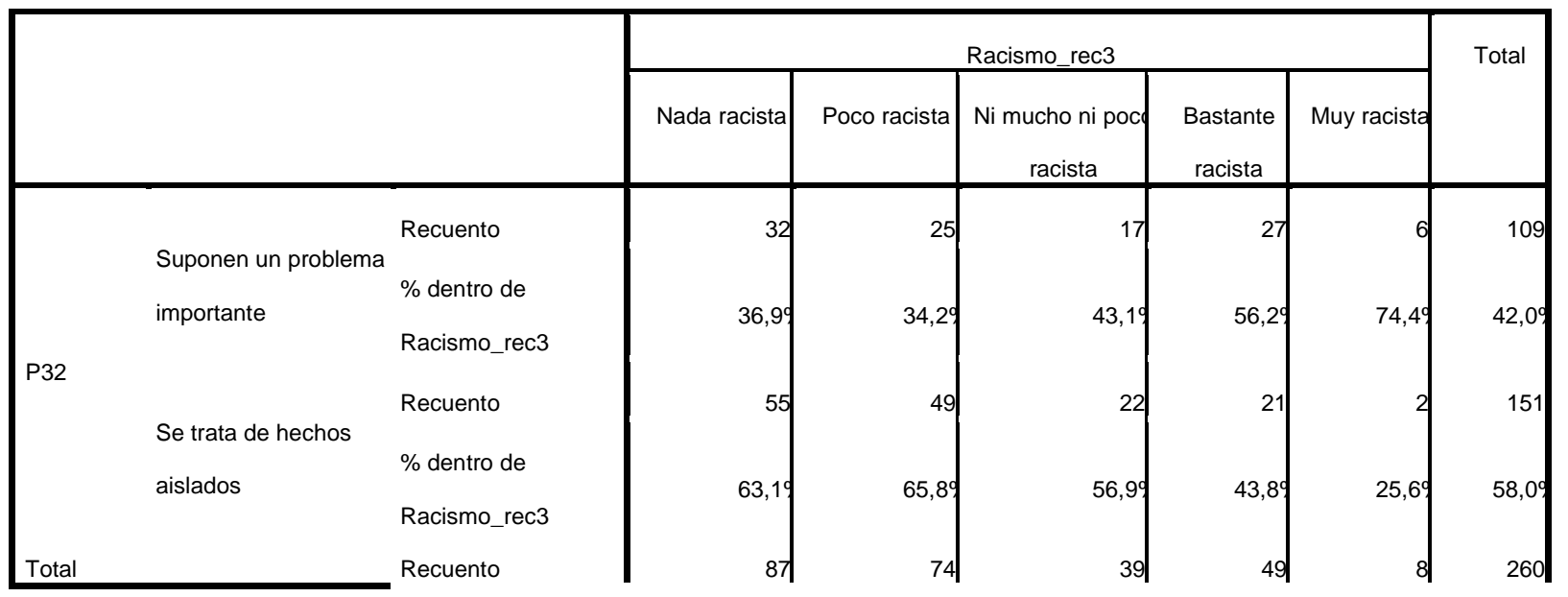




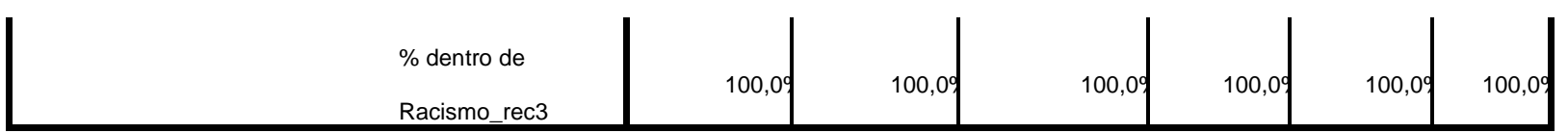

Fuente: Elaboración propia con datos del CIS; estudio 2918 (2011).

Significación del chi-cuadrado 0,000 . $0 \%$ de casilla con frecuencia esperada menor a 5 .

Tabla 8: Contingencia ataques o agresiones violentas de inmigrantes por grado de confianza

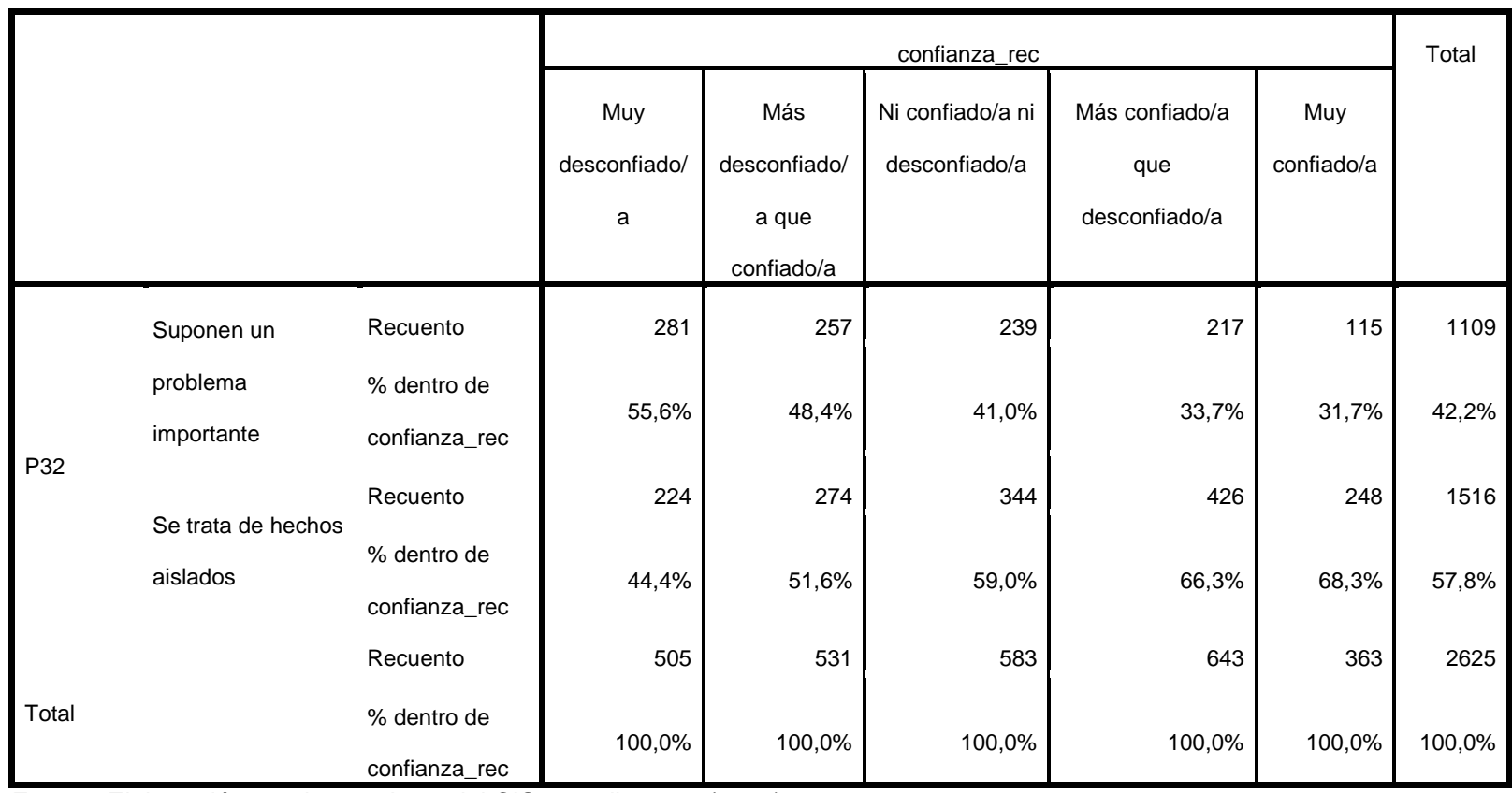

Fuente: Elaboración propia con datos del CIS; estudio 2918 (2011).

Significación del chi-cuadrado 0,000 . $0 \%$ de casilla con frecuencia esperada menor a 5 .

Tabla 9: Contingencia ataques o agresiones violentas de inmigrantes por amistades inmigrantes

\begin{tabular}{|c|c|c|c|c|c|}
\hline \multicolumn{5}{|c|}{ 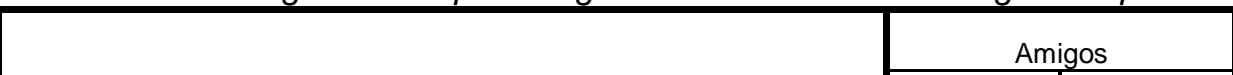 } & \multirow[t]{2}{*}{ Total } \\
\hline & & & Sí & No & \\
\hline \multirow{4}{*}{ P32 } & Suponen un problema & Recuento & 442 & 671 & 1113 \\
\hline & importante & $\%$ dentro de Amigos & $37,3 \%$ & $46,4 \%$ & $42,3 \%$ \\
\hline & & Recuento & 743 & 776 & 1519 \\
\hline & & $\%$ dentro de Amigos & $62,7 \%$ & $53,6 \%$ & $57,7 \%$ \\
\hline \multirow{2}{*}{ Total } & & Recuento & 1185 & 1447 & 2632 \\
\hline & & $\%$ dentro de Amigos & $100,0 \%$ & $100,0 \%$ & $100,0 \%$ \\
\hline
\end{tabular}

Fuente: Elaboración propia con datos del CIS; estudio 2918 (2011).

Significación del chi-cuadrado 0,000 . $0 \%$ de casilla con frecuencia esperada menor a 5 .

Tabla 10: Contingencia de la percepción del número de inmigrantes por nivel de estudios

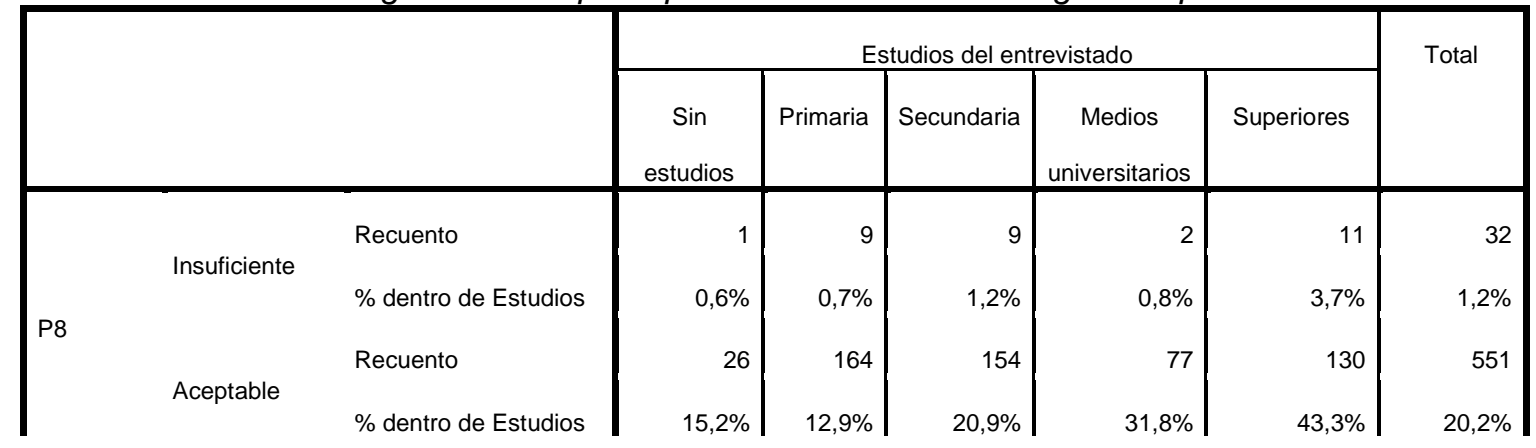




\begin{tabular}{|c|c|c|c|c|c|c|c|c|}
\hline & & Recuento & 47 & 408 & 266 & 86 & 96 & 903 \\
\hline & & $\%$ dentro de Estudios & $27,5 \%$ & $32,0 \%$ & $36,0 \%$ & $35,5 \%$ & $32,0 \%$ & $33,1 \%$ \\
\hline & & Recuento & 97 & 695 & 309 & 77 & 63 & 1241 \\
\hline & & $\%$ dentro de Estudios & $56,7 \%$ & $54,5 \%$ & $41,9 \%$ & $31,8 \%$ & $21,0 \%$ & $45,5 \%$ \\
\hline & & Recuento & 171 & 1276 & 738 & 242 & 300 & 2727 \\
\hline & & $\%$ dentro de Estudios & $100,0 \%$ & $100,0 \%$ & $100,0 \%$ & $100,0 \%$ & $100,0 \%$ & $100,0 \%$ \\
\hline
\end{tabular}

Fuente: Elaboración propia con datos del CIS; estudio 2918 (2011).

Significación del chi-cuadrado 0,000 . 15\% de casilla con frecuencia esperada menor a 5 .

Tabla 11: Contingencia de la percepción del número de inmigrantes por nivel de racismo

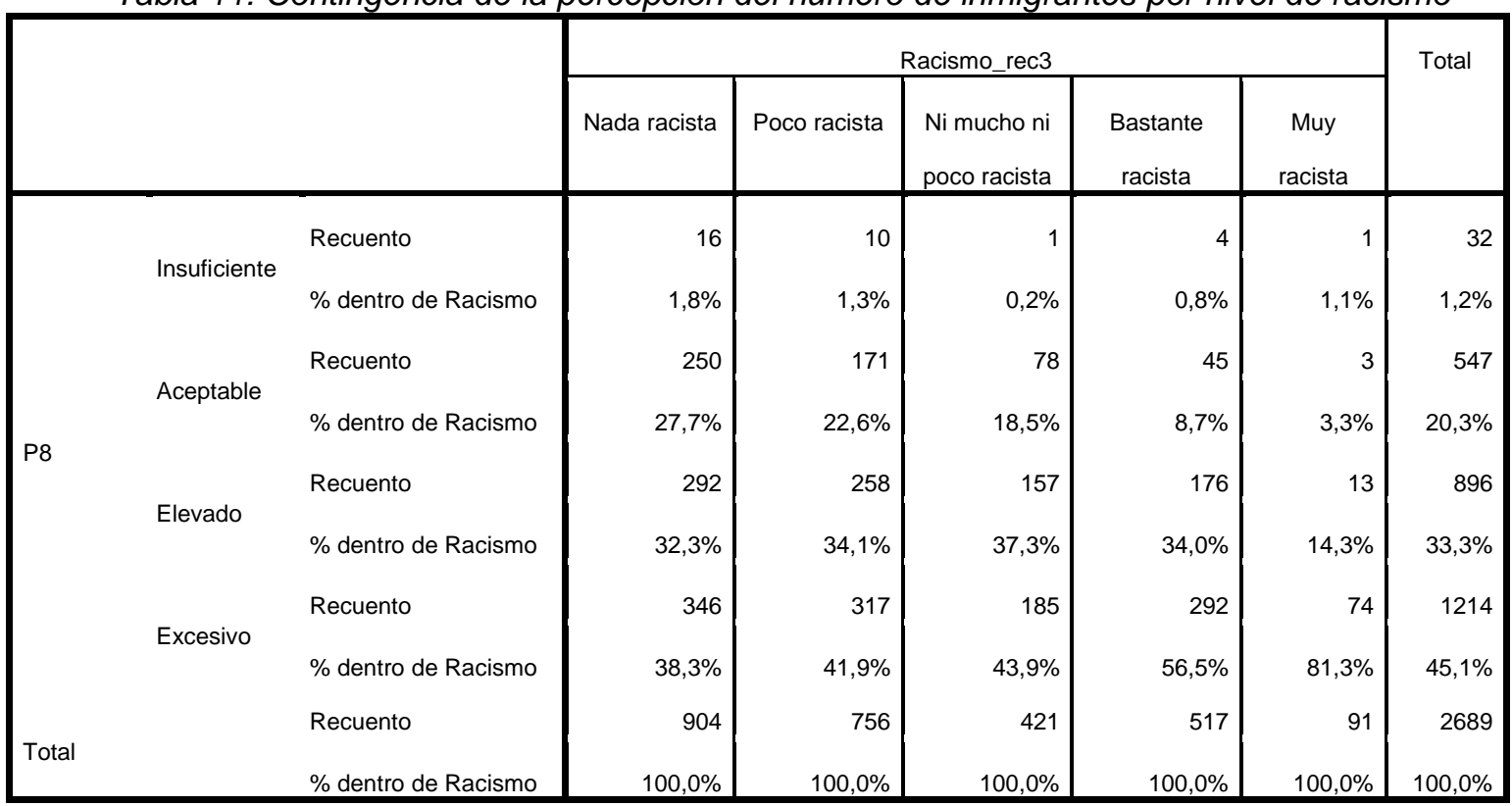

Fuente: Elaboración propia con datos del CIS; estudio 2918 (2011).

Significación del chi-cuadrado $0,000.5 \%$ de casilla con frecuencia esperada menor a 5 .

Tabla 12: Contingencia de la percepción del número de inmigrantes por amistades inmigrantes

\begin{tabular}{|c|c|c|c|c|c|}
\hline & & & Ami & & Total \\
\hline & & & Sí & No & \\
\hline & & Recuento & 20 & 13 & 33 \\
\hline & Insuficiente (se necesitan más) & O dentro do A mirnes & $17 \%$ & $09 \%$ & $12 \%$ \\
\hline & & Recuento & 339 & 210 & 549 \\
\hline & Aceptable & \% dentro de Amians & $282 \%$ & $138 \%$ & $202 \%$ \\
\hline P8 & & Recuento & 395 & 507 & 002 \\
\hline & Elevado & necuentio & & & 902 \\
\hline & & $\%$ dentro de Amigos & $32,9 \%$ & $33,3 \%$ & $33,1 \%$ \\
\hline & & Recuento & 447 & 792 & 1239 \\
\hline & Excesivo & $\%$ dentro de Amigos & $37,2 \%$ & $52,0 \%$ & $45,5 \%$ \\
\hline & & Recuento & 1201 & 1522 & 2723 \\
\hline Iotal & & $\%$ dentro de Amigos & $100,0 \%$ & $100,0 \%$ & $100,0 \%$ \\
\hline
\end{tabular}

Fuente: Elaboración propia con datos del CIS; estudio 2918 (2011).

Significación del chi-cuadrado $0,000.0 \%$ de casilla con frecuencia esperada menor a 5 .

Tabla 13: Contingencia de la postura respecto a la inmigración irregular por nivel de estudios 


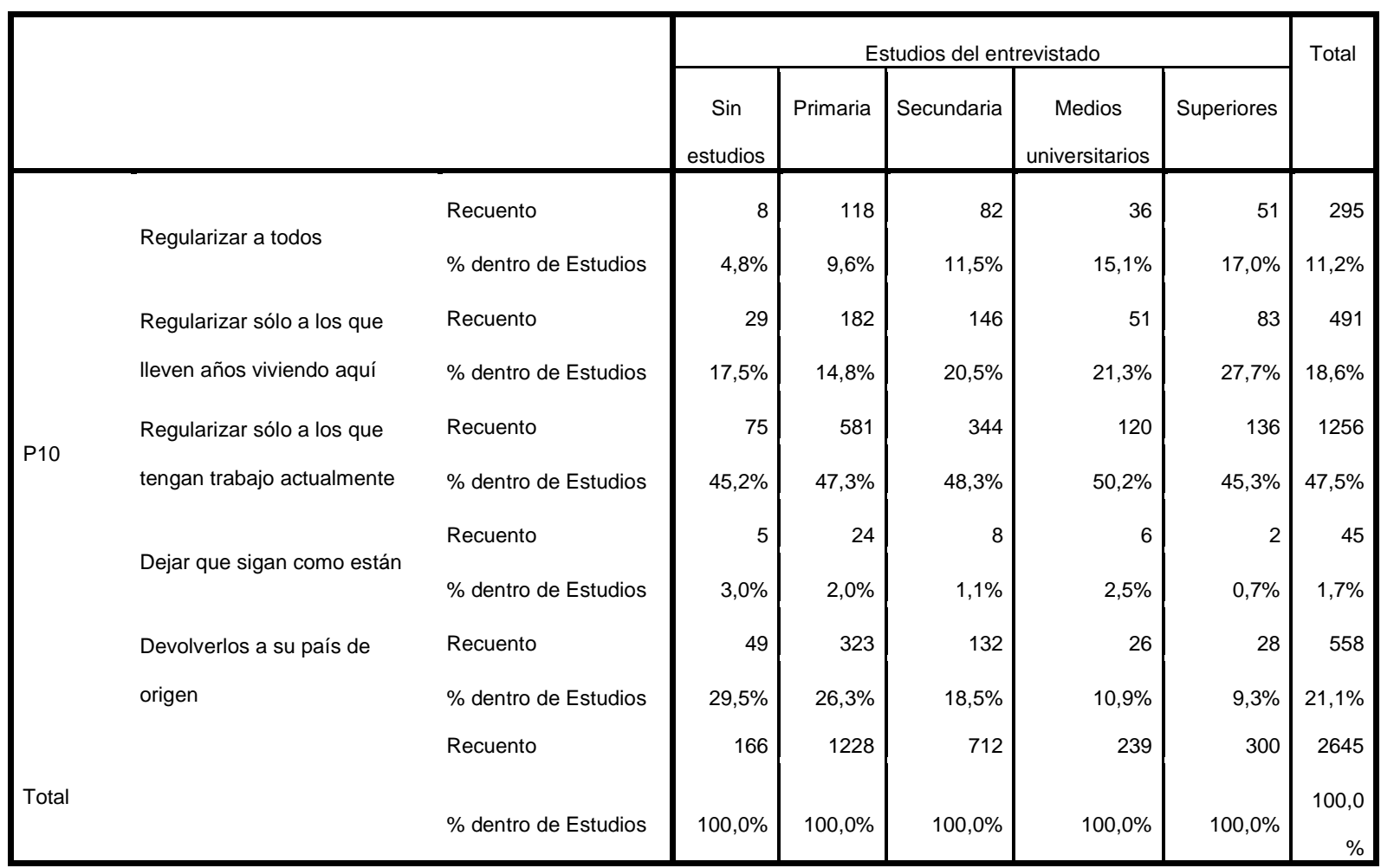

Fuente: Elaboración propia con datos del CIS; estudio 2918 (2011).

Significación del chi-cuadrado $0,000.8,2 \%$ de casilla con frecuencia esperada menor a 5 .

Tabla 14: Contingencia de la postura respecto a la inmigración irregular por ingresos

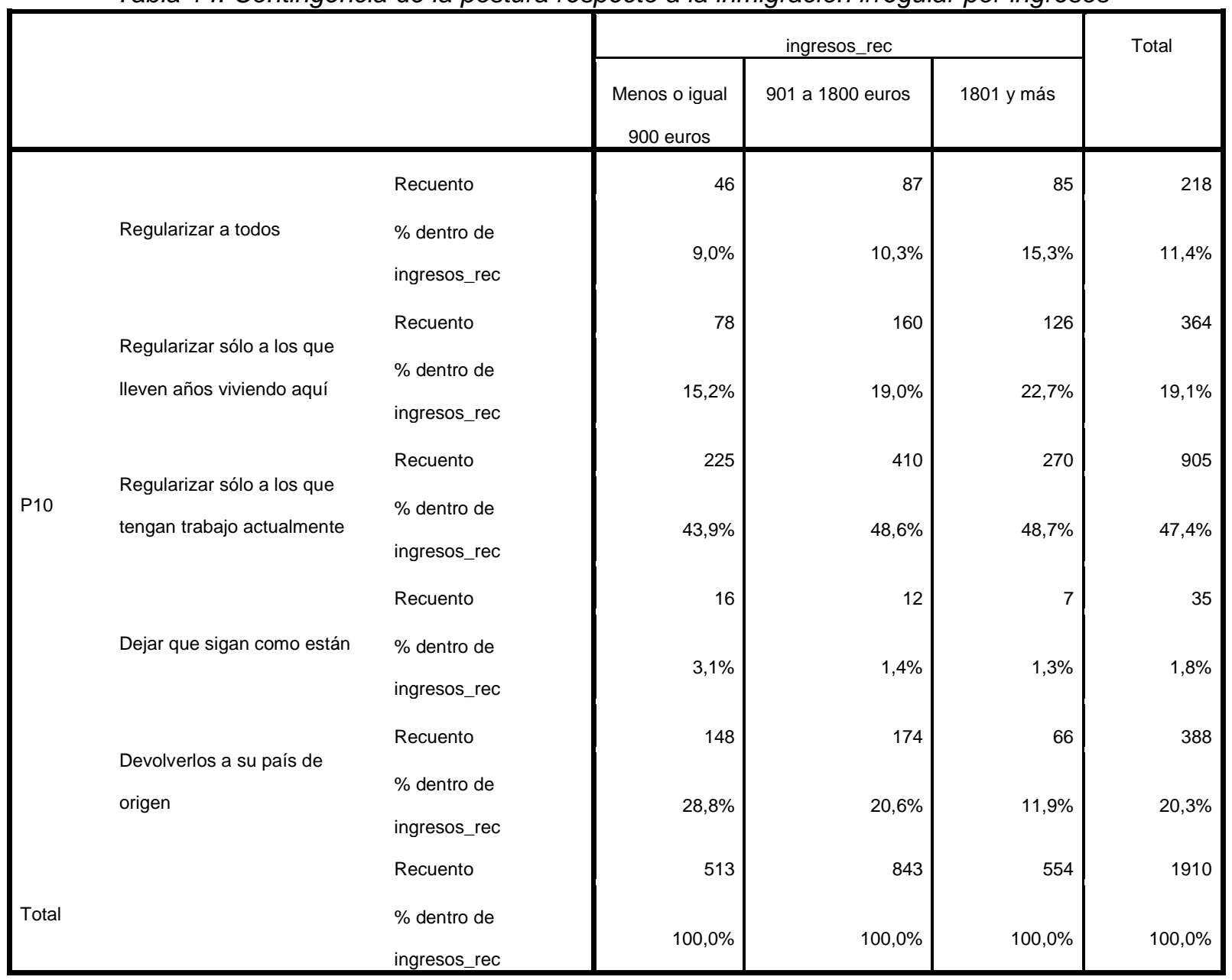


Fuente: Elaboración propia con datos del CIS; estudio 2918 (2011).

Significación del chi-cuadrado 0,000 . $0 \%$ de casilla con frecuencia esperada menor a 5 .

Tabla 15: Contingencia de la postura respecto a la inmigración irregular por amistades inmigrantes

\begin{tabular}{|c|c|c|c|c|c|}
\hline & & & $\mathrm{Am}$ & & Total \\
\hline & & & Sí & No & \\
\hline & & Recuento & 176 & 120 & 296 \\
\hline & neguidilzal a lucius & $\%$ dentro de Amigos & $15,0 \%$ & $8,2 \%$ & $11,2 \%$ \\
\hline & Regularizar sólo a los que & Recuento & 258 & 231 & 489 \\
\hline & lleven años viviendo aquí & $\%$ dentro de Amigos & $22,0 \%$ & $15,7 \%$ & $18,5 \%$ \\
\hline & Regularizar sólo a los que & Recuento & 523 & 729 & 1252 \\
\hline & tengan trabajo actualmente & $\%$ dentro de Amigos & $44,5 \%$ & $49,7 \%$ & $47,4 \%$ \\
\hline & & Recuento & 15 & 31 & 46 \\
\hline & & $\%$ dentro de Amigos & $1,3 \%$ & $2,1 \%$ & $1,7 \%$ \\
\hline & & Recuento & 202 & 356 & 558 \\
\hline & 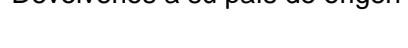 & $\%$ dentro de Amigos & $17,2 \%$ & $24,3 \%$ & $21,1 \%$ \\
\hline & & Recuento & 1174 & 1467 & 2641 \\
\hline 年 & & $\%$ dentro de Amigos & $100,0 \%$ & $100,0 \%$ & $100,0 \%$ \\
\hline
\end{tabular}

Fuente: Elaboración propia con datos del CIS; estudio 2918 (2011)

Significación del chi-cuadrado 0,000 . $0 \%$ de casilla con frecuencia esperada menor a 5 .

Tabla 16: Contingencia de la alquiler un piso a inmigrantes por edad

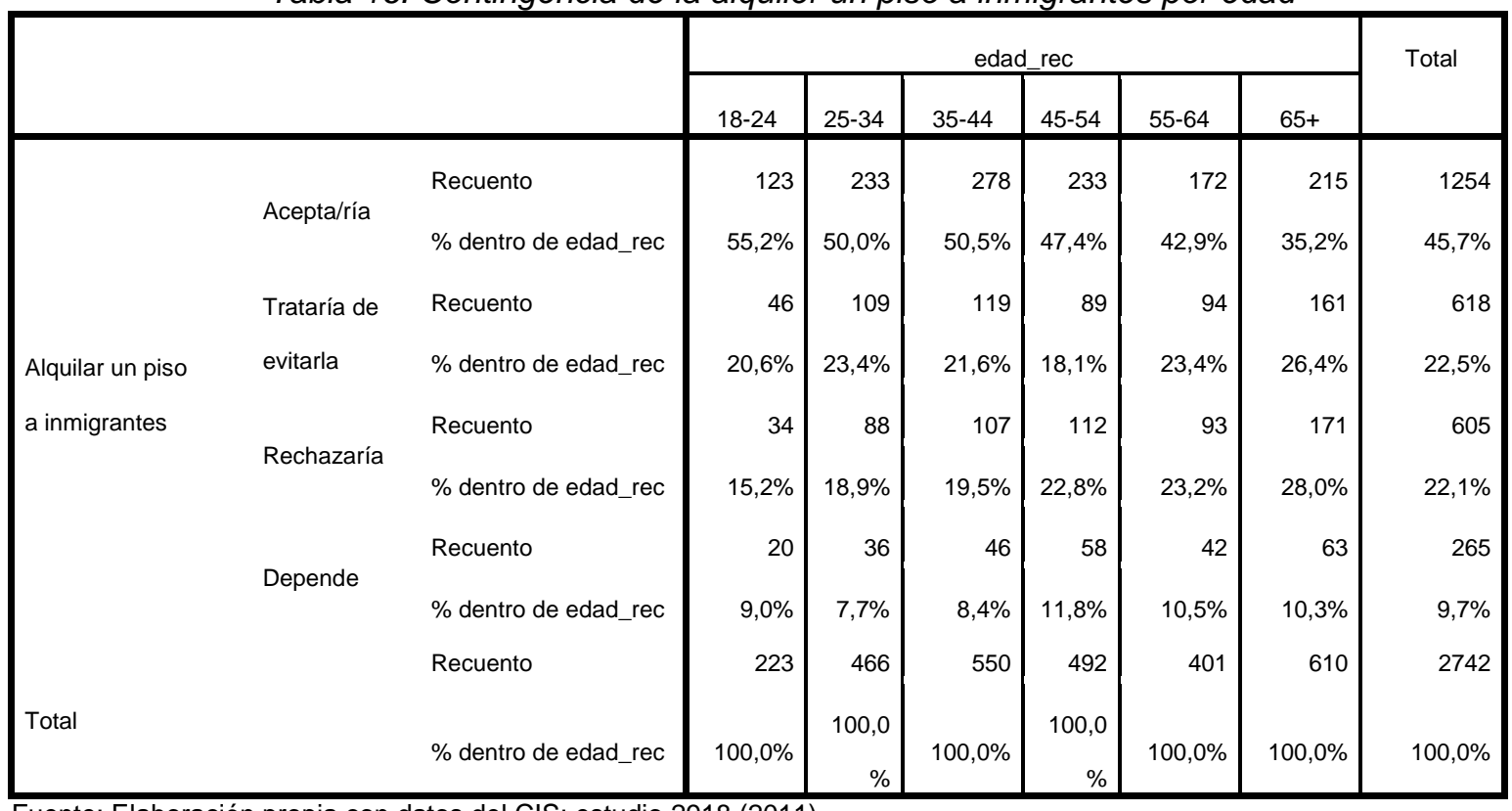

Fuente: Elaboración propia con datos del CIS; estudio 2918 (2011).

Significación del chi-cuadrado $0,000.0 \%$ de casilla con frecuencia esperada menor a 5 .

Tabla 17: Contingencia de la alquiler un piso a inmigrantes por grado de confianza en la gente

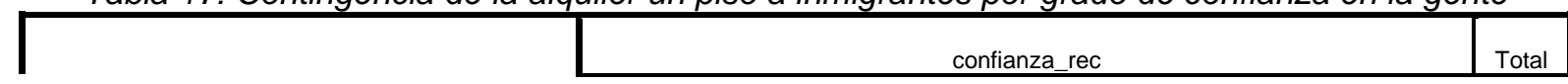




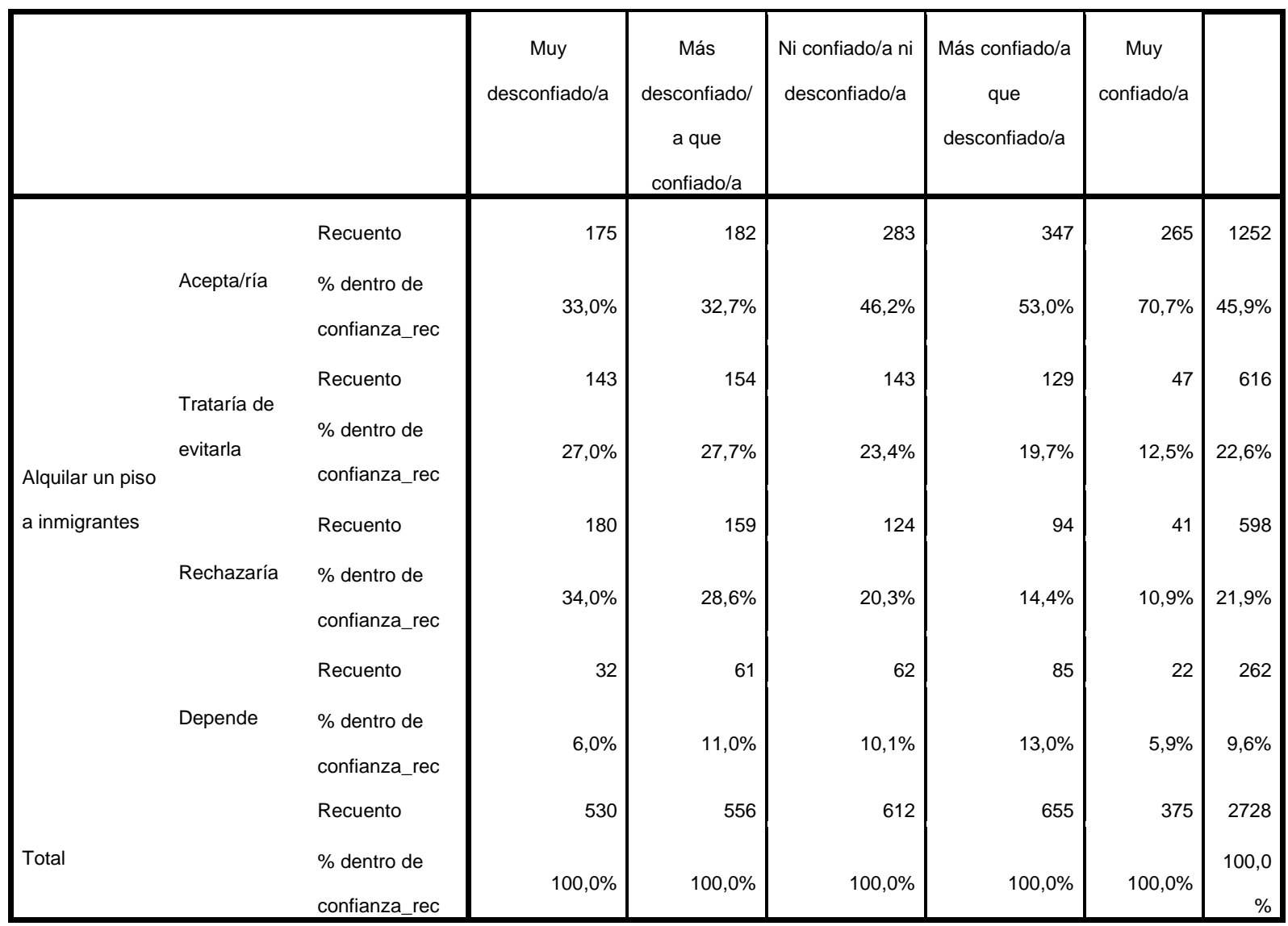

Fuente: Elaboración propia con datos del CIS; estudio 2918 (2011).

Significación del chi-cuadrado $0,000.0 \%$ de casilla con frecuencia esperada menor a 5 .

Tabla 18: Contingencia de la alquiler un piso a inmigrantes por tener vecinos inmigrantes

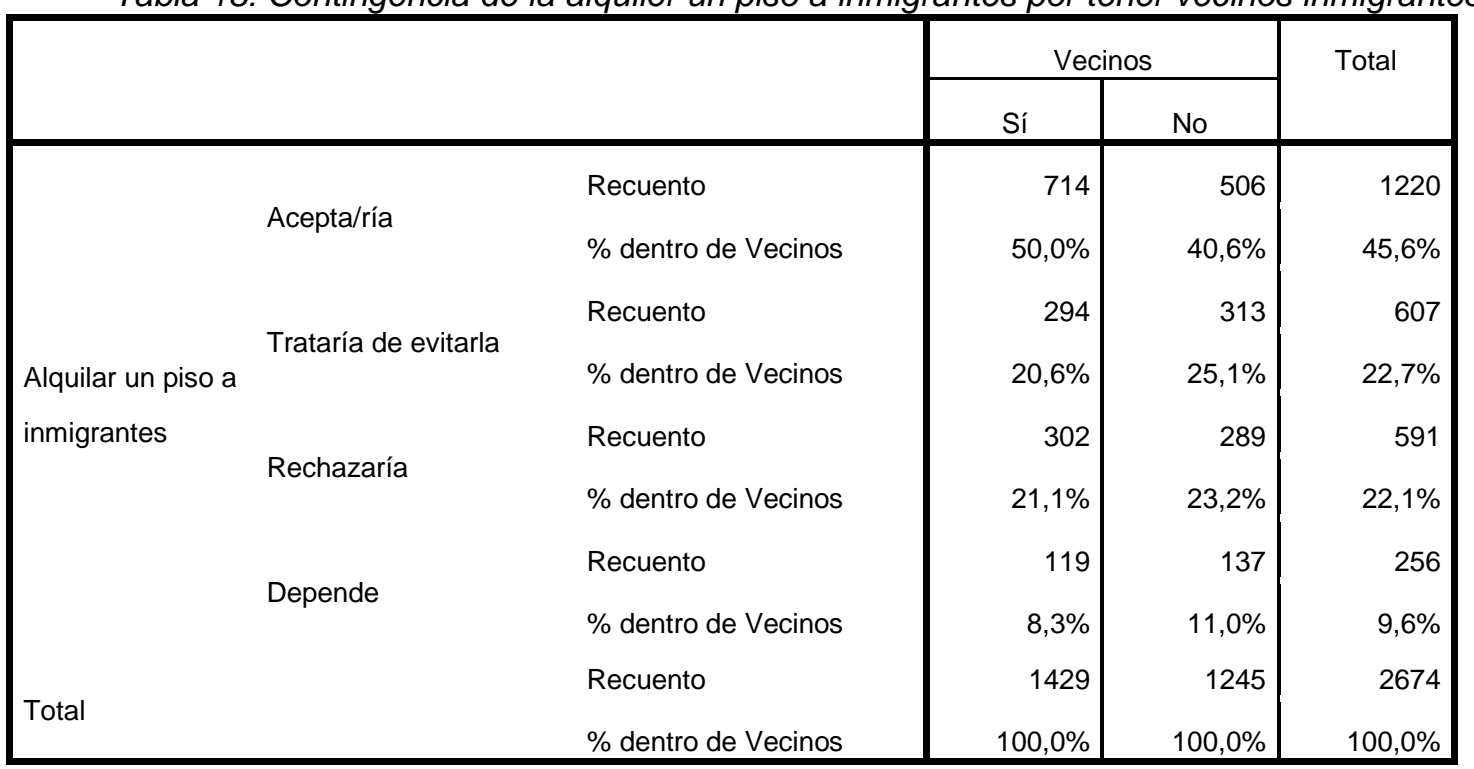

Fuente: Elaboración propia con datos del CIS; estudio 2918 (2011).

Significación del chi-cuadrado 0,000 . $0 \%$ de casilla con frecuencia esperada menor a 5 .

Tabla 19: Contingencia un inmigrante sea el jefe por el nivel de estudios

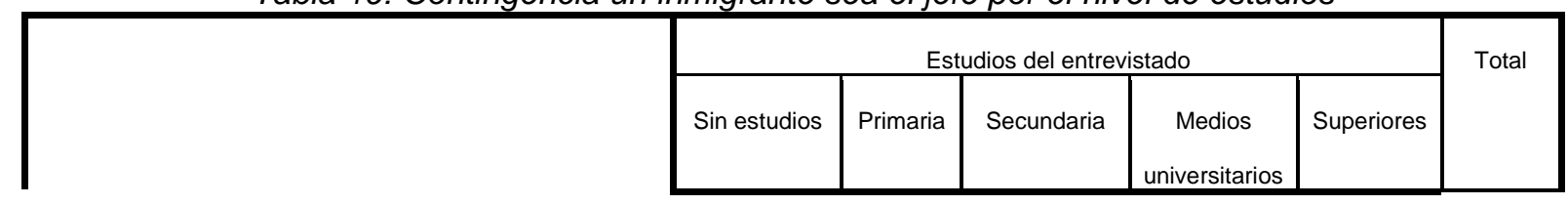




\begin{tabular}{|c|c|c|c|c|c|c|c|c|}
\hline \multirow{7}{*}{$\begin{array}{l}\text { Que un inmigrante } \\
\text { sea su jefe en el } \\
\text { trabajo }\end{array}$} & Acepta/ría & $\begin{array}{l}\text { Recuento } \\
\% \text { dentro de Estudios }\end{array}$ & $\begin{array}{r}115 \\
66,5 \%\end{array}$ & $\begin{array}{r}909 \\
72,6 \%\end{array}$ & $\begin{array}{r}600 \\
81,4 \%\end{array}$ & $\begin{array}{r}215 \\
86,3 \%\end{array}$ & 286 & 2125 \\
\hline & Trataría de & Recuento & 33 & 195 & 71 & 21 & 10 & 330 \\
\hline & evitarla & $\%$ dentro de Estudios & $19,1 \%$ & $15,6 \%$ & $9,6 \%$ & $8,4 \%$ & $3,2 \%$ & $12,1 \%$ \\
\hline & & Recuento & 21 & 82 & 35 & 4 & 7 & 149 \\
\hline & & $\%$ dentro de Estudios & $12,1 \%$ & $6,5 \%$ & $4,7 \%$ & $1,6 \%$ & $2,2 \%$ & $5,5 \%$ \\
\hline & & Recuento & 4 & 66 & 31 & 9 & 14 & 124 \\
\hline & & $\%$ dentro de Estudios & $2,3 \%$ & $5,3 \%$ & $4,2 \%$ & $3,6 \%$ & $4,4 \%$ & $4,5 \%$ \\
\hline & & Recuento & 173 & 1252 & 737 & 249 & 317 & 2728 \\
\hline & & $\%$ dentro de Estudios & $100,0 \%$ & $100,0 \%$ & $100,0 \%$ & $100,0 \%$ & $100,0 \%$ & $100,0 \%$ \\
\hline
\end{tabular}

Fuente: Elaboración propia con datos del CIS; estudio 2918 (2011).

Significación del chi-cuadrado 0,000 . $0 \%$ de casilla con frecuencia esperada menor a 5 .

Tabla 20: Contingencia un inmigrante sea el jefe por la situación laboral

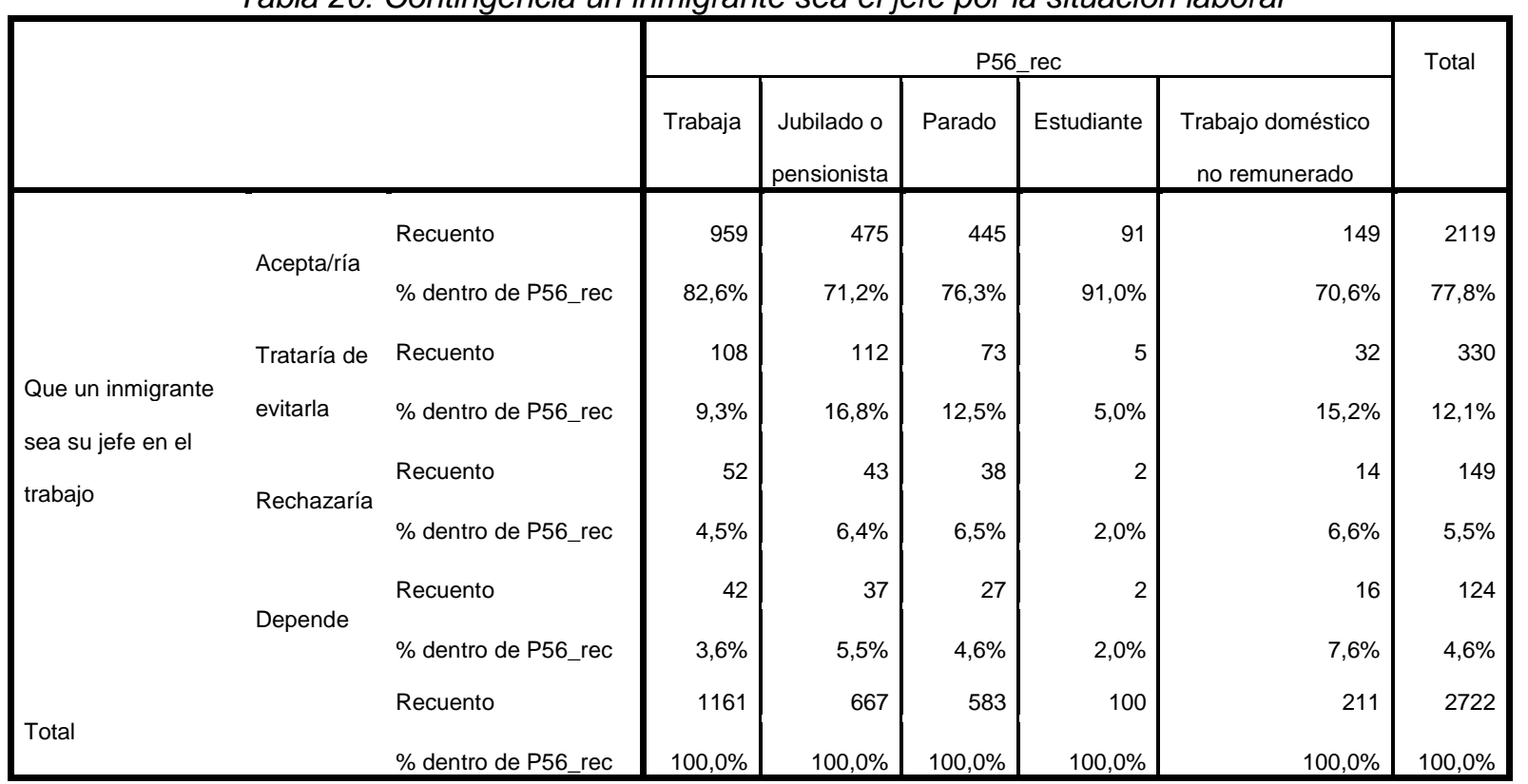

Fuente: Elaboración propia con datos del CIS; estudio 2918 (2011).

Significación del chi-cuadrado 0,000 . $5 \%$ de casilla con frecuencia esperada menor a 5 .

Tabla 21: Contingencia un inmigrante sea el jefe por tener compañeros inmigrantes

\begin{tabular}{|c|c|c|c|c|c|}
\hline & & & Comp & & Total \\
\hline & & & Sí & No & \\
\hline & & Recuento & 720 & 732 & 1452 \\
\hline & Acepta/ría & $\%$ dentro de Compañeros & $89,4 \%$ & $75,0 \%$ & $81,5 \%$ \\
\hline & Trataría de & Recuento & 48 & 143 & 191 \\
\hline Que un & evitarla & \% dentro de Compañeros & $6,0 \%$ & $14,7 \%$ & $10,7 \%$ \\
\hline jefe en el trabaio & & Recuento & 23 & 52 & 75 \\
\hline & & \% dentro de Compañeros & $2,9 \%$ & $5,3 \%$ & $4,2 \%$ \\
\hline & & Recuento & 14 & 49 & 63 \\
\hline & 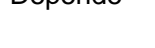 & $\%$ dentro de Compañeros & $1,7 \%$ & $5,0 \%$ & $3,5 \%$ \\
\hline
\end{tabular}




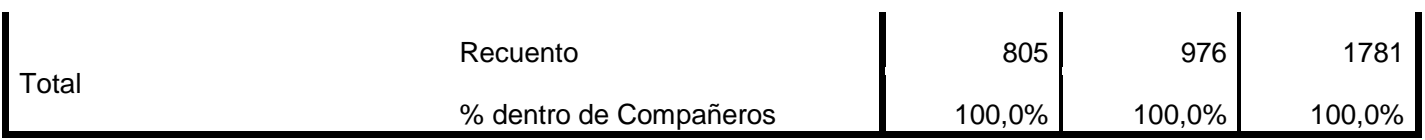

Fuente: Elaboración propia con datos del CIS; estudio 2918 (2011).

Significación del chi-cuadrado $0,000.5 \%$ de casilla con frecuencia esperada menor a 5 .

Tabla 22: Contingencia llevar a un colegio con niños inmigrantes por edad

\begin{tabular}{|c|c|c|c|c|c|c|c|c|c|}
\hline & \multicolumn{6}{|c|}{ edad_rec } & \multirow[t]{2}{*}{ Total } \\
\hline & & & $18-24$ & 25-34 & $35-44$ & $45-54$ & $55-64$ & $65+$ & \\
\hline \multirow{8}{*}{$\begin{array}{l}\text { Llevar a su hijo/a a } \\
\text { un colegio donde } \\
\text { haya muchos niños } \\
\text { hijos de inmigrantes }\end{array}$} & \multirow{2}{*}{ Acepta/ría } & Recuento & 143 & 300 & 338 & 287 & 242 & 328 & 1638 \\
\hline & & $\%$ dentro de edad_rec & $63,8 \%$ & $63,6 \%$ & $61,1 \%$ & $57,7 \%$ & $60,7 \%$ & $55,4 \%$ & $59,8 \%$ \\
\hline & Trataría de & Recuento & 62 & 118 & 155 & 146 & 108 & 178 & 767 \\
\hline & evitarla & $\%$ dentro de edad_rec & $27,7 \%$ & $25,0 \%$ & $28,0 \%$ & $29,4 \%$ & $27,1 \%$ & $30,1 \%$ & $28,0 \%$ \\
\hline & \multirow{2}{*}{ Rechazaría } & Recuento & 8 & 28 & 44 & 33 & 31 & 56 & 200 \\
\hline & & $\%$ dentro de edad_rec & $3,6 \%$ & $5,9 \%$ & $8,0 \%$ & $6,6 \%$ & $7,8 \%$ & $9,5 \%$ & $7,3 \%$ \\
\hline & \multirow{2}{*}{ Depende } & Recuento & 11 & 26 & 16 & 31 & 18 & 30 & 132 \\
\hline & & $\%$ dentro de edad_rec & $4,9 \%$ & $5,5 \%$ & $2,9 \%$ & $6,2 \%$ & $4,5 \%$ & $5,1 \%$ & $4,8 \%$ \\
\hline \multirow{2}{*}{ Total } & & Recuento & 224 & 472 & 553 & 497 & 399 & 592 & 2737 \\
\hline & & $\%$ dentro de edad rec & $100,0 \%$ & $100,0 \%$ & $100,0 \%$ & $100,0 \%$ & $100,0 \%$ & $100,0 \%$ & $100,0 \%$ \\
\hline
\end{tabular}

Fuente: Elaboración propia con datos del CIS; estudio 2918 (2011).

Significación del chi-cuadrado 0,065 . $5 \%$ de casilla con frecuencia esperada menor a 5 .

Tabla 23: Contingencia llevar a un colegio con niños inmigrantes por ideología

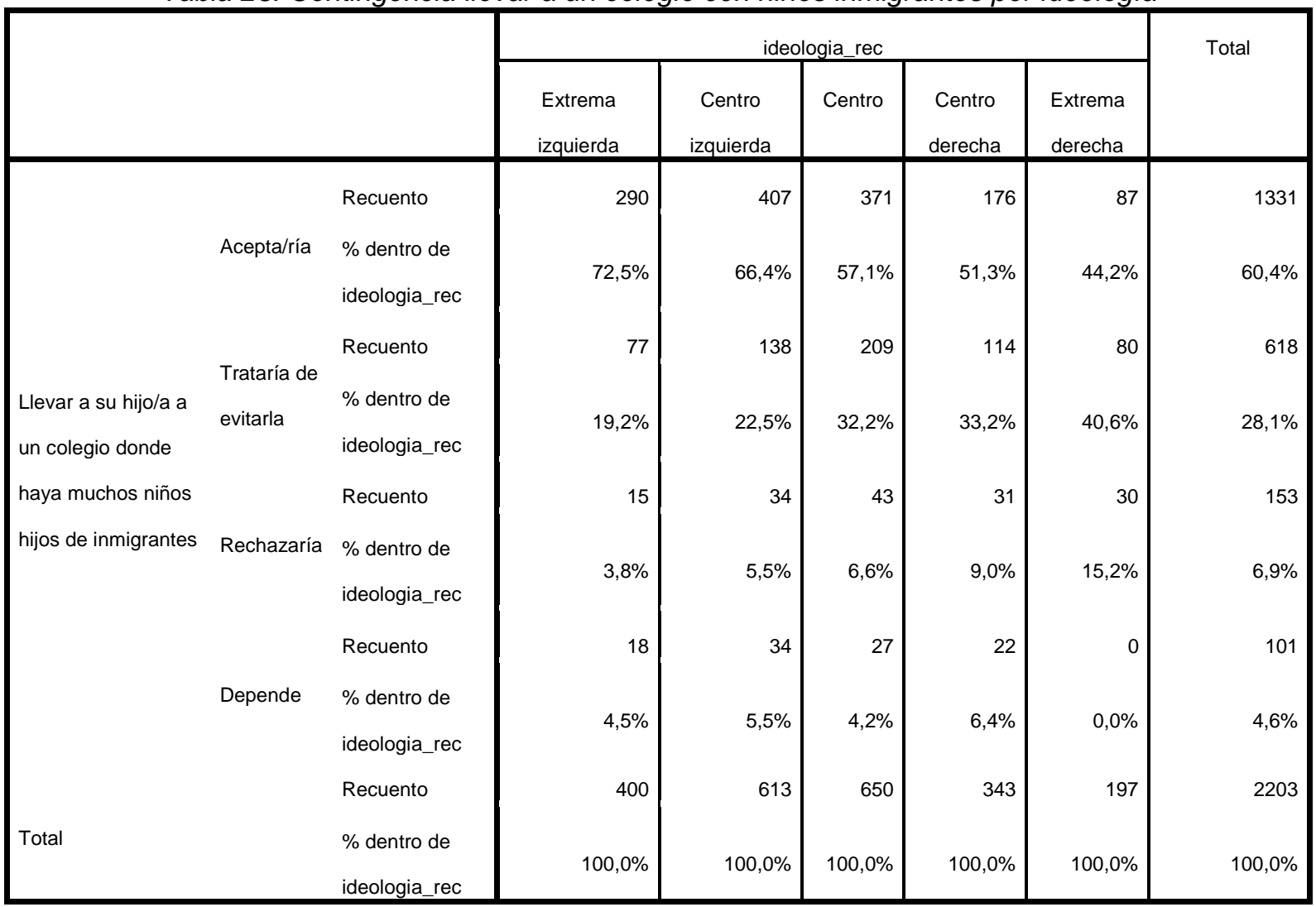

Fuente: Elaboración propia con datos del CIS; estudio 2918 (2011).

Significación del chi-cuadrado $0,000.5 \%$ de casilla con frecuencia esperada menor a 5 . 
Tabla 24: Contingencia llevar a un colegio con niños inmigrantes por familiares con inmigrantes

\begin{tabular}{|c|c|c|c|c|c|}
\hline & & & Fami & & Total \\
\hline & & & Sí & No & \\
\hline $\begin{array}{l}\text { Llevar a su hijo/a a } \\
\text { un colegio donde } \\
\text { haya muchos niños } \\
\text { hijos de inmigrantes }\end{array}$ & Acepta/ría & $\begin{array}{l}\text { Recuento } \\
\text { \% dentro de Familiares } \\
\text { Recuento } \\
\% \text { dentro de Familiares } \\
\text { Recuento } \\
\% \text { dentro de Familiares } \\
\text { Recuento } \\
\text { \% dentro de Familiares } \\
\text { Recuento } \\
\text { \% dentro de Familiares }\end{array}$ & $\begin{array}{r}368 \\
74,6 \% \\
91 \\
18,5 \% \\
19 \\
3,9 \% \\
15 \\
3,0 \% \\
493 \\
100,0 \%\end{array}$ & $\begin{array}{r}1264 \\
56,6 \% \\
674 \\
30,2 \% \\
179 \\
8,0 \% \\
117 \\
5,2 \% \\
2234 \\
100,0 \%\end{array}$ & $\begin{array}{r}1632 \\
59,8 \% \\
765 \\
28,1 \% \\
198 \\
7,3 \% \\
132 \\
4,8 \% \\
2727 \\
100,0 \%\end{array}$ \\
\hline
\end{tabular}

Fuente: Elaboración propia con datos del CIS; estudio 2918 (2011).

Significación del chi-cuadrado $0,000.5 \%$ de casilla con frecuencia esperada menor a 5 .

Tabla 25: Contingencia nacionalidades que generan antipatía por las causas

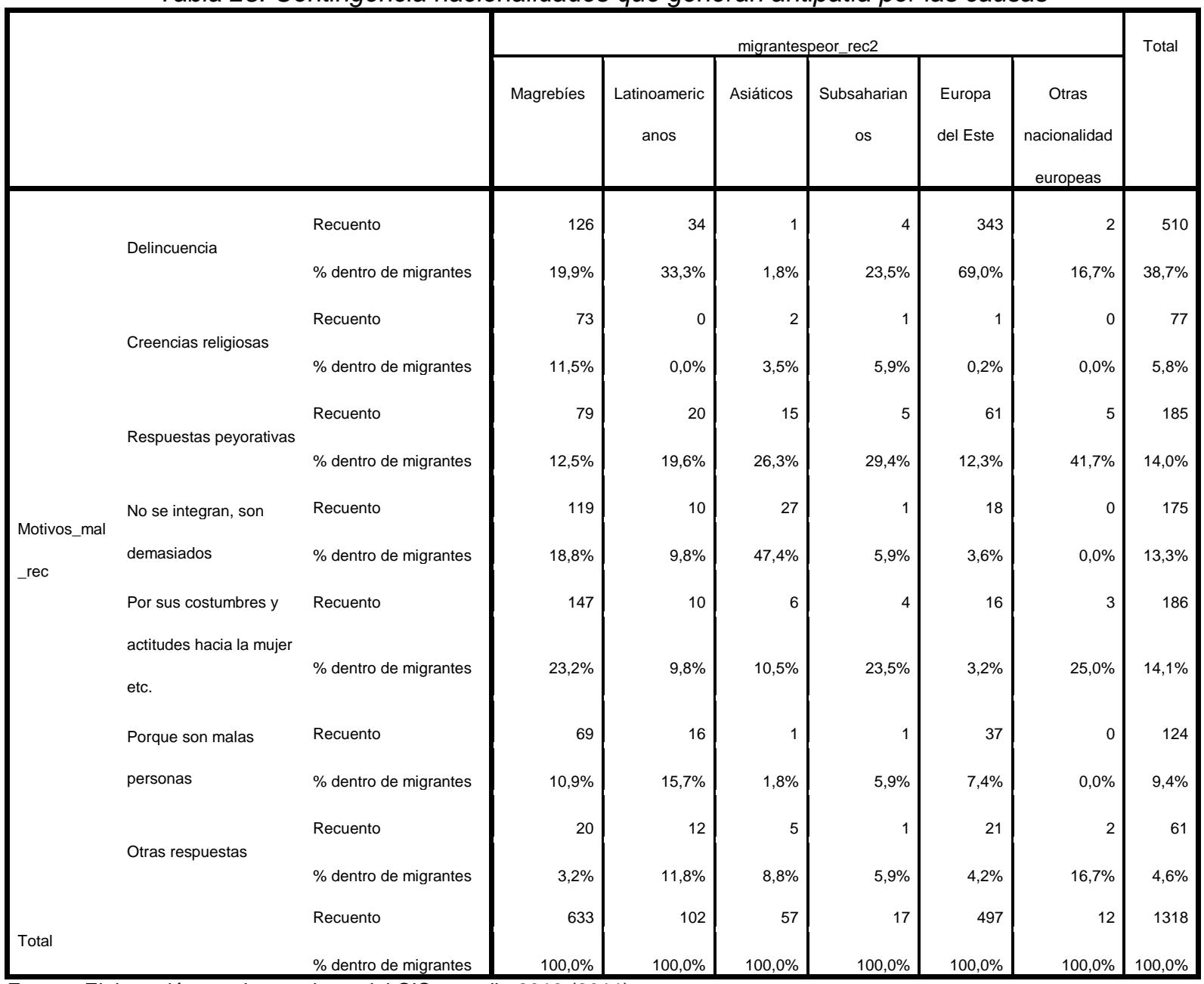

Fuente: Elaboración propia con datos del CIS; estudio 2918 (2011).

Significación del chi-cuadrado 0,000 . 38,1\% de casilla con frecuencia esperada menor a 5 . 


\section{ÍNDICE DE GRÁFICOS Y TABLAS}

Tabla 1: Evolución personas extranjeras empadronadas. (2000 a 2007)............ 32

Tabla 2: Factorial sobre la diversidad cultural en España............................78

Tabla 3: Factorial sobre la entrada de personas extranjeras a España................98

Gráfico 1: Percepción de la sociedad ante los principales problemas de España (2000 a 2013)

Gráfico 2: Percepción de la sociedad ante los problemas que le afectan personalmente (2000 a 2013).

Gráfico 3: Contacto directo de la sociedad española con inmigrantes (2008 a

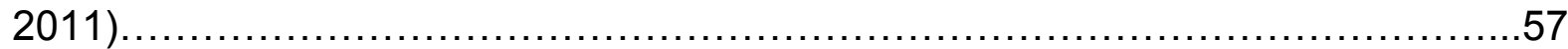

Gráfico 4: Concepto que la población asocia a la inmigración (2008 a 2011)........59

Gráfico 5: Inmigración como aspecto positivo o negativo para España (2008 a 2011)

Gráfico 6: Media del impacto del fenómeno migratorio en la vida cotidiana

Gráfico 7: Aceptación de un partido político racista o xenófobo en España (2008 a 2011)

Gráfico 8: Aceptación de los rasgos de los que España esté compuesta (2008 a 2011)

Gráfico 9: Los inmigrantes realizan trabajos que los españoles no quieren hacer (2008 a 2011)

Gráfico 10: Las personas inmigrantes quitan puestos de trabajo a la población española (2008 a 2011).

Gráfico 11: La población inmigrante hace una importante contribución al desarrollo económico de España (2008 a 2011).

Gráfico 12: Media del impacto del fenómeno migratorio en la economía .70

Gráfico 13: Ubicación en la que se escuchan o ven comentarios en contra de la población inmigrantes (2008 a 2011).

Gráfico 14: Atención de los medios de comunicación a la inmigración (2010 a 2011).

Gráfico 15: Imagen que transmiten los medios de comunicación sobre la inmigración (2009 a 2011) 
Gráfico 16: Rasgo más influyente en el trato de la ciudadanía española a la población inmigrante (2008 a 2011)...

Gráfico 17: Ataques o agresiones violentas de población inmigrante a población española (2008 a 2011).

Gráfico 18: Evolución de la percepción del número de inmigrantes (2008 a 2011).

Gráfico 19: Evolución del volumen de inmigrantes (2007 a 2011). .81

Gráfico 20: Inmigrantes reales y percibidos por principales grupos de nacionalidades (2008 a 2011).

Gráfico 21: Correspondencias entre el nivel de confianza y la percepción numérica de la inmigración.

Gráfico 22: Relevancia de los factores de admisión de personas inmigrantes (2008 a 2011).

Gráfico 23: Percepción de la legislación migratoria (2008 a 2011). 90

Gráfico 24: Postura respecto a la inmigración irregular (2008 a 2011). 92

Gráfico 25: Ayuda del Estado que reciben los grupos vulnerables (2007 a 2011)

Gráfico 26: Relación entre lo que aportan las personas inmigrantes y lo que reciben por parte del Estado (2008 a 2011). .94

Gráfico 27: Evolución número de intervenciones a personas inmigrantes por recursos aplicados (2008 a 2011).

Gráfico 28: Percepción de los derechos de las personas inmigrantes regulares (2007 a 2011)....

Gráfico 29: Vivir en el mismo barrio en el que viven muchas personas inmigrantes (2007 a 2011). 100

Gráfico 30: Alquilar un piso a inmigrantes (2007 a 2011). 101

Gráfico 31: Trabajar o estudiar con inmigrantes (2007 a 2011). 103

Gráfico 32: Que una persona inmigrante sea su jefe en el trabajo (2007 a 2011) 104

Gráfico 33: Correspondencias entre el nivel de estudios y que una persona inmigrante sea su jefe. 105

Gráfico 34: Llevar a su hija y/o hijo a un colegio donde haya muchas niñas y niños hijas e hijos de inmigrantes (2008 a 2011). 106 
Gráfico 35: Que su hija y/o hijo se case con una persona inmigrante (2007 a 2011). 109

Gráfico 36: Correspondencias entre ideología y que su hija/o se case con una persona inmigrante 110

Gráfico 37: Grupos de nacionalidades que causan más antipatía (2008 a 2011) 112

Gráfico 38: Razones por las que las personas inmigrantes causan antipatía (2009 a 2011) 113

Gráfico 39: Árbol de segmentación de perfiles de la población ante la inmigración 116

Representación cartográfica 1: Evolución de la percepción población extranjera en España por provincias (2007 a 2011) 84 